\title{
DURATION OF EXTREME WAVE CONDITIONS
}

US Army Corps

of Engineers

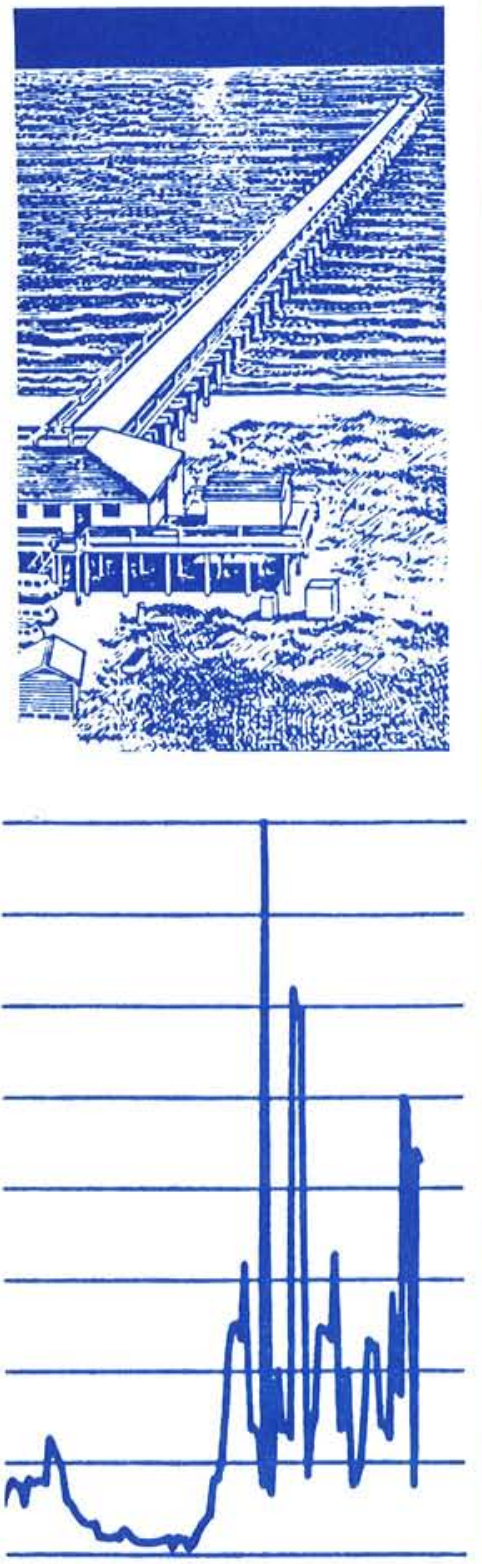

by

Orson P. Smith

Coastal Engineering Research Center

DEPARTMENT OF THE ARMY

Waterways Experiment Station, Corps of Engineers

PO Box 631, Vicksburg, Mississippi 39180-0631

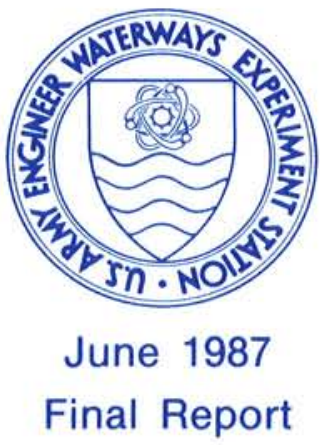

Approved For Public Release; Distribution Unlimited

Prepared for DEPARTMENT OF THE ARMY

US Army Corps of Engineers

Washington, DC 20314-1000 
Destroy this report when no longer needed. Do not return it to the originator.

The findings in this report are not to be construed as an official Department of the Army position unless so designated by other authorized documents.

The contents of this report are not to be used for advertising, publication, or promotional purposes. Citation of trade names does not constitute an official endorsement or approval of the use of such commercial products. 
Unclassified

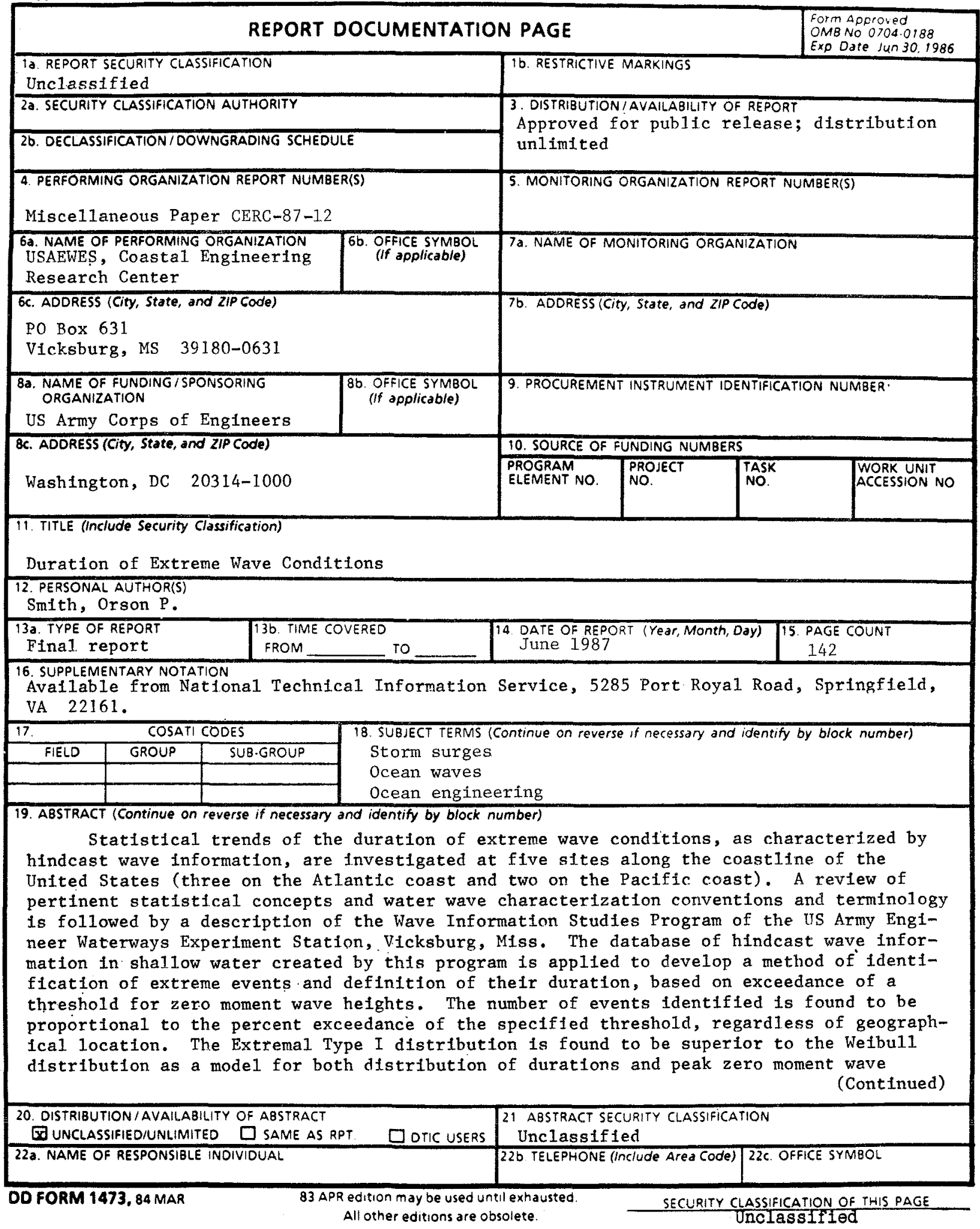


Unclassified

IREUAITY CLABSIFICATION OF TMIS PAOR

19. ABSTRACT (Continued).

heights of extreme events identified. A regression analysis of duration with various parameters representing peak wave conditions reveals only a weak linear relation with peak zero moment wave height and little evidence of a linear relation with any other parameter investigated. The assumption of independence of duration from peak wave conditions is proposed as an expedient method for estimating durations above a specified threshold, given a peak wave condition. 
Work leading to preparation of this manuscript was conducted as part of the "Develop Functional and Structural Design Criterla" work unit of the Coastal Structures Evaluation and Design research and development program of the US Army Corps of Engineers. Authorization from the Office, Chief of Engineers, to publish this report is gratefully acknowledged. This report was originally submitted by the author to Mississippi State University as partial fulfillment of the requirements for an M.S. degree in Civil Engineering.

This study was conducted and the report written by Mr. Orson P. Smfth, Coastal Design Branch ( $C D B$ ), Wave Dynamics Division (WDD), of the Coastal Engineering Research Center (CERC), US Army Engineer Waterways Experiment Station (WES). The author acknowledges the assistance of Dr. Robert E. Jensen of the Coastal Oceanography Branch, Research Division, CERC, whose technical guidance with regard to application of the Wave Information Studies database of hindcast wave information was appreciated throughout the course of the work. The author also is grateful for the technical guidance of Dr. Michael E. Andrew of the Prototype Measurement and Analysis Branch, Engineering Development Division, CERC, regarding statistical aspects of the work.

Work was performed under the general direction of Dr. Frederick E. Camfield, Chief, CDB; Mr. C. E. Chatham, Chief, WDD; Mr. Charles C. Calhoun, Jr. Assistant Chief, CERC; and Dr. James R. Houston, Chief, CERC.

The Director of WES during the course of the work was COL Allen F. Grum, USA. Commander and Director of WES during publication of this report was COL Dwayne G. Lee, CE. Technical Director was Dr. Robert W. Whalin. 


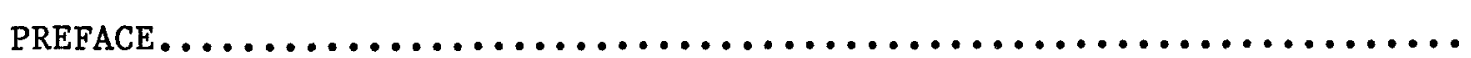

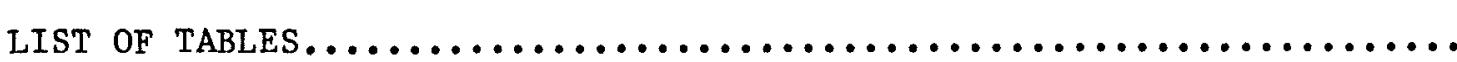

LIST OF FIGURES ................................... $1 v$

CHAPTER I $\quad$ INTRODUCTION...........................

Statement of the Problem...........................

Purpose and objectives.............................

Organization....................................

CHAPTER II: REVIEW OF PERTINENT STATISTICAL CONCEPTS............

Continuous Frequency Distributions....................

Distribution Parameters...........................

The Poisson Distribution...........................

The Exponential Distribution........................

The Weibul1 Distribution...........................

The Rayleigh Distribution..........................

The Extremal Type I Distribution......................

Joint Probability .................................

Concepts Related to Evaluation of Risk..................

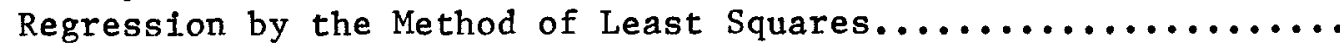

CHAPTER III: CHARACTERIZATION OF WAVE CONDITIONS..............

Basic Sinusoida]. Concepts............................ 17

Irregular Waves..................................... 21

CHAPTER IV: WAVE INFORMATION STUDIES HINDCAST DATABASE..........

Genera1. Background of Phases I and II..................... 27

Phase III Sha11ow-Water Wave Information. .................. 28

CHAPTER V: LITERATURE REVIEW OF STORM DURATION STUDIES.......... 32

Recent Literature on the Duration of Sea States............. 32

North Sea Investigations of Houmb and Vik.................. 33

CHAPTER VI: EXTREME EVENT IDENTIFICATION....................

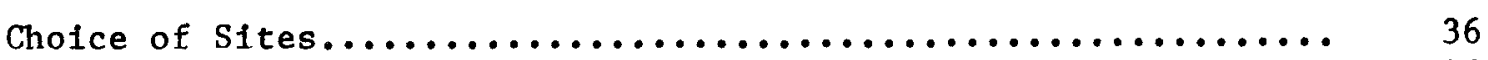

Basic Treatment of WIS Phase III Wave Information...........

The Problem of Extreme Event Identification................. 37

Analytical Procedure and Results......................... 41

CHAPTER VII: DISTRIBUTION OF DURATIONS..................... . . 47

Method of Analysis............................... $\ldots \ldots$

Discussion of the Distribution Analysis.................... 48

CHAPTER VIII: RELATIONSHIP OF DURATION TO PEAK CONDITIONS.......... 52

Method of Analysis.................................. 52

Discussion of Results of the Regression Analysis............ 53 
TABLE OF CONTENTS (continued)

\begin{tabular}{|c|c|c|}
\hline & & Page \\
\hline CHAPTER IX: & 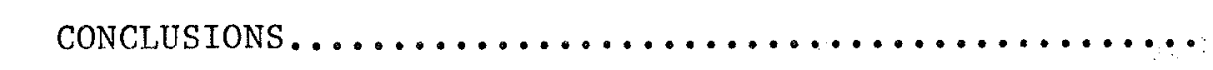 & 56 \\
\hline \multicolumn{2}{|c|}{ 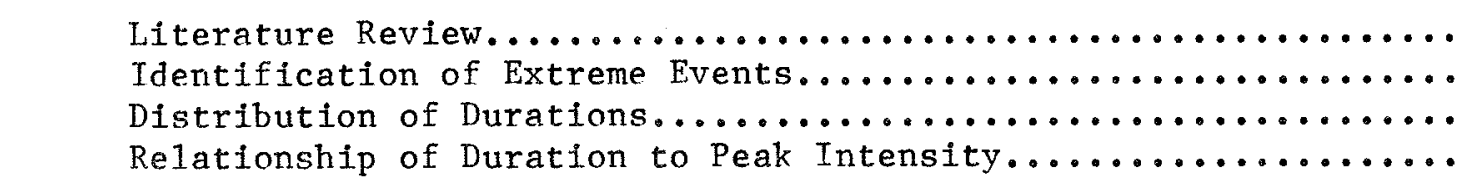 } & $\begin{array}{l}56 \\
56 \\
57 \\
57\end{array}$ \\
\hline CHAPTER X: & 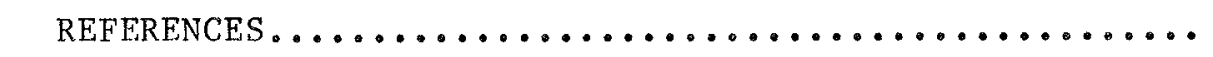 & 58 \\
\hline APPENDIX A: & 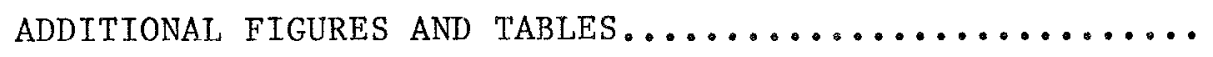 & A 1 \\
\hline APPENDIX B: & $\begin{array}{l}\text { PERTINENT DATA FROM THE WAVE INFORMATION } \\
\text { STUDIES PROGRAM. } \ldots \ldots \ldots \ldots \ldots \ldots \ldots \ldots \ldots \ldots \ldots\end{array}$ & B 1 \\
\hline APPENDIX C: & 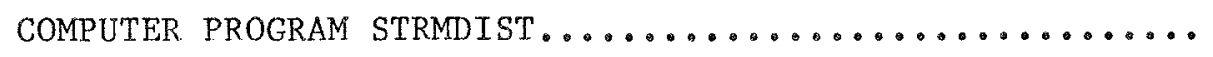 & $\mathrm{Cl}$ \\
\hline APPENDIX D: & $\begin{array}{l}\text { SPSS COMMAND FILE AS APPJIED IN THE } \\
\text { REGRESSION ANALYSIS } \ldots \ldots \ldots \ldots \ldots \ldots \ldots\end{array}$ & D1 \\
\hline
\end{tabular}


No.

1 Mean Durations of Weather Types in the British Isles..........

2 WIS Phase III Stations Investigated......................

LIST OF FIGURES

No.

Page

1 Relative form of four distribution functions................

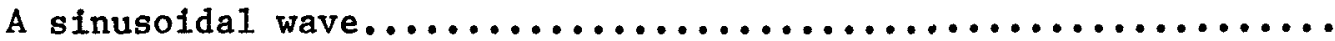

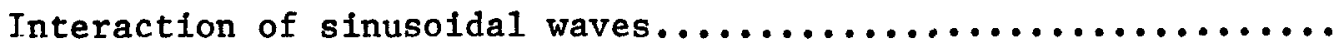

An example of a double-peaked energy density spectrum..........

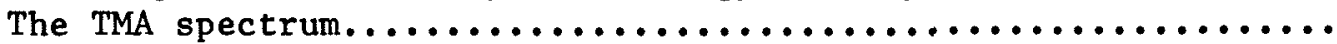

Geographic relation of sites investigated..................

7 Wave height time series: Nagshead, North Carolina,

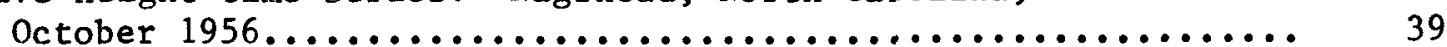

8 Eastern US surface weather patterns: October $1956 . \ldots \ldots \ldots \ldots \ldots$

9 Mean duration and standard deviation versus percent occurrence of wave height threshold, Nagshead,

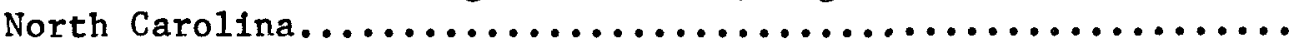

Extreme events per year versus percent occurrence, Nagshead,

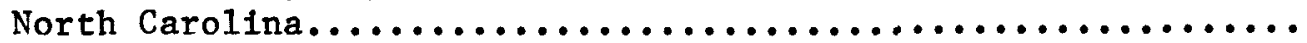

Duration cumulative probability: Nagshead, North Carolina......

Duration cumulative probability: Newport, Oregon.............

13 Correlation coefficient versus percent occurrence of wave height threshold, Nagshead, North Carolina................ Mean duration versus percent occurrence of wave height threshold, Nagshead, North Carolina..................... Duration standard deviation versus percent occurrence of wave height threshold, Nagshead, North Carolina................ 
CHAPTER I: INTRODUCTION

\section{Statement of the Problem}

Extreme wave conditions have been the cause of property loss, suffering, Injuries, and death since man first approached the sea. Coastal engineers therefore have always attempted to bulld works that would withstand, with little or no damage, the worst impact of waves from very rare events. The direct effect of sea waves striking coastal structures has long been recognized as a critical phenomenon with respect to structural integrity during a storm at sea. Ihe hydraulic impact of individual waves has traditionally been the specific force used as the basis of structural design criterla; therefore, characteristics of the worst few waves of a hypothetical extreme event have been estimated for application in most design computations. Rubble-mound structures, constructed of layered quarrystone or concrete shapes and built for centuries as wave barriers (breakwaters and jetties) or shore protection (revetments), are usually designed in this fashion.

The limits of functional performance of coastal structures have recently become more critical with respect to overall economic optimization. Public Ifnancing of coastal works has been more difficult to arrange than in past decades. The concept of designing a structure to be stable during a very extreme storm, but to be less than 100 percent effective in some extreme events of lesser intensity, has been in the minds of coastal engineers in an effort to conceive affordable harbor or shore protection plans. Life cycle cost also is receiving much more scrutiny, particularly with respect to expensive mobilization and challenging construction techniques required for repairs at many coastal projects. The bulwarks of extreme conservatism in coastal engineering design practice are beginning to buckle under pressure for more precise estimates of structural integrity and functional performance. These estimates may someday approach the precision of those now required for design of buildings and bridges.

One critical question in many new optimized designs is "What is the effect of duration of exposure?" Sandy beaches commonly change their shapes to a more stable configuration, given sufficient exposure to severe wave conditions, In theory approaching a new equilibrium (Bruun 1954). Some radical new rubble-mound concepts attempt to emulate this effect (Delft Hydraulics 
Laboratory 1985). Laboratory experiments which simulate natural irregular waves also have shown some duration effects on rubble mounds of more traditional design (Graveson et al. 1980; Van der Meer and Pilarczyck 1984; and Tenaud et al. 1981). The open literature contains little specific guidance, however, for researchers or designers to estimate the duration of a given intensity of extreme wave conditions.

\section{Purpose and Objectives}

The purpose of this work is to investigate the duration of extreme wave conditions estimated from hindcast wave data, with a view toward developing a means to characterize the variation of these durations for use in design of coastal structures. Hindcast wave data, which are discussed later in more detail, are one of the most valuable tools of coastal engineers, primarily because weather data on which they are based typically exist for much longer periods of record than other wave information sources. The 20-year (19561975) Wave Information Studies (WIS) database of hindcast wave data prepared and maintained by the US Army Engineer Waterways Experiment Station (WES) (Brooks and Corson 1984) is a key source of wave information in many US Army Corps of Engineers projects since it now extends along most of the coastline of the United States.

The specific objectives of this study were to (1) review existing literature regarding the duration of extreme wave conditions and related topics; (2) formulate a practical means of identifying individual events of extreme wave conditions, relying on the intensity of wave conditions as represented in the WIS database and associated publications; (3) address the probability distribution of extreme event durations by fitting selected distribution functions to representative data; and (4) address the possible relation of an extreme event's duration to the peak conditions during the extreme event by regression analysis.

\section{Organization}

This report presents reviews of pertinent statistical concepts and techniques, considerations regarding the characterization of wave conditions, and the specific nature of WIS hindcast data before proceeding to describe the 
progress toward and conclusion of the four objectives stated above. An overa11 summary and statement of conclusions then is followed by Appendix A containing figures and tables which were not presented in the main text for the sake of continuity and space conservation. Appendix $B$ includes pertinent wave information transcribed from the WIS database. Appendix $C$ includes a listing of the computer program STRMDIST which was used to identify extreme events, define durations, and fit parameterized distribution functions to both the durations and peak wave heights of extreme events identified. Appendix D includes the command file for the commercial statistical software package SPSS (Nie et al. 1975), which was applied to address the relationship of extreme event duration to peak wave conditions. 


\section{Continuous Frequency Distributions}

The primary tools of this study are statistical procedures which address the variability of parameters of interest, specifically duration of extreme events at sea and their peak intensity. A brief review of pertinent statistical concepts, which are critical to understanding the methods and conclusions of the analysis, is presented below.

Continuous random variables are variables whose values are measured on a continuous scale, as opposed to their discrete counterparts such as rolling dice or coin flipping. Most natural phenomena of varying intensity as measured by instruments are treated as continuous random variables. The probability that the value of a particular random variable, $x$, will fall within a certain range can be estimated by application of its probability density function, $f(x)$, which is analogous to a histogram for discrete variables. The following two conditions apply in defining probability density functions:

$$
f(x) \geq 0 \text { for all } x \text { within the domain of } f
$$

and

$$
\int_{-\infty}^{\infty} f(x) d x=1
$$

The probability that $x$ will fall within the range from $a$ to $b$ is given by:

$$
P(a \leq x \leq b)=\int_{a}^{b} f(x) d x
$$

Technically the probability of $x$ taking on a value of exactly a or $b$ is zero, but since physical measurements cannot be infinitely accurate, the interval from $a$ to $b$ can be considered inclusive. A transformation of the 
probability density function into its corresponding distribution function, $F(x)$, allows more expedient computation of probabilities:

$$
F(x)=\int_{-\infty}^{x} f(t) d t
$$

where $f(t)$ is the probability density function of a dummy variable $t$. The value of $F(x)$ varies between 0 and 1 . The probability that $x$ will have a value equal to or less than $a$ is $F(a)$. The probability that $x$ will have a value between $a$ and $b$ is $F(b)-F(a)$. The corresponding probability density function is:

$$
f(x)=\frac{d F(x)}{d x}
$$

It is important to define the domain of $f$ and that this domain include al1 the values of $x$ of interest. Furthermore, the function $f$ must be integrable within this domain (and $F$ differentiable) for the above definitions to app]y (Miller and Freund 1985).

\section{Distribution Parameters}

The mean or expected value of $x$ is defined by:

$$
\mu=\int_{-\infty}^{\infty} x f(x) d x
$$

The variance of probability density function is the expected value of the squared deviation from the mean, given by:

$$
\sigma^{2}=\int_{-\infty}^{\infty}(x-\mu)^{2} f(x) d x
$$


The variance, $\sigma^{2}$, and its square root, the standard deviation, $\sigma$, are both measures of the spread of the probability density about the mean. The standard deviation is expressed in the same units as $x$ and $\mu$. A small variance or standard deviation implies a strong central tendency while large values Imply significant spread or "variance" of $x$ values (Miller and Freund 1985).

\section{The Poisson Distribution}

A wide variety of distribution functions have been formulated by researchers and statisticians which have been shown to describe well the behavfor of certain random variables which occur in nature. One such function is the Yoisson distribution, defined by:

$$
f(x)=\frac{\lambda^{x} e^{-\lambda}}{x !} \quad \text { for } \quad x=0,1,2, \ldots
$$

This is a discrete distribution which has important associations with the continuous distributions that have been applied to describe weather-related variables. Specifically, the roisson distribution has been applied to describe the number of occurrences of events taking place randomly over continuous intervals of time. The parameter $\lambda$ is both the mean and the variance of the Polsson distribution. A key assumption behind application of this distribution is that the probability of an occurrence for the type of event in question during a small interval of time must not depend on what happened prior to that time. A random process which fits this criterion is called a Poisson process.

\section{The Exponential Distribution}

A continuous distribution which is often associated with the Poisson distribution is the exponential distribution, given by:

$$
\begin{aligned}
f(x) & =\frac{e^{-x / \beta}}{\beta} \text { for } x>0 \text { and } \beta>0 \\
& =0 \text { elsewhere }
\end{aligned}
$$


The corresponding distribution function is:

$$
F(x)=1-e^{-x / \beta}
$$

The mean and standard deviation of a variable represented by an exponential distribution are both $\beta$ and the variance is $\beta^{2}$. This distribution is often used with Poisson processes to model the waiting time between successive occurrences. If the $\lambda$ parameter of a Poisson distribution is the average number of occurrences in time $T$, then the average rate of occurrences per unit time is $\lambda / T$. The corresponding exponential distribution parameter is $\beta=T / \lambda$. This relation and the fact that both distributions are fully described by a single parameter make them easy to use in a wide range of applications dealing with the frequency of and waiting time between discrete events.

\section{The Weibul1 Distribution}

Another distribution, which is widely used to model the variation in intensities of natural extremes such as flood elevations and storm intensities, is the Weibull distribution, where:

$$
\begin{aligned}
f(x) & =\frac{1}{\beta^{\alpha}} \alpha^{x^{--1}} \exp \left[-\left(\frac{x}{\beta}\right)^{\alpha}\right] \text { for } x>0, \alpha>0, \beta>0 \\
& =0 \text { elsewhere }
\end{aligned}
$$

The corresponding Weibulj. distrubution function is very similar to the exponential distribution:

$$
F(x)=1-\exp \left[-\left(\frac{x}{\beta}\right)^{\alpha}\right]
$$

The parameter $\alpha$ is the "shape parameter" which defines the basic shape of the function. The $\beta$ parameter is the "scale parameter" which determines the degree of spread along the abscissa (Isaacson and Mackensie 1981). The mean and variance of the Weibull distribution are: 


$$
\begin{gathered}
\mu=\beta \Gamma\left(1-\frac{1}{\alpha}\right) \\
\sigma^{2}=\beta^{2}\left[\Gamma\left(1+\frac{2}{\alpha}\right)-\Gamma^{2}\left(1+\frac{1}{a}\right)\right]
\end{gathered}
$$

The gamma function is given by:

$$
\Gamma(z)=\int_{0}^{\infty} x^{z-1} e^{-x} d x=(z-1) !
$$

The Weibull distribution has two parameters which make it actually a family of functions. A three-parameter form is sometimes used to provide further flexibility in adapting the distribution to certain phenomena, where:

$$
F(x)=1-\exp \left[-\frac{(x-\varepsilon)}{\beta}\right]^{\alpha} \text { for } \varepsilon>0
$$

The parameter $\varepsilon$ is a "location parameter" which locates the position of the probability along the abscissa (x-axis). In the particular case of the Weibull distribution, $\varepsilon$ is in effect a lower limit to values of $x$. The $\varepsilon$ parameter is often taken as zero in practice. The Weibull distribution reduces to the exponential distribution when $\alpha=1$ and $\varepsilon=0$ (Isaacson and Mackensie 1.981).

\section{The Rayleigh Distribution}

The Weibull distribution reduces to a Rayleigh distribution when $\alpha=2$ and $\varepsilon=0$, a function widely used to model the distribution of wave heights passing a point during a stationary sea state. The term "stationary" refers to the common assumption that, for practical purposes, statistical properties of ocean waves tend to be time invariant during a period of a few minutes to an hour or more. The time for significant changes to occur in a sea state is thus assumed to be substantially longer than the time necessary to measure the form of a few hundred waves passing a fixed point. The Rayleigh distribution, for this purpose, is often expressed in the form: 


$$
F(H)=1-e^{-2\left(H_{s} / H_{s}\right)^{2}}
$$

where $H$ is an individual wave height in a sea state and $H_{s}$ is the "significant wave height," also defined as the average of the highest 1/3 waves. This relation has been found to be quite accurate in most conditions at sea, with the exception of waves nearing the point of breaking in shallow water (Massie 1976). The corresponding probability density function, mean, and variance of this form of the Rayleigh distribution are:

$$
\begin{gathered}
f(x)=4\left(\frac{H}{H_{s}^{2}}\right) e^{-2\left(H_{s} / H_{s}\right)^{2}} \\
\mu=\left(\frac{\pi}{8}\right)^{1 / 2} H_{s}=0.627 H_{s} \\
\alpha^{2}=\left(\frac{1-\pi}{8}\right) H_{s}^{2} \quad\left(\sigma=0.779 \mathrm{H}_{s}\right)
\end{gathered}
$$

\section{The Extremal Type I Distribution}

This distribution; sometimes called the "Gumbel" or "Fisher-Tippet Type I" distribution, also is frequently applied to model natural extremes such as storm intensities (Gumbe1 1958). The probability density and distribution functions have the following forms:

$$
\begin{gathered}
f(x)=\frac{e^{-e^{-[(x-\varepsilon) / \phi]}} e^{-[(x-\varepsilon) / \phi]}}{\beta} \quad \text { for } \begin{array}{l}
-\infty<x<\infty \\
-\infty<\varepsilon<\infty \\
\beta>0
\end{array} \\
F(x)=e^{-e^{-[(x-\varepsilon) / \beta]}}
\end{gathered}
$$

The mean and variance are: 


$$
\begin{aligned}
& \mu=\varepsilon-\gamma \beta \\
& \sigma^{2}=\frac{\pi^{2} \beta^{2}}{6}
\end{aligned}
$$

where $\gamma=$ Euler's constant $=0.5772$. The Extremal Type I distribution is also a two-parameter family of functions, in this case with a shape parameter of $\alpha=1$ in keeping with the usual practice for application to weatherrelated phenomena (Isaacson and Mackensie 1981 and Andrew et al. 1985). The $\varepsilon$ parameter is again the location parameter and $\beta$ the scale parameter. The Extremal Type I distribution is not constrained to positive values of $x$. Figure 1 illustrates the relative form of the Exponential, Weibull, Rayleigh, and Extremal. Type I distributions. The Exponential and Rayleigh

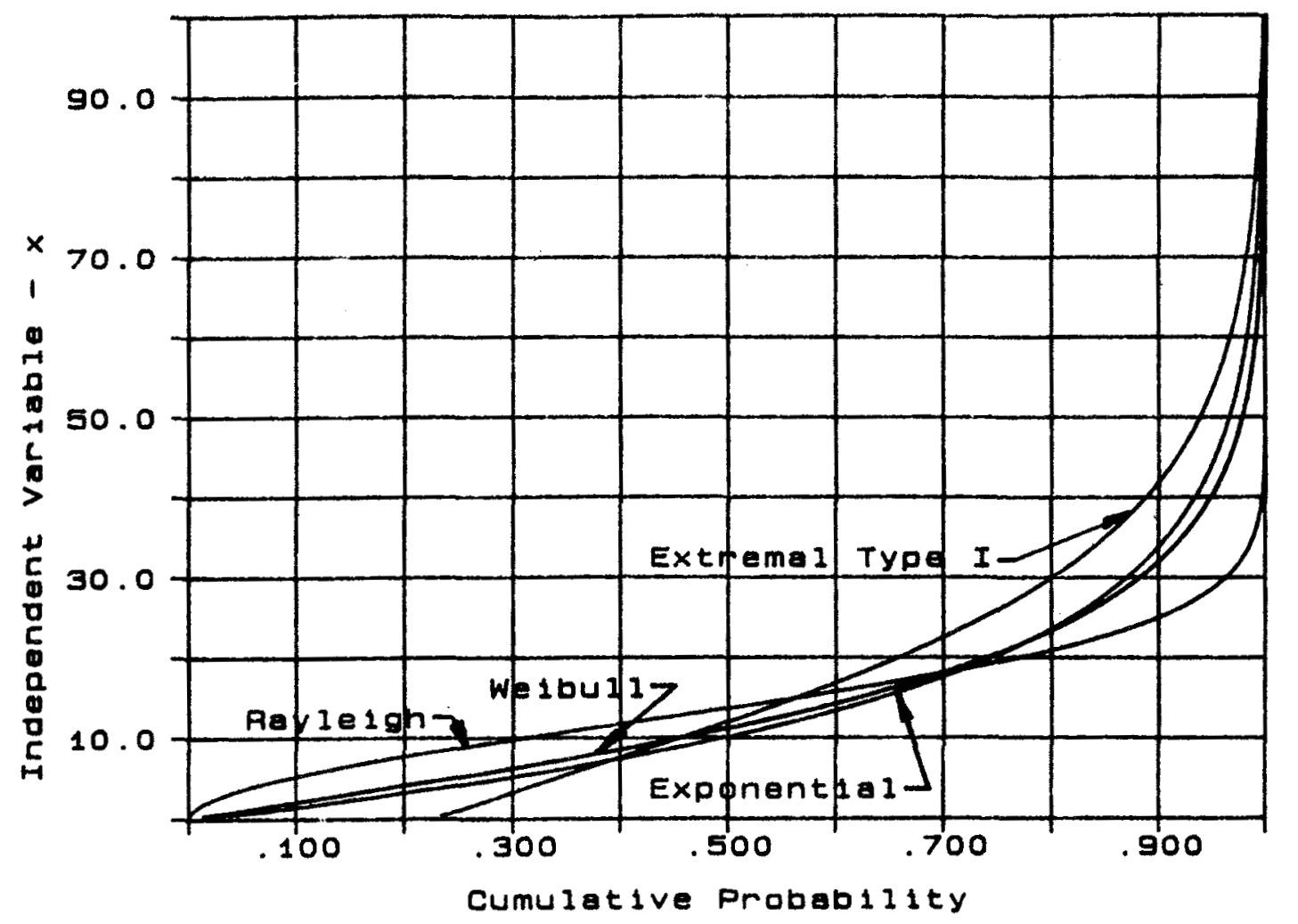

Figure 1. Relative form of four distribution functions curves shown in Figure 1 have the same mean as the Welbull curve. The Extremal Type I curve of Figure 1 was derfved from the same data as the Weibull curve. 


\section{Joint Probability}

It is often important to describe an event by more than one variable, such as both the duration and peak intensity, in which case the joint probability density must be evaluated. The probability that variables describing the event fall within specified ranges is determined from the joint probability density in a similar manner as with single variable probability density functions :

$$
\begin{aligned}
& P\left(a_{1}<x_{1}<b_{1}, a_{1}<x_{2}<b_{2}, \ldots, a_{n}<x_{n}<b_{n}\right) \\
&=\int_{a_{1}}^{b} \int_{a_{2}}^{b} \ldots \int_{a_{n}}^{b} f\left(x_{1}, x_{2}, \ldots, x_{n}\right) d x_{1} d x_{2} \ldots d x_{n} \\
& \text { when } f\left(x_{1}, x_{2}, \ldots, x_{n}\right) \geqq 0
\end{aligned}
$$

and

$$
\int_{-\infty}^{\infty} \int_{-\infty}^{\infty} \cdots \int_{-\infty}^{\infty} f\left(x_{1}, x_{2}, \ldots, x_{n}\right) d x_{1} d x_{2} \ldots d x_{n}=1
$$

A joint distribution function can be defined also:

$F\left(x_{1}, x_{2}, \ldots, x_{n}\right)=\int_{-\infty}^{x_{1}} \int_{-\infty}^{x_{2}} \int_{-\infty}^{x_{n}} f\left(t_{1}, t_{2}, \ldots, t_{n}\right) d t_{1} d t_{2} \ldots d t_{n}$

The marginal probability density of variable $x_{i}$ is determined by integrating the joint probability density function over the entire domain of all variables except $x_{i}:$

$$
f\left(x_{i}\right)=\int_{-\infty}^{\infty} \ldots \int_{-\infty}^{\infty} f\left(x_{1}, x_{2}, \ldots, x_{n}\right) d x_{1} \ldots d_{i-1} d x_{x+1} \ldots d_{n}
$$


An important feature of joint probabilities is that if the random variables involved are independent, then their joint distribution function is the product of their marginal distribution functions, such that:

$$
F\left(x_{1}, x_{2}, \ldots, x_{n}\right)=F\left(x_{1}\right) F\left(x_{2}\right) \ldots F\left(x_{n}\right)
$$

Another important concept of joint probabilities is conditional probability density, defined in the case of two random variables as the conditional probability density of the first, $x_{1}$, given that the second takes on a specified value, $x_{2}$, or:

$$
g_{1}\left(x_{1} \mid x_{2}\right)=\frac{f\left(x_{1}, x_{2}\right)}{f\left(x_{2}\right)} \text {, if } f\left(x_{2}\right)=0
$$

Conditional distribution functions, such as $F\left(x_{1} \mid x_{2}\right)$, also can be defined, expressing the cumulative probability density in a manner analogous to single variable density functions. Conditional probability densities or distribution functions do not require independence for their definition.

\section{Concepts Related to Evaluation of Risk}

A traditional measure of risk of encountering an event of a specified intensity $x$, such as a critical flood elevation, wind velocity, or wave height, is the return period, $R T(x)$. This is defined in practical terms as the average waiting period between exceedances of $x$. The return period for variables whose rate of occurrence is independent of their intensity (i.e., the number of occurrences per unit time is a Poisson process with a mean $\lambda$ ) is given by (Borgman and Resio 1982):

$$
\operatorname{RT}(\mathrm{x})=\frac{1}{\{\lambda[1-\mathrm{F}(\mathrm{x})]\}}
$$

The nonencounter probability, $N E(x)$, is defined as the probability that, during a specific time interval $L$, the largest intensity encountered will be less than or equal to $x$. This can be expressed in terms of the 
distribution function $F(x)$ for the case of a Poisson process as (Borgman and Resio 1982):

$$
N E(x)=e^{-\lambda L[1-F(x)]}
$$

Expressed in terms of the return period:

$$
N E(x)=e^{-L / R T(x)}
$$

This last relation demonstrates the danger of misinterpreting the return period as a frequency of occurrence for events of intensity $x$. When $L=\operatorname{RT}(x)$, then $N E(x)=0.37$. In other words, there is a 63 percent probability of encountering an event of intensity $x$ during the time interval $L$. The term "risk" is defined as the probability that an event of intensity $x$ or greater will occur at least once in the time interval $\mathrm{L}$, which is $1-\mathrm{NE}(\mathrm{x})$.

Another concept important in risk and optimization analyses is that of expectation, $E\{x\}$. This has actually already been defined as the mean of $f(x)$ :

$$
E \cdot x\}=\mu=\int_{-\infty}^{\infty} x t(x) d x
$$

One useful feature of the expectation as a long-term average of the values of $x$ is that the expectation of a function of $x, g(x)$ can be defined by:

$$
E[g(x)]=\int_{-\infty}^{\infty} g(x) f(x) d x
$$

Another feature with respect to Poisson processes worth noting regards the reterence time period for risk criteria, such as estimation of the average annual value of some variable. Relation of the Poisson parameter $\lambda$ to expectations of functions of the random variable $x$ (the outcome of a Poisson process, where the number of occurrences per unit time is independent of the value of $x$ ) is easiest demonstrated by an example. Assume that in 1 year $k$ 
extreme events occur, where $k$ is a Poisson variable. Intensities of extreme events are represented by signiticant wave heights, $H_{s i}(i=1,2,3, \ldots k)$. Damage to a structure caused by each extreme event is assumed to be a function of $\left.\mathrm{H}_{\mathbf{s}}, \mathrm{D}_{\mathbf{S}}\right)$. Total damage in the year's time is:

$$
\frac{D}{y r}=\sum_{i=1}^{k} D\left(H_{s i}\right)
$$

Since $\mathrm{k}$ and $\mathrm{H}_{\mathrm{si}}$ are independent, then the expectation with respect to $\mathrm{H}_{\mathrm{s}}$ is:

$$
E\left(\frac{D}{y r}\right)=\sum_{i=1}^{k} E\left[D\left(H_{s i}\right)\right]
$$

Since $H_{s i}$ values are independent identically distributed random variables, they alı have the same expectation, and:

$$
E\left(\frac{D}{y r}\right)=E(k) E\left[D\left(H_{s}\right)\right]
$$

Taking the expectation of $k$ to be the average number of extreme events per year ( $=$ the Poisson parameter, $\lambda$ ), the long-term average annual storm damage is:

$$
E\left(\frac{D}{y r}\right)=\lambda E\left[D\left(H_{s}\right)\right]=\lambda \int_{-\infty}^{\infty} D\left(H_{s}\right) f\left(H_{s}\right) d H_{s}
$$

This relation is critical in optimization of first costs against estimates of long-term maintenance costs.

\section{Regression by the Method of Least Squares}

An important part of many research efforts is the estimation of distribution parameters from measured data by regression using the method of least 
squares. Assumed linear relationships between an independent variable $x$ and a dependent variable $y$ of the form:

$$
y=\alpha+\beta x
$$

can be tested against a set of $x, y$ data and the differences, $\varepsilon$, between the estimated $y$ and the predicted value measured. These differences can be due to measurement errors or inadequacies in the assumed relationship, such as neglect of other independent variables which also affect the value of $y$. The method of least squares allows the parameters $\alpha$ and $\beta$ to be estimated by constants $a$ and $b$ such that resulting differences in the predicted versus measured $y$ values are a minumum. Since these differences, called residuals, could be both positive and negative and therefore have a tendency to offset each other, the square of the differences is minimized instead. Many nonlinear relationships can be transformed into a linear form to take advantage of this technique.

The accuracy or relfability of least squares estimates of the true linear parameters $\alpha$ and $\beta$ can be expressed in a number of ways. All possible true $y$ values are assumed to be independently normally distributed with means $\alpha+\beta x$ and the common variance $\sigma^{2}$. Measured values then can be written as:

$$
\mathrm{y}_{1}=\alpha+\beta \mathrm{x}_{1}+\varepsilon_{1}
$$

where $\varepsilon_{i}$ represents independent normally distributed random vartables with zero means and a common variance $\sigma^{2}$. This variance for " $n$ " $y$ values can be estimated in terms of the residuals as:

$$
s_{e}^{2}=\frac{1}{n-2} \sum_{i=1}^{n}\left[y_{i}-\left(a+b x_{i}\right)\right]^{2}
$$

where $s_{e}$ is the standard error of estimate. The standard error is in units of $y$ and represents the limft within which approximately 68 percent of the absolute values of all errors w1ll fall. Another quantitative measure of variance is the sum of the square residuals, or $(n-2) s_{e}^{2}$. 
The proportion of the variation of $y$ values which can be attributed to the assumed relationship with $x$ can be estimated as the ratio of the sum of squared residuals, $y-\hat{y}$, to the sum of squared deviations of $y$ from the measured mean, $\vec{y}$, subtracted from 1 , the square root of which is known as the nonlinear correlation coefficient, $r$ :

$$
r=\sqrt{1-\frac{\sum(y-\hat{y})^{2}}{\sum(y-\bar{y})^{2}}}
$$

The above relation has the advantage over other correlation formulas that it is not restricted to linear relationships, although it is more tedious to compute.

Confidence that can be placed on predictions made with an equation developed by the least squares method can be estimated by various methods (Miller and Freund 1985, Isaacson and MacKensie 1981). The upper 1imit of confidence in estimates applied as design criteria always should be addressed by engineers as an integral part of the design process, particularly if predictions are extrapolated beyond the range of measured data. Techniques for estimating statistical confidence are not discussed here in detail since this project does not directly involve extrapolation. It should be noted, however, that obtaining a large sample is very important in improving statistical confidence. LeMehaute and Wang (1984 and 1985) have made spectal note of the sensitive effect on confidence of wave statistics attributable to the number of years of record and frequency of recordings. Neglect of statistical confidence inherent in formulation of structural design criteria can lead to inadequate safety and higher than anticipated maintenance costs for structures involved. The 20 years of hindcast wave data at $3-\mathrm{hr}$ intervals available from the WIS program are valuable in this regard. 


\section{Basic Sinusoidal Concepts}

An understanding of the basic theory and terminology of water wave mechanics is necessary for interpretation of hindcast wave information and any analytical application of this information. Water surface waves are most easily described as wave forms of sinusoidal shape. Certain key terms with reference to this simplified concept of water waves, as illustrated in Figure 2, include:

1. Wave height, $H$ - the vertical distance between a consecutive trough and crest

2. Wave length, L - the horizontal distance between two consecutive crests (or troughs)

3. Wave period, $T$ - visualizing the wave form as traveling horizontally, the time for two consecutive crests (or troughs) to pass a fixed point, usually in seconds

4. Wave frequency, $f$ - nominally, the rate at which consecutive crests (or troughs) pass a fixed point $(=1 / T)$, in hertz (cycles per second)

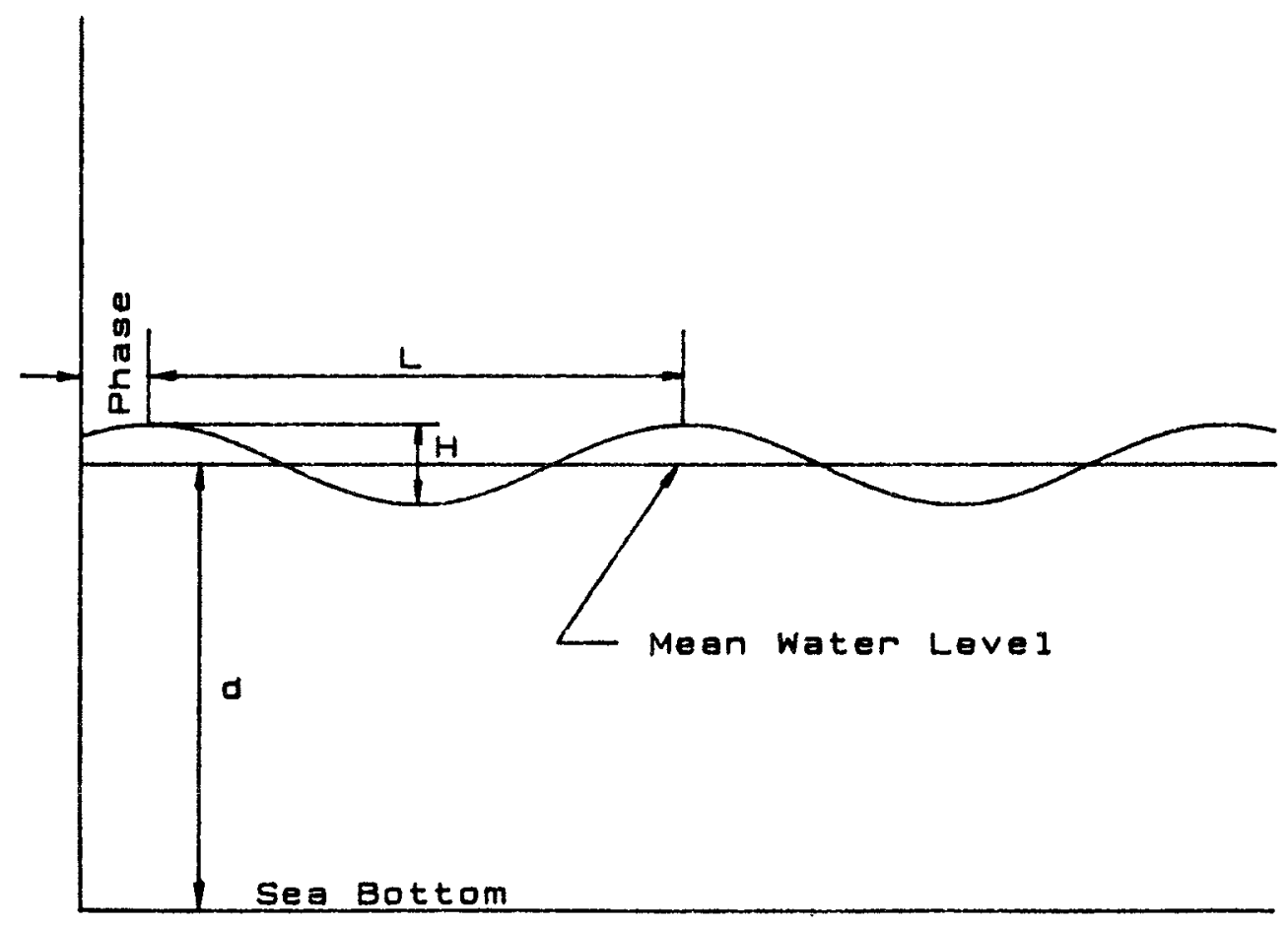

Figure 2. A sinusoidal wave 
5. Radial frequency, $\omega$ - the radial equivalent of frequency $(\omega=2 \pi / T)$, also in hertz

6. Wave number, $k$ - the radial equivalent of wave length $(=2 \pi / L)$

7. Phase, $\phi$ - the radial equivalent of the horizontal displacement, $x^{\prime}$, of a wave crest from the origin of the reference axis at time, $t=0$ $\left(=2 \pi / x^{\prime}\right)$

The basic equation which defines the wave profile in these terms is:

$$
n(x, t)=\frac{H}{2} \cos (k x-\theta t+\phi)
$$

where $n(x, t)$ is the instanteous position of the water surface. Consideration of the sum of potential and kinetic energy inherent in a traveling wave of this form (per unit surface area) can be estimated by:

$$
E=\frac{\rho \mathrm{gH}^{2}}{8}
$$

where $\rho$ is the mass density of the seawater. This total energy is notably a function only of the wave height squared (Dean and Dalrymple 1984).

A consideration of surface, bottom, and transverse boundary conditions, with simplifications which eliminate all but first-order differential terms, ylelds the mathematical equation, known as the dispersion relation, which predicts effects of depth on wave length:

$$
\omega^{2}=g k \tanh (k d)
$$

where $g$ is the acceleration due to gravity and tanh is the hyperbolic tangent. A feature of sinusoidal waves which is consistent with this relation is that deepwater wave length, $\mathrm{L}_{0}=(\mathrm{g} / 2 \pi) \mathrm{T}^{2}=5.12 \mathrm{~T}^{2} \mathrm{ft}$ or $1.56 \mathrm{~T}^{2} \mathrm{~m}$. The speed at which a wave crest travels, the phase velocity, $C$, in deep water $=\mathrm{L}_{\mathrm{o}} / \mathrm{T}=5.12 \mathrm{~T} \mathrm{ft} / \mathrm{sec}$ or $1.56 \mathrm{~T} \mathrm{~m} / \mathrm{sec}$. The change that occurs in shallower water is that wavelength shortens and phase velocity, $C=\mathrm{L} / \mathrm{T}$, increases. The wave height also is affected, first slightly decreasing, then increasing as the water grows more shallow. The overall tendency of water waves to 
change form as depths decrease is known as shoaling. The change in wave height due to shoaling is governed by:

$$
\mathrm{K}_{\mathrm{s}}=\frac{\mathrm{H}}{\mathrm{H}_{\mathrm{o}}}=\left(\frac{\mathrm{C}_{\mathrm{o}}}{2 \mathrm{C}_{\mathrm{g}}}\right)^{1 / 2}
$$

where $H$ and $H_{0}$ are shoaled and deepwater wave heights and $K_{S}$ is the shoaling coefficient. The variable $\mathrm{C}_{\mathrm{g}}$ is the shoaled group velocity, the speed at which groups of waves travel which is also the speed at which wave energy approaches shore:

$$
C_{g}=\frac{c}{2}\left[1+\frac{2 k d}{\sinh (2 k d)}\right]
$$

where $C$ is the shoaled phase velocity $(=\mathrm{L} / \mathrm{T})$ and $\sinh$ is the hyperbolic sin function (Dean and Dalrymple 1984).

The wave form becomes steeper in decreasing depths, ultimately reaching an unstable state when breaking occurs. The point at which breaking actually occurs is not fully understood at this time, but, based on the theory of solitary waves, generally occurs at the point where the wave height, $\mathrm{H}=0.78 \mathrm{~d}$. Some field data tend to show that most locally wind-generated waves (i.e. "seas") break in deeper water, with breaking heights on the order of $0.6 \mathrm{~d}$ to $0.7 \mathrm{~d}$. Very long waves not locally generated (i.e. "swell") may not break until they are in very shallow water, however, since they may form surging breakers analogous to hydraulic phenomena known as "bores" or "hydraulic jumps."

The discussion above is meant to point out that there are practical limits to wave heights at most coastal sites due to breaking, but that these limits are as yet difficult to reliably define in practice. Furthermore, simplifications inherent in first-order sinusoidal theory are not suffictently accurate for engineering purposes in many shallow-water situations and predictions made with a higher order wave theory must be applied.

Shoaling occurs on $1 y$ as a function of depth, but refraction also affects the wave form as a function of wave direction with respect to depth contours of the sea bottom. Refraction of water waves is analogous to refraction in classical physics of a ray of light passing through a pane of glass at an 
angle. The most frequently observed effect of water wave refraction is for waves approaching the coast at an angle to bend around as their crests tend to become parallel to the shoreline in shallow water. Snell's Law is usually applied to describe the change in angle of water waves by refraction in much the same way as it is in optics, commonly stated as:

$$
\frac{\sin \theta}{\mathrm{C}}=\frac{\sin \theta_{0}}{\mathrm{C}_{0}}
$$

where $C$ and $C_{0}$ are the refracted and deepwater phase velocities $(=L / T$ and $\mathrm{L}_{0} / \mathrm{T}$ ) and $\theta$ and $\theta_{0}$ are the refracted and deepwater angles of wave crests with the bottom contours. Snell's Law assumes straight and parallel contours between deep water and the depth at which the above relation is applied. The relation can be applied in increments of incident versus refracted angles and thus applied to gently curving contours. Refraction usually (except in cases of convergence at convex contours) causes a reduction in wave height, which is superimposed on the effect of shoaling, according to the ratio:

$$
\mathrm{K}_{\mathrm{r}}=\frac{\mathrm{H}}{\mathrm{H}_{\mathrm{o}}}=\left(\frac{\cos \theta_{0}}{\cos \theta^{1 / 2}}\right.
$$

where $H$ and $H_{0}$ are the refracted and deepwater wave heights and $K_{r}$ is the refraction coefficient (Dean and Dalrymple 1984).

Wave diffraction describes the effect which a partial barrier has on wave heights beyond the barrier. It is the process which allows wave energy to leak sideways behind an obstruction or laterally from an area of high energy to an adjacent area of lower energy. The head of a breakwater, for example, will cause waves to diffract behind the breakwater into its geometric shadow, even though it may prevent any other form of wave transmission. Larger scale landforms and submerged formations can cause a degree of wave diffraction. Precise predictions of the effects of diffraction are more complicated than for shoaling and refraction, but the combined effects of these three forms of wave transformation are important in explaining observed behavior of water waves in many practical situations. The complexity of 
diffraction often requires the use of physical scale models to ensure with confidence satisfactory performance of protective structures such as breakwaters enclosing a port or harbor area.

\section{Irregular Waves}

The fact that real ocean waves typically appear chaotic with little regular form was mentioned previously. An explanation of this reality is that wave groups from many different sources with different heights, periods, phases, and directions are interacting in the small area we observe with the resulting superpositions appearing as chaos. Figure 3 illustrates a

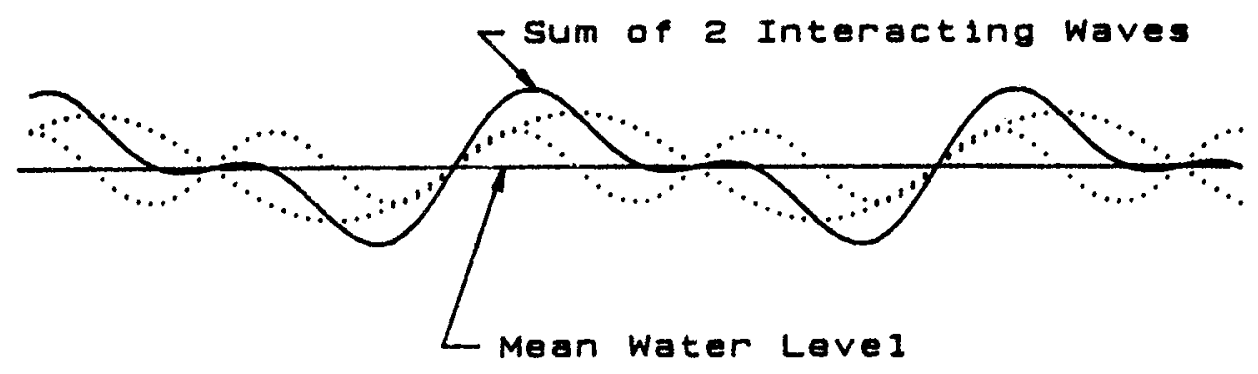

Figure 3. Interaction of sinusoldal waves

hypothetical point in time when two sinusoidal wave groups interact, one with 50 percent greater height and period and a $\pi / 4$ phase difference. The waves would appear criss-crossed when viewed from above if their directions were not parallel.

Actually, winds that create the waves generate a range of heights and periods. Since phase velocity varies with period, longer period waves travel faster and soon leave shorter period waves behind. Swell, as previously defined, refers to waves which have completely left the area in which they were generated. These waves typically have periods greater than about 9 or $10 \mathrm{sec}$, but a clear distinction does not exist. Waves which are still within the influence of the generating wind system are called "seas" and typically are dominated by shorter period waves (1ess than $9 \mathrm{sec}$ ).

The distribution of individual wave heights in a stationary sea state has been found in most cases to follow a Rayleigh distribution, as discussed in the previous paragraphs on statistical concepts. Stationarity technically is the condition during which all moments (including the mean and variance) 
are time invariant (Bendat and Piersol 1971). A small sample thus can be analyzed and taken to represent the entire period during which conditions remain stationary. Waves at sea are assumed by most investigators to be weakly stationary for periods of about $3 \mathrm{hr}$, occasionally for as much as $6 \mathrm{hr}$, but seldom longer. This is more of a tradition related to the practicalities of collecting wave data than a precisely defined interval. The parameters derived from an instanteous measurement (such as the case of synoptic hindcasting) or from a 20-min recording of the water surface elevations are therefore typically taken to represent a much longer period during which conditions do not change. This, of course, is not really true, but as long as the changes are not drastic and are generally within the confidence limits of the statistical parameters of interest, this practice is acceptable.

Wave periods do not lend themselves as readily as do wave heights to representation by a standard statistical distribution such as the Raleigh distribution. Bretschneider (1959), however, found that the distribution of squared wave periods, $\mathrm{T}^{2}$, for seas followed a Rayleigh distribution. Other investigators have applied a variety of standard distributions, and specialized empirical distributions also have been developed.

The practice of coastal engineers in the last 10 years has largely shifted from considerations of wave period exclusively in the time domain to frequency domain considerations. Decomposition of a time series of water surface elevations into a set of incremental sinusoids, each represented by an amplitude $(=\mathrm{H} / 2)$ and a frequency $(=1 / \mathrm{T})$, can be accomplished by transformation of the time series into its equivalent Fourier series. Wave conditions thus can be represented by the distribution of wave energy (proportional to amplitude squared per Equation 44) as a function of frequency, or a wave spectrum.

Figure 4 illustrates a wave spectrum with two "peaks," one representing swell-type waves and the other representing coexistent seas. The inverse frequency of the dominant peak is in practice usually taken as the peak period, which is generally assumed as the most probable period in the sea state. This is a "one-dimensional" spectrum which does not account for the direction of wave energy propagation. More complex procedures have been developed to express the distribution of wave energy as a function of both frequency and direction. The most common practice is to treat the directional spread of wave energy to be independent of the distribution of energy by frequency. This 


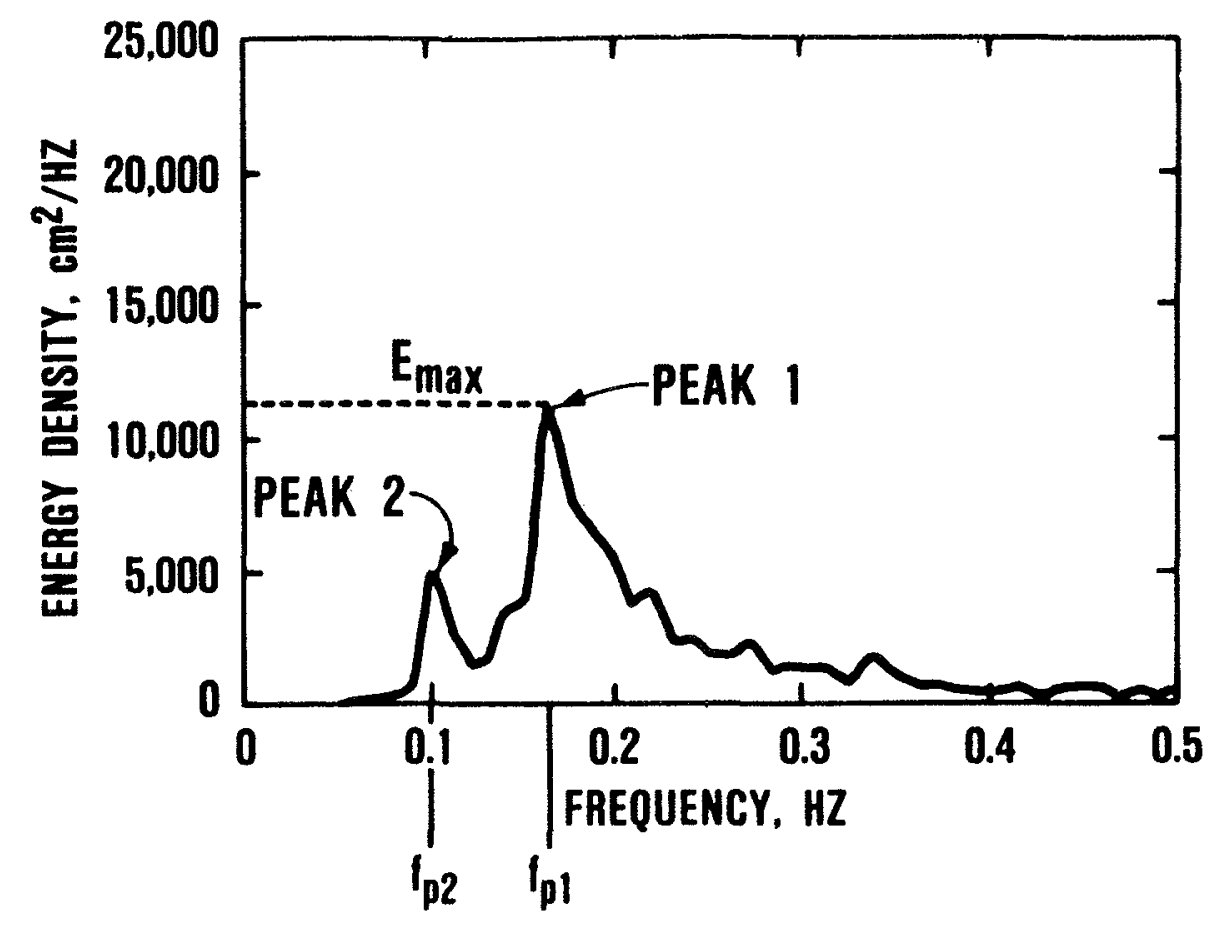

Figure 4. An example of a double-peaked energy density spectrum

allows application of a spreading function $\theta(\theta)$ which, when multiplied by the one-dimensional spectrum $S(f)$, yields the two-dimensional spectrum $S(f, \theta)$ :

$$
S(f, \theta)=S(f) \theta(\theta)
$$

The form of a spectrum is quite sensitive to the analytical procedures applied, particularly "smoothing" performed to improve statistical confidence at the cost of resolution. Most spectral analysis procedures actually deal with discrete frequencies ( $=2 \pi / T$ of the individual sinusoids) which, when averaged over equal intervals, yield a smoother looking plot with more narrow confidence bands. A jagged looking spectrum will have wider confidence limits than a smoothed spectrum computed from the same data.

Integration of a wave spectrum which has been computed as energy per frequency band, $E / \Delta f\left(e . g . \mathrm{m}^{2} / \mathrm{Hz}\right)$, versus frequency yields the total energy of the sea state. This relates directly to actual variance of the water surface elevations such that: 


$$
\sigma_{w s}^{2}=\int S(f) d f
$$

where $\sigma_{w s}^{2}$ is the variance of the water surface elevations and $S(f)$ is the computed energy density spectrum. Spectra in this form are often taken as continuous functions since it is reasonable to expect wave energy to be generated in continuous frequencies.

A parameter in units of wave height which has been used to represent the range of wave heights in a sea state is the zero moment wave height, $\mathrm{H}_{\mathrm{mo}}=4 \sigma_{\mathrm{wS}}$. The "zero moment" title comes from integration of $\mathrm{f}^{\mathrm{n}} \mathrm{S}(\mathrm{f})$ with respect to $f$ where $n$, the power of $f$ in the integral, is zero as with Equation 51. This wave height has been found to be very close to the significant wave height, $\mathrm{H}_{\mathrm{s}}$, of Rayleigh distributed seas in deep water. $\mathrm{H}_{\mathrm{s}}$ typically departs from $\mathrm{H}_{\text {mo }}$ in shallow water (Thompson and Vincent 1983). The zero moment wave heights corresponding to two interacting wave groups of double-peaked energy density spectra, as illustrated in Figure 4, can be estimated by splitting the spectrum between peaks and integrating each side separately. There is no widely accepted way to estimate the parameters of multiple wave groups from their combined spectrum, but this method gives an indication of their relative intensity as potential structural design criteria.

A number of parameterized spectra have been developed in the effort to relate wave conditions to winds and geographical factors which constrain generation of waves at sea. These parametric spectral forms nearly all apply to waves in the generation phase, i.e. seas, not swel1. The four most important factors in wave generation are wind velocity (and resultant stress) over water, duration of that velocity, fetch (distance over water which the wind blows), and water depth. Depth limitations on wave spectra are the most recent effects to be reliably defined in combination with other primary constraints. Other factors which also can be significant are preexisting waves (wave-wave interaction) and the presence of strong currents (wave-current interaction). Waves generated by winds of a given velocity in water of a given depth thus are either duration limited, fetch limited, or fully developed and may be affected by waves coming into the generation area from a distant source and strong currents. Virtually all parametric spectral shapes have the "tall" of the spectrum, the portion to the right of the peak, 
proportional to $\mathrm{f}^{-5}$, following the work of Phillips (1977). An advanced form, as an example, is the TMA spectrum (Hughes 1984), which includes the depth limitation:

$$
S(f, d)=\alpha g^{2} f^{-5}(2 \pi)^{-4} \phi(2 \pi f, d) e^{-5 / 4\left(f / f_{p}\right)^{-4}} \gamma^{\exp -\left(f / f_{p}-1\right)^{2} / 2 \sigma_{*}^{2}}
$$

where $\phi(2 \pi f, d)$ is a function of depth (d), $k$ (the wave number, $2 \pi / L$ ), and $\omega$ (the radial frequency, $2 \pi / T$ ) allowing portions of the spectrum to be transformed by linear wave theory. The term $\alpha$ is the Phillips equilibrium constant, which has recently been taken to be a function of depth, wind speed, and peak frequency, $f_{p}$. The $\gamma$ term is the "shape parameter" which is a function of wind speed and fetch. The $\sigma_{*}$ term is an empirical factor affecting shape of the spectrum on either side of the peak. This form applies to fully developed or "saturated" seas in decreasing depths. Figure 5 illustrates the effect of changing depth on TMA spectral shape. The deepwater predecessor of the TMA spectrum, the JONSWAP spectrum, now is widely used to predict both fetch and duration limited wave growth in deep water (Vincent 1984). 


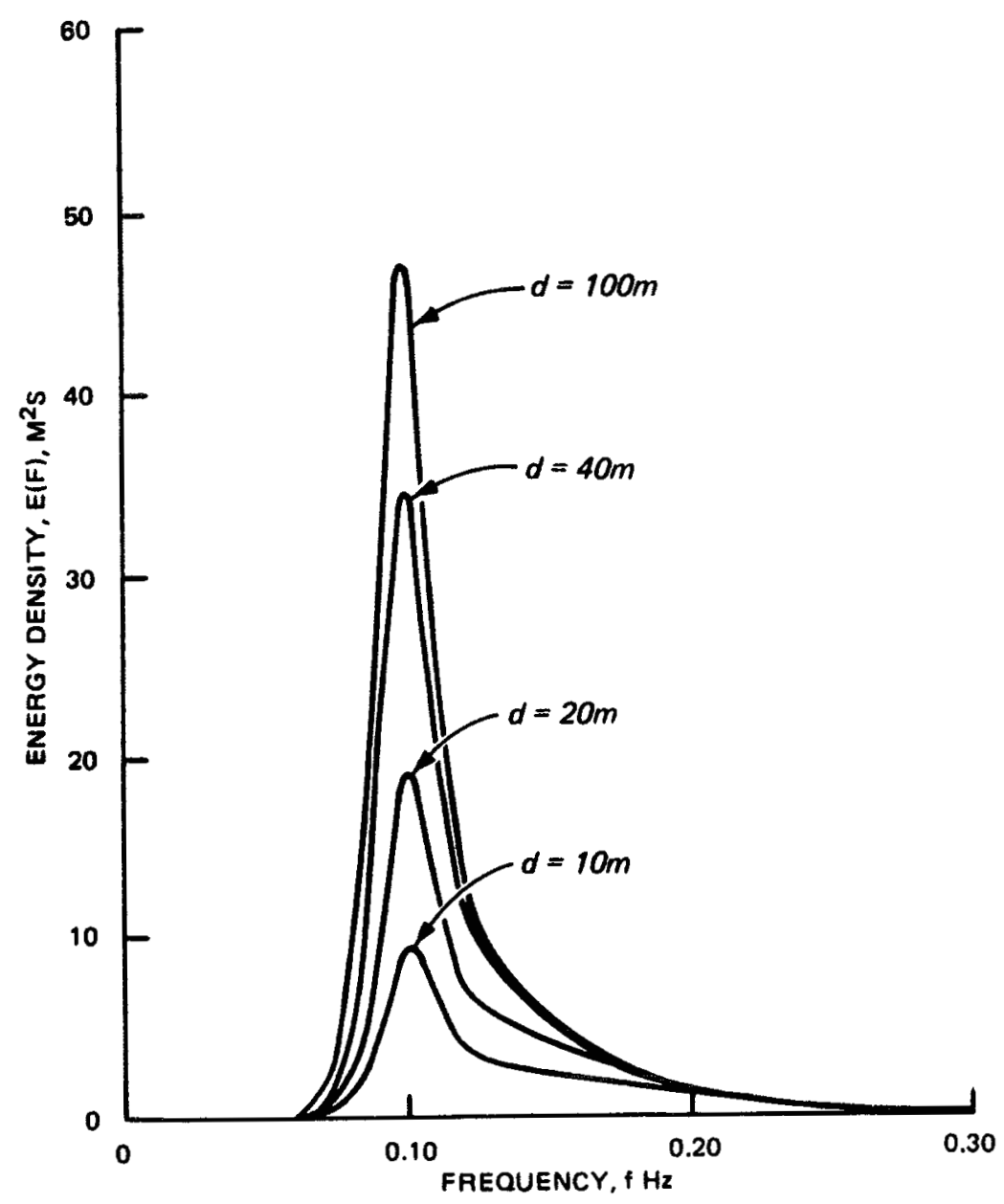

Figure 5. The TMA spectrum 


\section{General Background of Phases I and II}

The WIS program of the US Army Engineer Waterways Experiment Station began in 1976 with the goal of providing a long-term (20-year) hindcast of wave information for use in development of design criteria for coastal projects. The term "hindcast" refers to the technfque of simulating historical wind and wave generation from pressure data available from surface weather charts. The basic raw data for hindcasting thus are instanteous pressure recordings which meteorologists have applied to produce pressure fields delineated by isobars and other notation common to surface weather charts. These "highs," "lows," "fronts," "troughs," and "ridges" are then applied to simulate the effect of corresponding wind fields on the surface of the ocean.

The WIS program first transcribed into digital form pressures from surface weather charts from 1956-1975 for the North Atlantic, Gult of Mexico, and North Pacific, with as much checking for accuracy and consistency as the basic data allowed (Corson, Resio, and Vincent 1980). I'his information was available at 6-hr intervals. Winds which would have existed with each consecutive distribution of pressures next were simulated by a series of numerical models assuming quasigeostrophic flows and a planetary boundary layer which yielded surface level (19.5-m elevation) wind fields. These wind fields were in turn adjusted with observations of actual wind velocities, wherever possible (Resio, Vincent, and Corson 1982).

Given the database of surface level winds created by the steps above, basin geometry and grid were defined for numerical simulation of deepwater wave generation. Figures $\mathrm{A}-1$ and $\mathrm{A}-2$ illustrate deepwater (Phase I) grids for the North Atlantic and North Pacific 0ceans. Execution of a deepwater numerical model of wave generation, which took into account fetch, duration, directional spreading effects, and wave-wave interaction, produced a database of two-dimensional spectra and related parameters at intersections of the grid lines. Detailed wave information was retained only at intersections marked with dots and published in written form (Corson et a1. 1981 and Ragsdale 1983) tor the numbered sites.

Phase II of the WIS program performed simulations at 3-hr intervals of wave generation in a manner similar to Phase I (deep water), but at a finer 
scale and in transitional depths of the continental shelf. Figures $\mathrm{A}-3$ and A-4 show the Atlantic and Pacific Phase 11 grids and stations where wave information has been published (Corson et al. 1982 and Ragsdale 1983). In addition to Phase I factors, Phase II simulations took into account the sheltering effect of large-scale land masses, refraction, and shoaling. The Phase I wave information served as a boundary condition at the seaward limit of the Phase II grid.

Neither Phase I nor Phase II distinguished seas and swe11, but rather dealt with individual discrete frequency bands over the entire two-dimensional spectrum at any point. Phase III decomposed this spectrum into seas and swe11, treating seas as two-dimensional spectra and swe11 as monochromatic, unidirectional wave groups. The definition of swell as waves which have travelled beyond the area in which they were generated was applied. This approach economized computations by taking advantage of the fact that swell typically has its energy highly concentrated in a narrow band of frequencies, which is close to a monochromatic condition. Wave parameters computed and recorded in the Phase III database included zero moment wave height, peak period, and dominant direction of propagation. Monochromatic equivalents were recorded in the case of swell and combined wave heights were recorded as:

$$
\mathrm{H}_{\text {combined }}=\sqrt{\mathrm{H}_{\text {sea }}^{2}+\mathrm{H}_{\text {swel1 }}^{2}}
$$

Period and direction recorded in the "combined" category corresponded to the peak period and dominant direction of either the sea or swell, whichever had the higher zero moment wave height (Brooks and Corson 1984). The Phase III approach is most valid for coasts with straight and parallel contours and is less precise in more complex bathymetry.

\section{Phase III Shallow-Water Wave Information}

Phase III efforts of the WIS program were directed at providing wave information suitable as design criteria for a great many coastal endeavors in a depth of $10 \mathrm{~m}$ at 10 -mile (16.1-km) intervals along the Atlantic (Jensen 1983a) and Pacific (Ragsdale 1983) coasts of the continental United States. This task dealt with transformation of wave conditions from Phase II stations to 
166 Atlantic and 134 Pacific Phase III stations. Figure A-5 11lustrates a section of the Atlantic Phase III stationing system and adjacent Phase II stations. The magnitude of data processing requirements and complexity of the coast at this finer scale led to procedures for estimating wave conditions in shallow water ( $10 \mathrm{~m}$ depth) described briefly below.

A spectral (frequency domain) approach to wave transformation was sought to reduce computational time required to simulate wave transformation in the time domain. A parameterized spectrum was necessary for this, but one as complex as the TMA spectrum, or the most refined spectral forms available at the time of the Phase III procedure tormulation, would have provided an unmanageable computational burden. The one-dimensional parameterized spectrum chosen for Phase Ill simulations had the following form:

$$
\begin{gathered}
S(f)=\alpha g^{2} f^{-5}(2 \pi)^{-4} \quad \text { for } f \geq f_{p} \\
S(f)=\alpha g_{p}^{2} f_{p}^{-5}(2 \pi)^{-4} \exp \left[1-\left(\frac{f}{f_{p}}\right)^{-4}\right] \text { for } f<f_{p}
\end{gathered}
$$

which applied the wel1-accepted $f^{-5}$ right-hand tail, but 1imited free parameter determination to only two variables, $\alpha$ and $f_{p}$ (Kitalgordskif 1962). A spreading function, assumed to be independent of the one--dimensional spectral form, was defined as:

$$
\theta(\theta)=\frac{8}{3 \pi} \cos ^{4}\left(\theta-\theta^{\prime}\right)
$$

where $\theta^{\prime}$ is the predominant direction of propagation. Thus, the twodimensional form was:

$$
S(f, \theta)=S(f) \theta(\theta)
$$

Within each 10-mile $(16.1-\mathrm{km})$ interval defined as Phase III stations along the coast, bottom contours were assumed to be straight and parallel. A specific orientation was assigned to each interval such that departure of this assumption from the true situation was minimized. The processes of refraction 
and shoaling, as defined by Snell's Law and sinusoidal theory, were applied to increments of trequency and direction of the directional distribution defined by $S(f, \theta)$. Wave energy propagating seaward was ignored.

The geometric relationship between a Phase III station and adjacent Phase II stations from which the model derived its input was the most important consideration in addressing sheltering in Phase 1II. Basically, the geometric shadow of a landform to wave energy from a specific direction was considered as absolute, i.e., no energy was propagated into the shadow area. This is a gross simplification, but it made the simulation of sheltering effects practical for Phase III. Discrete combinations of frequency and direction were considered incrementally with respect to sheltering, as they were with refraction and shoaling.

The problem of wave-wave interaction and the losses it can cause, evidenced by white caps and other signs of turbulent energy dissipation, was addressed by definition of another spectral form for shallow water. Principles of similarity were applied to derive a form consistent with Phase I and II deepwater considerations, which predicted the spectrum in shallow water:

$$
S(f)=\alpha g h(8 \pi)^{-2} f^{-3} \quad \text { for } \quad f \geq f_{p}
$$

This relation is consistent with the visualization that energy losses due to wave-wave interaction tend to occur at high frequencles, while energy at lower frequencies is conserved. A further application of equilibrium principles allowed derivation of an integrated form of this equation which describes the dependency of sea wave heights on depth:

$$
\left(\mathrm{H}_{\text {seas }}\right)_{\max }=\frac{(\alpha g d)^{1 / 2}}{\pi f_{c}}
$$

where $f_{c}=0.9 f_{p}$ is a energy cutoff frequency (lower integration limit) and $\left(\mathrm{H}_{\text {seas }}\right)_{\max }$ is the upper limit of seas wave heights. Surf zone breaking was treated difterently for swe11, however, in the manner of estimating breaker heights for monochromatic waves. A breaking coefficient of 0.6 was applied, which is consistent with recent measurements of breaking waves by the WES (Jensen, Robert E., verbal communication, February 1986): 


$$
\mathrm{H}_{\max }=0.6 \mathrm{~d}
$$

Extensive comparisons have been made between the limited measured wave data avallable and WIS wave information, generally with acceptable results (Corson and Resio 1981). The reduction of measurements made by wave gages a1so involves compounded assumptions, and discrepancies between wave information based on gage data and Phase IIJ wave information could not always be resolved. More accurate techniques are avallable for site-specific simulation of the transformation of waves into shallow water. These methods unfortunately were too complex to apply systematically on the scale of the WIS Phase III endeavor, though improvements are under consideration. The presently available end product of Phase. III is, however, an excellent tool for coastal engineers to use in the planning and preliminary design stages of coastal projects for development of design criteria. More complex and expensive numerical simulations and physical scale models can be performed in the detailed desfgn phase after the economic feasibility and financeability of the project has been ensured. Even in the final stage, some basis of experiment design and cross-check on other sources of wave information is necessary. The 20-year period of record for the WIS database can rarely be exceeded by other reliable sources. The WIS wave information provides, therefore, a vast improvement to the confidence of each design effort to which it is applied. 
CHAPTER V: LITERATURE REVIEW OF STORM DURATION STUDIES

Recent Literature on the Duration of Sea States

Table 1 presents mean durations for various weather types in the British Isles which were excerpted from Barry and Perry (1973). The weather type

Table 1

Mean Durations of Weather Types in the British Isles

\begin{tabular}{lcccc}
\hline & \multicolumn{4}{c}{ Mean Duration (days) } \\
\cline { 2 - 5 } Weather Type & \multicolumn{2}{c}{ January } & \multicolumn{1}{c}{ July } \\
\cline { 2 - 5 } Westerly & $1910-1930$ & $\frac{1948-1968}{1.1}$ & $\frac{1910-1930}{2}$ & $\frac{1948-1968}{2.6}$ \\
Northerly & 1.9 & 1.8 & 2.0 & 2.7 \\
Easterly & 2.0 & 2.6 & 2.0 & 1.8 \\
Southerly & 1.4 & 1.8 & 1.7 & 1.8 \\
Cyclonic & 2.2 & 1.3 & 1.7 & 1.3 \\
Anticyclonic & & 1.9 & 2.5 & 2.2 \\
& & & & \\
\hline
\end{tabular}

identified as "cyclonic" is assumed to meet the standard definition of winds circulating around a low pressure area (Lester 1973), corresponding to the extratropical cyclonic events which are simulated in the WIS program. This type of weather is noted to have a mean duration of 1 to 2 days in Great Britain, with some seasonal variation. Statistics of this type would surely vary from region to region, but the order of magnitude in hours, say less than 100 but more than 10 , can serve in this investigation of storm characteristics as a rough first measure of a reasonable mean duration. The untrained intuition of any regular viewer of television weather reports would likely agree with this typical range.

Surprisingly little material was available in the coastal engineering and oceanographic literature which dealt directly with the duration of extreme events at sea or of extreme wave conditions. Occasional references were made to a 3-hr period of wave height stationarity assumed for practical purposes in measurement programs (e.g., Agerschou et a1. 1983 and Massie 1976). The Interval between samples of wave measurements is commonly set at $3 \mathrm{hr}$. 
Publications of WIS wave information (Corson et al. 1981 and 1982 and Jensen 1983a) tabulated durations of significant wave heights above selected thresholds, but did not discuss trends or other implications inherent in this information.

\section{North Sea Investigations of Houmb and Vik}

The most rigorous work to date has been a series of studies by two Norwegian investigators (Houmb 1971, Houmb and Vik 1975, Vik and Houmb 1976, and Houmb and Vik 1.977). Other authors have reviewed this work (e.g. Battjes 1977, PIANC 1979, and Bruun 1985), but no significant advances seem to have been made regarding the characterization of extreme event durations following Houmb and Vik (1977). Their work on the duration of sea states culminated in the findings of the last reference, which will be reviewed in detail in the following paragraphs.

Houmb and Vik (1977) considered both the duration of extreme events, specified as the time during which the significant wave height exceeded a given threshold, and the duration of "calms" between these extremes. The basis of their investigations was wave recordings made at five North Sea sites where depths varied from 80 to $250 \mathrm{~m}$. Three sites involved time series measurements made for $20 \mathrm{~min}$ every $3 \mathrm{hr}$. A fourth site involved 10-min time series measured every $4 \mathrm{hr}$. The sequences of these measurements were not continuous and varied in total period of record from 3 to 31 months. The fifth site provided observations from a rescue vessel every $3 \mathrm{hr}$ from 1959 to 1974 during October through March only. These observations classiffed predominant wave heights into classes of $0.5 \mathrm{~m}$.

A theoretical approach toward prediction of variation of storm durations was first proposed by Houmb and Vik (1977) which took the frequency, or marginal probability density, of threshold up-crossings (i.e. $\mathrm{H}_{\mathrm{s}}^{\prime}=\mathrm{dH}_{\mathrm{s}} / \mathrm{dt}$ was positive) as:

$$
f\left(H_{t}\right)=H_{s}^{\prime} f\left(H_{t}, H_{s}^{\prime}\right) d H_{s}^{\prime}
$$

where $H_{t}$ is the specified threshold and $f\left(H_{t}, H_{s}^{\prime}\right)$ is the joint probability density of $\mathrm{H}_{s}$ and its time derivation, $\mathrm{H}_{S}^{\prime}$. The average duration of extreme events, $t\left(H_{t}\right),\left(H_{s}>H_{t}\right)$ was derived to be: 


$$
t\left(H_{t}\right)=\frac{L\left[1-F\left(H_{t}\right)\right]}{f\left(H_{t}\right) L}=\frac{\left[1-F\left(H_{t}\right)\right]}{f\left(H_{t}\right)}
$$

where $L$ is the period of interest (say 50 years) and $F\left(H_{t}\right)$ is the cumulative distribution of $\mathrm{H}_{s}$ evaluated at $\mathrm{H}_{t}$, or the probability that $\mathrm{H}_{\mathrm{s}}$ is equal to or less than $H_{t}$. The quantity $\left[1-F\left(H_{t}\right)\right]$ is the probability that

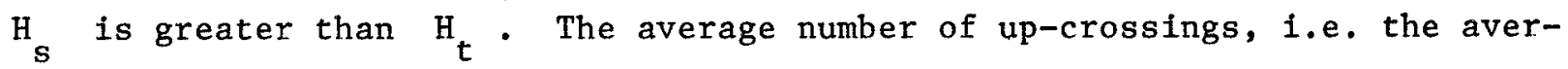
age number of extreme events, during the period $L$ was taken to be $f\left(H_{t}\right) L$, where $f\left(H_{t}\right)$ is the probability density of $H_{s}$ at $H_{t}$ given above.

The rate at which $\mathrm{H}_{\mathrm{s}}$ changes (from one stationary period to the next) was assumed to be a Poisson process, $i . e . H_{S}^{\prime}$ was assumed to be independent of $\mathrm{H}_{S}$. The joint probability density function $f\left(\mathrm{H}_{S}, \mathrm{H}_{S}^{\prime}\right)$ could then be evaluated as:

$$
f\left(H_{s}, H_{s}^{\prime}\right)=f\left(H_{s}\right) f\left(H_{s}^{\prime}\right)
$$

The marginal probability density function $f\left(\mathrm{H}_{\mathrm{s}}\right)$ was assumed to follow a Weibull distribution whose corresponding distribution function had the form:

$$
f\left(H_{s}\right)=1-\exp \left(-\frac{H_{s}-H_{o}}{H_{c}-H_{o}}\right)^{T}
$$

and

$$
f\left(H_{s}\right)=\frac{T\left(H_{s} H_{o}\right)^{T-1}}{\left(H_{c}-H_{o}\right)^{T}} \exp \left(-\frac{H_{s}-H_{o}}{H_{c}-H_{o}}\right)^{T}
$$

where $\mathrm{H}_{\mathrm{c}}, \mathrm{H}_{\mathrm{o}}$, and $\mathrm{T}$ are parameters of the distribution.

The function $f\left(\mathrm{H}_{\mathrm{S}}^{\prime}\right)$ was assumed to be normally distributed with zero mean for positive values of $\mathrm{H}_{\mathrm{s}}^{\prime}$ (increasing $\mathrm{H}_{\mathrm{S}}$ ). The data seemed to support this assumption. This gave $\left.\mathrm{f}_{\mathrm{s}}^{\prime} \mathrm{H}_{\mathrm{s}}^{\prime}\right)$ as:

$$
f\left(H_{s}^{\prime}\right)=\frac{1}{2 \pi \sigma_{h}} \exp \left(\frac{-H_{s}^{\prime 2}}{2 \sigma_{h}^{2}}\right)
$$


where $\sigma_{h}$ is the standard deviation of $H_{S}^{\prime}$ which was evaluated from the data. The differences between $\sigma_{h}$ values computed for increasing and decreasing $\mathrm{H}_{\mathrm{s}}$ were found to be negligible. Furthermore $\sigma_{h}$ was not noted to follow a seasonal pattern. This application of the above normal distribution with zero mean gave the advantage of requiring only one parameter, $\sigma_{h}$, to be determined empirically, in addition to those $\left(\mathrm{H}_{c}, \mathrm{H}_{0}\right.$, and $\mathrm{T}$ ) for $\mathrm{F}\left(\mathrm{H}_{\mathrm{s}}\right)$. The resulting function for the mean duration $t\left(\mathrm{H}_{t}\right)$ reduced to:

$$
t\left(H_{t}\right)=\frac{2 \pi\left(H_{c}-H_{o}\right)^{T}}{T \sigma_{h}\left(H_{t}-H_{o}\right)^{T-1}}
$$

The cumulative distribution of measured durations was found to be well represented by a Weibull distribution of the form:

$$
F(t)=1-\exp \left[-\left(\frac{t}{t_{c}}\right)^{\alpha}\right]
$$

where $\alpha$ is the shape parameter and $t_{c}$ is the scale parameter. Average durations estimated by the $\mathrm{t}_{\mathrm{t}}\left(\mathrm{H}_{\mathrm{t}}\right)$ function derived above also compared well with means computed from the set of measured durations. Houmb and Vik (1977) gave examples of how this formulation could be applied in the conduct of offshore ofl explorations, as in prediction of duration of operation down time caused by extreme wave conditions.

The formulation of Houmb and Vik (1977) was well defended in terms of conceptual limits of parameters such as $H_{s}^{\prime}$ and $\sigma_{h}$. They tested their hypotheses as well as possible with their limited data set, but urged in their conclusions that further investigations be pursued with more comprehensive wave intormation. 


\section{Choice of Sites}

Each Phase III site includes 58,440 records of wave information $3 \mathrm{hr}$ apart from 0000 (midnight) January 1, 1956, to 2400 (midnight) December 31, 1975 (20 years). Four sites were originally chosen for analysis, two on the Atlantic coast and two on the Pacific coast. A third Atlantic site was later chosen when it was discovered the first two had very similar distributions of significant wave heights. The five sites ultimately investigated are listed in Table 2. They were intended to represent a wide geographical spread in

Table 2

WIS Phase IIJ Stations Investigated

\begin{tabular}{|c|c|c|c|}
\hline Station & Site & Latitude & Longitude \\
\hline A3061 & Atlantic City, New Jersey & $39.34^{\circ} \mathrm{N}$ & $74.47^{\circ} \mathrm{W}$ \\
\hline A3083 & Nagshead, North Carolina & $35.94^{\circ} \mathrm{N}$ & $75.61^{\circ} \mathrm{W}$ \\
\hline A3142 & Daytona Beach, Florida & $29.20^{\circ} \mathrm{N}$ & $81.00^{\circ} \mathrm{W}$ \\
\hline P3036 & Newport, Oregon & $43.63^{\circ} \mathrm{N}$ & $124.08^{\circ} \mathrm{W}$ \\
\hline P3105 & Half-Moon Bay, California & $37.45^{\circ} \mathrm{N}$ & $122.45^{\circ} \mathrm{W}$ \\
\hline
\end{tabular}

hopes that analysis would reveal any important universal traits or significant geographical differences. Figure 6 shows their relative location along the US coasts. Statistics published by the WIS program (Jensen 1983a, b) for the Atlantic sites are presented in Appendix A. Wave helght frequency tables (not yet published by the WIS program) for the two Pacific sites also are presented In Appendix A.

\section{Basic Treatment of WIS Phase III Wave Information}

Table Al 11lustrates format and unit conventions of the WIS Phase III database. Dates are given as year/month/day and times referenced to the 24-hr clock (1.e., military time). Wave heights, 1.e. the zero moment wave heights derlved for each 3-hr time step, are reported in centimetres. Wave periods, 


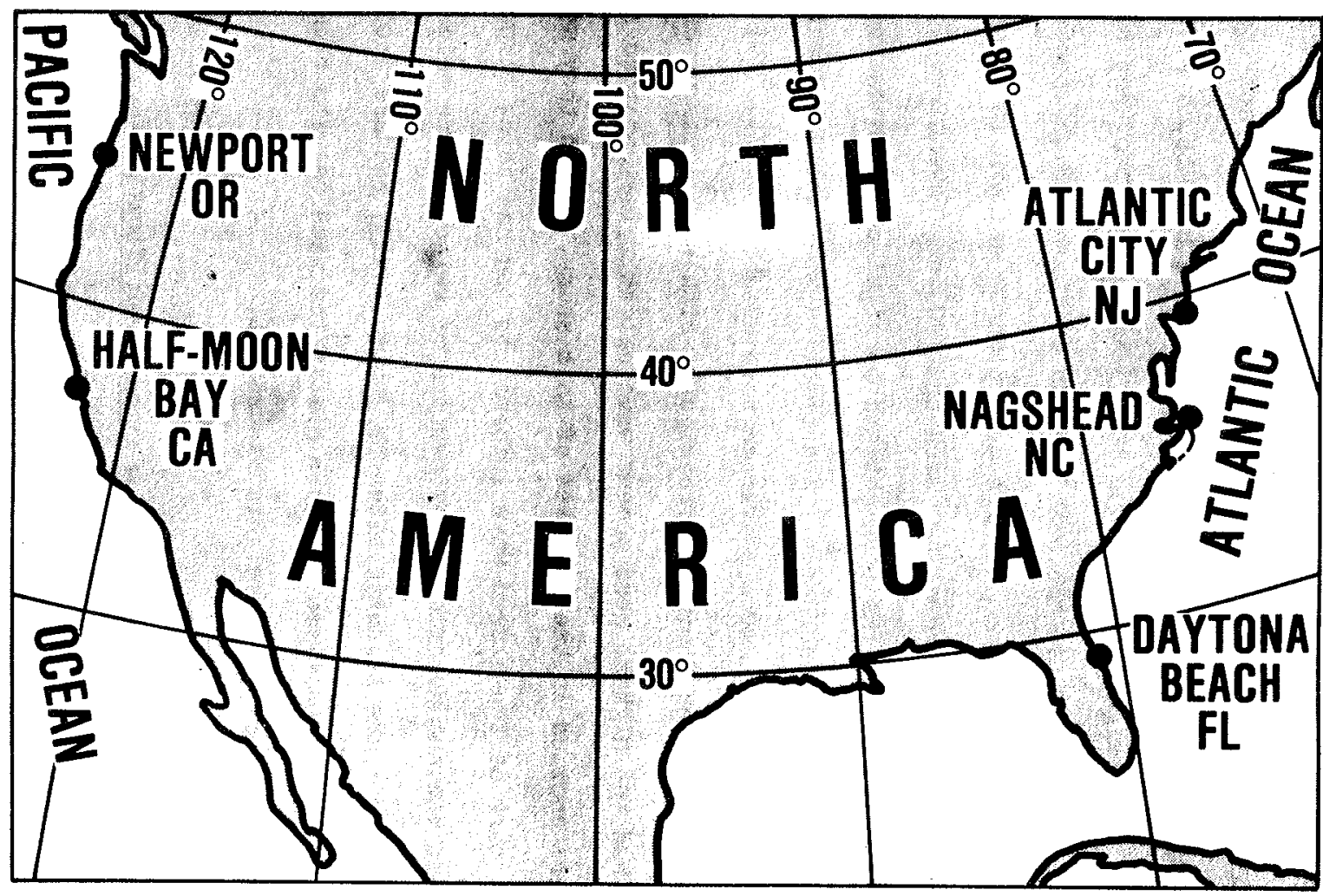

Figure 6. Geographic relation of sites investigated

i.e. the peak periods of the hindcast spectra, are reported to the nearest second. Direction or azimuth is reported in degrees relative to the shoreline, such that $90 \mathrm{deg}$ is a wave direction travelling straight into the straight and parallel contours assumed for each 10-mile (10.1-km) shoreline increment. Combined statistics presented in Table Al include the geometric average wave height (Equation 53) and the peak period and predominant direction of either seas or swell, whichever had the highest zero moment wave height. Combined statistics were applied in analyses of this study, though they were not actually a part of stored wave information and had to be computed. Mean and maximum duration of exceedance of selected wave heights were reported for the Atlantic sites by Jensen (1983b) and are included in Appendix B. A comparison of those statistics with results from this investigation is made later in this report.

\section{The Problem of Extreme Event Identification}

The work of Houmb and Vik (1977) on duration of sea states was apparently performed exclusively with significant wave heights crossing an 
arbitrary threshold. This implies that the significant (or zero moment) wave height is the most appropriate measure of the extreme events' intensities for applications of duration statistics. Other parameters can be conceived, however, which might be better representatives of the overall intensity or extreme nature of a storm. The most obvious alternate parameter would be peak period, to which refraction, shoaling, and wave breaking are all quite sensitive. Wave length might be another, although wave length at any depth is a function of period. Wave steepness, H/L, is commonly associated with breaker characteristics and forces on coastal structures. If the ratio of zero moment wave height to deepwater wavelength corresponding to the peak period is used, representative wave steepness becomes $2 \pi \mathrm{H} / \mathrm{gT}^{2}$. The $2 \pi \mathrm{fac}-$ tor is commonly dropped as a part of this dimensionless steepness parameter in favor of $\mathrm{H} / \mathrm{gr}^{2}$.

Wave severity, $\mathrm{H}^{2} \mathrm{~L}$, has recently become of interest as a factor closely related to stabilfty of rubble-mound structures (Graveson et al. 1980 and Ahrens 1984). Wave severity can be thought of as the ratio of wave height cubed (the traditional wave parameter for evaluation of rubble-mound stability) to wave steepness, H/L . Again, significant or zero moment wave height and deepwater wave length corresponding to the peak period of the spectrum are used for convenience, yielding $\mathrm{H}^{2} \mathrm{~L}=2 \mathrm{\pi H}^{2} / \mathrm{gT}^{2}$. It should be noted that the four parameters discussed so far vary the relative influence of wave height and period in the following order: $H, T, H / T^{2}$, and $H^{2} / T^{2}$. These parameters also could be used to define extreme event duration as the time during which consecutive parameter values exceed a specified threshold value.

A fifth parameter which might be important with respect to duration of extreme wave conditions is predominant wave direction. This certainly would be true for sites naturally protected in all but one narrow sector. WIS Phase III data did not include any such sites, however, assuming an open coast with sheltering only from major landforms.

Figure 7 illustrates the time series for wave heights during October 1956 at Nagshead, North Carolina. This particular time span was chosen for presentation because it included rapid changes in wave conditions, especially on October 27 and 28, 1956, as indicated by sharp spikes near the end of the wave helght time series plot of Figure 7. Table Al includes Phase III wave information recorded for these 2 days.

Figure A6 shows the time series of peak wave period during this same 


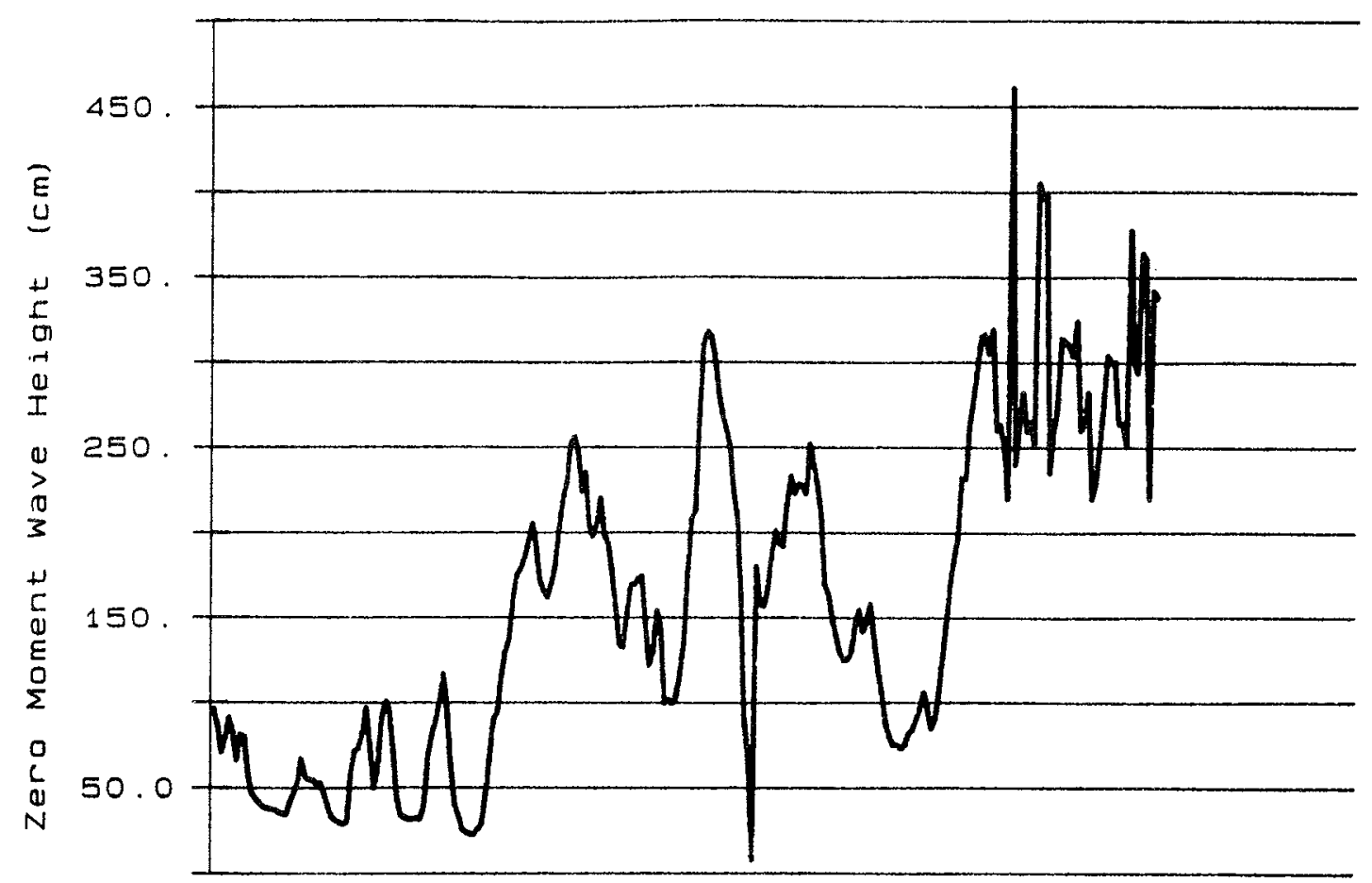

Figure 7. Wave height time series: Nagshead, North Carolina, October 1956

month for Nagshead, North Carolina. The wave period can be seen to vary somewhat out of phase with wave height and to have a tendency to remain constant for significant time spans and then change abruptly. A plot of ${\mathrm{H} / \mathrm{gT}^{2}}^{2}$ for the same period at Nagshead (Figure A7) appears more like the wave period time serles than the wave height time series, also tending to vary slowly for significant time spans and change abruptly (the influence of $T^{2}$ in the denominator). A plot of wave severity, $\mathrm{H}^{2} \mathrm{~L}$ (Figure A8), for the same time period dramatically delineates extremes of the wave height time series. When plotted in Figure $A 9$ as $\left(H^{2} \mathrm{~L}\right)^{1 / 3}$, however, wave severity very closely resembles the wave height time series plot. Wave severity in this form has the same units as wave height and includes the influence of $\mathrm{H}^{2}$ to balance the influence of $\mathrm{T}^{2}$ in the denominator. The plot of direction (Figure Al0) does not indicate direct relation to the wave height plot and is much more erratic, even in nonextreme periods. Direction can be considered to be practically independent of the intensity of wave conditions since it is controlled almost exclusively by geometric factors.

The convention of previous investigators (Houmb and Vik 1977) to rely solely on variation in zero moment wave height for definition of extreme event 
durations was maintained in this study. This parameter is most easy to visualize and has a long tradition as the critical measure of intensity of extreme events at sea. Variations of $H^{2} \mathrm{~L}$ and $\left(\mathrm{H}^{2} \mathrm{~L}\right)^{1 / 3}$ show promise, but the large units of $\mathrm{H}^{2} \mathrm{~L}$ make results of computations rather abstract and the variation of $\left(H^{2} L\right)^{1 / 3}$ seemed quite close to that of $H$. Relationships of individual extreme event durations (measured by variation of $H$ ) to peak conditions measured by all parameters discussed above were investigated, however, and the results of that analysis are reported later in this report.

An investigation of actual weather conditions on the Atlantic coast in the time frame surrounding October 27-28, 1956, was conducted to better understand what events were actually driving the numerical simulations to produce irregularities in the time series of Figure 7. First, Phase II data input to the Phase III numerical wave transformation were inspected. Table A2 presents Phase 11 information at Station A2037, at $36.06^{\circ} \mathrm{N}$ latitude and $74.92^{\circ} \mathrm{W}$ longitude, approximately 33 nautical miles $(61 \mathrm{~km})$ east-southeast of Nagshead in about $240 \mathrm{ft}(73 \mathrm{~m})$ of water. The intermittent appearance and disappearance of swell can be seen to follow a similar pattern in the Phase III site of interest (Station A3083) and the Phase II site directly offshore (Station A2037). Wave heights in deeper water are higher, lacking the depth limitations inherent in Phase III simulations. Wave periods of both sites are identical, unaffected by the wave transformation processes simulated in Phase III. The direction convention in Phase II is different, indicating the direction from which waves are travelling toward the center of the compass rose. Phase II data do not include anything significantly revealing about the irregularities of interest, basically showing the same patterns in this case.

The nearest Phase I site offshore of Nagshead was Station Al005 at $35.4^{\circ} \mathrm{N}$ latitude and $72.3^{\circ} \mathrm{W}$ longitude, located in deep water approximately 163 nautical mfles $(302 \mathrm{~km})$ east-southeast of Nagshead, North Carolina. Table A3 shows Phase I information recorded for October 26-28, 1956. There is only one record which included swe11; that record did not dominate the combined wave height, which appears to be steadily decreasing at that time. It is important to recognize that a significant travel time would be involved between this Phase I site and Stations A2037 or A3083 (approximately 8 and $10 \mathrm{hr}$, respectively, for waves of $11-\mathrm{sec}$ period), so the conditions at a given date and time should be "out of phase" by three to four records.

An inspection of surface weather charts during the later part of October 
1956 for North America and the north Atlantic Ocean was made to Identify synoptic weather systems which may have dominated Phase I and Phase II information. An explanation was sought for the sudden appearance and disappearance of swel1 in the data, as well as an explanation of differences between Phase I and Phase II wave information. Figure 8 illustrates recorded weather patterns of October 26-28, 1956, showing the presence of a generally stationary, weakly defined, low pressure system of fluctuating intensity offshore of Cape Hatteras. This location is close to Station A1005; thus, the basic definition of swe1l as waves which have left their area of generation could explain the lack of swell in Phase I data. The wave field at this point would have been under the influence of cyclonic winds of the low pressure system and thus only seas would have existed, as defined by WIS conventions. The relative position of Stations A2037 and A3083 in combination with the fluctuating intensity of the low pressure system appears to have caused swell either to come from too tar south to affect Nagshead or to exist only as seas, except for the spikes of Figure 7. This set of circumstances is probably exceptional, but an understanding of the real weather patterns driving numerical simulations of the WIS program in this instance may help explain trends of duration revealed by further analysis of WIS data.

\section{Analytical Procedure and Results}

A FORTRAN computer program was written which read the 58,440 records stored for each Phase III site and maintained a record of the number of consecutive records, each of which had a combined wave height above a specified wave height threshold, $\mathrm{Hl}$. Subsequent use of the term "extreme event" refers to events defined in this manner. The number of extreme events was counted and statistics including the maximum, minimum, mean, and standard deviation durations were computed. Peak conditions of each extreme event were noted as the highest combined wave height in a consecutive series above the threshold, and the period and direction of sea or swe11, whichever had the highest incremental wave height. Maximum, minimim, mean and standard deviation wave heights also were computed. Each data set included 20 years of record, so the number of extreme events per year (the Poisson lambda parameter) was computed as the total number of events divided by 20 .

Initial runs of this extreme event identification program resulted in a 

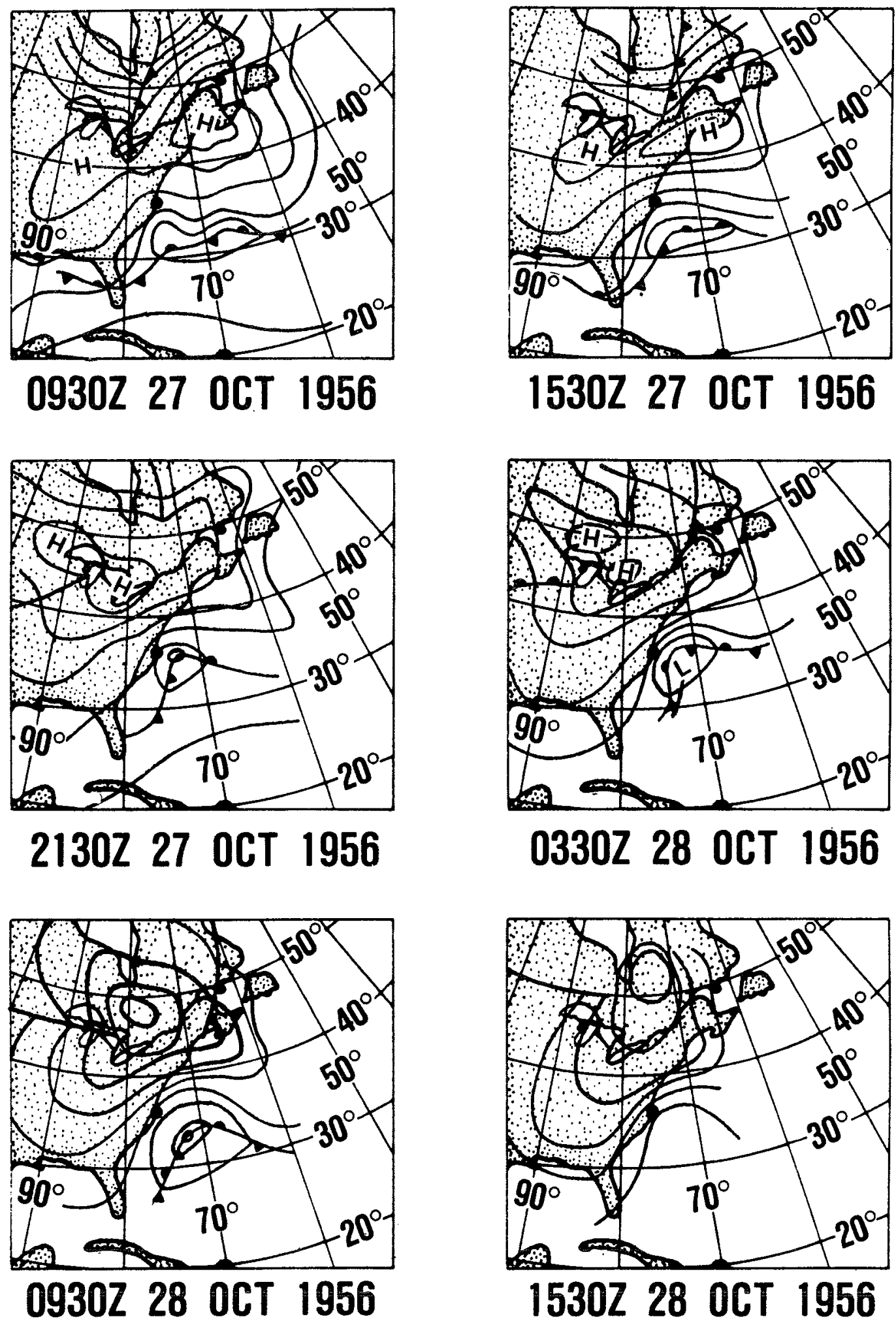

Figure 8. Eastern US surface weather patterns: October 1956 
surprisingly large number of extreme events, consistently on the order of 30 to 40 percent of all extreme events identified, to be only $3 \mathrm{hr}$ in duration, i.e., only one record above the threshold. The actual duration could be anywhere from 0 to $6 \mathrm{hr}$ for a single record above the threshold, but an average value of $3 \mathrm{hr}$ was consistently assumed in such cases. Variation of the threshold had little effect on the percentage, although the total number of extreme events was of course affected. Review of climatology considerations Inherent in WIS simulations (Kesio and Hayden 1973; and Corson, Resio, and vincent 1980) did not uncover a rationale for excluding a priori durations that short. In fact, a duration of $3 \mathrm{hr}$ is efther implicitly or explicitly assumed for peak conditions in many wave forecasts, designs, and research efforts relating to the tradition of sampling wave gages at this interval. Average low pressure systems which would generate extreme wave conditions are known to typically last much longer, however, as in the case of the system illustrated in Figure 8 .

In view of this last fact and the example of late October 1956 at Nagshead, the program was adjusted to ignore a lapse below the threshold of only one record ( $1 . e ., 6 \mathrm{hr}$ ) between consecutive extreme events, as Identified previously. This adjustment lowered the number of extreme events of only $3 \mathrm{hr}$ duration (one record above the threshold) only slightly, but a neglect of longer lapses or other adjustments to the identification procedure could not be rationalized. Tables A4-A8 give duration results, following the procedures described above, for the five sites at all thresholds investigated.

Mean and maximum durations for the three Atlantic sites are virtually f.dentical to those reported by Jensen (1983a), with the occasional exception caused by combination of two events separated by only one record with $H$ below the threshold. The mean duration was slightly higher in these few cases.

The percent occurrence of wave heights (percent records $H>H 1$ ) was of special interest since this statistic for a range of $\mathrm{Hl}$ levels is now or will be published and readily avallable for all WIS stations of all three phases. It was hoped this nondimensional parameter could be used as a tool for choosing threshold levels for duration computations which would preclude many of the iterations which otherwise might be necessary. The number of extreme events per year was also of special interest since this parameter is so important in extremal statistics and expectations. 
Figure 9 shows the mean and standard deviation of duration plotted against percent occurrence (actually exceedance) of wave heights above the

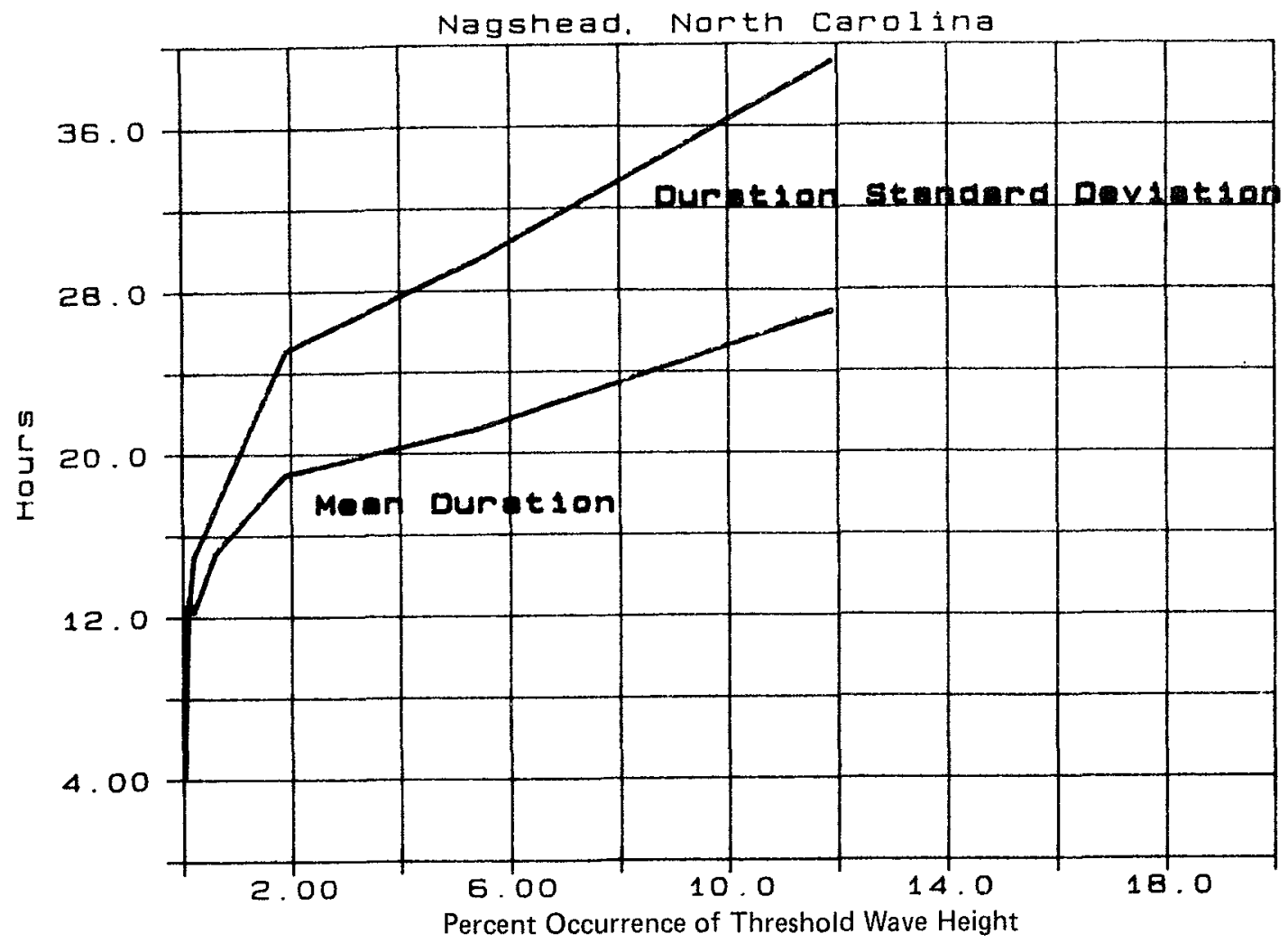

Figure 9. Mean duration and standard deviation versus percent occurrence of wave height threshold, Nagshead, North Carolina

specified threshold for Nagshead. Figures Al1-Al4 show mean and standard deviation durations for the other four sites plotted against percent occurrence of wave helghts above the threshold. Figure 10 shows the nearly linear relationship of the number of extreme events per year with percent occurrence of wave helghts above a specified threshold for Nagshead. A similar trend is evident for higher wave with similar percent occurrence at Newport, Oregon, as shown in Figure A15. These plots in themselves do not indicate an outstanding range of percent occurrence as a choice for definition of extreme events and durations. Some subjective choices can be made since an important purpose of this exercise is to Identify extreme events. Clearly, an excessively large number of extreme events per year, say more than 20, will probably include some events that can hardly be regarded as "extremes" in the practical sense. On the other hand, an average number of extreme events per year less than one or two would generally imply exclusion of some events which belong in a 


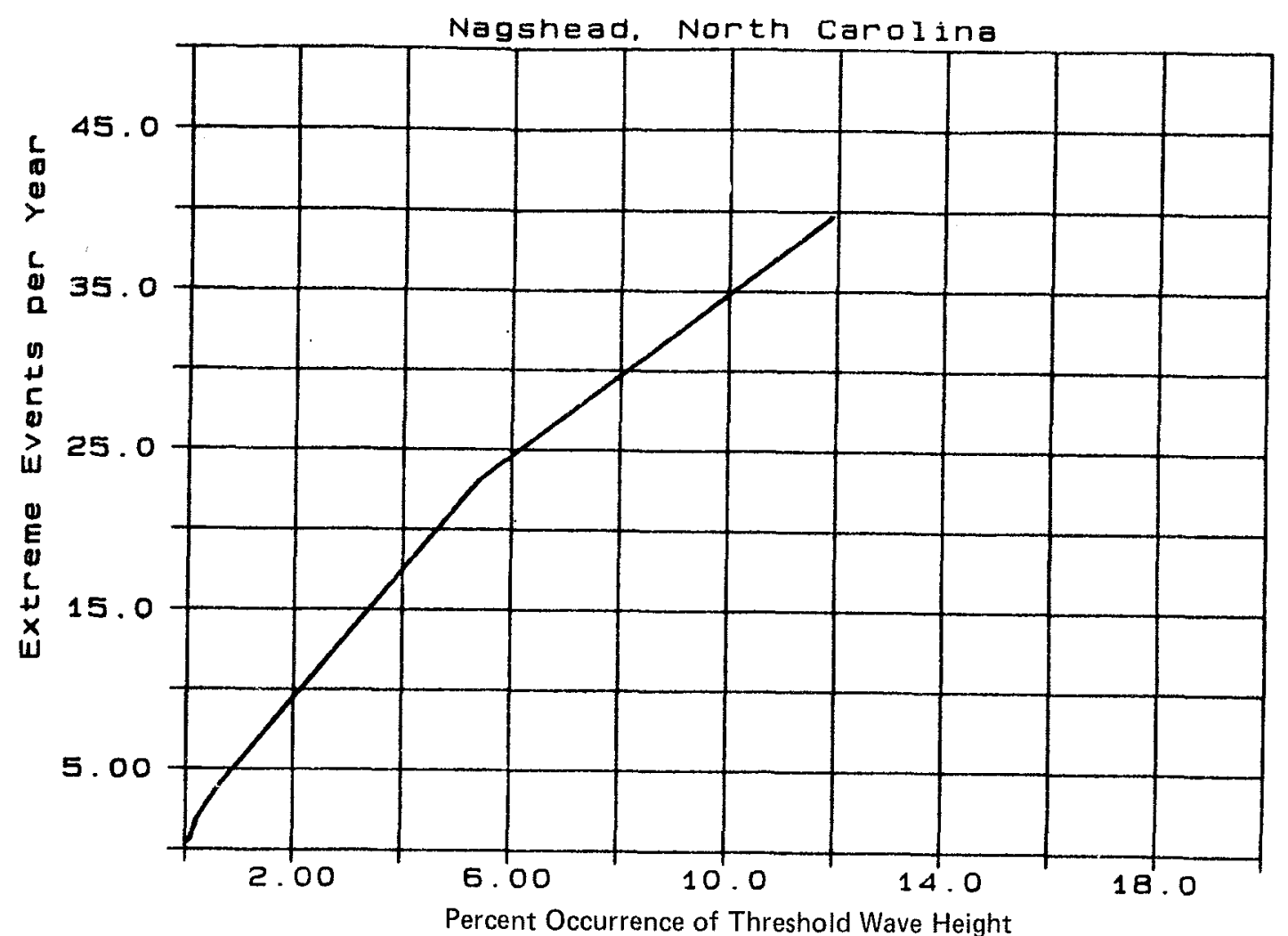

Figure 10. Extreme events per year versus percent occurrence, Nagshead, North Carolina

population of extremes. These considerations are consistent with the author's experience in developing design criterla based on extremal statistics of peak wave helght conditions (e.g. Andrew, Smith, and McKee 1985).

A simple linear regression of extreme events per year with percent occurrence of wave helghts above the threshold, constrained to pass through the origin, for the 41 cases considered at all. five sites indicates that percent occurrence $=0.3 \lambda$ with a correlation coefficient of 0.97 . This relation ap plies to both the Atlantic and Pacific sites addressed individually, even though the absolute value of wave heights themselves on the Pacific are substantially higher than those on the Atlantic at the same percent occurrence leve1s. A range in $\lambda$ of 2 to 20 thus would correspond to a range in percent occurrence of 0.6 to 6.0 percent for the choice of a desirable threshold leve1, $H 1$. The lower limit of this range would guarantee a sample size of at least 40 extreme events, which is generally desirable for most statistical considerations. The choice of a threshold wave height may be made more precisely when some physical tolerance level is at issue, for example the point 
at which some operation at sea must be temporarily terminated.

The other parameters presented in Tables A4-A8 show interesting trends. The minimum duration was $3 \mathrm{hr}$ in every case except one where only three extreme events were identified. A count of extreme events with a 3-hr duration for the Nagshead cases indicated 32 to 48 percent of extreme events shared the minimum duration. No relation of the number of extreme events with a 3-hr duration to the threshold level was apparent. 'the maximum duration can be seen to be proportional to percent occurrence of wave heights above the threshold and typical1y many standard deviations above the mean. The mean duration accordingly also is proportional to percent occurrence of wave heights above the threshold. The standard deviation was rarely less than the mean, but always of the same order of magnitude. A lack of central tendency for durations was noted by Houmb and Vik (1977).

Another scheme of extreme event identification was investigated which actually applied a lower threshold $H 1$ in the same way for determination of duration, but only to extreme events whose peak (combined) wave height was above a second higher threshold, $\mathrm{H} 2$. The most notable effects of the second threshold were to substantially reduce the number of extreme events per year for a given $\mathrm{HI}$ threshold and to reduce the number of extreme events with a 3-hr duration to zero in nearly every case. Variation of $\mathrm{Hl}$ with a fixed H2 had little effect on the number of extreme events per year. The central tendency of durations was somewhat stronger in these subsets, with the standard deviation often, but not always, less than the mean. These two parameters consistently retained the same order of magnitude.

Tables A9 and Al0 present the parameter values computed for various combinations of $\mathrm{H} 1$ and $\mathrm{H} 2$ at the Nagshead and Daytona Beach sites. Figures A16 and A17 show variation of the mean and standard deviation durations with percent occurrence of the lower threshold $\mathrm{H} 1$ at a upper threshold $\mathrm{H} 2$ tor peak conditions fixed at $300 \mathrm{~cm}(0.6$ percent) and $300 \mathrm{~cm}(0.8$ percent) for the Newport and Nagshead sites. This scheme of double thresholds for extreme event identitication was not pursued further since it was considered more desirable to address trends in peak conditions separately from durations above a specified threshold. An approach which addressed marginal distributions versus conditional distributions was preterred. 
CHAPTER VII: DISTRIBUTION OF DURATIONS

Method of Analysis

The cumulative probability of durations derived by the single threshold method described above is estimated by application of a plotting formula commonly applied in analyses of this type (Gumbel 1958, and Isaacson and MacKensie 1981):

$$
F\left(t_{1}\right)=\frac{1}{(n+1)} \quad 1=1,2,3, \ldots, n
$$

where $F\left(t_{i}\right)$ is the estimated cumulative probability of the " ${ }_{1}$ " smallest duration and $n$ is the number of extreme events. Durations are first ordered from smallest to largest for this purpose and the corresponding cumulative probability computed. Other plotting formulae were considered (e.g., Gringorten 1963), but this more commonly used approach is preferable for general application since no additional parameters need be estimated.

Two continuous distributions are considered as models for the cumulative probability of durations because of their common application to peak wave height conditions: the Extremal (Fisher-Tippett) Type I and the Weibull distributions. An existing FORTRAN program (US Army Engineer Waterways Experiment Station 1985), originally designed to fit these distributions to wave height data by the method of least squares, applying the plotting formula convention described above, was adapted to work instead with duration data derived by the extreme event identification program. The extreme event identification program was ultimately combined with the program-estimating distribution parameters and titled STRMDIST, a listing of which is presented in Appendix $C$. The program STRMDIST, in addition to the extreme event indentification and duration derivation computations already described, computes distribution parameters ( $\varepsilon$ and $\beta$ for the Extremal. Type $I$ and $\alpha$ and $\beta$ for the Weibu11), estimated (distribution) mean and standard deviation, correlation coefficient, sum of the square residuals, and standard error. These parameters also are computed for peak wave heights of extreme events identified. Tables All-Al5 give results of the STRMDIST analysis for five Phase III sites. 
Figures 11 and 12 demonstrate fit of the least squares regression distribution to the data as represented by the plotting formula for one case each

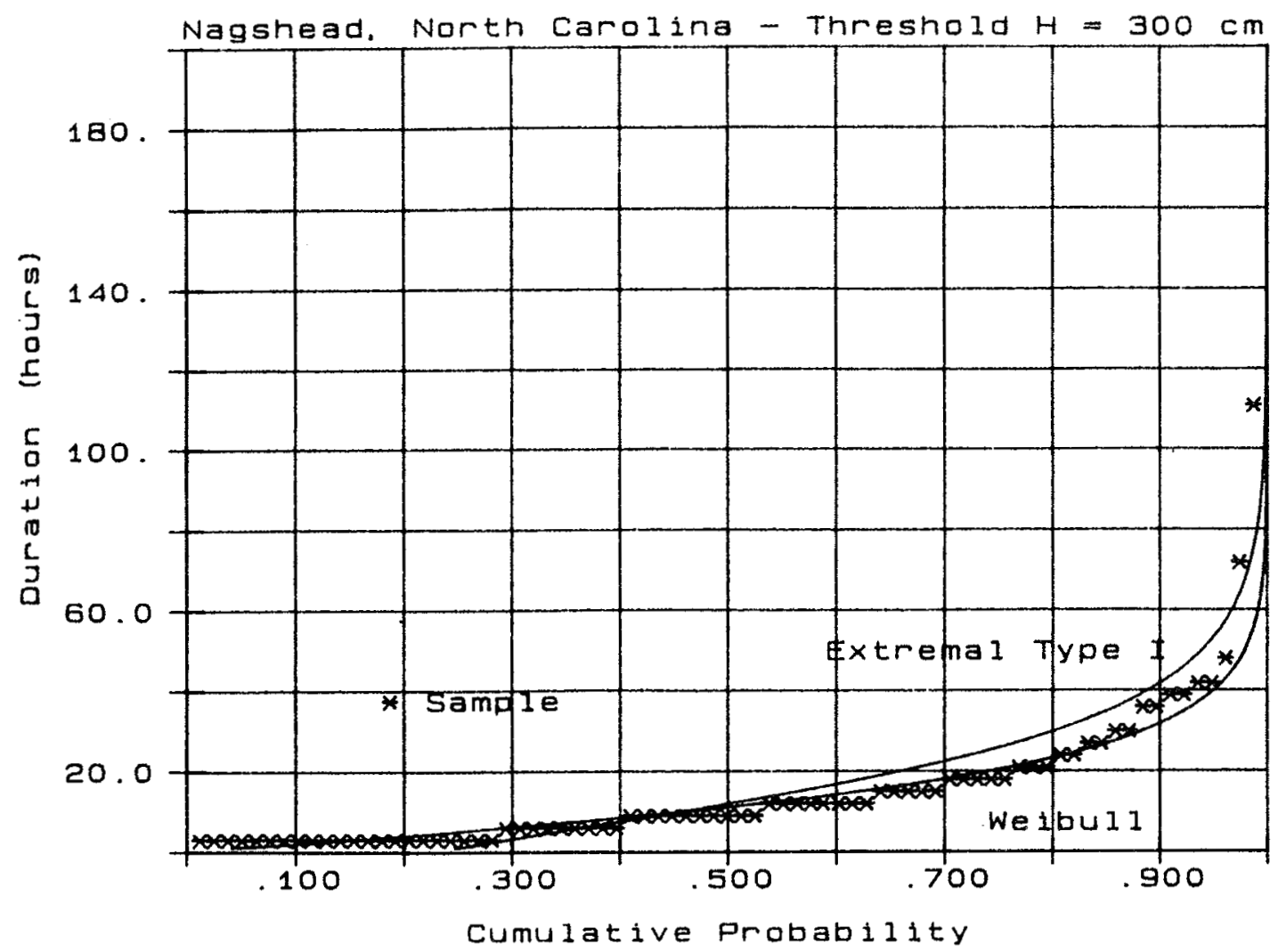

Figure 11. Duration cumulative probability: Nagshead, North Carolina

at Nagshead, North Carolina, and Newport, Oregon. The Weibull distribution in both these cases can be seen to generally fit the overall data spread better, but the Extremal Type I comes closer to the few most extreme durations. The correlation coefficients, sums of square residuals, and standard errors in Tables A11-A15 indicate that the Weibull distribution generally fits the data better than the Extremal Type I, but both distributions fit it acceptably well in practical terms. Correlation coefficients above 0.90 would provide a ruleof-thumb acceptable $f 1 t$ in exercises of this type with weather-related data. Both distributions generally exceed this criterion.

Figure 13 shows correlation coefficients for both distributions plotted against percent occurrence of wave heights above the specified threshold, HI , for Nagshead. Figure Al6 shows a similar plot for Newport. 


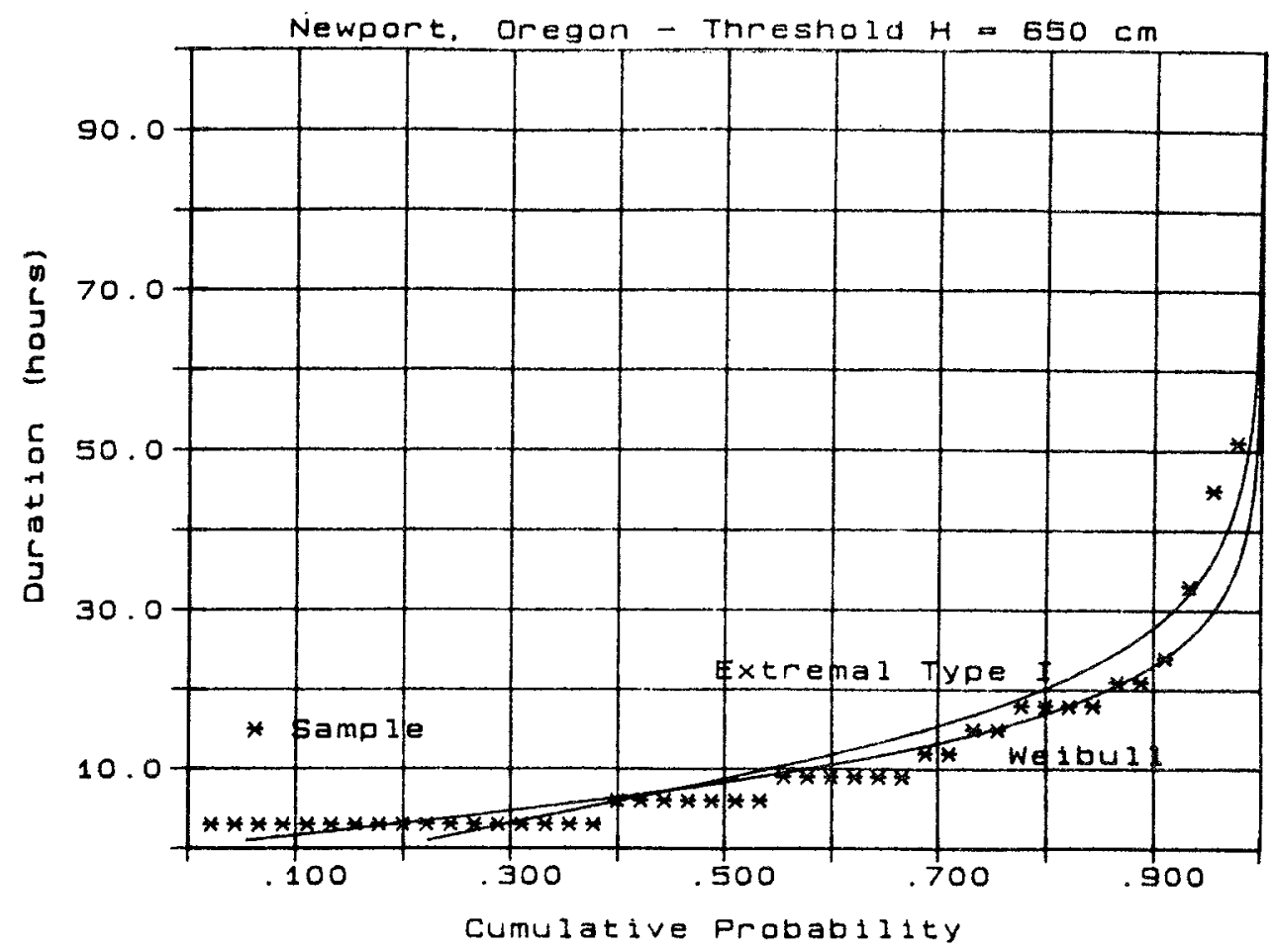

Figure 12. Duration cumulative probability: Newport, Oregon

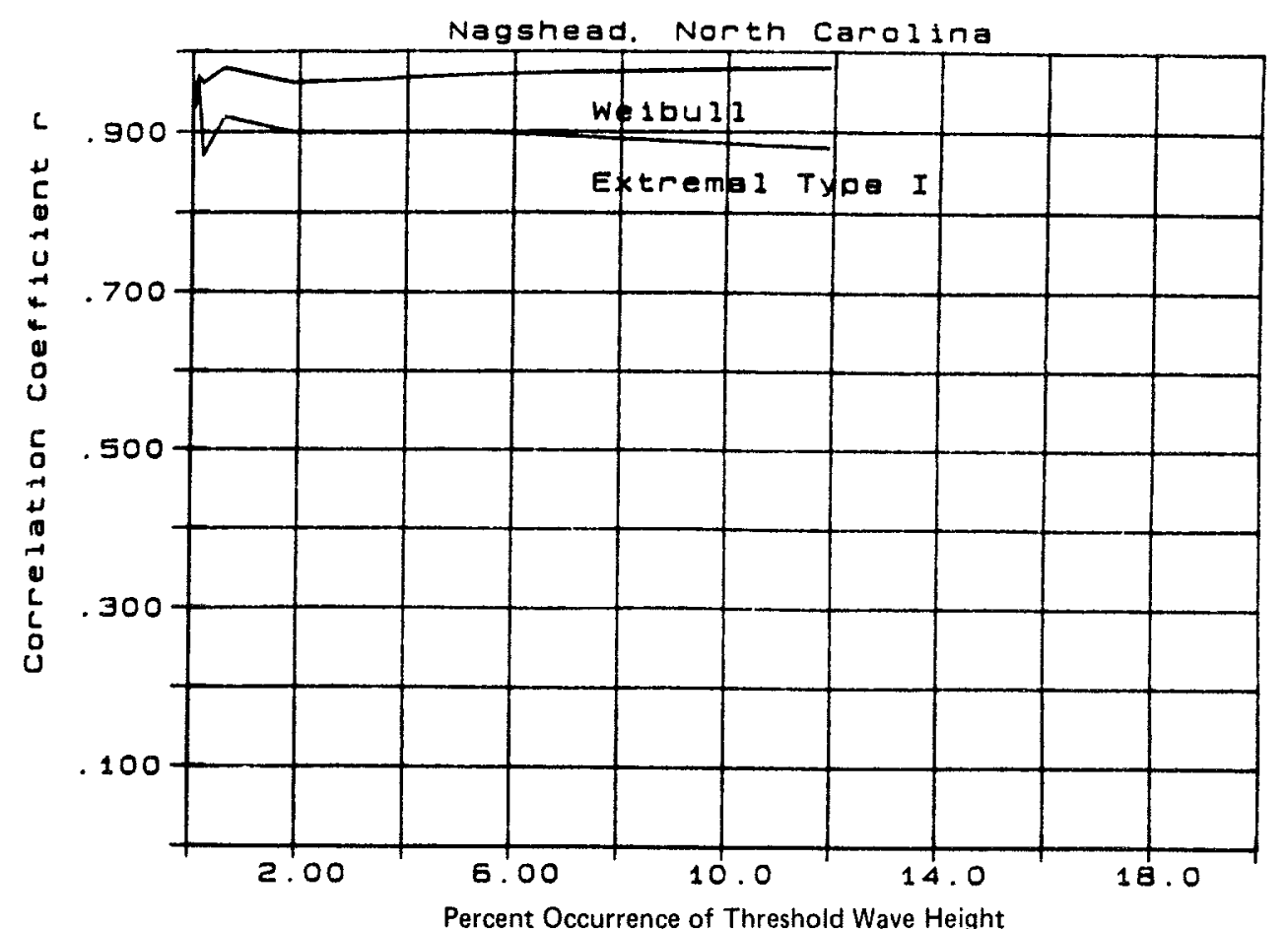

Figure 13. Correlation coefficient versus percent occurrence of wave helght threshold, Nagshead, North Carolina 
Figures $A 17$ and A18 show the correlation coefficients for both distributions at Nagshead and Newport plotted against the number of extreme events per year. No obvious maximum occurs which could reliably be taken as an indication of an optimal choice for either $\lambda$ or $\mathrm{H} 1$.

Figures $A 19$ and $A 21$ are plots of the standard error against extreme events per year and percent occurrence for Nagshead, North Carolina. Figures A20 and A22 show the same information for Newport, Oregon. Again, no obvious minimum generally occurs to indicate an optimal choice for $\lambda$ or $\mathrm{Hl}$. Figures 14 and 15 are graphs of the sample and distribution means and sample and distribution standard deviations plotted against percent occurrence and the number of extreme events per year both for Nagshead. Figures A23 and A24 are similar graphs for Newport. The Extremal Type I distribution mean and standard deviation can be seen to generally come closer to the sample mean and standard deviation. This is desirable, particularly in the case of the mean. The Central Limit Theorem states that sample means from an infinite population can be considered as random variables with a mean equal to the population mean. The standard deviation, as a measure of the spread of duration values about the mean, is an important indicator of how conservative a parameterized distribution might be. The Extremal Type I distribution can be seen to be closer to and consistently larger than (i.e. on the conservative side of) the sample standard deviation. The Weibull distribution standard deviation is both farther from the sample standard deviation and generally lower, i.e., predicting more central tendency than the sample. The Extremal Type I distribution in these respects appears superfor to the Weibull distribution. 


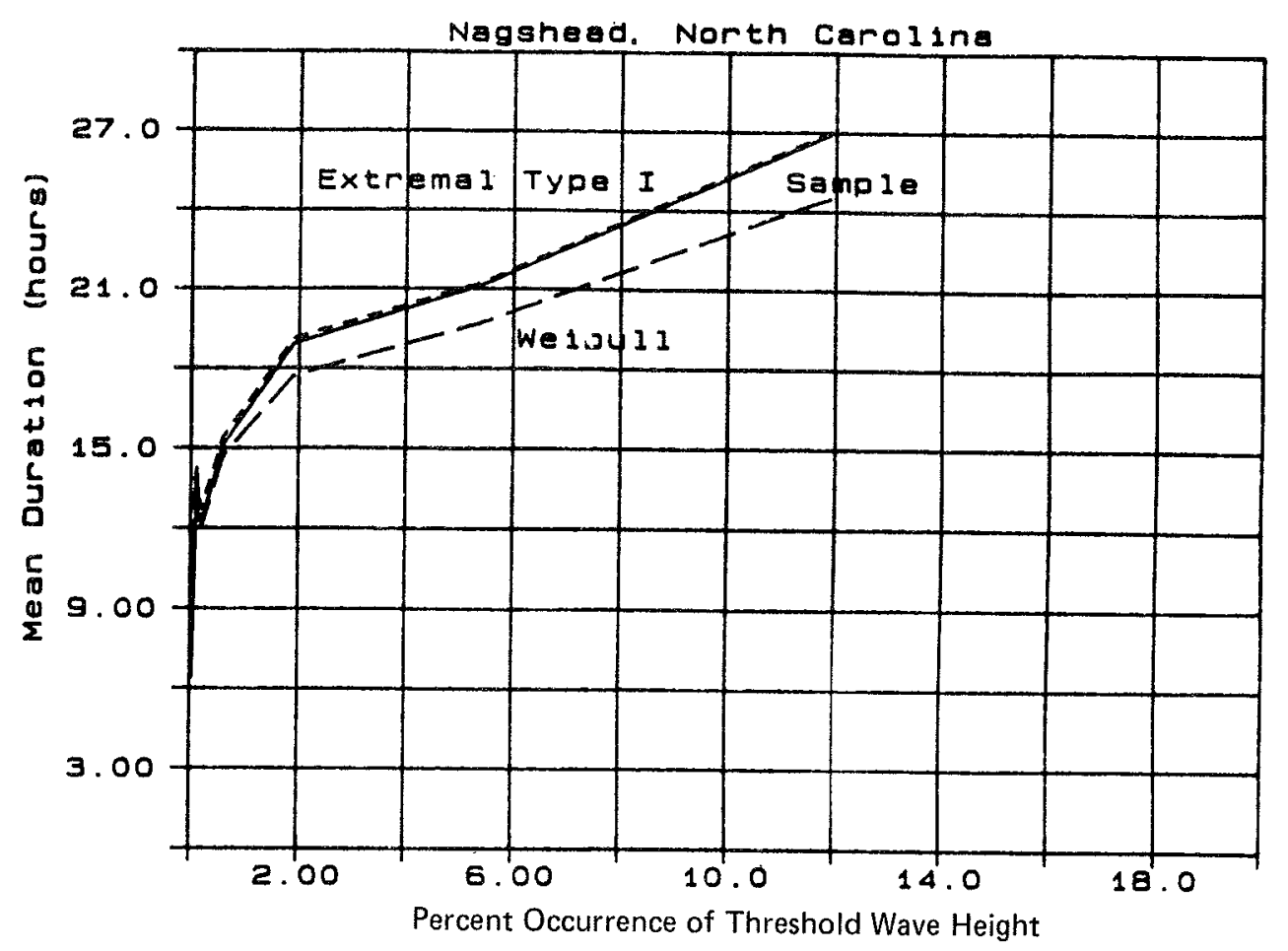

Figure 14. Mean duration versus percent occurrence of wave height threshold, Nagshead, North Carolina

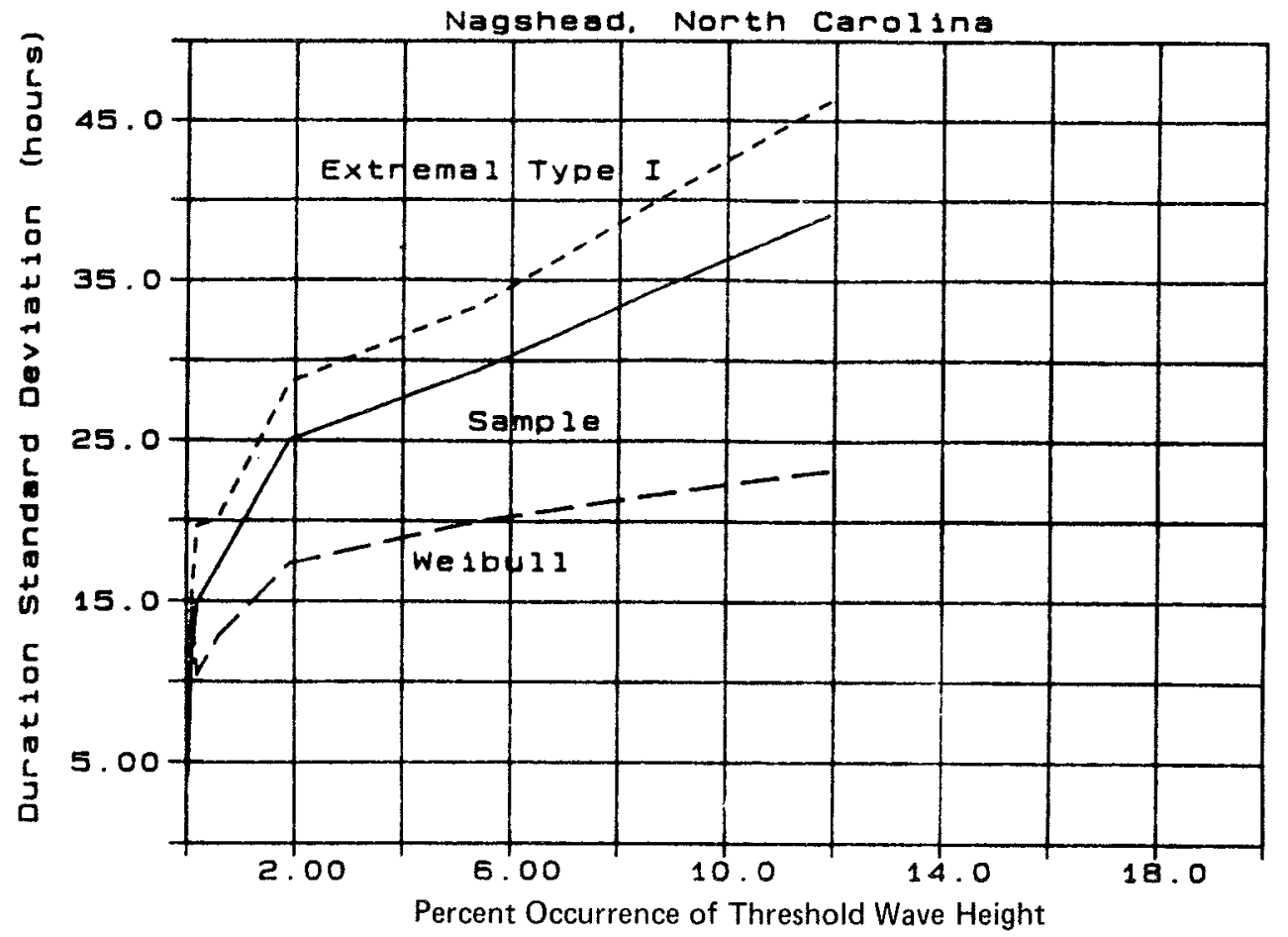

Figure 15. Duration standard deviation versus percent occurrence of wave height threshold, Nagshead, North Carolina 
Method of Analysis

The potential linear or nonlinear relationship of an extreme event's duration with peak conditions of the extreme event were investigated with the aid of statistical software package SPSS (Nie et al. 1975). The stepwise multiple regression capabilities of SPSS were of particular value in testing whether extreme event duration appeared to be dependent on peak conditions, as measured by various parameters such as $\mathrm{H}, \mathrm{T}, \mathrm{H}^{2}, \mathrm{~T}^{2}, \mathrm{H} / \mathrm{gT}^{2}, \mathrm{H}^{2} \mathrm{~L}$, and direction. Simple linear regressions of extreme event durations, as derived by a range of thresholds, first were performed. In the same program execution, SPSS allowed a stepwise multiple regression of duration against $H$, $\mathrm{H}^{2}, \mathrm{~T}$, and $\mathrm{T}^{2}$ to be performed. This procedure estimated the incremental contribution of each of these potentially controlling (independent) variables to the data fit by the least squares method. An equation of the following form was thus possible, assuming the contribution of each of these tested parameters was significant:

$$
t=a H+b H^{2}+c T+d T^{2}
$$

where $a, b, c$, and $d$ are constants.

The purpose in this exercise was not to derive a predictor equation, but to see if a significant relationship existed. Therefore, the obvious interdependence of $\mathrm{H}^{2}$ with $\mathrm{H}$ and $\mathrm{T}^{2}$ with $\mathrm{T}$ was not of undesirable consequence. One common technique to test for existence of a nonlinear relationship, versus a linear relationship, is also to test the square of the variable on a trial basis. A substantially improved fit with the square of the parameter included in the regression equation generally indicates that a nonlinear relationship, whether polynomial or otherwise, is more rellable than a simple linear relationship. The correlation coefficlent, $r$, as applied above in the fit of distribution functions, was taken as the primary measure of the strength of a relationship in this analysis.

Tables A16-A20 show resul.ts from execution of SPSS for all cases tested for each of the five Phase III sites. A listing of the SPSS command file used to perform each of these executions is presented in Appendix $D$ along with a 
sample output. The tables give correlation coefficients for duration against $\mathrm{H}, \mathrm{H}^{2}, \mathrm{~T}$, and $\mathrm{T}^{2}$ (individual simple linear regressions), against all four of these parameters in a stepwise procedure and against $\mathrm{H}^{2} \mathrm{~L}$ (simple linear regression). There is little indication in any case of a linear relationship of duration with ${\mathrm{H} / \mathrm{gT}^{2}}^{2}$ with correlation coefficients for this parameter consistently near zero. Similarly, correlation coefficients of duration with predominant direction of wave propagation at the peaks of extreme events were consistently near zero.

\section{Discussion of Results of the Regression Analysis}

The parameter $H$, the peak zero moment wave height, is consistently the most significant parameter, which confirms that an extreme event identification and duration definition procedure using this parameter is best. Another notable trend indicated by the above results is the observation that correlation coefficients for the Pacific sites are consistently lower than those for Atlantic sites. A possible explanation for this is the fact that Pacific storms typically form well away from the coast and travel onshore. They tend to be well formed when their effects first become significant and their tracks are more or less in the same direction (eastward to some degree). Atlantic (extratropical) storms can form onshore and travel seaward, travel longshore, or linger in one spot, as exemplifled by the previous account of conditions in late October 1956. This more variable track (particularly the potential for a roughly stationary storm) may cause the duration above a specified threshold in many cases to be more dependent on the time-history of the storm's internal intensity than its track past a fixed site.

l'here was no strong correlation of duration (applying the rule-of-thumb criterion of 0.90 ) with any of the variables on either coast. The regression slopes, 1.e. the $\beta$ parameter in Equation 40 , also were consistently small numbers, much closer to zero than to one. The low slopes, even for $H$, ind1cate that dependence of durations on peak wave conditions is weak. A fully rigorous proot of dependence or otherwise would require many more tests and computations than those presented here. The lack of an obvious strong dependence, however, raises the suggestion that, for practical purposes, extreme event duration might be taken as independent of peak conditions of the extreme event. This would make estimates of joint probability, for example forecast 
of durations of wave heights above a threshold for a rare event (e.g., the 5Uor 100-year extreme event), relatively easy to compute. An example of how such an estimate might be made follows:

Example Computation of Peak Wave Height and Duration Joint Probability

Problem: What is the joint probability of zero moment wave heights greater than $3.0 \mathrm{~m}$ lasting longer than $12 \mathrm{hr}$ during an extreme event whose peak zero moment wave height is greater than $4.5 \mathrm{~m}$ at Nagshead, North Carolina?

Solution: The definition of duration at $\mathrm{H} l$ allows the associated parameters presented in Table Al2 to be applied. Choosing the Extremal Type I distribution to represent both marginal distribution of peak wave heights and marginal distribution of durations: $\varepsilon_{t}=6.30, \beta_{t}=15.8, \varepsilon_{H}=326.3$, and $\beta_{H}=48.0$.

The Poisson parameter, $\lambda$, from Table A5, is 3.8. The marginal probabilities of exceedance are:

$$
\begin{aligned}
P\left(t^{\prime}>t\right)=1-F(t) & =1-\exp \left\{-\exp \left[-\frac{\left(t-\varepsilon_{t^{\prime}}\right)}{\beta_{t}}\right]\right\} \\
& =1-\exp \left\{-\exp \left[-\frac{(12-6.30)}{15.8}\right]\right\} \\
& =0.502 \\
P\left(H^{\prime}>\mathrm{H}\right)=1-F(H) & =1-\exp \left\{-\exp \left[-\frac{\left(H-\varepsilon_{H}\right)}{\beta_{H}}\right]\right\} \\
& =1-\exp \left\{-\exp \left[-\frac{(450-326.3)}{48.0}\right]\right\} \\
& =0.073 \quad\{\quad\}
\end{aligned}
$$

The joint probability, taken as the product of independent marginal probabilities defined from the same population $(H 1=300)$, is :

$$
\mathrm{P}\left(\mathrm{t}^{\prime}>12, \mathrm{H}^{\prime}>450 \mid \mathrm{H} 1=300\right)=0.502(0.073)=0.037
$$


The associated return period is:

$$
\operatorname{RT}(t, H)=\frac{1}{\{\lambda[1-F(t, H)]\}}=\frac{1}{[3.8(0.037)]}=7.0 \text { years }
$$

The associated nonencounter probability in a 50-year time period is :

$$
\mathrm{NE}(t, H)=\exp \left[\frac{-L}{\mathrm{RT}(t, H)}\right]=\exp \left(\frac{-50}{7.0}\right)=0.00079=0.08 \%
$$

The associated risk of encountering such a condition in a 50-year time span is $1-\mathrm{NE}(\mathrm{t}, \mathrm{H})=0.921=92.1 \%$.

Discussion: Given the assumptions stated above, the probability of exceedance of a peak wave height of $4.5 \mathrm{~m}$ of any duration is 7.3 percent. The condition of duration exceeding $12 \mathrm{hr}$ eliminates about half of the possibilities; therefore, the joint probability is about half as much. The joint return period is also correspondingly longer. The Poisson assumption inherent in definition of return period and nonencounter probability can be extended to the joint peak wave height and duration distribution if waiting periods between extreme events are much greater than durations of the extreme events. The Poisson distribution is a discrete distribution, and its application technically extends only to discrete events. 


\section{Literature Review}

A review of scientific and engineering literature related to duration of sea states reveals little direct work in this area. The work of Houmb and Vik (1977) is most pertinent to objectjves of this study. These investigators worked with several years of intermittently measured wave information at five points along the North Sea coast of Norway. They found the duration of extreme sea states, as defined by the exceedance of a wave height threshold, to fit a Weibull distribution. They approached the problem as much as possible from a theoretical perspective in order to maximize the reliability of observations based on 1imited data.

\section{Identification of Extreme Events}

This study applies the Phase III (shallow water) Wave Information Studf.es (WIS) database of hindcast wave data because of its unusually long, continuous 20-year period of record and because of its synoptic (ocean wide) perspective on wave conditions. The WIS numerical simulations involve some practical simplifications, but no database of measured wave information is available which could be used to investigate such a long period of record over a wide geographical area. Data from five Phase III stations are applied in this study to investigate duration of extreme wave conditions. Three are on the Atlantic coast (from New Jersey to central Florida) and two are on the Pacific coast (Oregon to central California).

The conventional parameter for long-term wave statistics, zero moment wave height, is chosen as the most practical and reliable indicator of intensity of wave conditions. A computer program is presented which reviews Phase III information and records the number of sequential records (each $3 \mathrm{hr}$ apart) in which the geometric average (combined) sea and swell wave height is above a specific threshold. A single record below the threshold between two that were above is ignored, $1 . e$. , the two records above are treated as part of a single event. The percent occurrence of waves above a threshold is found to vary linearly with the number of extreme events 1dentified, regardless of absolute intensity of wave climate on either coast. 


\section{Distribution of Durations}

The Weibu11 and Extrema1 Type I distributions are fit by the method of least squares to durations of extreme events identified and to peak wave heights. Both distributions show acceptable correlation to the wave data, but the Extremal Type $I$ is found to provide superior estimates of both durations and peak wave heights.

\section{Relationship of Duration to Peak Intensity}

A multilinear regression analysis is performed to address the potential relationship of extreme event duration to peak conditions of the extreme event. Peak intensity, as measured by the zero moment wave height, has only a weak linear relationship to duration. Other alternate parameters of intensity show little evidence of significant linear relation to duration. The investigation does not rigorously prove statistical independence, but the assumption of independence of duration from peak intensity is proposed as an expedient measure. This assumption greatly simplifies prediction of durations of wave conditions above a critical threshold. 
Agerschou, H., Lundgren, H., Sorensen, T., Ernst, T., Korsgaard, J., Schmidt, L., and Chi, W., Planning and Design of Ports and Marine Terminals, John Wiley and Sons, New York, 1983, 320 pp.

Ahrens, J., "Reef Type Breakwaters," Proceedings 19 th Coastal Engineering Conference, American Society of Civil Engineers, New York, 1984, pp. 2648-2662.

Andrew, M., Smith, O., and McKee, J., "Extremal Analysis of Hindcast and Measured Wind and Wave Data at Kodiak, Alaska," Technical Report CERC-85-4, US Army Engineer Waterways Experiment Station, Vicksburg, MS, 1985, 75 pp.

Barry, R., and Perry, A., Synoptic Climatology - Methods and Applications, Methuen and Co. Ltd, London, 1973, 555 pp.

Battjes, J., "Probabilistic Aspects of Ocean Waves," Report No. 77-2, Department of Civil Engineering, Delft University of Technology, Delft, The Netherlands, $1977,52 \mathrm{pp}$.

Bendat, J. and Plersol, D., Random Data: Analysis and Measurement Procedures, Wiley-Interscience, New York, 1971, 407 pp.

Borgman, L., and Resio, D., "Extremal Statistics in Wave C1imatology," Topics in Ocean Physics, Soc. Italiana di Fislca, Corsica, Italy, 1982, pp. 439-471.

Bretschneider, C., "Wave Variability and Wave Spectra for Wind Generated Grav1ty Waves," Beach Erosion Board Technica1 Memorandum 118, US Army Engineer Waterways Experiment Station, Vicksburg, MS, 1959.

Brooks, R., and Corson, W., "Summary of Archived Atlantic Coast Wave Information Study Pressure, Wind, Wave, and Water Level Data," WIS Report No. 13, US Army Engineer Waterways Experiment Station, Vicksburg, MS, 1984, 54 pp.

Bruun, P., "Coast Erosion and the Development of Beach Profiles," Beach Erosion Board Technical Memorandum No. 44, US Army Engineer Waterways Experiment Station, Vicksburg, MS, 1954.

Bruun, P., "Design and Construction of Mounds for Breakwaters and Coastal Protection," Elsevier Science Publishers B.V., Amsterdam, The Netherlands, 1985, 938 pp.

Corson, W., and Resto, D., "Comparisons of Hindcast and Measured Deepwater, Significant Wave Helghts," WIS Report 3, US Army Engineer Waterways Experiment Station, Vicksburg, MS, 1981 .

Corson, W., Resio, D., and Vincent, C., "Wave Information Study for US Coastlines," WIS Report No. 1, US Army Engineer Waterways Experiment Station, Vicksburg, MS, $1980,76 \mathrm{pp}$. 
Corson, W., Resio, D., Brooks, R., Ebersole, B., Jensen, R., Ragsdale, D., and Tracy, B., "Atlantic Coast Hindcast, Deepwater Significant Wave Information," WIS Report No. 2, US Army Engineer Waterways Experiment Station, Vicksburg, MS, 1981.

Corson, W., Resio, D., Brooks, R., Ebersole, B., Jensen, R., Ragsdale, D., and Tracy, B., "Atlantic Coast Hindcast, Phase II Wave Information," WIS Report No. 6, US Army Engineer Waterways Experiment Station, Vicksburg, MS, 1982, $1,186 \mathrm{pp}$.

Dean, $R_{\bullet}$, and Dalrymple, R., Water Wave Mechanics for Engineers and Scientists, Prentice-Hall, Inc., Englewood Cliffs, NJ, 1984, $353 \mathrm{pp}$.

Delft Hydraulics Laboratory, "St. George Harbor, Alaska, Report on Model Investigation," Report M 2102, Delft, The Netherlands, 1985, 220 pp.

Graveson, H., Jensen, 0. J., and Sorensen, T., "Stability of Rubble Mound Breakwaters II," Danish Hydraulic Institute, Horsholm, Denmark, 1980, 19 pp.

Gringorten, I., "A P1otting Rule for Extreme Probability Paper," Journal of Geophysica1 Research, Vo1. 68, No. 3, February 1963, pp. 813-814.

Gumbe1, E., Statistics of Extremes, Columbia University Press, New York, 1958, $375 \mathrm{pp}$.

Houmb, 0., "On the Duration of Storms in the North Sea," Proceedings, Port and Ocean Engineering under Arctic Conditions, Technical University of Norway, Trondheim, Norway, 1971, pp. 423-439.

Houmb, 0., and Vik, I., "Durations of Storms in Northern Waters," Proceedings, Port and Ocean Engineering Under Arctic Conditions, University of Alaska, Fairbanks, AK, 1975.

Houmb, 0., and Vik, I., "On the Duration of Sea State," The Norwegian Institute of Technology, Trondheim, Norway, $1977,33 \mathrm{pp}$.

Hughes, S., "The TMA Shallow-Water Spectrum: Description and Applications," Technical Report CERC-84-7, US Army Englneer Waterways Experiment Station, Vicksburg, MS, $1984,42 \mathrm{pp}$.

Isaacson, M., and MacKensie, N., "Long-Term Distributions of Ocean Waves: A Review," Journa1, Waterway, Port, Coastal and Ocean Division, American Society of Engineers, Vo1. 107, No. WW2, May 1981, pp. 93-109.

Jensen, 0., A Monograph on Rubble Mound Breakwaters, Danish Hydraulic Institute, Horsholm, Denmark, 1984, 209 pp.

Jensen, R., "Atlantic Coast Hindcast, Shallow-Water, Signfficant Wave Information," WIS Report No. 9, US Army Engineer Waterways Experiment Station, Vicksburg, MS, 1983a, $711 \mathrm{pp}$. 
Jensen, R., "Methodology for the Calculation of a Sha11ow-Water Wave Climate," WIS Report No. 8, US Army Engineer Waterways Experiment Station, Vicksburg, MS , $1983 \mathrm{~b}, 80 \mathrm{pp}$.

Kitaigordskil, S., "Application of the Theory of Similarity to the Analysis of Wind-Generated Wave Motion as a Stochastic Process," Bull. Acad. Sci., USSR, Ser. Geophysics, No. 1, Vol. 1, 1962, pp. 105-117.

LeMehaute, B., and Wang, S., "Effects of Measurement Error on Long Term Wave Statistics," Proceedings, 19th Coastal Engineering Conference, American Society of Civil Engineers, New York, 1984, pp. 345-361.

LeMehaute, B., and Wang, S., "Wave Statistical Uncertainties and Design of Breakwater," Journal, Waterway, Port, Coastal and Ocean Engineering, American Society of Civil Engineers, New York, Vol. III, No. 5, September 1985, pp. 921-938.

Lester, R., The Observer's Book of Weather, Frederick Warne and Co., Inc., New York, 1973, 152 pp.

Massie, W., ed., "Coastal Engineering, Volume I - Introduction," Delft University of Technology, Delft, The Netherlands, 1976, 211 pp.

Miller, I., and Freund, J., Probability and Statistics for Engineers, 3rd ed., Prentice-Ha11, Inc., Englewood Cliffs, NJ, 1985, 530 pp.

Nie, N., Hul1, C., Jenkins, J., Steinbrenner, K., and Bent, D., Statistical Package for the Social Sciences, McGraw-Hill Co., New York, 1975, 675 pp.

Permanent International Association of Navigation Congresses, International Commission for the Reception of Large Ships, "Report of Working Group 1," Annex to Bulletin No. 32, Vol. 1, Brussels, Belgium, 1979, $32 \mathrm{pp}$.

Phillips, 0., The Dynamics of the Upper Ocean, Cambridge University Press, New York, 1977, 336 pp.

Ragsdale, Danielle S., "Sea-State Engineering Analysis System (SEAS)," WIS Report 10, US Army Engineer Waterways Experiment Station, Vicksburg, MS, 1983.

Resio, D., and Hayden, B., "An Integrated Model of Storm-Generated Waves," Technical Report No. 8, Department of Environmental Sclences, University of Virginia, Charlottesville, VA, 1973, 288 pp.

Resio, D., Vincent, C., and Corson, W., "Objective Specification of Atlantic Ocean Wind Fields from Historical Data," WIS Report 4, US Army Engineer Waterways Experiment Station, Vicksburg, MS, 1982.

Tenaud, R., Coeffe, Y., and Feulllet, J., "Le Dimentionnement des Digues a Talus: Prise en Compte du Caractere Aleatoire de la Houle," Permanent International Association of Navigation Congresses, Vol. III, Bulletin No. 40, 1981, pp. 51-66 (in French). 
Thompson, E., and Vincent, C., "Prediction of Wave Height in Shallow Water," Proceedings, Coastal Structures 83, American Society of Civil Engineers, New York, 1983, pp. 1000-1008.

US Army Engineer Waterways Experiment Station, "Computer Program: WAVDIST (MACE-17) Extremal Significant Wave Height Distribution," CETN I-40, Vicksburg, MS, 1985, 7 pp.

Van der Meer, J. M., and Pilarczyck, K. W., "Stability of Rubble Mound Slopes under Random Wave Attack," 19th International Conference on Coastal Engineering, Houston, 1984, $17 \mathrm{pp}$.

Vik, I., and Houmb, 0., "Wave Statistics at Utsira with Special Reference to Duration and Frequency of Storms," The Norwegian Institute of Technology, Trondheim, Norway, 1976.

Vincent, C., "Deepwater Wind Wave Growth with Fetch and Duration," Technical Report CERC-84-13, US Army Engineer Waterways Experiment Station, Vicksburg, MS, $1984,32 \mathrm{pp}$. 


\section{APPENDIX A}

ADDITIONAL FIGURES AND TABIES

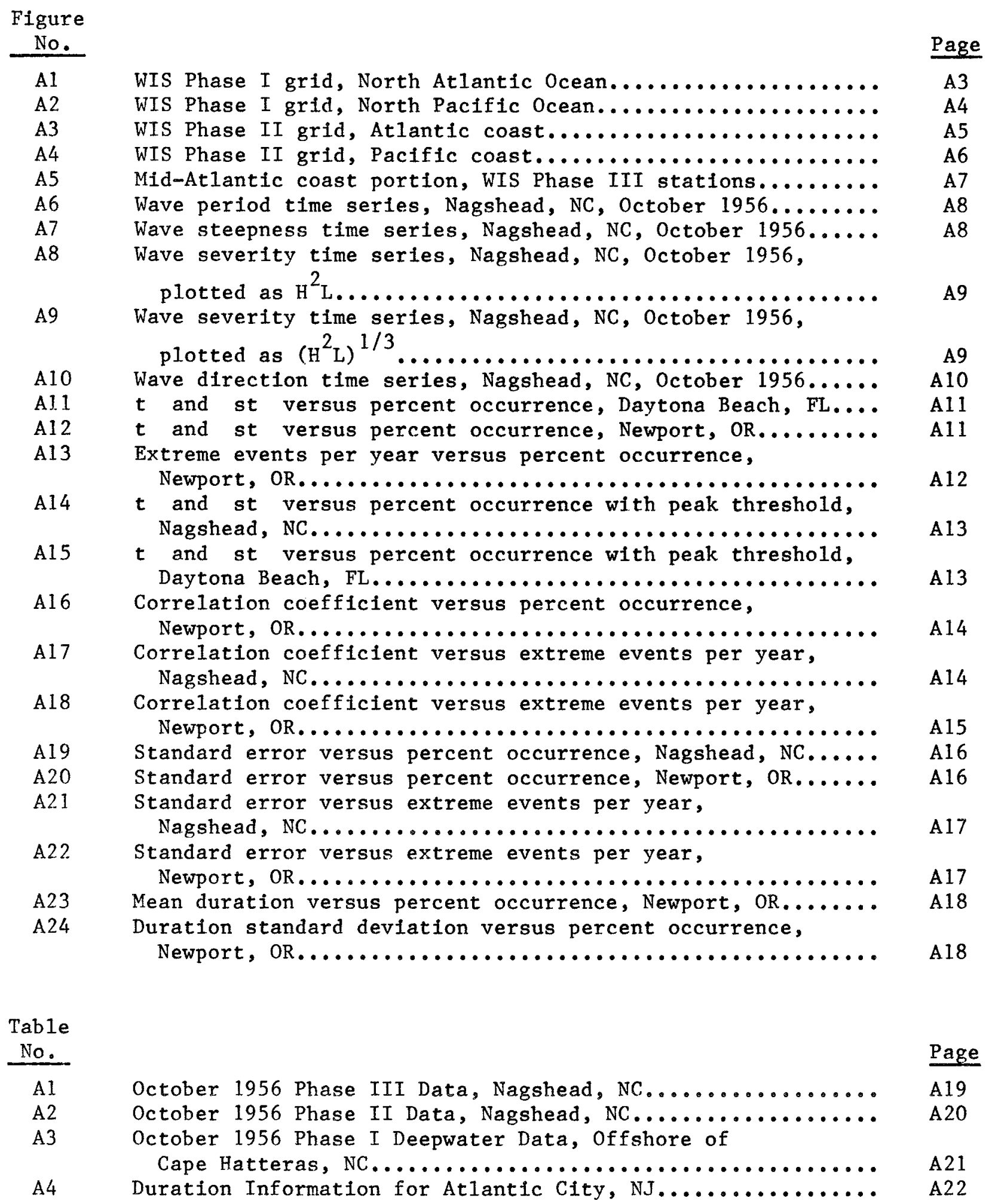




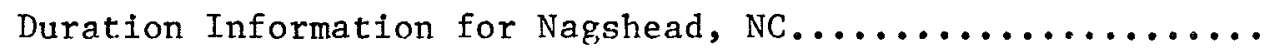

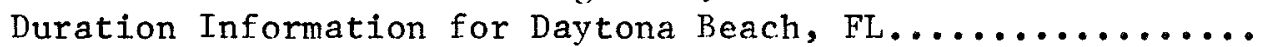

Duration Information for Newport, OR................ A23

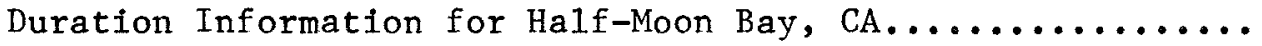

Duration Parameters with a Peak Wave Height Threshold,

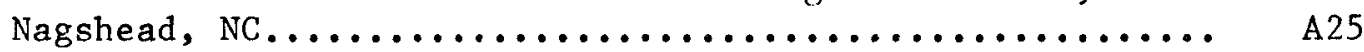

A10 Duration Parameters with a Peak Wave Height Threshold,

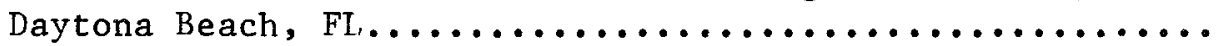

A11 Distribution Parameters for Durations and Peak Wave Heights

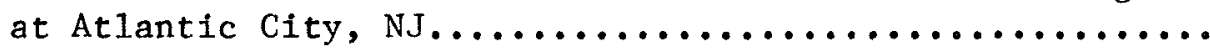

A12 Distribution Parameters for Durations and Peak Wave Heights

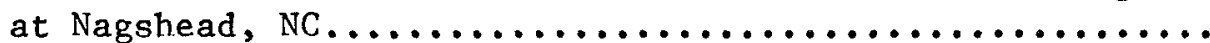

A13 Distribution Parameters for Durations and Peak Wave Heights

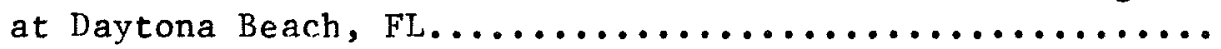

Distribution Parameters for Durations and Peak Wave Heights

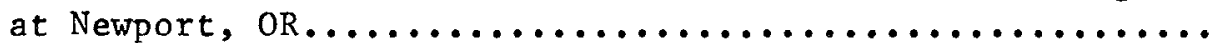

A15 Distribution Parameters for Durations and Peak Wave Heights

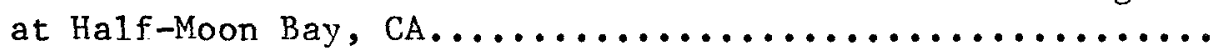

A16 Results of Regression of Duration Against Conditions at the

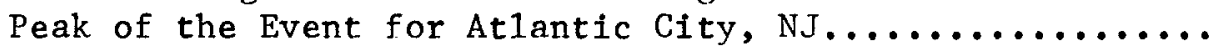

A17 Results of Regression of Duration Against Conditions at the

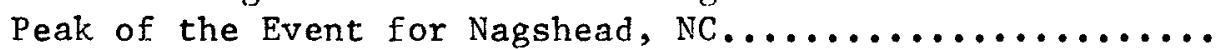

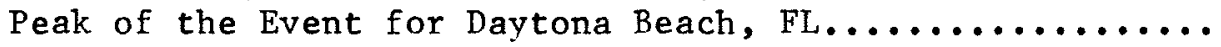

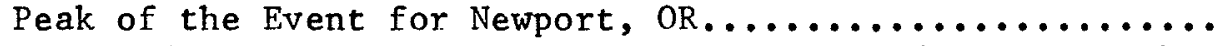




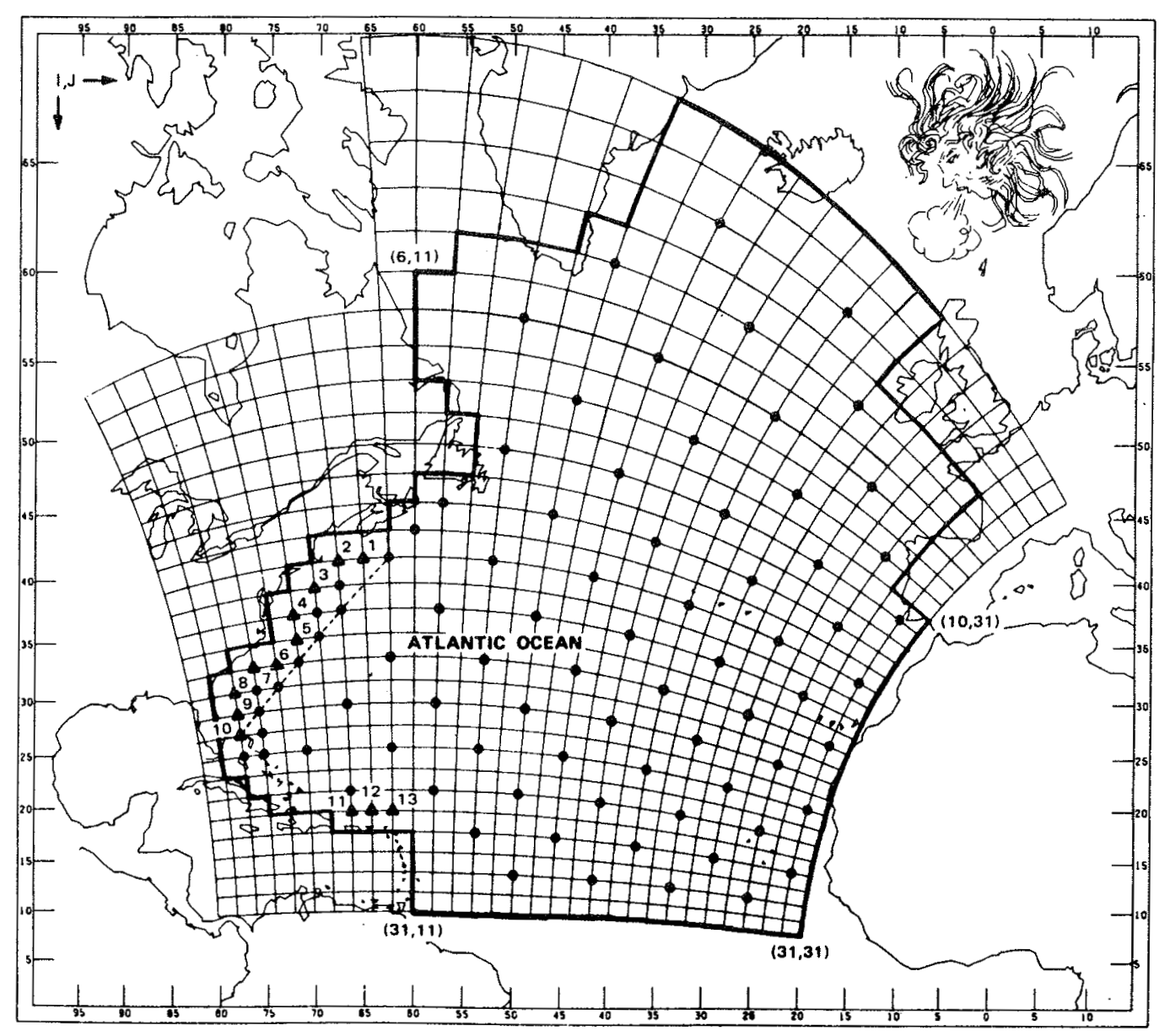

Figure Al. WIS Phase I grid, North Atlantic Ocean 


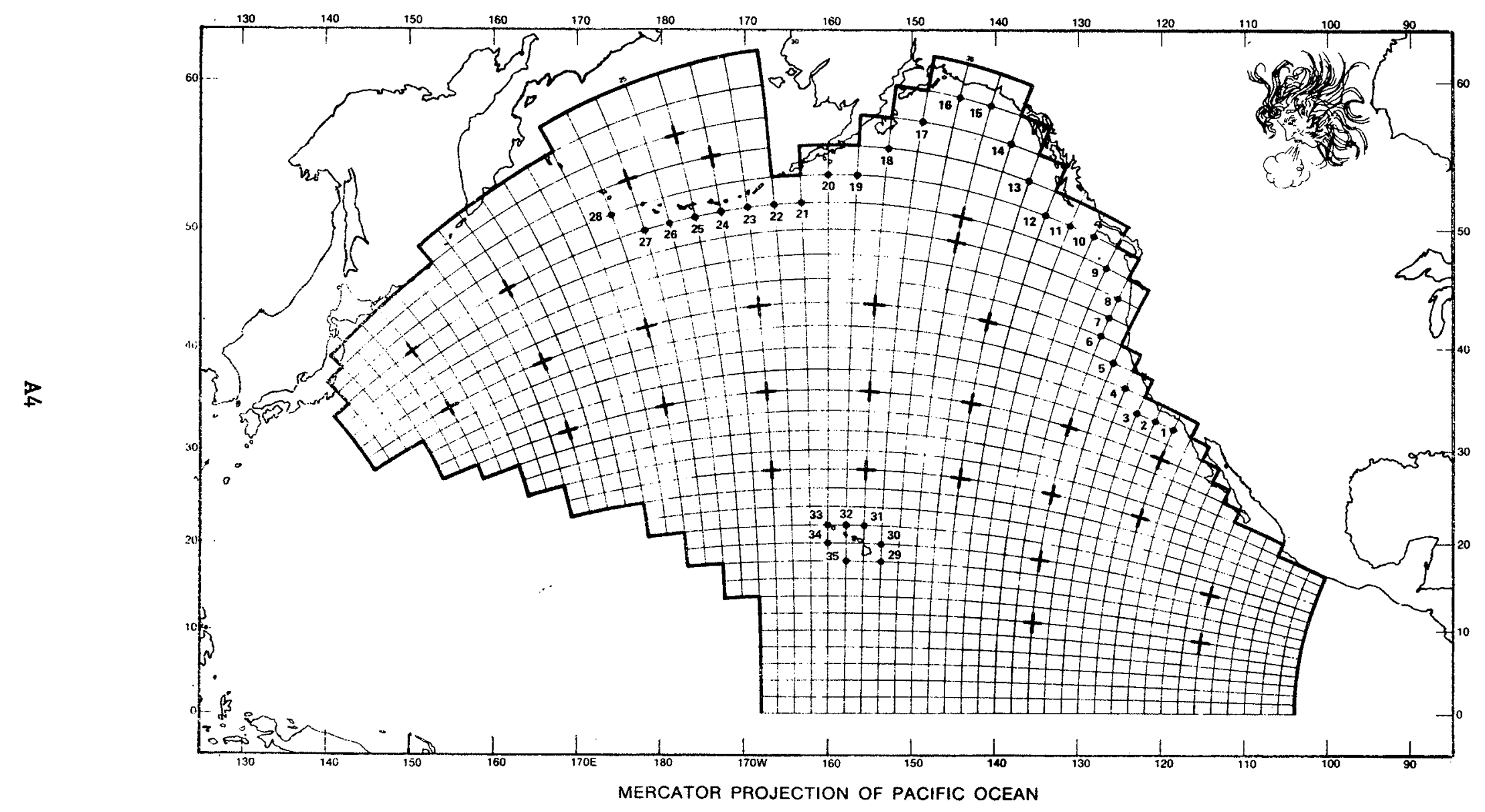

Figure A2. WIS Phase I grid, North Pacific Ocean 


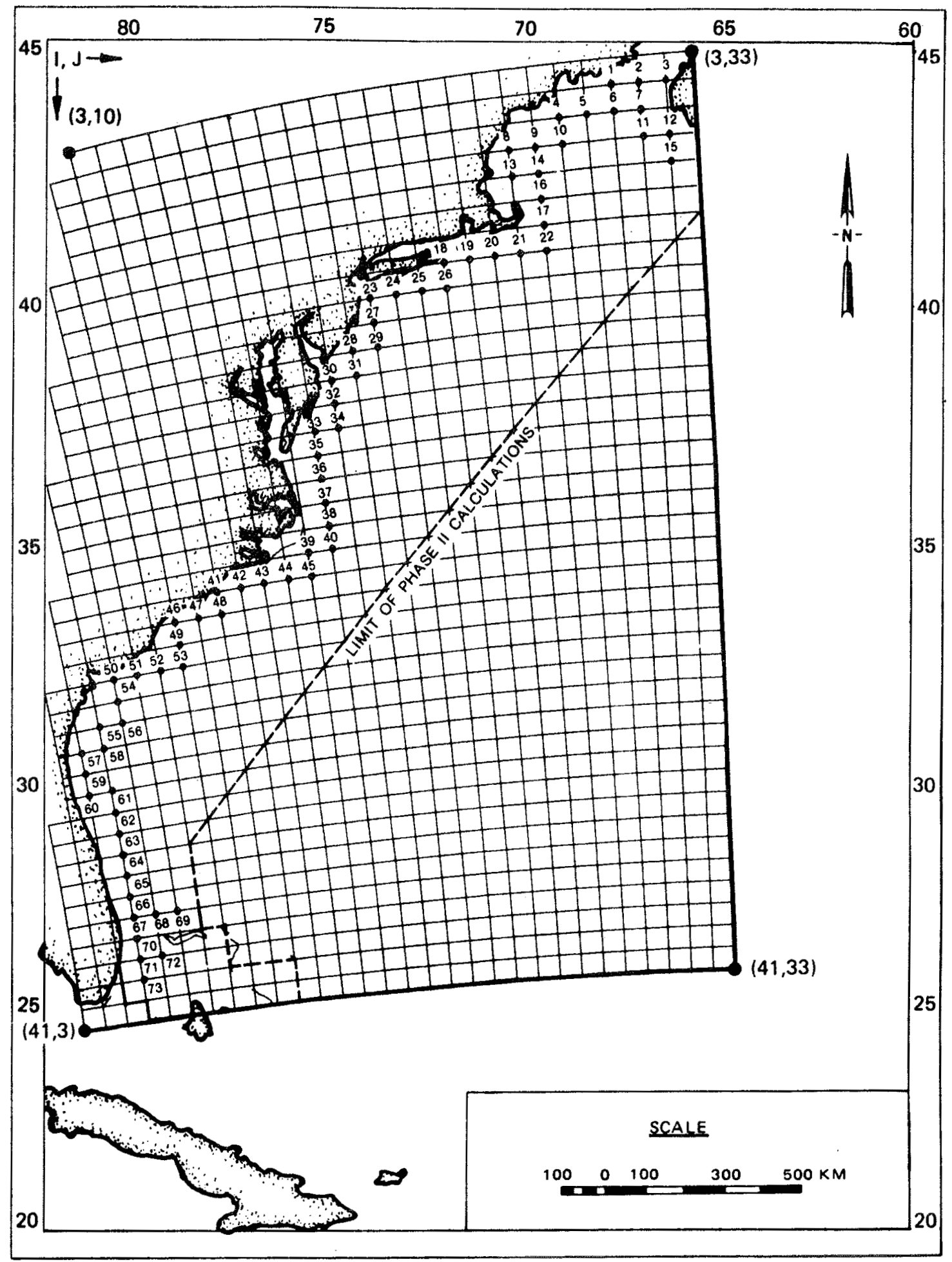

Figure A3. WIS Phase II grid, Atlantic coast 


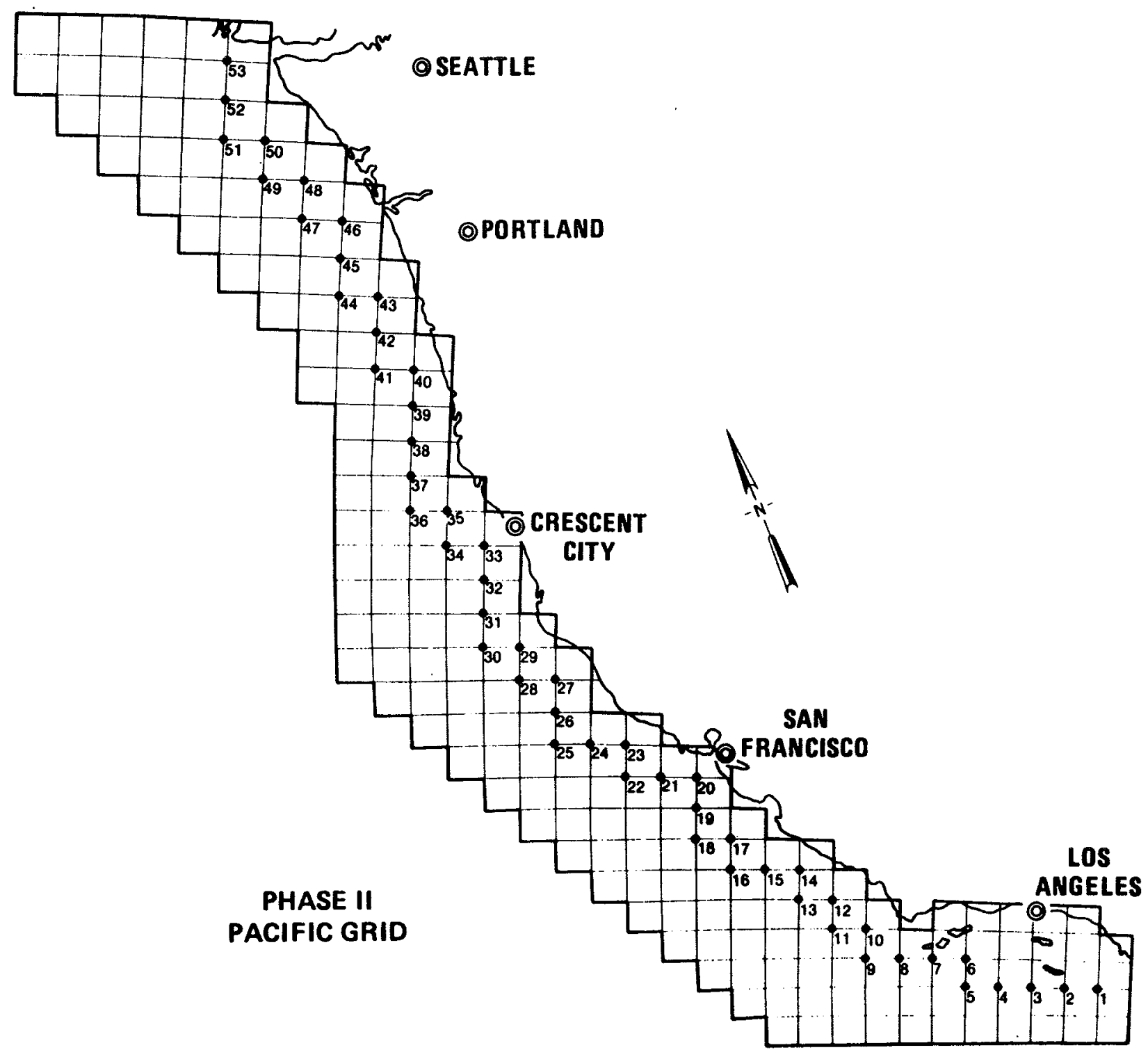

Figure A4. WIS Phase II grid, Pacific coast 


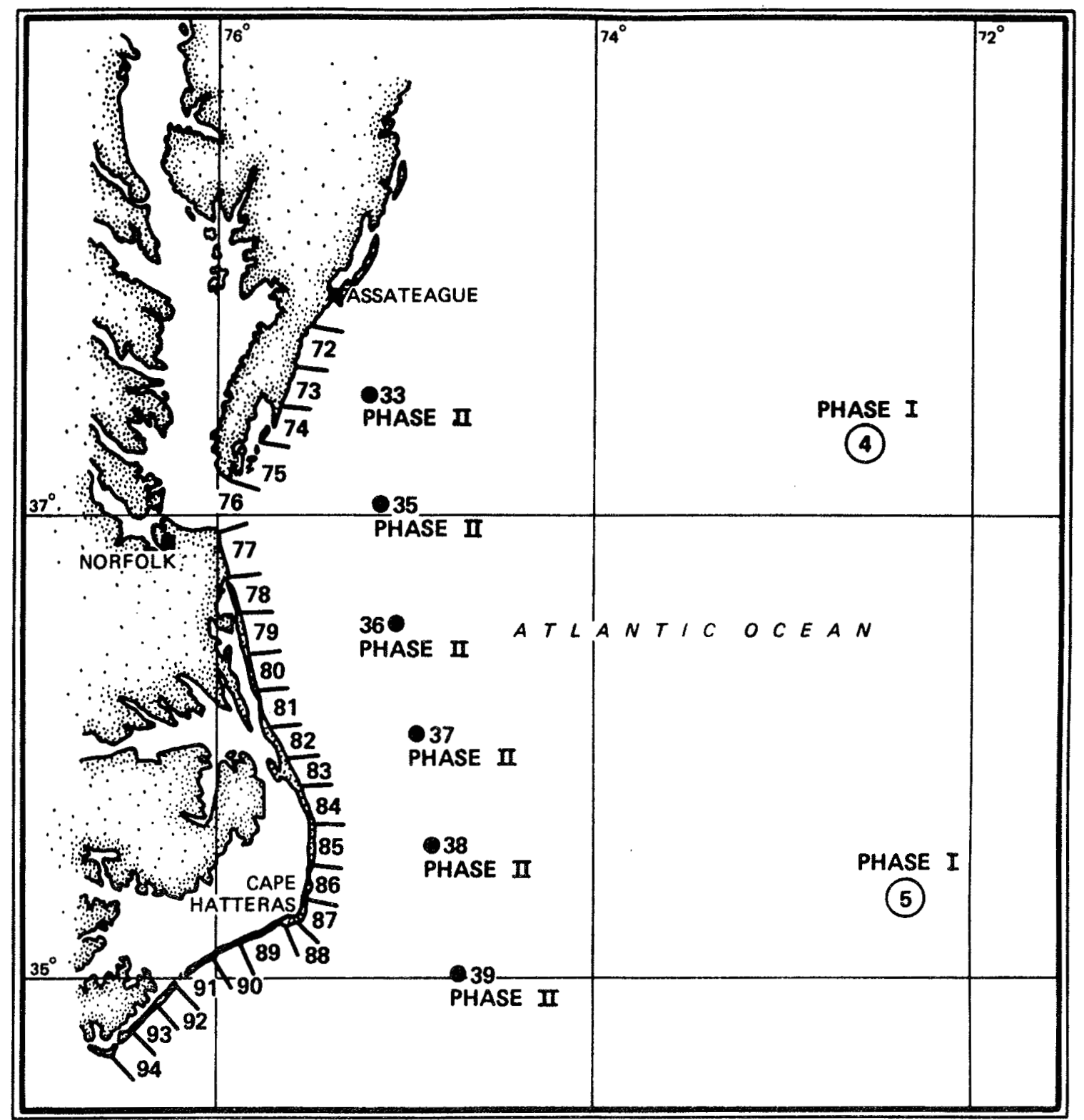

Figure A5. Mid-Atlantic coast portion, WIS Phase III stations 


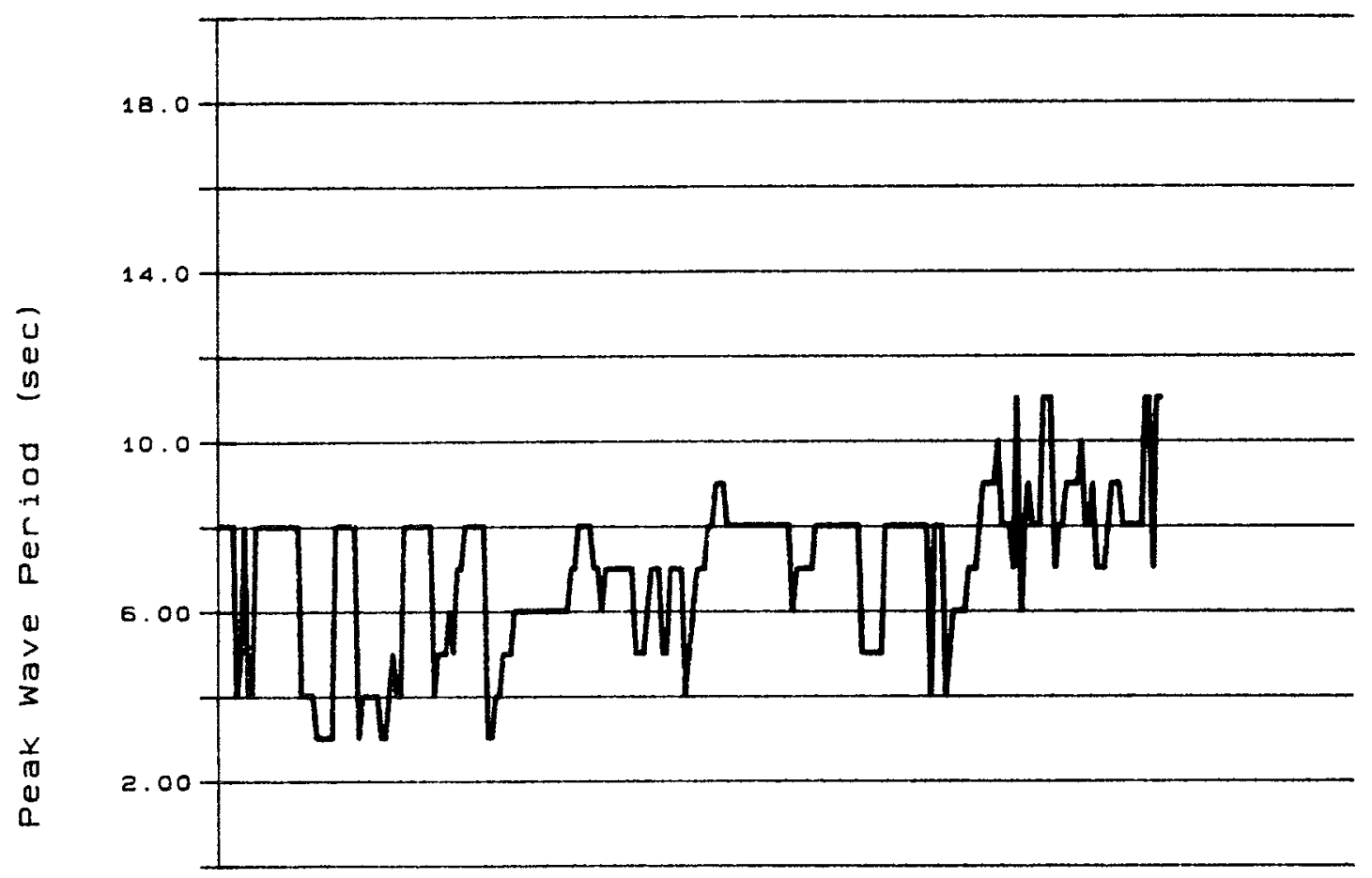

Figure A6. Wave period time series, Nagshead, NC, October 1956

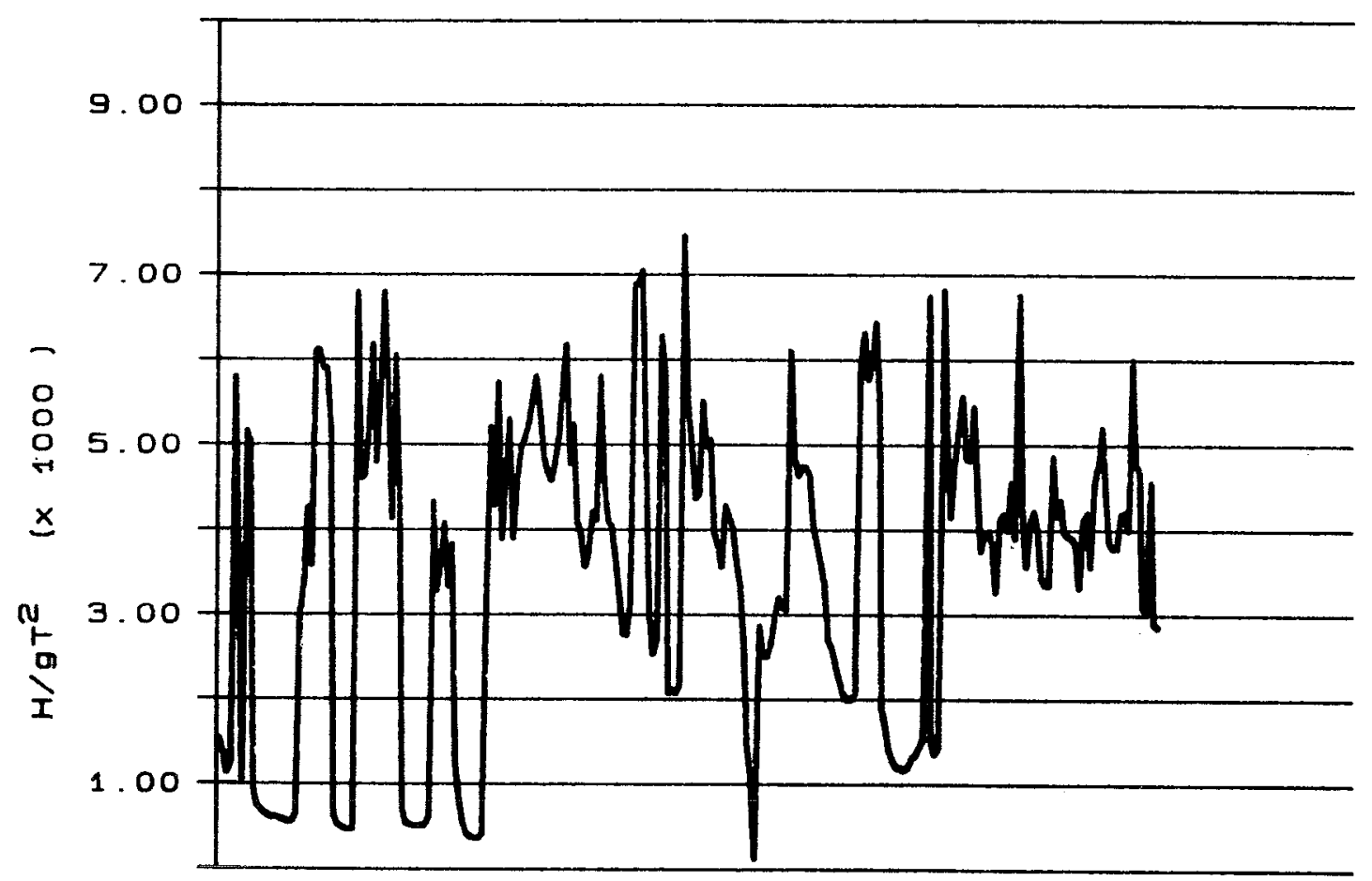

Figure A7. Wave steepness time series, Nagshead, NC, October 1956 


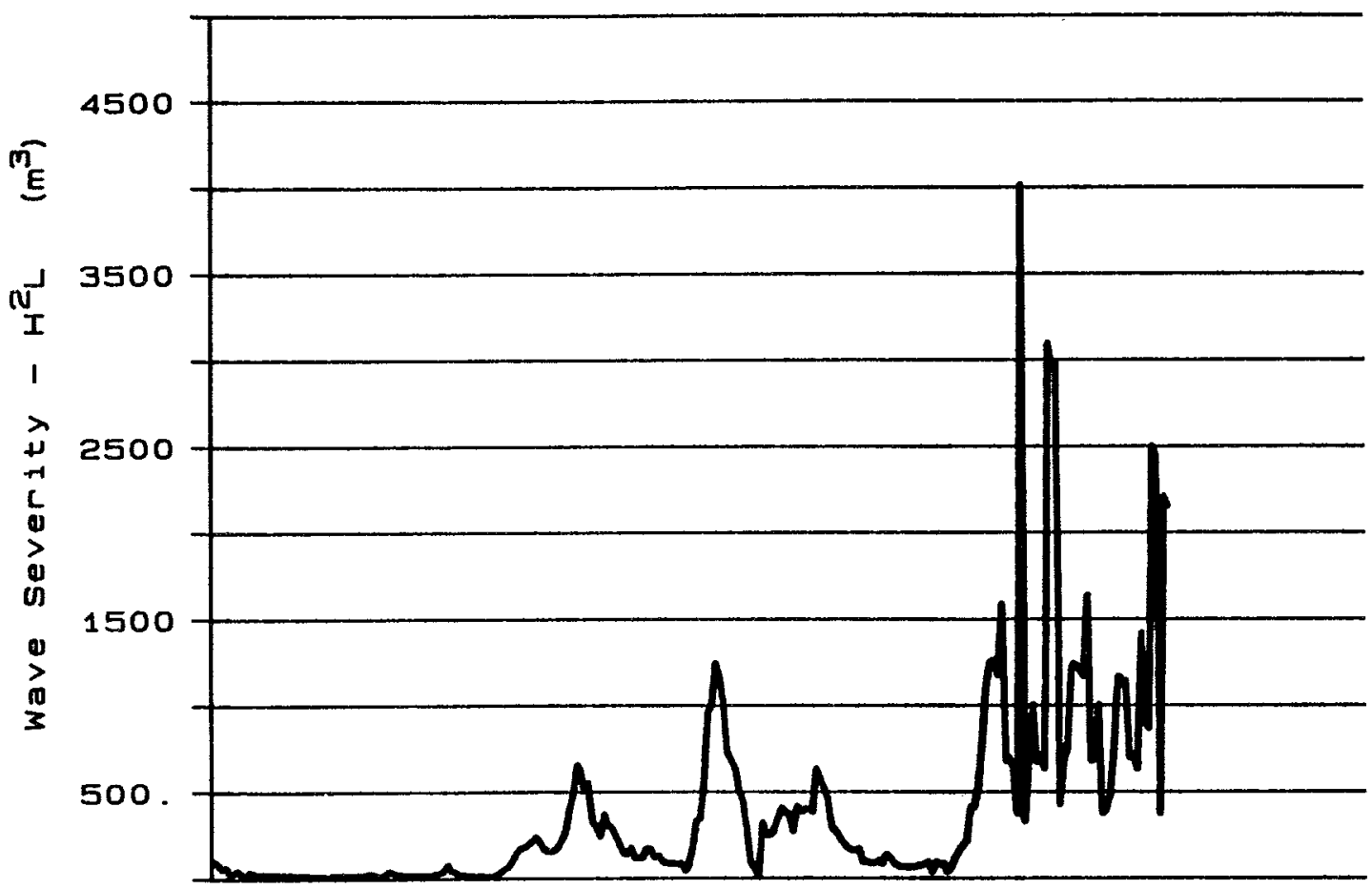

Figure A8. Wave severity time serfes, Nagshead, NC, October 1956, plotted as $\mathrm{H}^{2} \mathrm{~L}$

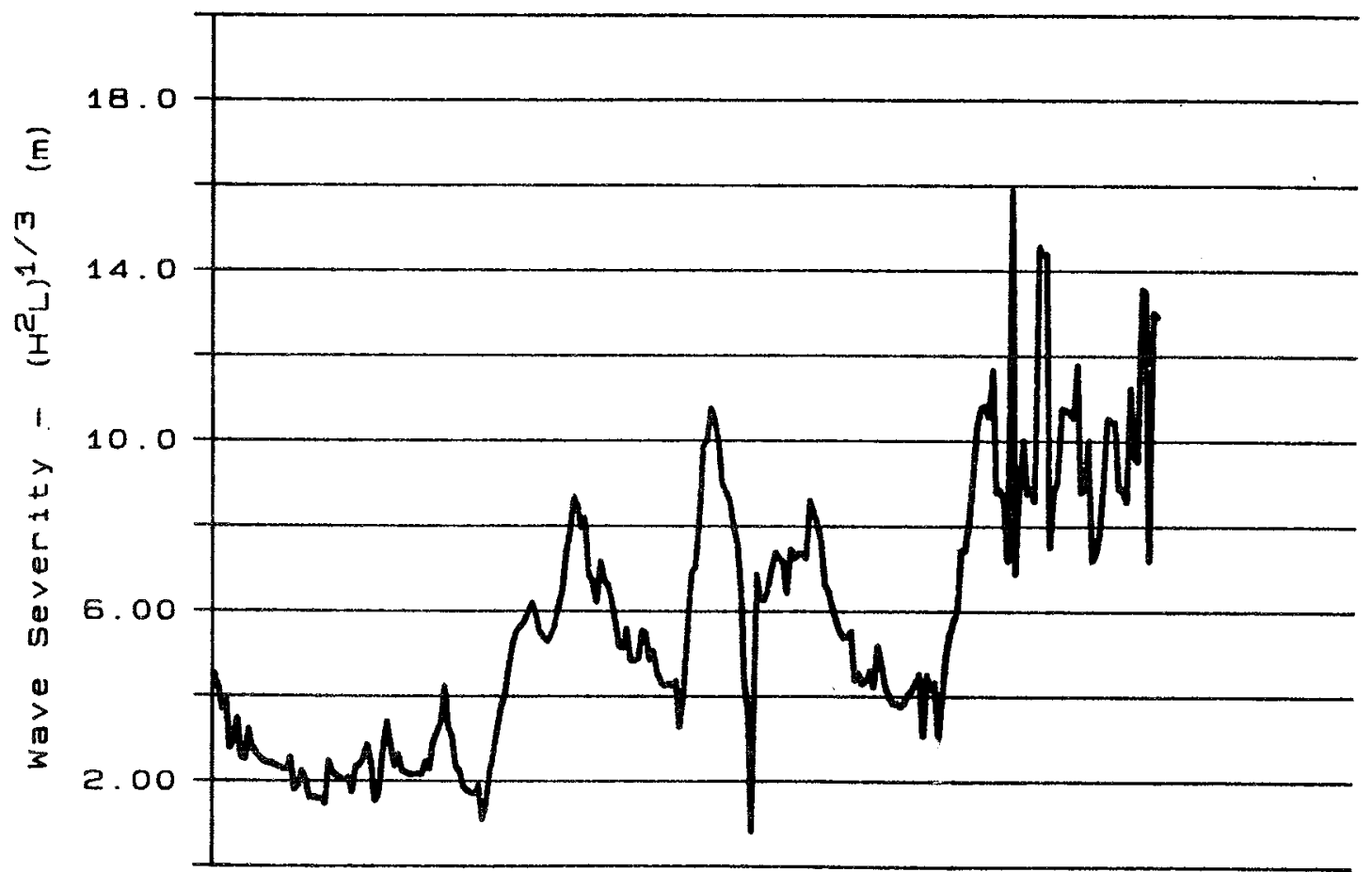

Figure A9. Wave severity time series, Nagshead, NC, October 1956, plotted as $\left(\mathrm{H}^{2} \mathrm{~L}\right)^{1 / 3}$ 


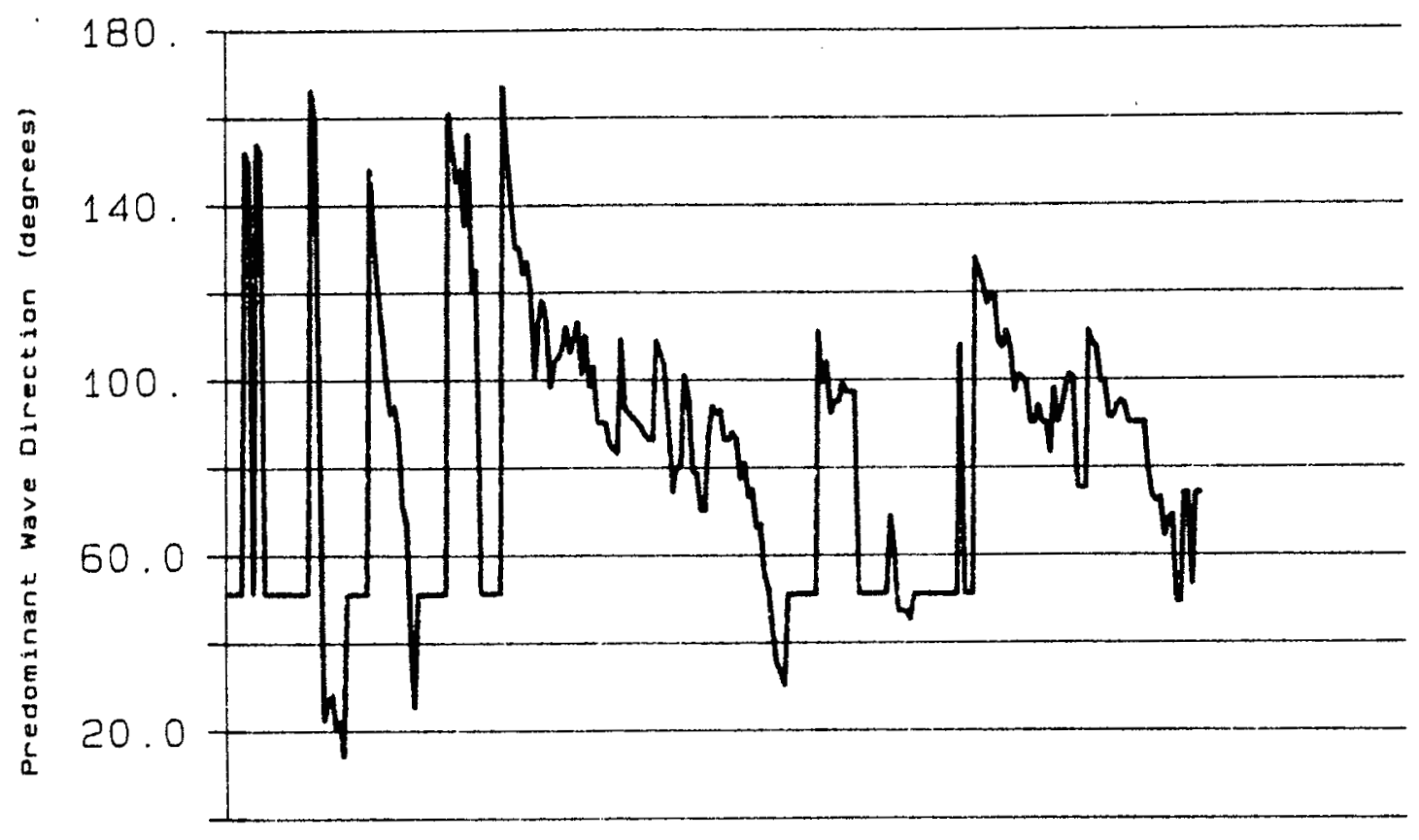

Figure A10. Wave direction time series, Nagshead, NC, October 1956 


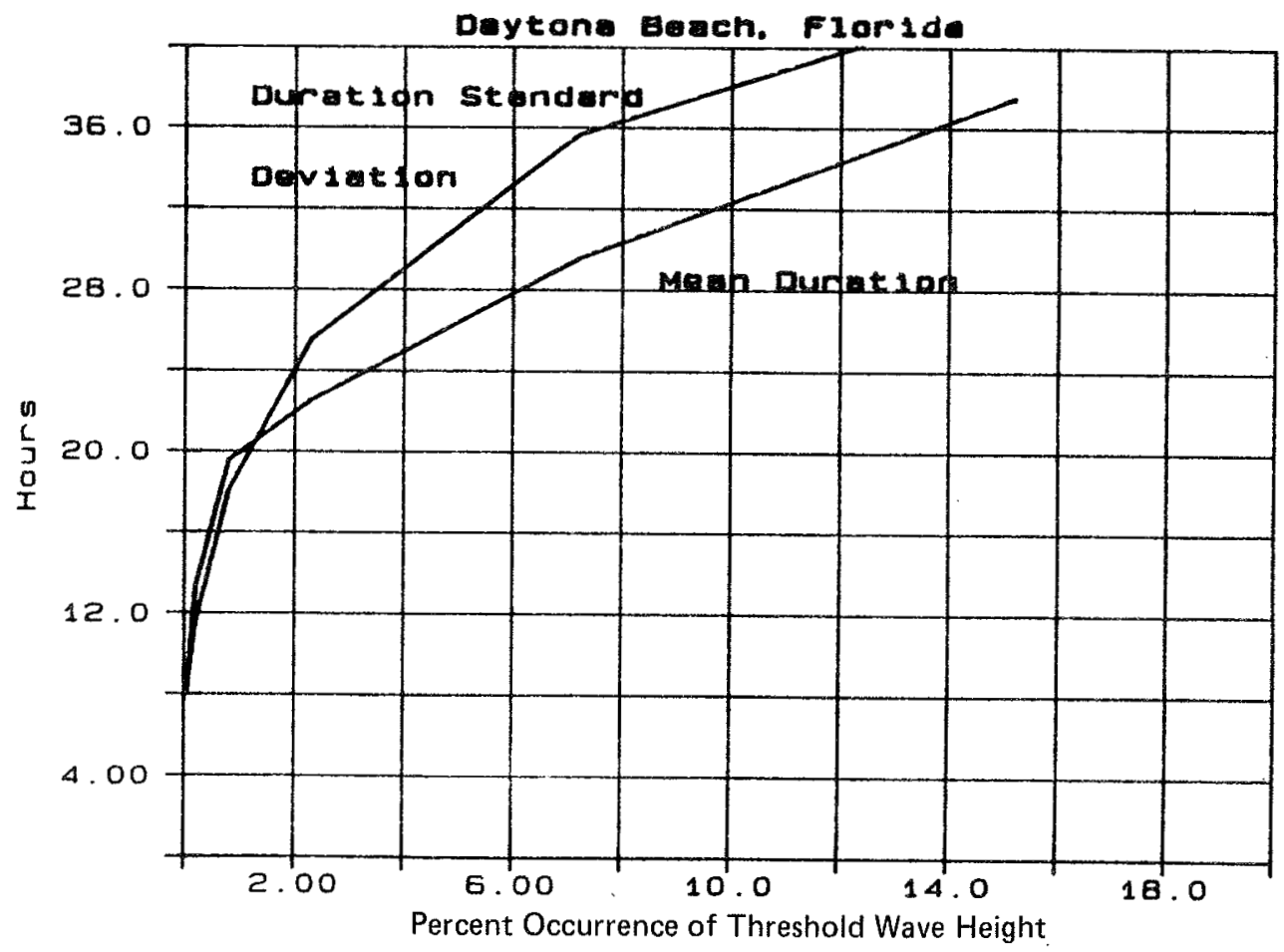

Figure All. $t$ and $s t$ versus percent occurrence, Daytona Beach, FL

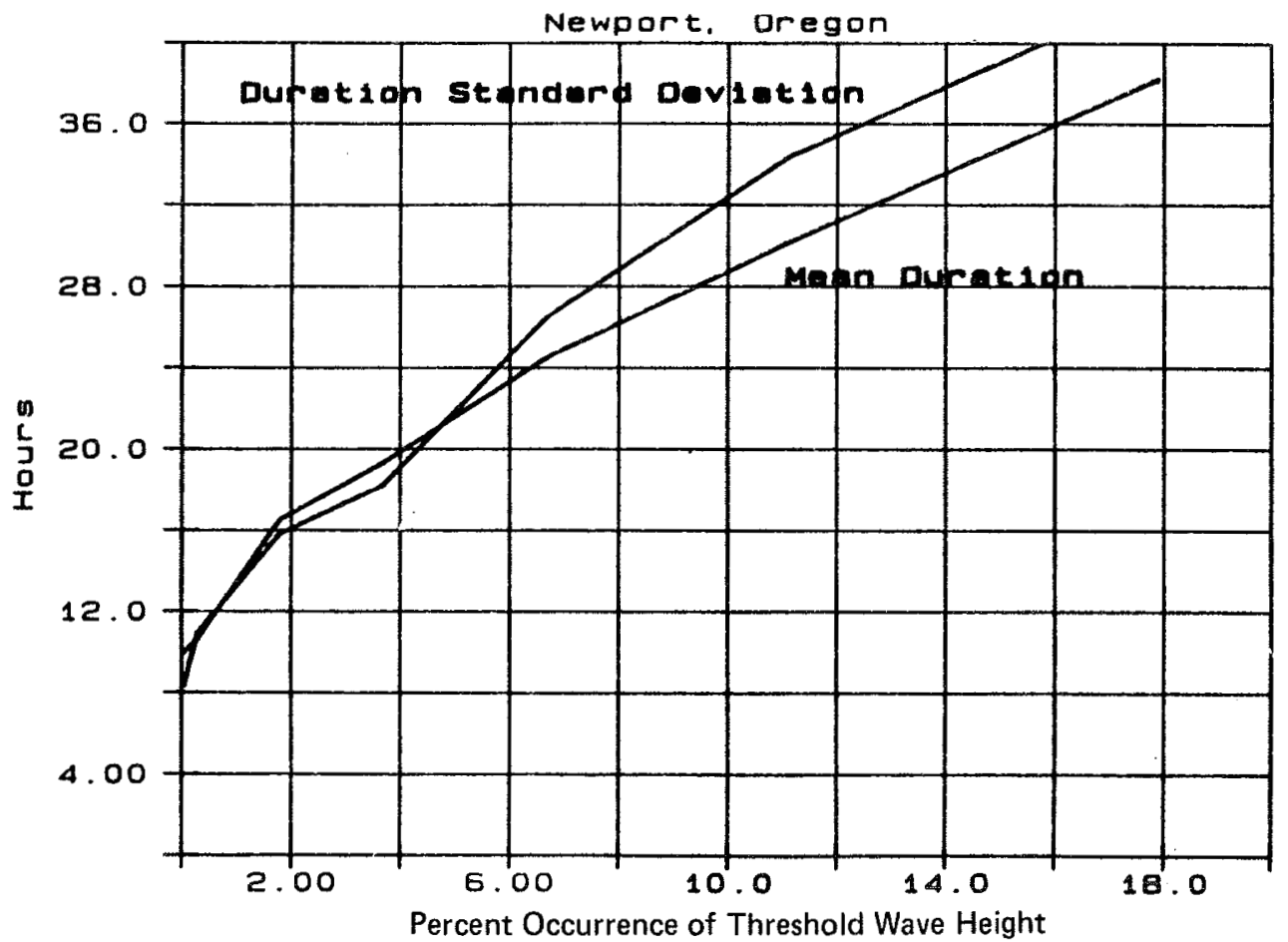

F1gure A12. $t$ and st versus percent occurrence, 


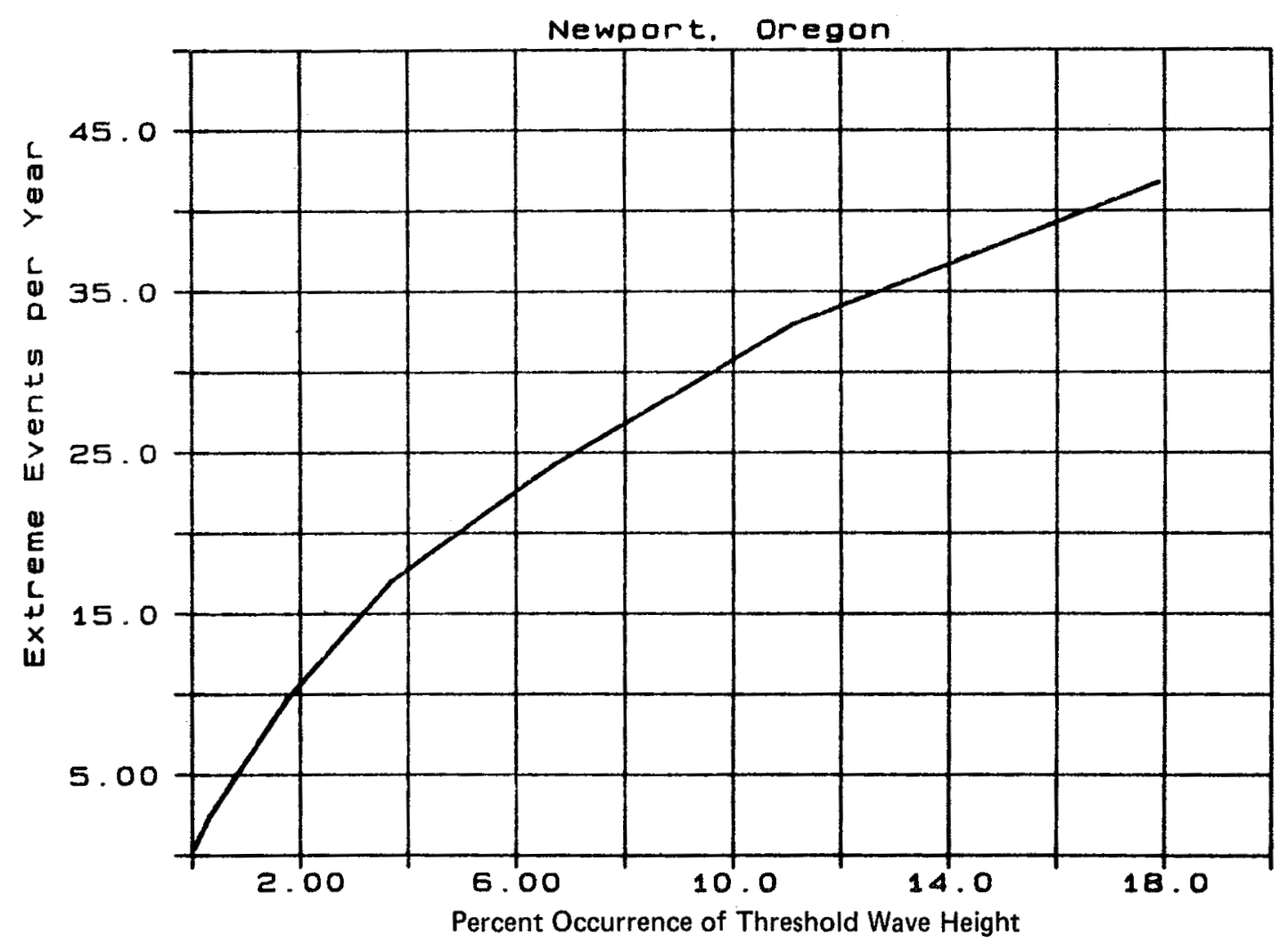

Figure A13. Extreme events per year versus percent occurrence, Newport, OR 


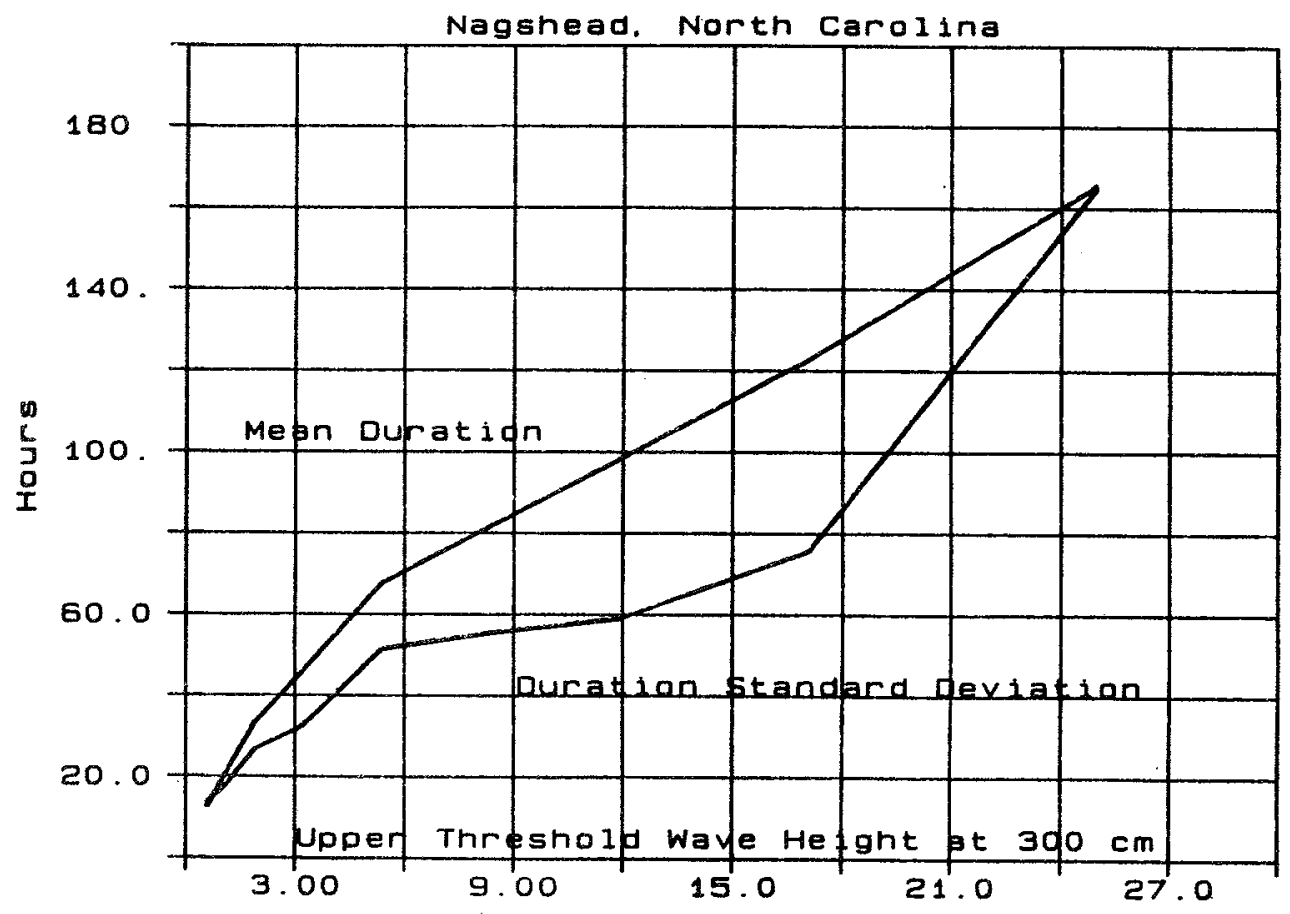

Percent Occurrence of Lower Threshold Wave Height

Figure A14. $t$ and st versus percent occurrence with peak threshold, Nagshead, NC

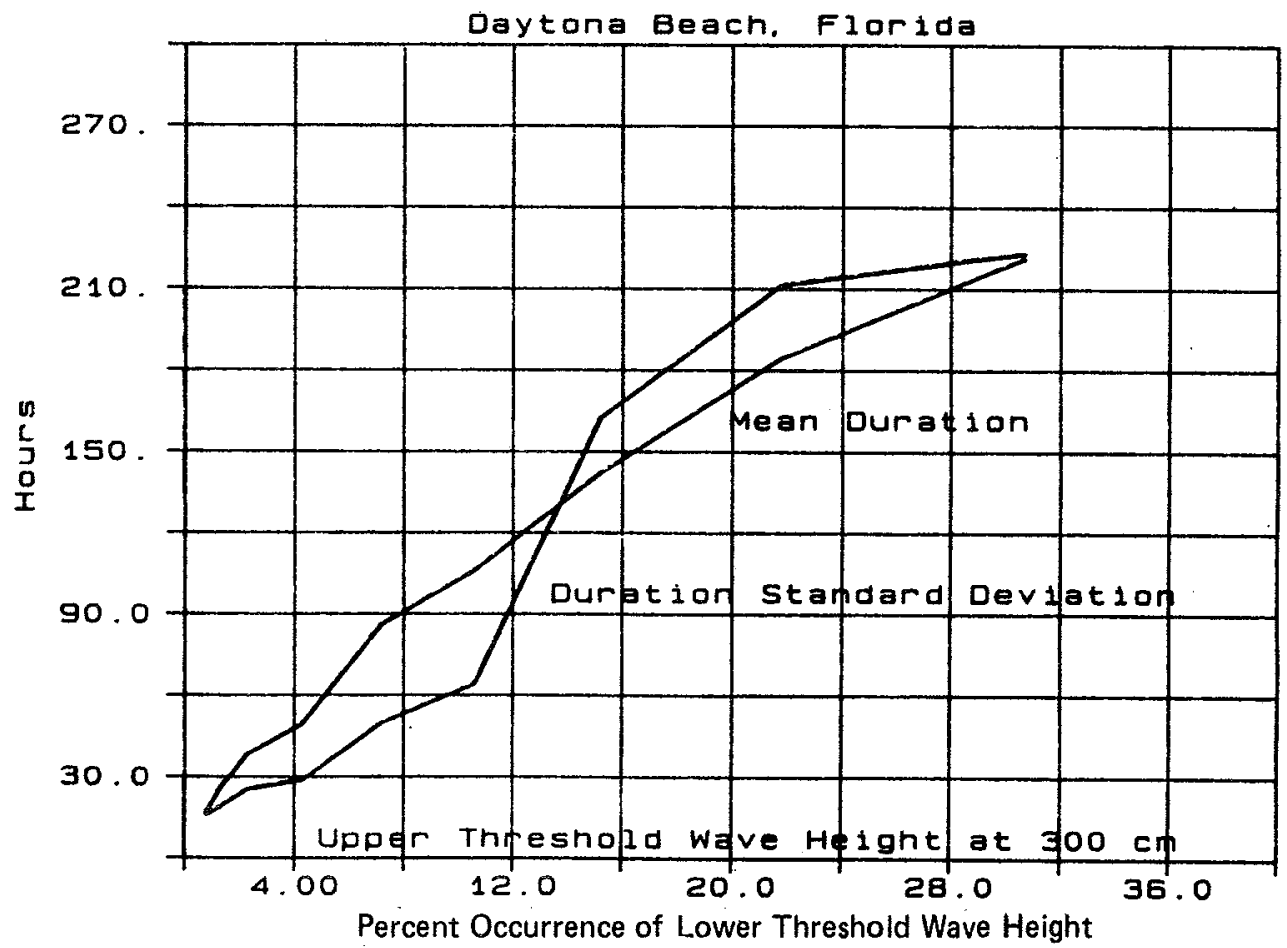

Figure A15. $t$ and st versus percent occurrence with peak threshold, Daytona Beach, FL 


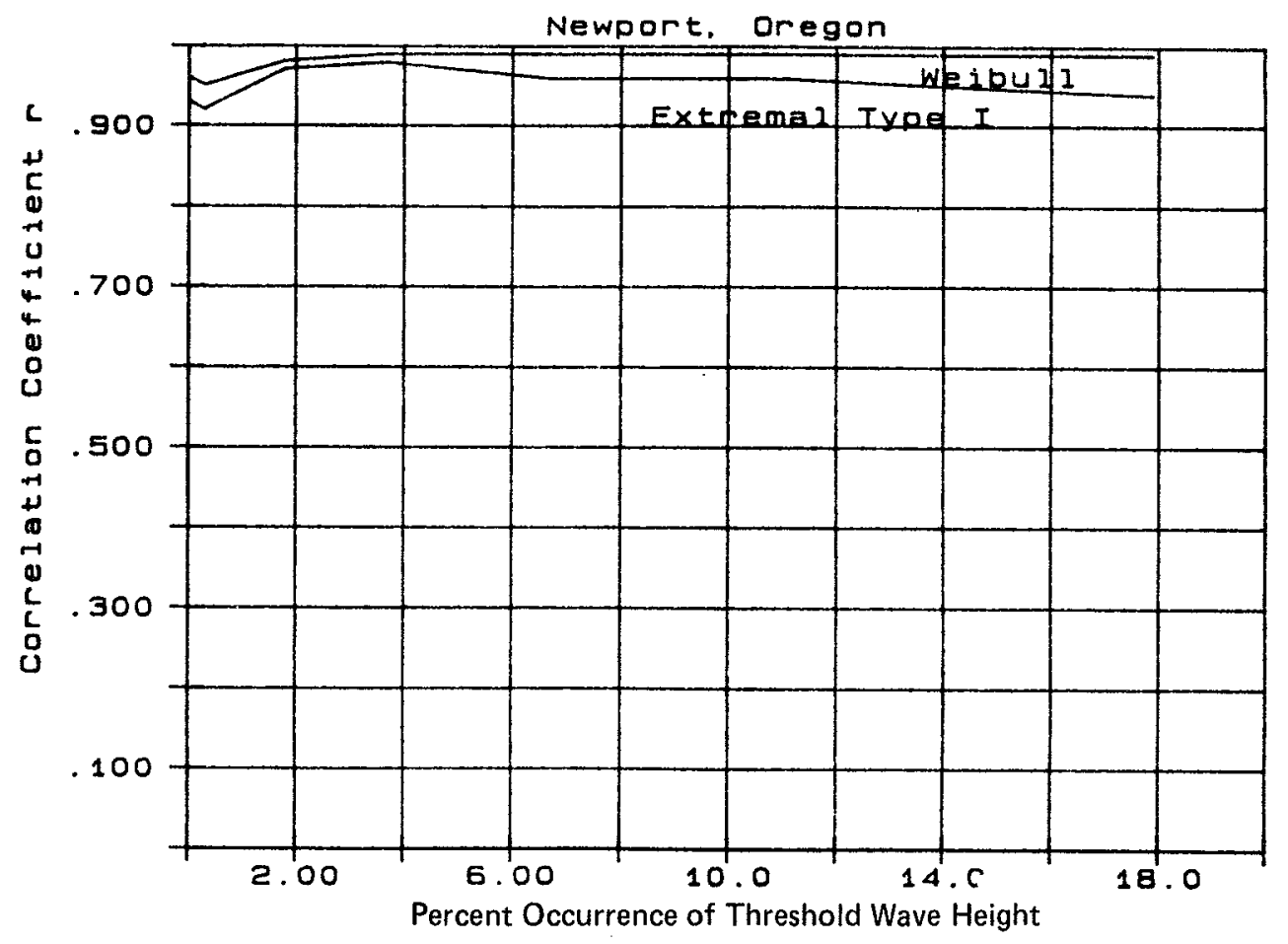

Figure A16. Correlation coefficient versus percent occurrence, Newport, $O R$

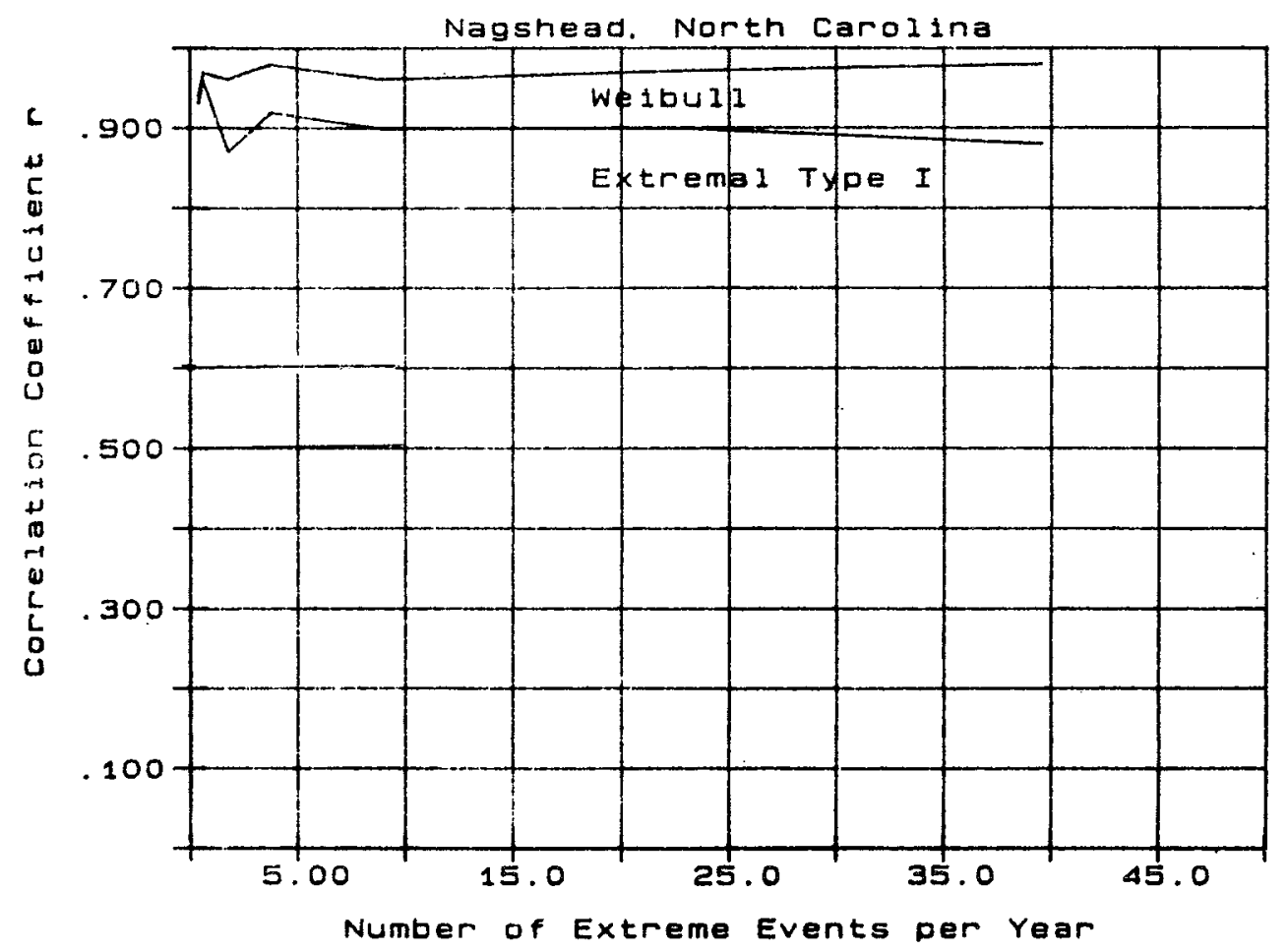

Figure A17. Correlation coefficient versus extreme events per year, Nagshead, NC 


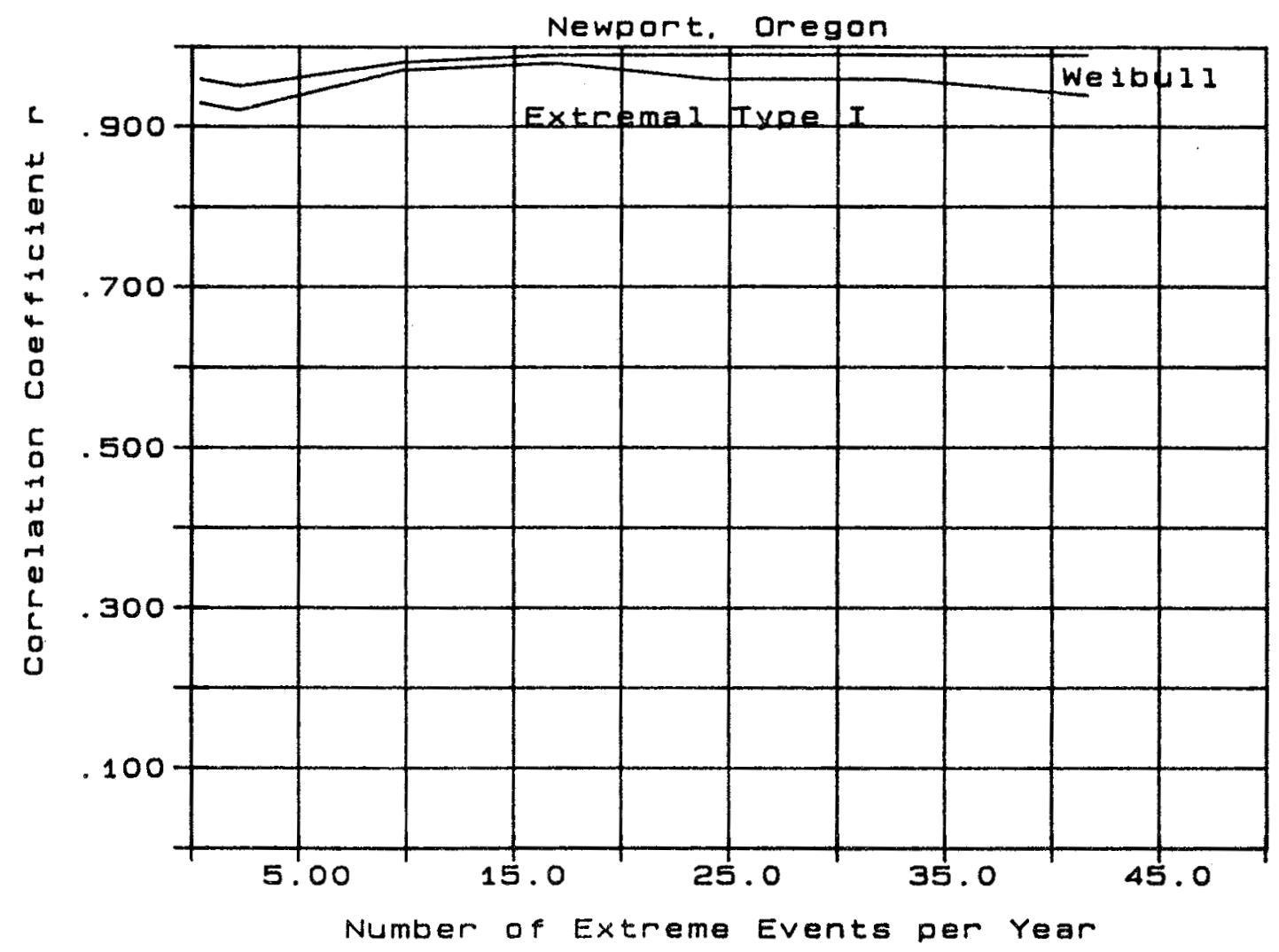

Figure A18. Correlation coefficient versus extreme events per year, Newport, OR 


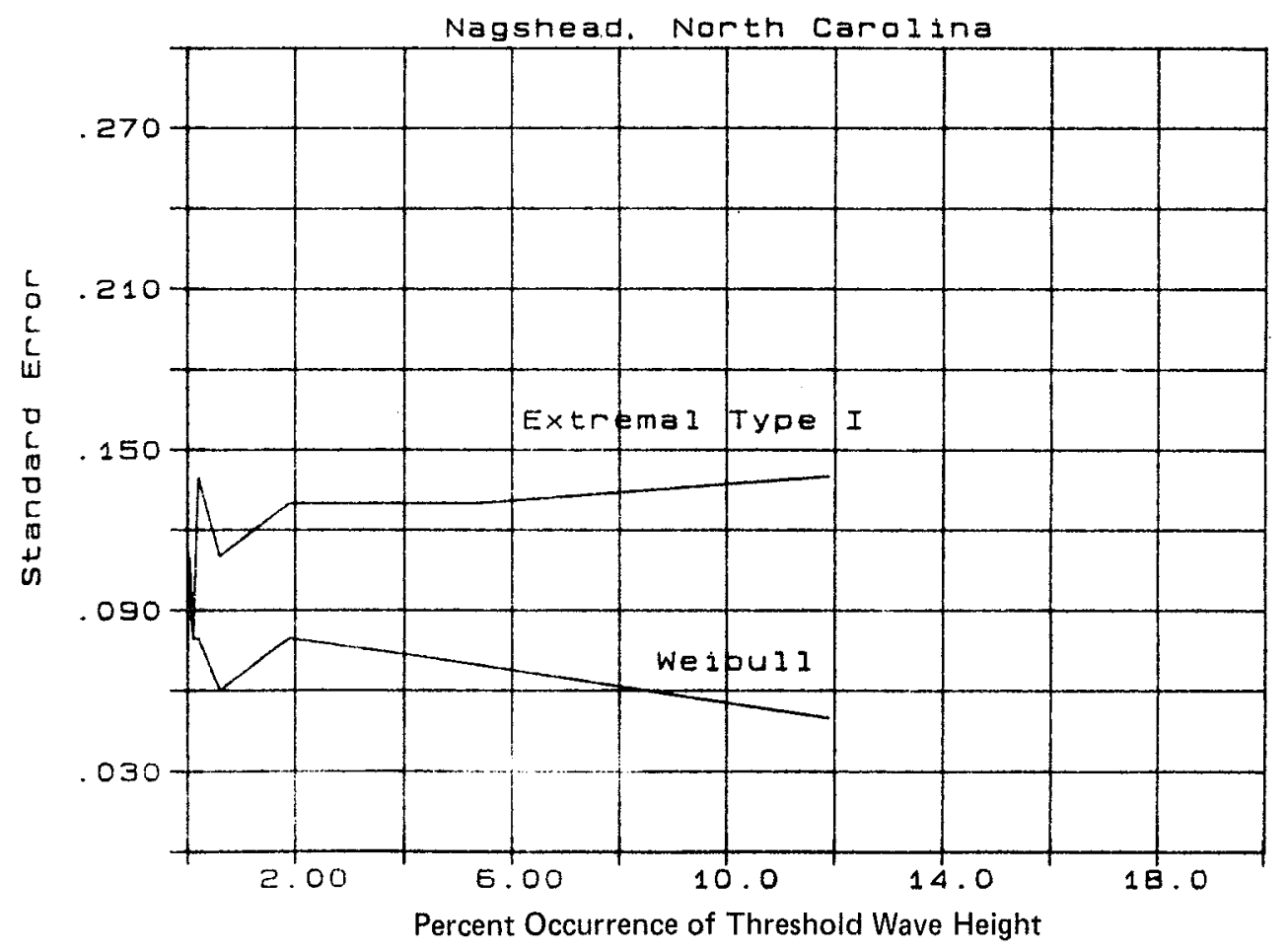

Figure A19. Standard error versus percent occurrence, Nagshead, NC

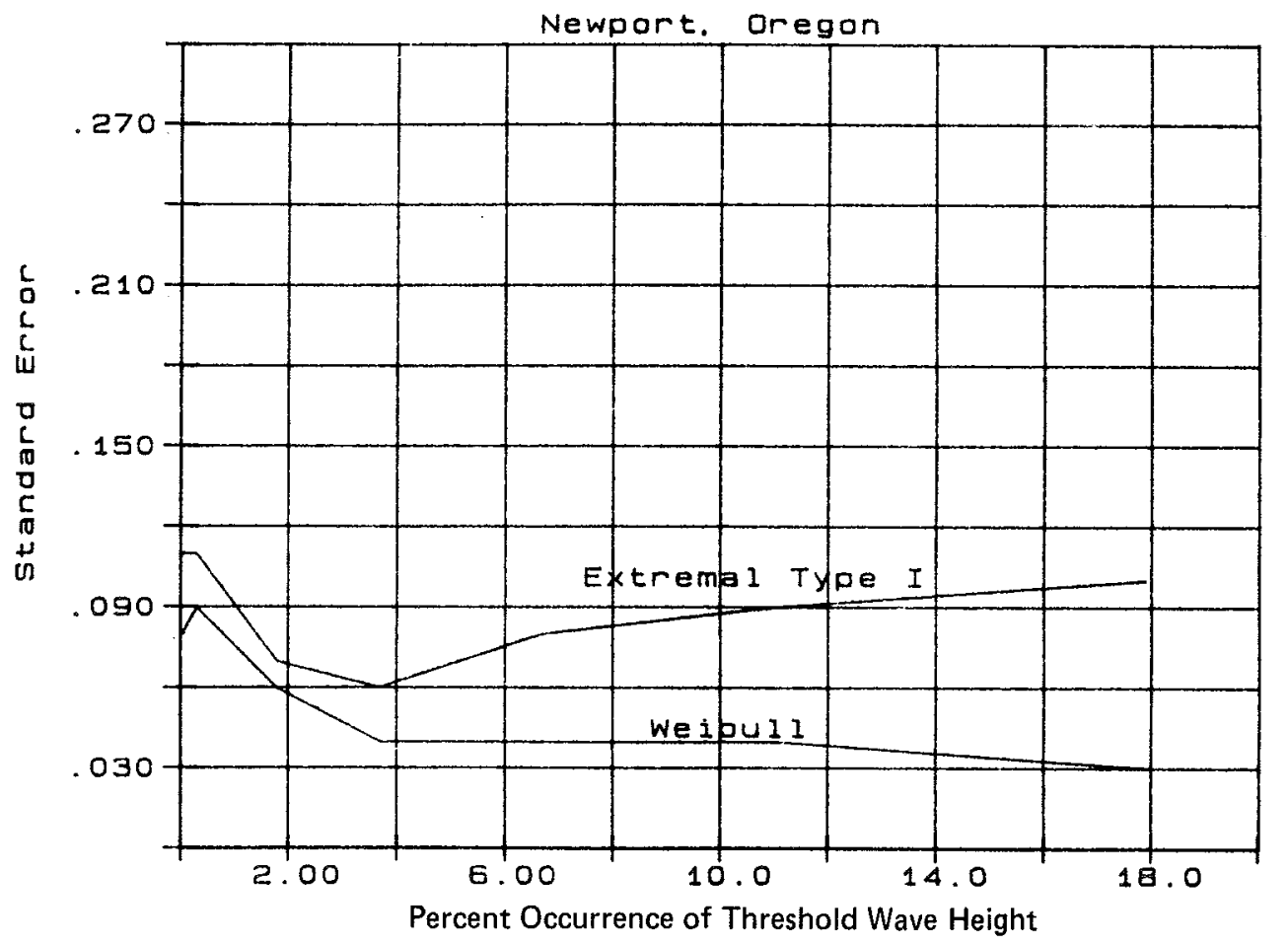

Figure A20. Standard error versus percent occurrence, Newport, OR 


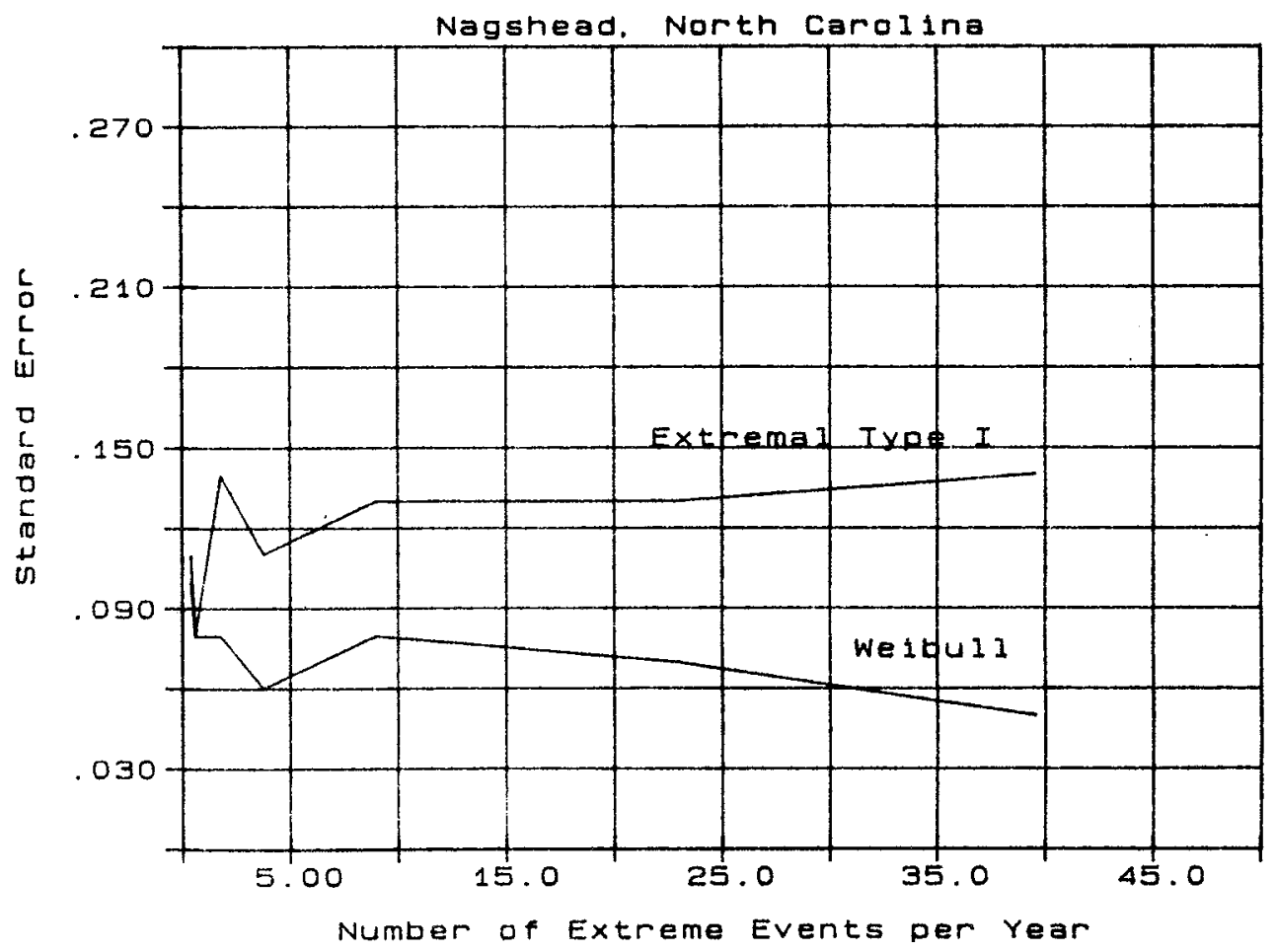

Figure A21. Standard error versus extreme events per year, Nagshead, NC

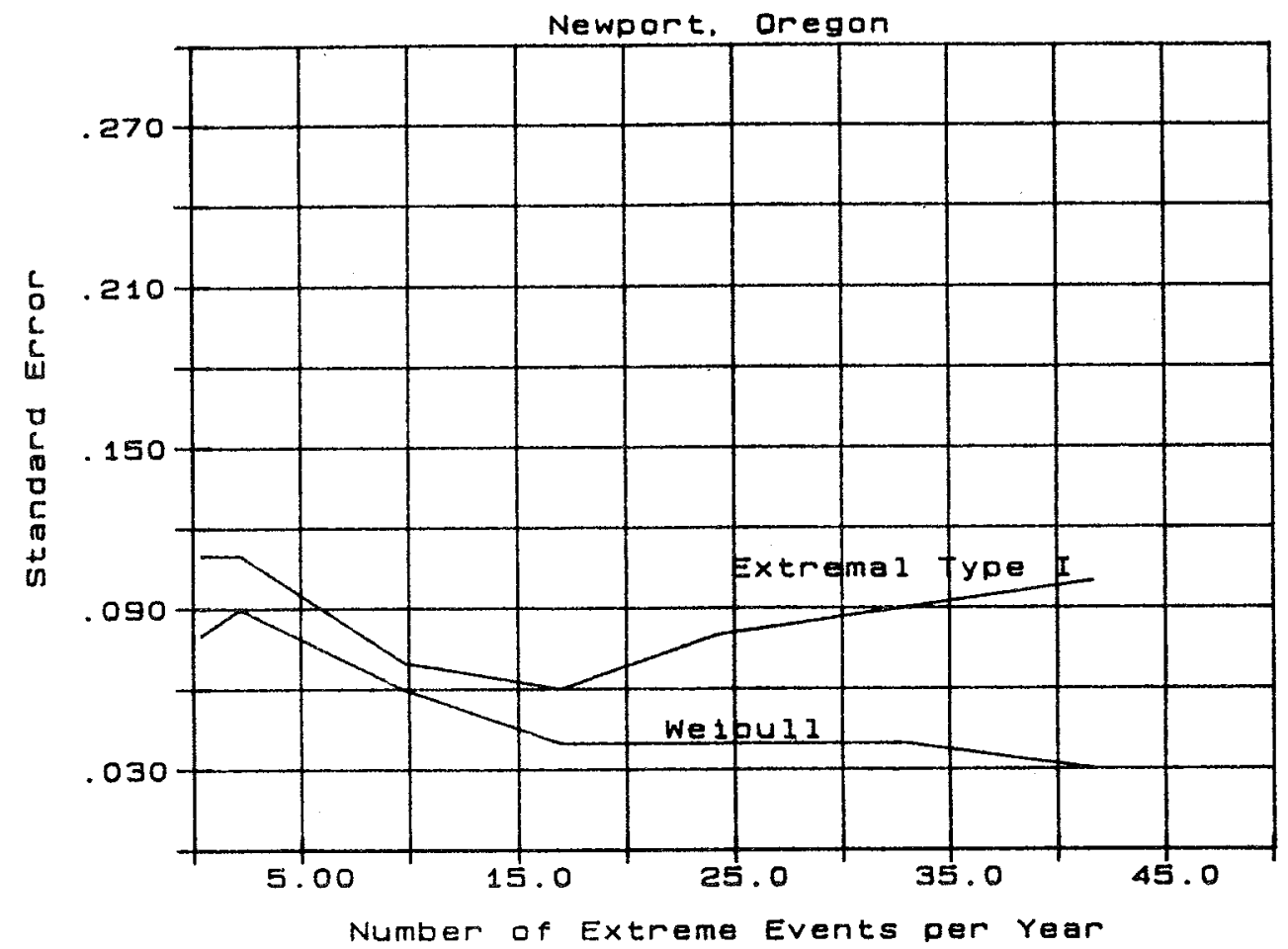

Figure A22. Standard error versus extreme events per year, Newport, OR 


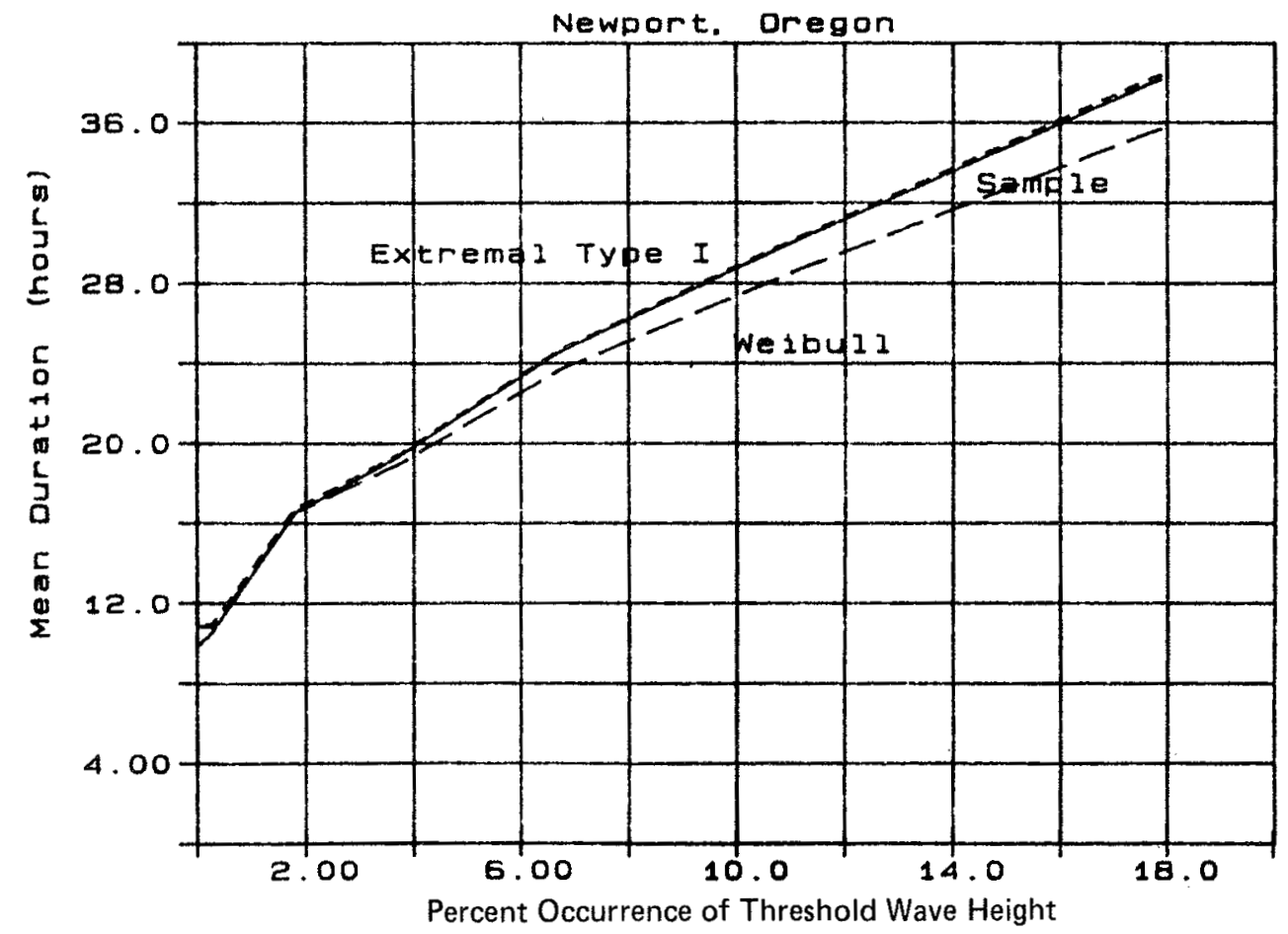

Figure A23. Mean duration versus percent occurrence, Newport, OR

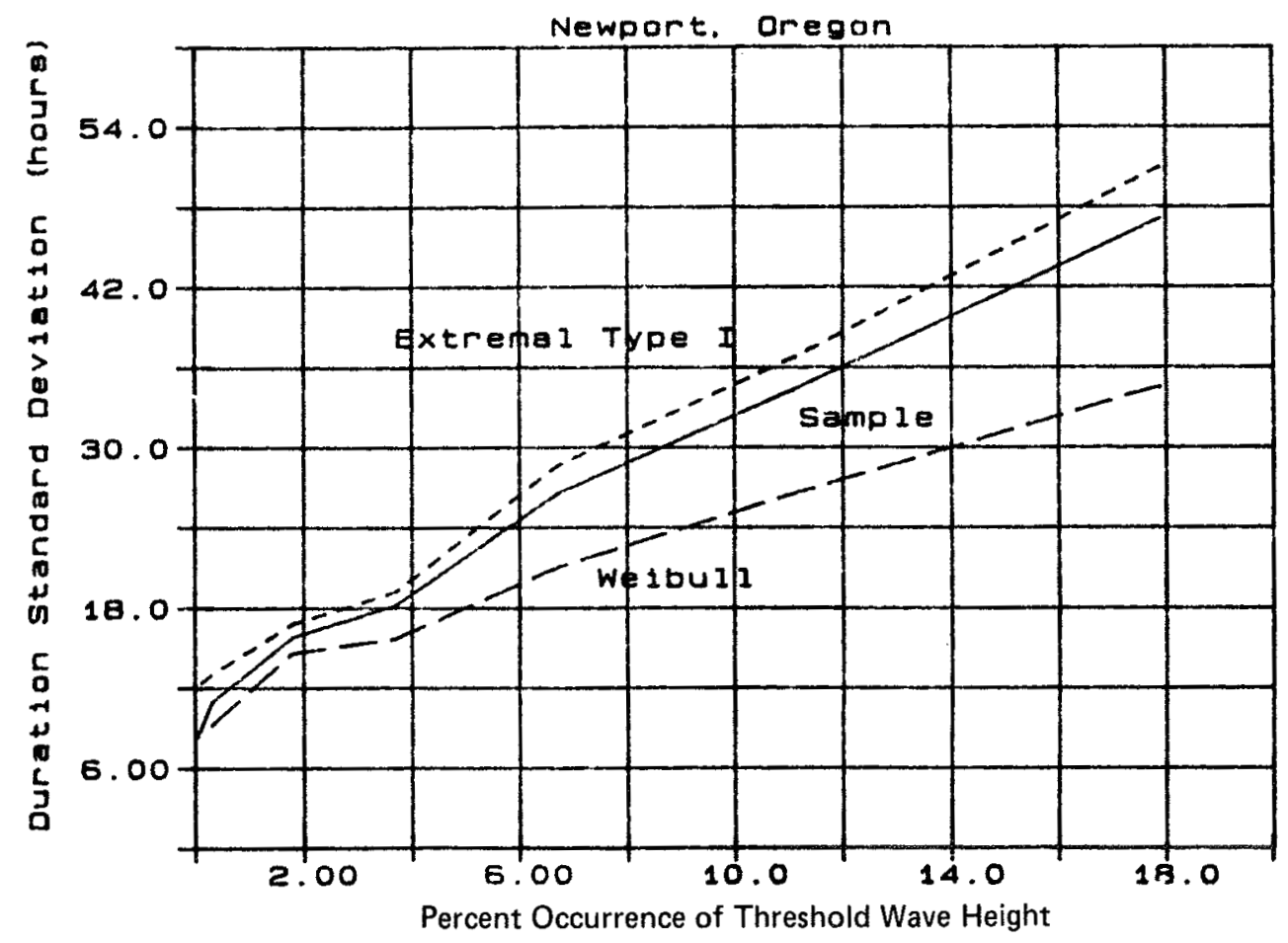

Figure A24. Duration standard deviation versus percent occurrence, Newport, OR 
Table A1

October 1956 Phase III Data, Nagshead, NC

\begin{tabular}{|c|c|c|c|c|c|c|c|c|c|c|}
\hline \multirow{2}{*}{$\begin{array}{l}\text { Station: } \\
\text { Date } \\
\text { YY/MM/DD }\end{array}$} & \multirow{2}{*}{$\begin{array}{l}\text { A3083 } \\
\text { Hour }\end{array}$} & \multicolumn{3}{|c|}{---- Sea Readings----- } & \multicolumn{3}{|c|}{-----Swell Readings----- } & \multicolumn{3}{|c|}{$-\cdots---$ Combined $-\cdots$} \\
\hline & & $\begin{array}{l}\text { He ight } \\
(\mathrm{cm}) \\
\end{array}$ & $\begin{array}{l}\text { Period } \\
\text { (secs) }\end{array}$ & $\begin{array}{l}\text { Direct } \\
\text { (azim) }\end{array}$ & $\begin{array}{l}\text { He ight } \\
(\mathrm{cm})\end{array}$ & $\begin{array}{l}\text { Period } \\
\text { (secs) } \\
\end{array}$ & $\begin{array}{l}\text { Direct } \\
\text { (azim) }\end{array}$ & $\begin{array}{l}\text { He ight } \\
(\mathrm{cm})\end{array}$ & $\begin{array}{l}\text { Period } \\
\text { (secs) }\end{array}$ & $\begin{array}{l}\text { Direct } \\
\text { (azim) }\end{array}$ \\
\hline $56 / 10 / 27$ & $00: 00$ & 219 & 7 & 90 & 0 & 0 & 0 & 219 & 7 & 90 \\
\hline $56 / 10 / 27$ & $03: 00$ & 137 & 6 & 103 & 441 & 11 & 83 & 462 & 11 & 83 \\
\hline $56 / 10 / 27$ & $06: 00$ & 208 & 6 & 98 & 119 & 11 & 83 & 240 & 6 & 98 \\
\hline $56 / 10 / 27$ & $09: 00$ & $26 i$ & 8 & 90 & 0 & 0 & 0 & 261 & 8 & 90 \\
\hline $56 / 10 / 27$ & $.12: 00$ & 282 & 9 & 93 & 0 & 0 & 0 & 282 & 9 & 93 \\
\hline $56 / 10 / 27$ & $15: 00$ & 258 & 8 & 98 & 0 & 0 & 0 & 258 & 8 & 98 \\
\hline $56 / 10 / 27$ & $18: 00$ & 265 & 8 & 101 & 0 & 0 & 0 & 265 & 8 & 101 \\
\hline $56 / 10 / 27$ & $21: 00$ & 250 & 8 & 100 & 0 & 0 & 0 & 250 & 8 & 100 \\
\hline $56 / 10 / 28$ & $00: 00$ & 93 & 5 & 130 & 395 & 11 & 75 & 406 & 11 & 75 \\
\hline $56 / 10 / 28$ & $03: 00$ & 117 & 5 & 130 & 378 & 11 & 75 & 396 & 11 & 75 \\
\hline $56 / 10 / 28$ & $06: 00$ & 149 & 6 & 127 & 369 & 11 & 75 & 398 & 11 & 75 \\
\hline $56 / 10 ; 28$ & $09: 00$ & 234 & 7 & 111 & 0 & 0 & 0 & 234 & 7 & 111 \\
\hline $56 / 10 / 28$ & $12: 00$ & 260 & 8 & 108 & 0 & 0 & 0 & 260 & 8 & 108 \\
\hline $56 / 10 / 28$ & $15: 00$ & 273 & 8 & 107 & 0 & 0 & 0 & 273 & 8 & 107 \\
\hline $56 / 10 / 28$ & $18: 00$ & 314 & 9 & 99 & 0 & 0 & 0 & 314 & 9 & 99 \\
\hline $56 / 10 / 28$ & $21: 00$ & 311 & 9 & 99 & 0 & 0 & 0 & 311 & 9 & 99 \\
\hline
\end{tabular}


Table A2

October 1956 Phase II Data, Nagshead, NC

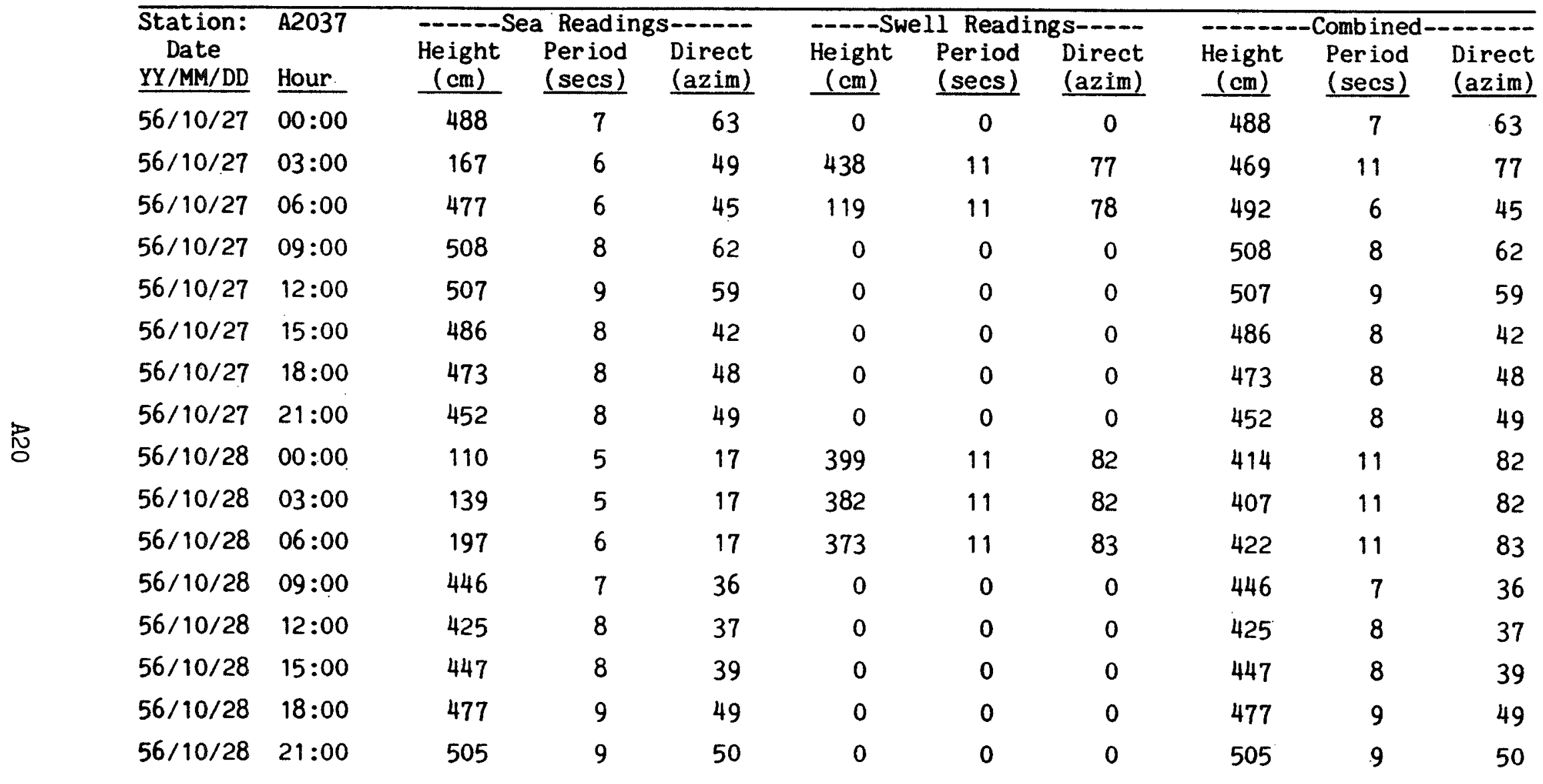


Table A3

October 1956 Phase I Deepwater Data, Offshore of Cape Natteras, NC

\begin{tabular}{|c|c|c|c|c|c|c|c|c|c|c|}
\hline \multirow{2}{*}{$\begin{array}{l}\text { Station: } \\
\text { Date } \\
\text { YY/MM/DD }\end{array}$} & \multirow{2}{*}{$\begin{array}{l}\text { A1005 } \\
\text { Hour }\end{array}$} & \multicolumn{3}{|c|}{ - } & \multicolumn{3}{|c|}{----Swell Readings----- } & \multicolumn{3}{|c|}{$-\cdots--$ Comb ined $-\cdots---$} \\
\hline & & $\begin{array}{l}\text { He ight } \\
(\mathrm{cm})\end{array}$ & $\begin{array}{l}\text { Period } \\
\text { (secs) }\end{array}$ & $\begin{array}{l}\text { Direct } \\
\text { (azim) }\end{array}$ & $\begin{array}{l}\text { Height } \\
(\mathrm{cm})\end{array}$ & $\begin{array}{l}\text { Period } \\
\text { (secs) }\end{array}$ & $\begin{array}{l}\text { Direct } \\
\text { (azim) }\end{array}$ & $\begin{array}{l}\text { Height } \\
(\mathrm{cm})\end{array}$ & $\begin{array}{l}\text { Period } \\
\text { (secs) }\end{array}$ & $\begin{array}{l}\text { Direct } \\
\text { (azim) }\end{array}$ \\
\hline $56 / 10 / 26$ & $00: 00$ & 515 & 8 & 39 & 0 & 0 & 0 . & 515 & 8 & 39 \\
\hline $56 / 10 / 26$ & $03: 00$ & 571 & 9 & 40 & 0 & 0 & 0 & 571 & 9 & 40 \\
\hline $56 / 10 / 26$ & $06: 00$ & 624 & 9 & 42 & 0 & 0 & 0 & 624 & 9 & 42 \\
\hline $56 / 10 / 26$ & $09: 00$ & 646 & 9 & 45 & 0 & 0 & 0 & 646 & 9 & 45 \\
\hline $56 / 10 / 26$ & $12: 00$ & 660 & 9 & 47 & 0 & 0 & 0 & 660 & 9 & 47 \\
\hline $56 / 10 / 26$ & $15: 00$ & 648 & 9 & 49 & 0 & 0 & 0 & 648 & 9 & 49 \\
\hline $56 / 10 / 26$ & $18: 00$ & 620 & 8 & 50 & 0 & 0 & 0 & 620 & 8 & 50 \\
\hline $56 / 10 / 26$ & $21: 00$ & 611 & 9 & 53 & 0 & 0 & 0 & 611 & 9 & 53 \\
\hline $56 / 10 / 27$ & $00: 00$ & 598 & 9 & 56 & 0 & 0 & 0 & 598 & 9 & 56 \\
\hline $56 / 10 / 27$ & $03: 00$ & 554 & 8 & 57 & 0 & 0 & 0 & 554 & 8 & 57 \\
\hline $56 / 10 / 27$ & $06: 00$ & 518 & 7 & 62 & 0 & 0 & 0 & 518 & 7 & 62 \\
\hline $56 / 10 / 27$ & $09: 00$ & 489 & 6 & 64 & 0 & 0 & 0 & 489 & 6 & 64 \\
\hline $56 / 10 / 27$ & $12: 00$ & 464 & 6 & 65 & 0 & 0 & 0 & 464 & 6 & 65 \\
\hline $56 / 10 / 27$ & $15: 00$ & 443 & 6 & 66 & 0 & 0 & 0 & 443 & 6 & 66 \\
\hline $56 / 10 / 27$ & $18: 00$ & 228 & 5 & 69 & 360 & 12 & 157 & 426 & 12 & 157 \\
\hline $56 / 10 / 27$ & $2 \hat{i}: 00$ & 415 & 7 & 69 & 0 & 0 & 0 & 415 & 7 & 69 \\
\hline $56 / 10 / 28$ & $00: 00$ & 431 & 8 & 70 & 0 & 0 & 0 & 431 & 8 & 70 \\
\hline $56 / 10 / 28$ & $03: 00$ & 425 & 7 & 69 & 0 & 0 & 0 & 425 & 7 & 69 \\
\hline $56 / 10 / 28$ & $06: 00$ & 416 & 6 & 69 & 0 & 0 & 0 & 416 & 6 & 69 \\
\hline $56 / 10 / 28$ & $09: 00$ & 421 & 6 & 69 & 0 & 0 & 0 & 421 & 6 & 69 \\
\hline $56 / 10 / 28$ & $12: 00$ & 423 & 6 & 69 & 0 & 0 & 0 & 423 & 6 & 69 \\
\hline $56 / 10 / 28$ & $15: 00$ & 420 & 65 & 70 & 0 & 0 & 0 & 420 & 6 & 70 \\
\hline $56 / 10 / 28$ & $18: 00$ & 414 & 6 & 69 & 0 & 0 & 0 & 414 & 6 & 69 \\
\hline $56 / 10 / 28$ & $21: 00$ & 446 & 8 & 70 & 0 & 0 & 0 & 446 & 8 & 70 \\
\hline $56 / 10.29$ & $00: 00$ & 549 & 9 & 68 & 0 & 0 & 0 & 549 & 9 & 68 \\
\hline
\end{tabular}


Table A4

Duration Information for Atlantic City, NJ

\begin{tabular}{ccccccccc}
\hline $\begin{array}{l}H 1 \\
\mathrm{~cm}\end{array}$ & $\begin{array}{c}\mathrm{H}>\mathrm{H} 1 \\
\mathrm{~cm}\end{array}$ & $\begin{array}{c}\mathrm{H}>\mathrm{H} 1 \\
\%\end{array}$ & $\begin{array}{c}\text { Number } \\
\text { of } \\
\text { Events }\end{array}$ & $\begin{array}{c}\text { Number } \\
\text { of } \\
\text { Events/yr }\end{array}$ & $\begin{array}{c}t_{\min } \\
\mathrm{hrs}\end{array}$ & $\begin{array}{c}t_{\max } \\
\mathrm{hrs}\end{array}$ & $\begin{array}{c}\bar{t} \\
\mathrm{hrs}\end{array}$ & $\begin{array}{c}\sigma_{t} \\
\mathrm{hrs}\end{array}$ \\
200 & 1442 & 2.5 & 323 & 16.2 & 3 & 54 & 12.8 & 10.9 \\
250 & 384 & 0.7 & 112 & 5.6 & 3 & 30 & 9.9 & 7.3 \\
300 & 81 & 0.1 & 29 & 1.4 & 3 & 24 & 8.1 & 6.8 \\
350 & 18 & 0.03 & 9 & 0.4 & 3 & 15 & 5.7 & 4.1 \\
\hline
\end{tabular}

Table A5

Duration Information for Nagshead, NC

\begin{tabular}{|c|c|c|c|c|c|c|c|c|}
\hline $\begin{array}{l}\mathrm{H} 1 \\
\mathrm{~cm} \\
\end{array}$ & $\begin{array}{l}\mathrm{H}>\mathrm{H} 1 \\
\mathrm{~cm}\end{array}$ & $\begin{array}{c}H>{ }^{H} 1 \\
\% \\
\end{array}$ & $\begin{array}{c}\text { Number } \\
\text { of } \\
\text { Events }\end{array}$ & $\begin{array}{c}\text { Number } \\
\text { of } \\
\text { Events/yr }\end{array}$ & $\begin{array}{l}t_{\min } \\
\mathrm{hrs} \\
\end{array}$ & $\begin{array}{l}t_{\max } \\
\mathrm{hrs} \\
\end{array}$ & $\begin{array}{c}\bar{t} \\
\text { hrs }\end{array}$ & $\begin{array}{l}\sigma_{t} \\
\text { hrs }\end{array}$ \\
\hline 150 & 6983 & 11.9 & 792 & 39.6 & 3 & 570 & 26.9 & 39.1 \\
\hline 200 & 3167 & 5.4 & 460 & 23.0 & 3 & 306 & 21.1 & 29.4 \\
\hline 250 & 1093 & 1.9 & 179 & 9.0 & 3 & 165 & 18.9 & 25.0 \\
\hline 300 & 374 & 0.6 & 77 & 3.8 & 3 & 111 & 15.1 & 17.2 \\
\hline 350 & 143 & 0.2 & 36 & 1.8 & 3 & 84 & 12.2 & 14.9 \\
\hline 400 & 56 & 0.10 & 13 & 0.6 & 3 & 42 & 12.9 & 12.0 \\
\hline 450 & 16 & 0.03 & 8 & 0.4 & 3 & 15 & 6.4 & 4.1 \\
\hline
\end{tabular}


Table A6

Duration Information for Daytona Beach, EL

\begin{tabular}{|c|c|c|c|c|c|c|c|c|}
\hline $\begin{array}{l}\mathrm{H} 1 \\
\mathrm{~cm}\end{array}$ & $\begin{array}{l}\mathrm{H}>\mathrm{H} 1 \\
\quad \mathrm{~cm} \\
\end{array}$ & $\begin{array}{c}H>H 1 \\
-q\end{array}$ & $\begin{array}{c}\text { Number } \\
\text { of } \\
\text { Events }\end{array}$ & $\begin{array}{c}\text { Number } \\
\text { of } \\
\text { Events/yr }\end{array}$ & $\begin{array}{l}t_{\min } \\
\text { hrs } \\
\end{array}$ & $\begin{array}{l}t_{\max } \\
\mathrm{hrs} \\
\end{array}$ & $\begin{array}{c}\bar{t} \\
\text { hrs }\end{array}$ & $\begin{array}{c}\sigma_{t} \\
h r s\end{array}$ \\
\hline 150 & 8855 & 15.2 & 716 & 35.8 & 3 & 1032 & 37.5 & 65.5 \\
\hline 200 & 4183 & 7.2 & 432 & 21.6 & 3 & 303 & 29.5 & 35.6 \\
\hline 250 & 1340 & 2.3 & 186 & 9.3 & 3 & 129 & 22.5 & 25.5 \\
\hline 300 & 478 & 0.8 & 75 & 3.8 & 3 & 81 & 19.5 & 18.0 \\
\hline 350 & 143 & 0.2 & 33 & 1.6 & 3 & 60 & 13.3 & 11.5 \\
\hline 400 & 31 & 0.05 & 12 & 0.6 & 3 & 33 & 8.0 & 8.4 \\
\hline 450 & 8 & 0.01 & 3 & 0.2 & 3 & 18 & 9.0 & 7.9 \\
\hline
\end{tabular}

Table A7

Duration Information for Newport, $O R$

\begin{tabular}{cccccccccc}
\hline $\begin{array}{c}H 1 \\
\mathrm{~cm}\end{array}$ & $\begin{array}{c}\mathrm{H}>\mathrm{H} 1 \\
\mathrm{~cm}\end{array}$ & $\begin{array}{c}\mathrm{H}>\mathrm{H} 1 \\
\%\end{array}$ & $\begin{array}{c}\text { Number } \\
\text { of } \\
\text { Events }\end{array}$ & $\begin{array}{c}\text { Number } \\
\text { of } \\
\text { Events } / \mathrm{yr}\end{array}$ & $\begin{array}{c}\mathrm{t}_{\min } \\
\mathrm{hrs}\end{array}$ & $\begin{array}{c}\mathrm{t}_{\max } \\
\mathrm{hrs}\end{array}$ & $\begin{array}{c}\overline{\mathrm{t}} \\
\mathrm{hrs}\end{array}$ & $\begin{array}{c}\sigma_{\mathrm{t}} \\
\mathrm{hrs}\end{array}$ \\
450 & 6472 & 17.9 & 834 & 41.7 & 3 & 405 & 38.2 & 47.1 \\
500 & 3897 & 11.1 & 658 & 32.9 & 3 & 279 & 30.1 & 34.3 \\
550 & 2152 & 3.7 & 341 & 17.0 & 3 & 108 & 19.3 & 18.2 \\
600 & 1049 & 1.8 & 196 & 9.8 & 3 & 81 & 16.5 & 15.8 \\
650 & 151 & 0.3 & 44 & 2.2 & 3 & 51 & 10.6 & 10.9 \\
700 & 22 & 0.04 & 7 & 0.4 & 3 & 27 & 9.9 & 8.3 \\
\hline
\end{tabular}




\section{Table A8}

Duration Information for Half-Moon Bay, CA

\begin{tabular}{cccccccccc}
\hline $\begin{array}{l}H 1 \\
\mathrm{~cm}\end{array}$ & $\begin{array}{c}\mathrm{H}>\mathrm{H} 1 \\
\mathrm{~cm}\end{array}$ & $\begin{array}{c}\mathrm{H}>\mathrm{H} 1 \\
q\end{array}$ & $\begin{array}{c}\text { Number } \\
\text { of } \\
\text { Events }\end{array}$ & $\begin{array}{c}\text { Number } \\
\text { of } \\
\text { Events } / \mathrm{yr}\end{array}$ & $\begin{array}{c}t_{\min } \\
\mathrm{hrs}\end{array}$ & $\begin{array}{c}t_{\max } \\
\mathrm{hrs}\end{array}$ & $\begin{array}{c}t \\
\mathrm{hrs}\end{array}$ & $\begin{array}{c}\sigma_{t} \\
\mathrm{hrs}\end{array}$ \\
500 & 768 & 1.3 & 105 & 5.2 & 3 & 123 & 21.7 & 21.2 \\
550 & 373 & 0.6 & 50 & 2.5 & 3 & 108 & 22.0 & 21.7 \\
600 & 168 & 0.3 & 23 & 1.2 & 3 & 78 & 21.5 & 17.8 \\
650 & 17 & 0.03 & 3 & 0.2 & 12 & 21 & 17.0 & 4.6
\end{tabular}


Table A9

Duration Parameters with a Peak Wave Height Threshold, Nagshead, NC

\begin{tabular}{|c|c|c|c|c|c|c|c|c|}
\hline $\begin{array}{l}\mathrm{H} 1 \\
\mathrm{~cm} \\
\end{array}$ & $\begin{array}{l}\mathrm{H} 2 \\
\mathrm{~cm} \\
\end{array}$ & $\begin{array}{l}\% \text { Records } \\
\mathrm{H}>\mathrm{H} 1 \\
\end{array}$ & $\begin{array}{c}\text { Number } \\
\text { of } \\
\text { Events }\end{array}$ & $\begin{array}{c}\begin{array}{c}\text { Number } \\
\text { of } \\
\text { Events/yr }\end{array} \\
\end{array}$ & $\begin{array}{l}t_{\min } \\
\mathrm{hrs} \\
\end{array}$ & $\begin{array}{l}t_{\max } \\
h r s \\
\end{array}$ & $\begin{array}{c}\bar{t} \\
h r s\end{array}$ & $\begin{array}{c}\sigma_{t} \\
h r s\end{array}$ \\
\hline 100 & 300 & 25.0 & 52 & 2.6 & 18 & 1056 & 165.3 & 164.8 \\
\hline 125 & 300 & 17.1 & 52 & 2.6 & 15 & 381 & 122.6 & 75.5 \\
\hline 150 & 300 & 11.9 & 52 & 2.6 & 12 & 375 & 98.0 & 58.8 \\
\hline 175 & 300 & 8.4 & 54 & 2.7 & 9 & 333 & 81.7 & 55.3 \\
\hline 200 & 300 & 5.4 & 55 & 2.8 & 6 & 306 & 67.6 & 51.3 \\
\hline 225 & 300 & 3.2 & 62 & 3.1 & 6 & 174 & 45.6 & 32.1 \\
\hline 250 & 300 & 1.9 & 68 & 3.4 & 3 & 165 & 33.1 & 26.5 \\
\hline 275 & 300 & 1.1 & 77 & 3.8 & 3 & 117 & 20.5 & 17.6 \\
\hline 300 & 300 & 0.6 & 90 & 4.5 & 3 & 102 & 12.5 & 13.6 \\
\hline 100 & 250 & 25.0 & 118 & 5.9 & 18 & 1056 & 119.6 & 120.6 \\
\hline 125 & 250 & 17.1 & 119 & 6.0 & 15 & 381 & 92.5 & 64.1 \\
\hline 150 & 250 & 11.9 & 123 & 6.2 & 12 & 375 & 74.6 & 52.6 \\
\hline 175 & 250 & 8.4 & 129 & 6.4 & 6 & 333 & 60.0 & 47.4 \\
\hline 200 & 250 & 5.4 & 136 & 6.8 & 3 & 306 & 45.4 & 40.3 \\
\hline 225 & 250 & 3.2 & 173 & 8.6 & 3 & 174 & 26.0 & 25.6 \\
\hline 250 & 250 & 1.9 & 212 & 10.6 & 3 & 165 & 15.5 & 19.9 \\
\hline
\end{tabular}


Table A10

Duration Parameters with a Peak Wave Height Threshold, Daytona Beach, FL

\begin{tabular}{|c|c|c|c|c|c|c|c|c|}
\hline $\begin{array}{l}\mathrm{H} 1 \\
\mathrm{~cm}\end{array}$ & $\begin{array}{l}\mathrm{H} 2 \\
\mathrm{~cm}\end{array}$ & $\begin{array}{l}\text { \% Records } \\
\mathrm{H}>\mathrm{H} 1 \\
\end{array}$ & $\begin{array}{c}\text { Number } \\
\text { of } \\
\text { Events }\end{array}$ & $\begin{array}{c}\text { Number } \\
\text { of } \\
\text { Events/yr }\end{array}$ & $\begin{array}{l}t_{\min } \\
\mathrm{hrs} \\
\end{array}$ & $\begin{array}{l}t_{\max } \\
\mathrm{hrs} \\
\end{array}$ & $\begin{array}{c}\begin{array}{c}E \\
\text { hrs }\end{array} \\
\end{array}$ & $\begin{array}{l}\sigma_{t} \\
h r s\end{array}$ \\
\hline 100 & 300 & 30.7 & 49 & 2.4 & 36 & 1197 & 221.0 & 223.1 \\
\hline 125 & 300 & 21.8 & 49 & 2.4 & 24 & 1191 & 184.3 & 211.1 \\
\hline 150 & 300 & 15.2 & 51 & 2.6 & 15 & 1035 & 141.8 & 162.1 \\
\hline 175 & 300 & 10.6 & 54 & 2.7 & 12 & 354 & 105.7 & 63.8 \\
\hline 200 & 300 & 7.2 & 54 & 2.7 & 9 & 303 & 85.8 & 49.5 \\
\hline 225 & 300 & 4.3 & 68 & 3.4 & 3 & 141 & 49.1 & 28.4 \\
\hline 250 & 300 & 2.3 & 69 & 3.4 & 3 & 114 & 38.1 & 25.1 \\
\hline 275 & 300 & 1.3 & 75 & 3.8 & 3 & 87 & 25.5 & 18.7 \\
\hline 300 & 300 & 0.8 & 84 & 4.2 & 3 & 81 & 17.1 & 15.8 \\
\hline 100 & 250 & 30.7 & 119 & 6.0 & 9 & 1197 & 162.6 & 162.1 \\
\hline 125 & 250 & 21.8 & 121 & 6.0 & 9 & 1191 & 131.0 & 147.8 \\
\hline 150 & 250 & 15.2 & 127 & 6.4 & 6 & 1035 & 101.5 & 111.5 \\
\hline 175 & 250 & 10.6 & 133 & 6.6 & 6 & 354 & 78.0 & 52.4 \\
\hline 200 & 250 & 7.2 & 140 & 7.0 & 3 & 303 & 59.9 & 41.3 \\
\hline 225 & 250 & 4.3 & 193 & 9.6 & 3 & 141 & 30.9 & 24.8 \\
\hline 250 & 250 & 2.3 & 238 & 11.9 & 3 & 114 & 16.9 & 20.0 \\
\hline
\end{tabular}


Table A11

Distribution Parameters for Durations and Peak Wave Heights at Atlantic City, NJ

\begin{tabular}{|c|c|c|c|c|c|c|}
\hline \multirow[b]{2}{*}{ Parameter } & \multicolumn{3}{|c|}{----- Duration- - - - } & \multicolumn{3}{|c|}{--- Peak Wave Height- - } \\
\hline & Sample & Type I & Weibull & Sample & Type I & We ibull \\
\hline \multicolumn{7}{|c|}{$\mathrm{H} 1=200 \mathrm{~cm}(2.5 \%$ occurrence level $)$} \\
\hline$\varepsilon / \alpha$ & - & 7.75 & 1.23 & - & 222.6 & 7.06 \\
\hline$\beta$ & - & 8.93 & 14.0 & - & 32.1 & 258.0 \\
\hline$x$ & 12.8 & 12.9 & 13.1 & 240.9 & 241.1 & 241.4 \\
\hline$\sigma$ & 10.9 & 11.4 & 10.7 & 39.5 & 41.1 & 40.2 \\
\hline $\boldsymbol{r}$ & - & 0.97 & 0.97 & - & 0.98 & 0.93 \\
\hline $\operatorname{sres}^{2^{*}}$ & - & 1.40 & 1.47 & - & 0.838 & 3.51 \\
\hline std.err. & - & 0.066 & 0.068 & - & 0.051 & 0.104 \\
\hline \multicolumn{7}{|c|}{$\mathrm{H} 1=250 \mathrm{~cm}(0.7 \%$ occurrence $)$} \\
\hline$\varepsilon / \alpha$ & - & 6.36 & 1.45 & - & 271.4 & 9.77 \\
\hline B & - & 6.23 & 11.04 & - & 27.3 & 301.9 \\
\hline $\mathrm{x}$ & 9.9 & 10.0 & 10.0 & 286.8 & 287.2 & 287.0 \\
\hline$\sigma$ & 7.3 & 8.0 & 7.0 & 32.7 & 35.0 & 35.3 \\
\hline$r$ & - & 0.97 & 0.97 & - & 0.99 & 0.93 \\
\hline $\operatorname{Lres}^{2^{*}}$ & - & 0.512 & 0.534 & - & 0.222 & 1.21 \\
\hline std.err. & - & 0.068 & 0.070 & - & 0.045 & 0.105 \\
\hline
\end{tabular}

* Sum of the square residuals. 
Table A11. (Concluded)

\begin{tabular}{|c|c|c|c|c|c|c|}
\hline Parameter & Sample & $\begin{array}{l}\text {-Duratio } \\
\text { Type I }\end{array}$ & $\begin{array}{l}\text { Weibul1 } \\
\text { We-- }\end{array}$ & $\begin{array}{l}---P e ́ \\
\text { Sample }\end{array}$ & $\begin{array}{l}\mathrm{k} \text { Wave H} \\
\text { Type I }\end{array}$ & $\begin{array}{l}\text { eight-- } \\
\text { Weibull }\end{array}$ \\
\hline \multicolumn{7}{|c|}{$\mathrm{H} 1=300 \mathrm{~cm}(0.1 \%$ occurrence $)$} \\
\hline$\varepsilon / \alpha$ & - & 4.65 & 1.45 & - & 318.7 & 12.6 \\
\hline B & - & 6.39 & 9.20 & - & 25.2 & 345.5 \\
\hline $\mathbf{x}$ & 8.1 & 8.3 & 8.6 & 332.2 & 333.2 & 331.6 \\
\hline$\sigma$ & 6.8 & 8.2 & 7.1 & 27.7 & 32.3 & 32.0 \\
\hline $\mathbf{r}$ & - & 0.92 & 0.92 & - & 0.98 & 0.97 \\
\hline $\operatorname{sres}^{2 *}$ & - & 0.366 & 0.366 & - & 0.067 & 0.139 \\
\hline std.err. & - & 0.116 & 0.116 & - & 0.050 & 0.072 \\
\hline \multicolumn{7}{|c|}{$H 1=350 \mathrm{~cm}(0.03 \%$ occurrence $)$} \\
\hline$\varepsilon / \alpha$ & - & 3.43 & 1.36 & - & 354.5 & 15.4 \\
\hline$B$ & - & 4.57 & 6.78 & - & 21.8 & 376.6 \\
\hline$x$ & 5.7 & 6.1 & 6.2 & 365.2 & 367.1 & 364.0 \\
\hline$\sigma$ & 4.1 & 5.9 & 4.6 & 18.4 & 28.0 & 29.0 \\
\hline$r$ & - & 0.89 & 0.89 & - & 0.86 & 0.77 \\
\hline $\operatorname{cres}^{2 *}$ & - & 0.128 & 0.122 & - & 0.159 & 0.243 \\
\hline std.err. & - & 0.135 & 0.132 & - & 0.151 & 0.186 \\
\hline
\end{tabular}

- Sum of the square residuals. 
Table A12

Distribution Parameters for Durations and Peak Wave Heights at

Nagshead, NC

\begin{tabular}{|c|c|c|c|c|c|c|}
\hline \multirow[b]{2}{*}{ Parameter } & \multicolumn{3}{|c|}{$\cdots-\cdots$ Duration $\cdots-\cdots$} & \multicolumn{3}{|c|}{--- Peak Wave Height--- } \\
\hline & Sample & Type I & Weibul1 & Sample & Type I & Weibull \\
\hline \multicolumn{7}{|c|}{$\mathrm{H} 1=150 \mathrm{~cm}(11.9 \%$ occurrence $)$} \\
\hline$\varepsilon / \alpha$ & - & 6.19 & 1.06 & - & 181.5 & 4.80 \\
\hline B & - & 36.0 & 25.0 & - & 44.5 & 226.8 \\
\hline$x$ & 26.9 & 27.0 & 24.5 & 207.0 & 207.2 & 207.7 \\
\hline o & 39.1 & 46.2 & 23.2 & 55.1 & 57.1 & 49.4 \\
\hline $\mathbf{r}$ & - & 0.88 & 0.98 & - & 0.99 & 0.95 \\
\hline $\operatorname{sres}^{2}$ & - & 14.5 & 2.18 & - & 1.59 & 6.43 \\
\hline std.err. & - & 0.14 & 0.05 & - & 0.04 & 0.09 \\
\hline \multicolumn{7}{|c|}{$\mathrm{H} 1=200 \mathrm{~cm}(5.4 \%$ occurrence $)$} \\
\hline$\varepsilon / \alpha$ & - & 6.20 & 0.99 & - & 218.5 & 5.55 \\
\hline B & - & 26.0 & 19.6 & - & 43.2 & 264.8 \\
\hline $\mathrm{x}$ & 21.1 & 21.2 & 19.7 & 243.2 & 243.4 & 244.6 \\
\hline$\sigma$ & 29.4 & 33.4 & 20.0 & 51.8 & 55.4 & 51.0 \\
\hline$r$ & - & 0.90 & 0.97 & - & 0.95 & 0.89 \\
\hline Eres ${ }^{2}$ & - & 7.35 & 2.53 & - & 3.50 & 7.81 \\
\hline std.err. & - & 0.13 & 0.07 & - & 0.09 & 0.13 \\
\hline
\end{tabular}

(Continued)

(Sheet 1 of 4 ) 
Table A12 (Continued)

\begin{tabular}{|c|c|c|c|c|c|c|}
\hline Parameter & Sample & --Duratio & We-and & $\begin{array}{l}\text {---Pea } \\
\text { Samnle }\end{array}$ & k Wave $\mathrm{k}$ & eight-- \\
\hline $\mathrm{H} 1=250 \mathrm{~cm}$ & occurre & ence) & & & & \\
\hline$\varepsilon / \alpha$ & - & 6.21 & 1.02 & - & 272.3 & 6.35 \\
\hline$B$ & - & 22.3 & 17.9 & - & 45.4 & 321.4 \\
\hline$x$ & 18.9 & 19.1 & 17.7 & 298.0 & 298.5 & 299.1 \\
\hline$\sigma$ & 25.0 & 28.6 & 17.3 & 53.9 & 58.2 & 55.0 \\
\hline$r$ & - & 0.90 & 0.96 & - & 0.96 & 0.90 \\
\hline$\sum r e s^{2}$ & - & 2.79 & 1.04 & - & 1.05 & 2.73 \\
\hline std.err. & - & 0.13 & 0.08 & - & 0.08 & 0.12 \\
\hline $\mathrm{H} 1=300 \mathrm{cn}$ & occurre & ence) & & & & \\
\hline$\varepsilon / \alpha$ & - & 6.30 & 1.15 & - & 326.3 & 7.03 \\
\hline B & - & 15.8 & 15.5 & - & 48.0 & 378.0 \\
\hline$x$ & 15.1 & 15.4 & 14.7 & 353.0 & 354.0 & 353.7 \\
\hline$\sigma$ & 17.2 & 20.2 & 12.8 & 55.7 & 61.6 & 59.2 \\
\hline$r$ & - & 0.92 & 0.98 & - & 0.97 & 0.92 \\
\hline $\operatorname{Lres}^{2}$ & - & 0.91 & 0.30 & - & 0.35 & 0.95 \\
\hline std.err. & - & 0.11 & 0.06 & - & 0.07 & 0.11 \\
\hline
\end{tabular}

(Continued)

(Sheet 2 of 4 ) 
Table A12 (Continued)

\begin{tabular}{|c|c|c|c|c|c|c|}
\hline \multirow[b]{2}{*}{ Parameter } & \multicolumn{3}{|c|}{$\cdots-\cdots$ Duration $\cdots \cdots$} & \multicolumn{3}{|c|}{----Peak Wave Height--- } \\
\hline & Sample & Type I & Weibull & Sample & Type I I & Weibull \\
\hline \multicolumn{7}{|c|}{$\mathrm{H} 1=350 \mathrm{~cm}(0.2 \%$ occurrence $)$} \\
\hline$\varepsilon / \alpha$ & - & 3.9 & 1.16 & - & 375.0 & 7.9 \\
\hline $\boldsymbol{\beta}$ & - & 15.2 & 12.6 & - & 48.5 & 426.4 \\
\hline $\mathrm{x}$ & 12.2 & 12.7 & 12.0 & 401.2 & 402.9 & 401.3 \\
\hline$\sigma$ & 14.9 & 19.6 & 10.4 & 53.4 & 62.2 & 60.3 \\
\hline$r$ & - & 0.87 & 0.96 & - & 0.96 & 0.90 \\
\hline $\operatorname{rres}^{2}$ & - & 0.68 & 0.22 & - & 0.21 & 0.52 \\
\hline std.err. & - & 0.14 & 0.08 & - & 0.08 & 0.12 \\
\hline \multicolumn{7}{|c|}{$H 1=400 \mathrm{~cm}(0.10 \%$ occurrence $)$} \\
\hline$\varepsilon / \alpha$ & - & 6.8 & 0.97 & - & 428.9 & 8.4 \\
\hline$B$ & - & 12.1 & 14.3 & - & 53.5 & 481.7 \\
\hline$x$ & 12.9 & 13.8 & 14.5 & 456.0 & 459.8 & 454.5 \\
\hline$\sigma$ & 12.0 & 15.5 & 15.0 & 53.4 & 68.6 & 64.8 \\
\hline$r$ & - & 0.96 & 0.97 & - & 0.97 & 0.95 \\
\hline $\operatorname{sres}^{2}$ & - & 0.08 & 0.06 & - & 0.05 & 0.10 \\
\hline std.err. & - & 0.08 & 0.08 & - & 0.07 & 0.10 \\
\hline
\end{tabular}

(Continued) 
Table A12 (Concluded)

\begin{tabular}{|c|c|c|c|c|c|c|}
\hline & $-\cdots$ & uratic & $n-\infty-\cdots$ & $----\mathrm{Pea}$ & Wave $\mathrm{He}$ & ight--- \\
\hline Parameter & Sample & ype I & Weibull & Sample & Type I & Weibull \\
\hline $\mathrm{H} 1=450 \mathrm{c}$ & \% occur & ce) & & & & \\
\hline$\varepsilon / \alpha$ & - & 4.2 & 1.51 & - & 460.4 & 8.6 \\
\hline B & - & 4.5 & 7.52 & - & 52.9 & 512.2 \\
\hline$x$ & 6.4 & 6.8 & 6.8 & 486.0 & 490.9 & 484.1 \\
\hline$\sigma$ & 4.1 & 5.8 & 4.6 & 46.3 & 67.9 & 66.9 \\
\hline$r$ & - & 0.93 & 0.94 & - & 0.89 & 0.84 \\
\hline $\operatorname{rres}^{2}$ & - & 0.07 & 0.06 & - & 0.10 & 0.16 \\
\hline std.err. & - & 0.11 & 0.10 & - & 0.13 & 0.16 \\
\hline
\end{tabular}


Table A13

Distribution Parameters for Durations and Peak Wave Heights at Daytona Beach, FL

\begin{tabular}{|c|c|c|c|c|c|c|}
\hline \multirow[b]{2}{*}{ Parameter } & \multicolumn{3}{|c|}{------ Duration $--\cdots--$} & \multicolumn{3}{|c|}{--- Peak Wave Height--- } \\
\hline & Sample & Type I & Weibull & & & \\
\hline \multicolumn{7}{|c|}{$\mathrm{H} 1=200 \mathrm{~cm}(7.2 \%$ occurrence $)$} \\
\hline$\varepsilon / \alpha$ & - & 12.4 & 0.96 & - & 221.3 & 5.63 \\
\hline B & - & 30.0 & 27.9 & - & 42.4 & 266.9 \\
\hline $\mathrm{x}$ & 29.5 & 29.7 & 28.4 & 295.3 & 245.7 & 246.7 \\
\hline$\sigma$ & 35.6 & 38.5 & 29.7 & 51.4 & 54.4 & 50.7 \\
\hline $\mathbf{r}$ & - & 0.95 & 0.98 & - & 0.97 & 0.90 \\
\hline $\operatorname{sres}^{2}$ & - & 3.56 & 1.11 & - & 2.43 & 6.52 \\
\hline std.err. & - & 0.09 & 0.05 & - & 0.08 & 0.12 \\
\hline$H 1=250 \cdot c$ & occurre & nce) & & & & \\
\hline$\varepsilon / \alpha$ & - & 10.2 & 1.01 & - & 217.0 & 6.48 \\
\hline$B$ & - & 21.6 & 21.9 & - & 42.8 & 318.1 \\
\hline$x$ & 22.5 & 22.7 & 21.8 & 295.3 & 295.7 & 296.3 \\
\hline$\sigma$ & 25.5 & 27.6 & 21.7 & 51.4 & 54.9 & 53.5 \\
\hline$r$ & - & 0.95 & 0.98 & - & 0.97 & 0.90 \\
\hline $\operatorname{sres}^{2}$ & - & 1.51 & 0.68 & - & 1.02 & 2.79 \\
\hline std.err. & - & 0.09 & 0.06 & - & 0.07 & 0.12 \\
\hline
\end{tabular}

(Continued) 
Table A13 (Concluded)

\begin{tabular}{|c|c|c|c|c|c|c|}
\hline Parameter & \multicolumn{3}{|c|}{----- Duration $-\cdots \cdots$} & $\begin{array}{l}--- \text { Pea } \\
\text { Sample }\end{array}$ & $\begin{array}{l}\text { Wave He } \\
\text { Type I }\end{array}$ & $\begin{array}{l}\text { ight--- } \\
\text { Weibull }\end{array}$ \\
\hline \multicolumn{7}{|c|}{$\mathrm{H} 1=300 \mathrm{~cm}(0.8 \%$ occurrence $)$} \\
\hline$\varepsilon / \alpha$ & - & 10.8 & 1.21 & - & 329.7 & 8.43 \\
\hline B & - & 15.5 & 20.6 & - & 39.4 & 372.6 \\
\hline $\mathrm{x}$ & 19.5 & 19.8 & 19.3 & 351.6 & 352.4 & 351.7 \\
\hline 0 & 18.0 & 19.9 & 16.1 & 46.4 & 50.5 & 49.7 \\
\hline$r$ & - & 0.98 & 0.99 & - & 0.99 & 0.93 \\
\hline $\operatorname{Lres}^{2}$ & - & 0.29 & 0.11 & - & 0.17 & 0.78 \\
\hline std.err. & - & 0.06 & 0.04 & - & 0.05 & 0.10 \\
\hline \multicolumn{7}{|c|}{$\mathrm{H} 1=350 \mathrm{~cm}(0.2 \%$ occurrence $)$} \\
\hline$\varepsilon / \alpha$ & - & 7.39 & 1.40 & - & 375.7 & 10.4 \\
\hline$B$ & - & 10.9 & 14.6 & - & 35.4 & 413.9 \\
\hline$x$ & 13.3 & 13.7 & 13.3 & 394.8 & 396.2 & 394.4 \\
\hline $\boldsymbol{\sigma}$ & 11.5 & 14.0 & 9.61 & 39.4 & 45.4 & 45.7 \\
\hline $\mathbf{r}$ & - & 0.95 & 0.98 & - & 0.98 & 0.93 \\
\hline $\operatorname{rres}^{2}$ & - & 0.27 & 0.10 & - & 0.13 & 0.36 \\
\hline std.err. & - & 0.09 & 0.06 & - & 0.06 & 0.11 \\
\hline
\end{tabular}


Table $\mathrm{A} 14$

Distribution Parameters for Durations and Peak Wave Heights at Newport, OR

\begin{tabular}{|c|c|c|c|c|c|c|}
\hline Parameter & Sample & $\begin{array}{l}\text { Duratic } \\
\text { Type I }\end{array}$ & Weibull & & ----Peak Wave Height--- & $\begin{array}{l}\text { ight--- } \\
\text { Weibull }\end{array}$ \\
\hline $\mathrm{H} 1=400$ & 6 occurr & nce) & & & & \\
\hline$\varepsilon / \alpha$ & - & 15.4 & 1.03 & - & 457.9 & 7.45 \\
\hline$B$ & - & 39.7 & 36.2 & - & 62.7 & 527.3 \\
\hline$x$ & 38.2 & 38.4 & 35.7 & 493.9 & 494.1 & 494.8 \\
\hline $\boldsymbol{\sigma}$ & 47.1 & 51.0 & 34.6 & 77.7 & 80.4 & 78.5 \\
\hline$r$ & - & 0.94 & 0.99 & - & 0.99 & 0.95 \\
\hline $\operatorname{sres}^{2}$ & - & 8.07 & 0.87 & - & 1.52 & 6.81 \\
\hline std.err. & - & 0.10 & 0.03 & - & 0.04 & 0.09 \\
\hline $\mathrm{H1}=450 \mathrm{C}$ & 6 occurr & $n c e)$ & & & & \\
\hline$\varepsilon / \alpha$ & - & 13.6 & 1.08 & - & 505.5 & 7.51 \\
\hline $\boldsymbol{B}$ & - & 28.6 & 29.4 & - & 53.5 & 565.4 \\
\hline $\mathrm{x}$ & 30.1 & 30.2 & 28.6 & 536.2 & 536.4 & 536.7 \\
\hline$\sigma$ & 34.3 & 36.7 & 26.5 & 65.9 & 63.6 & 67.7 \\
\hline $\mathbf{r}$ & - & 0.96 & 0.99 & - & 0.99 & 0.96 \\
\hline $\operatorname{sres}^{2}$ & - & 4.75 & 0.92 & - & 1.55 & 3.96 \\
\hline std.err. & - & 0.09 & 0.04 & - & 0.05 & 0.08 \\
\hline
\end{tabular}

(Continued)

(Sheet 1 of 4 ) 
Table A14 (Continued)

\begin{tabular}{|c|c|c|c|c|c|c|}
\hline \multirow[b]{2}{*}{ Parameter } & \multicolumn{3}{|c|}{$\cdots-$ Duration- } & \multicolumn{3}{|c|}{--- Peak Wave Height--- } \\
\hline & Sample & Type I & Weibul1 & Sample & Type I & Weibull \\
\hline \multicolumn{7}{|c|}{$\mathrm{H} 1=500 \mathrm{~cm}(3.7 \%$ occurrence $)$} \\
\hline$\varepsilon / \alpha$ & - & 11.8 & 1.13 & - & 547.4 & 13.0 \\
\hline $\mathbf{B}$ & - & 22.3 & 24.7 & - & 41.6 & 594.6 \\
\hline $\mathrm{x}$ & 24.5 & 24.6 & 23.6 & 571.3 & 571.5 & 571.5 \\
\hline$\sigma$ & 26.5 & 28.6 & 21.0 & 51.4 & 53.4 & 53.5 \\
\hline$r$ & - & 0.96 & 0.99 & - & 0.98 & 0.98 \\
\hline rres $^{2}$ & - & 3.01 & 0.72 & - & 1.24 & 1.68 \\
\hline std.err. & - & 0.08 & 0.04 & - & 0.05 & 0.06 \\
\hline \multicolumn{7}{|c|}{$\mathrm{H} 1=550 \mathrm{~cm}(3.7 \%$ occurrence $)$} \\
\hline$\varepsilon / \alpha$ & - & 10.8 & 1.21 & - & 585.0 & 18.9 \\
\hline B & - & 14.9 & 20.2 & - & 29.8 & 619.3 \\
\hline$x$ & 19.3 & 19.4 & 18.9 & 602.0 & 602.2 & 602.0 \\
\hline $\boldsymbol{\sigma}$ & 18.2 & 19.2 & 15.7 & 37.1 & 38.2 & 39.5 \\
\hline $\boldsymbol{r}$ & - & 0.98 & 0.99 & - & 0.99 & 0.97 \\
\hline rres $^{2}$ & - & 1.32 & 0.61 & - & 0.40 & 1.47 \\
\hline std.err. & - & 0.06 & 0.04 & - & 0.03 & 0.07 \\
\hline
\end{tabular}

(Continued)

(Sheet 2 of 4 ) 
Table A14 (Continued)

\begin{tabular}{|c|c|c|c|c|c|c|}
\hline \multirow[b]{2}{*}{ Parameter } & \multicolumn{3}{|c|}{ - - - Duration- } & \multicolumn{3}{|c|}{--- Peak Wave Height--- } \\
\hline & Sample & Type I & Weibul1 & Sample & Type I 1 & Weibull \\
\hline \multicolumn{7}{|c|}{$\mathrm{H} 1=600 \mathrm{~cm}(1.8 \%$ occurrence $)$} \\
\hline$\varepsilon / a$ & - & 9.1 & 1.13 & - & 616.6 & 24.4 \\
\hline B & - & 13.1 & 17.2 & - & 22.6 & 643.6 \\
\hline $\mathrm{x}$ & 16.5 & 16.7 & 16.5 & 629.5 & 629.7 & 629.5 \\
\hline$\sigma$ & 15.8 & 16.8 & 14.6 & 27.6 & 29.0 & 32.1 \\
\hline$r$ & - & 0.97 & 0.98 & - & 0.99 & 0.98 \\
\hline $\operatorname{sres}^{2}$ & - & 1.09 & 0.75 & - & 0.41 & 2.53 \\
\hline std.err. & - & 0.07 & 0.06 & - & 0.05 & 0.11 \\
\hline \multicolumn{7}{|c|}{$\mathrm{H} 1=650 \mathrm{~cm}(0.3 \%$ occurrence $)$} \\
\hline$\varepsilon / \alpha$ & - & 5.1 & 1.12 & - & 663.7 & 32.2 \\
\hline B & - & 10.1 & 11.4 & - & 18.8 & 685.1 \\
\hline $\mathrm{x}$ & 10.6 & 11.0 & 10.8 & 673.9 & 674.5 & 673.5 \\
\hline$\sigma$ & 10.9 & 13.0 & 9.2 & 21.4 & 24.1 & 26.3 \\
\hline $\mathbf{r}$ & - & 0.92 & 0.95 & - & 0.98 & 0.93 \\
\hline $\operatorname{sres}^{2}$ & - & 0.52 & 0.34 & - & 0.13 & 0.50 \\
\hline std.err. & - & 0.11 & 0.09 & - & 0.06 & 0.11 \\
\hline
\end{tabular}

(Continued)

(Sheet 3 of 4 ) 
Table A14 (Concluded)

\begin{tabular}{|c|c|c|c|c|c|c|}
\hline Parameter & Sample & $\begin{array}{l}\text {-Duratio } \\
\text { Type I }\end{array}$ & Weibull & $\begin{array}{l}--- \text { Pea } \\
\text { Sample }\end{array}$ & $\begin{array}{l}\text { Wave He } \\
\text { Type I }\end{array}$ & $\begin{array}{l}\text { ight-a } \\
\text { Weibull }\end{array}$ \\
\hline \multicolumn{7}{|c|}{$H 1=700(0.04 \%$ occurrence $)$} \\
\hline$\varepsilon / \alpha$ & - & 5.4 & 1.15 & - & 711.5 & 71.9 \\
\hline$B$ & - & 9.4 & 11.5 & - & 10.4 & 721.1 \\
\hline$x$ & 9.9 & 10.8 & 10.9 & 716.4 & 717.5 & 715.5 \\
\hline 0 & 8.3 & 12.1 & 9.5 & 9.2 & 13.3 & 12.6 \\
\hline$r$ & - & 0.93 & 0.96 & - & 0.97 & 0.98 \\
\hline $\operatorname{sres}^{2}$ & - & 0.06 & 0.03 & - & 0.03 & 0.02 \\
\hline std.err. & - & 0.11 & 0.08 & - & 0.07 & 0.06 \\
\hline
\end{tabular}


Table A15

Distribution Parameters for Durations and Peak Wave Heights at

Half-Moon Bay, CA

\begin{tabular}{|c|c|c|c|c|c|c|}
\hline Parameter & \multicolumn{3}{|c|}{------ Duration $-\cdots---$} & \multicolumn{3}{|c|}{--- Peak Wave Height--- } \\
\hline$H 1=500 \mathrm{c}$ & occurr & nce) & & & & \\
\hline$\varepsilon / a$ & - & 11.7 & 1.11 & - & 533.1 & 14.2 \\
\hline B & - & 18.0 & 22.5 & - & 36.3 & 574.0 \\
\hline $\mathbf{x}$ & 21.7 & 22.0 & 21.7 & 553.4 & 554.0 & 553.3 \\
\hline$\sigma$ & 21.2 & 23.1 & 19.6 & 43.7 & 46.6 & 47.6 \\
\hline $\mathbf{r}$ & - & 0.98 & 0.99 & - & 0.99 & 0.97 \\
\hline $\operatorname{sres}^{2}$ & - & 0.42 & 0.19 & - & 0.12 & 0.58 \\
\hline std.err. & - & 0.06 & 0.04 & - & 0.03 & 0.08 \\
\hline $\mathrm{H} 1=550 \mathrm{cl}$ & occurr & ace) & & & & \\
\hline$\varepsilon / \alpha$ & - & 11.4 & 1.14 & - & 575.9 & 19.4 \\
\hline B & - & 19.4 & 22.9 & - & 28.3 & 607.4 \\
\hline $\mathrm{x}$ & 22.0 & 22.6 & 21.8 & 591.3 & 592.1 & 590.8 \\
\hline $\boldsymbol{\sigma}$ & 21.7 & 24.9 & 19.2 & 32.4 & 36.1 & 37.7 \\
\hline$r$ & - & 0.96 & 0.99 & - & 0.99 & 0.95 \\
\hline $\operatorname{sres}^{2}$ & - & 0.32 & 0.09 & - & 0.06 & 0.39 \\
\hline std.err. & - & 0.08 & 0.04 & - & 0.04 & 0.09 \\
\hline
\end{tabular}

(Continued) 
Table A15 (Concluded)

\begin{tabular}{|c|c|c|c|c|c|c|}
\hline \multirow[b]{2}{*}{ Parameter } & \multicolumn{3}{|c|}{--- Duration---- } & \multicolumn{3}{|c|}{$-\cdots-$ Peak Wave Height--- } \\
\hline & Sample & Type I & Weibull & Sample & Type I & Weibull \\
\hline \multicolumn{7}{|c|}{$\mathrm{H} 1=600 \mathrm{~cm}(0.3 \%$ occurrence $)$} \\
\hline$\varepsilon / \alpha$ & - & 12.8 & 1.17 & - & 607.1 & 20.0 \\
\hline$\beta$ & - & 16.6 & 23.7 & - & 26.9 & 637.4 \\
\hline $\mathrm{x}$ & 21.5 & 22.3 & 22.4 & 621.3 & 622.7 & 620.5 \\
\hline$\sigma$ & 17.8 & 21.3 & 19.3 & 28.0 & 34.5 & 38.4 \\
\hline r & - & 0.99 & 0.99 & - & 0.93 & 0.86 \\
\hline$\Sigma \mathrm{res}^{2}$ & - & 0.05 & 0.02 & - & 0.22 & 0.46 \\
\hline std.err. & - & 0.05 & 0.03 & - & 0.10 & 0.15 \\
\hline
\end{tabular}


Table A16

Results of Regression of Duration Against Conditions at the Peak of the Event for Atlantic City, NJ

\begin{tabular}{|c|c|c|c|c|c|c|c|}
\hline H1 & $q(H>H 1)$ & $r_{H}$ & $r_{H}^{2}$ & $\mathrm{r}_{\mathrm{T}}$ & $r_{T}^{2}$ & $\mathrm{r}_{\mathrm{H}, \mathrm{H}^{2}, \mathrm{~T}, \mathrm{~T}^{2}}$ & $\mathrm{r}_{\mathrm{HL}}^{2}$ \\
\hline 200 & 2.5 & 0.71 & 0.69 & 0.54 & 0.52 & 0.74 & 0.66 \\
\hline 250 & 0.7 & 0.69 & 0.69 & 0.40 & 0.38 & 0.71 & 0.63 \\
\hline 300 & 0.1 & 0.80 & 0.80 & 0.23 & 0.21 & 0.80 & 0.65 \\
\hline 350 & 0.03 & 0.10 & 0.10 & 0.24 & 0.22 & 0.63 & 0.21 \\
\hline
\end{tabular}

Table A17

Results of Regression of Duration Against Conditions at the Peak of the Event for Nagshead, NC

\begin{tabular}{|c|c|c|c|c|c|c|c|}
\hline $\mathrm{HT}$ & $\%(\mathrm{H}>\mathrm{H} 1)$ & $r_{H}$ & $\mathrm{r}_{\mathrm{H}}^{2}$ & $\mathrm{r}_{\mathrm{T}}$ & $r_{T}^{2}$ & $r_{H, H}{ }^{2}, T, T^{2}$ & $r_{\mathrm{HL}}^{2}$ \\
\hline 200 & 5.6 & 0.82 & 0.81 & 0.61 & 0.62 & 0.82 & 0.75 \\
\hline 250 & 2.0 & 0.80 & 0.79 & 0.50 & 0.51 & 0.81 & 0.72 \\
\hline 300 & 0.7 & 0.72 & 0.72 & 0.60 & 0.62 & 0.74 & 0.73 \\
\hline 350 & 0.3 & 0.55 & 0.54 & 0.54 & 0.56 & 0.70 & 0.56 \\
\hline
\end{tabular}


Table A18

Results of Regression of Duration Against Conditions at the Peak of the Event for Daytona Beach, FL

\begin{tabular}{|c|c|c|c|c|c|c|c|}
\hline H1 & $\%(\mathrm{H}>\mathrm{H} 1)$ & $\underline{r_{H}}$ & $r_{H}^{2}$ & $r_{T}$ & $\mathrm{r}_{\mathrm{T}}^{2}$ & $r_{H, H}{ }^{2}, T, T^{2}$ & $r_{\mathrm{HL}}^{2}$ \\
\hline 200 & 7.1 & 0.76 & 0.73 & 0.50 & 0.48 & 0.79 & 0.65 \\
\hline 250 & 2.2 & 0.81 & 0.79 & 0.46 & 0.46 & 0.82 & 0.72 \\
\hline 300 & 0.8 & 0.51 & 0.50 & 0.46 & 0.47 & 0.59 & 0.52 \\
\hline 350 & 0.2 & 0.44 & 0.46 & 0.52 & 0.55 & 0.66 & 0.59 \\
\hline
\end{tabular}

Table A19

Results of Regression of Duration Against Conditions at the Peak of the Event for Newport, $O R$

\begin{tabular}{|c|c|c|c|c|c|c|c|}
\hline $\mathrm{H} 1$ & $q\left(H>H_{1}\right)$ & $\mathrm{r}_{\mathrm{H}}$ & $r_{\mathrm{H}}^{2}$ & $\mathrm{r}_{\mathrm{T}}$ & $\mathrm{r}_{\mathrm{T}}^{2}$ & $r_{H, H}{ }^{2}, T, T^{2}$ & $r_{H L}^{2}$ \\
\hline 500 & 6.9 & 0.59 & 0.60 & 0.32 & 0.32 & 0.61 & 0.55 \\
\hline 550 & 3.8 & 0.59 & 0.59 & 0.24 & 0.24 & 0.59 & 0.50 \\
\hline 600 & 1.9 & 0.42 & 0.42 & 0.20 & 0.20 & 0.45 & 0.38 \\
\hline 650 & 0.3 & 0.66 & 0.66 & -0.08 & -0.08 & 0.66 & 0.26 \\
\hline
\end{tabular}


Table A20

Results of Regression of Duration Against Conditions at the Peak of the Event for Half-Moon Bay, CA

\begin{tabular}{|c|c|c|c|c|c|c|c|}
\hline $\mathrm{H} 1$ & $q(\mathrm{H}>\mathrm{H} 1)$ & $\mathrm{r}_{\mathrm{H}}$ & $\mathrm{r}_{\mathrm{H}}^{2}$ & $r_{T}$ & $\mathrm{r}_{\mathrm{T}}^{2}$ & $r_{H, H}{ }^{2}, T, T^{2}$ & $r_{H L}^{2}$ \\
\hline 500 & 1.3 & 0.62 & 0.61 & 0.24 & 0.24 & 0.63 & 0.52 \\
\hline 550 & 0.6 & 0.52 & 0.52 & 0.22 & 0.22 & 0.57 & 0.48 \\
\hline 600 & 0.3 & 0.32 & 0.32 & 0.09 & 0.09 & 0.34 & 0.26 \\
\hline
\end{tabular}




\section{APPENDIX B}

PERTINENT DATA FROM THE WAVE INFORMATION STUDIES PROGRAM

Figures

Page

B1 Phase III wave rose, Atlantic City, NJ............ B2

B2 Phase III wave rose, Nagshead, NC............... B3

B3 Phase III wave rose, Daytona Beach, FL............ B4

Tables

B1 Phase III Wave Data, Atlantic City, NJ........... B2

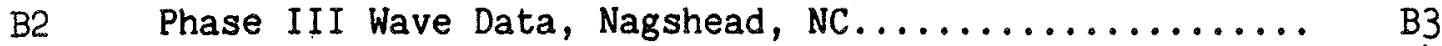

B3 Phase III Wave Data, Daytona Beach, FL............ B4

B4 Phase III Wave Data, Newsport, OR.............. B5

B5 Phase III Wave Data, Half-Moon Bay, CA............ B5

B6 Phase III Duration Data, Atlantic Coast............. B6 
Table B1

Phase III Wave Data, Atlantic City, NJ

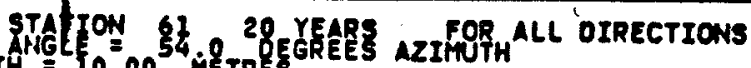
SHORELTETH

PERCENT OCCURRENCE $X I O O$ ) OF HEIGHT ANO PETIOD FOR ALL DIRECTIONS HEIGHT (METRES) PERIOD ( SECONDS)

TOTAL

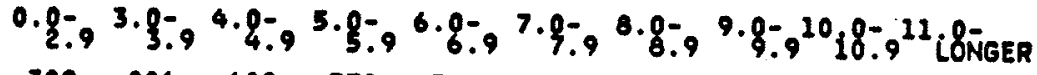
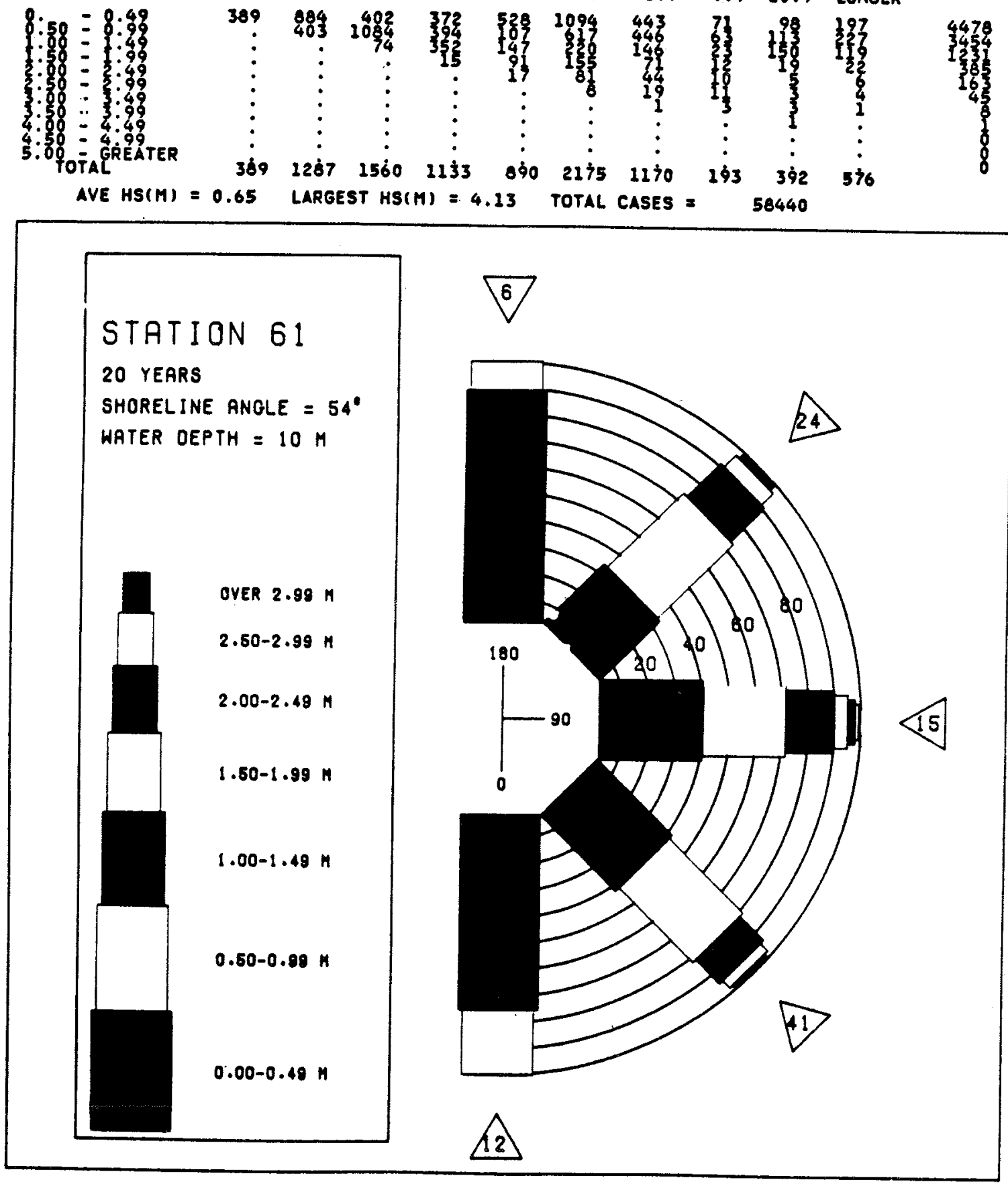

Figure B1. Phase III wave rose, Atlantic City, NJ 


\section{Table B2}

Phase III Wave Data, Nagshead, NC

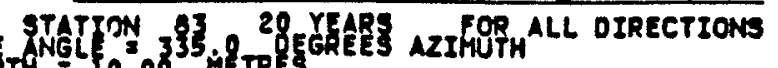

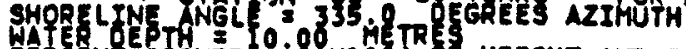

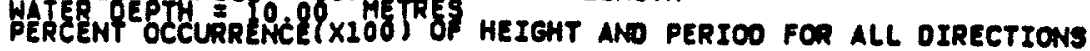
HEIGHT(METRES) PERIOO (SECONDS)

TOTAL

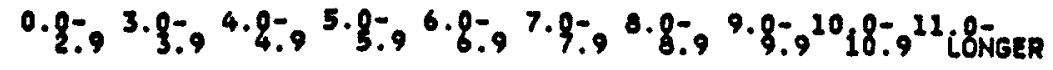

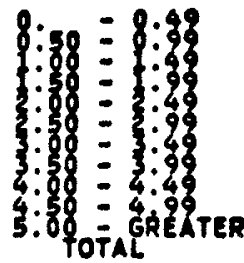

47923

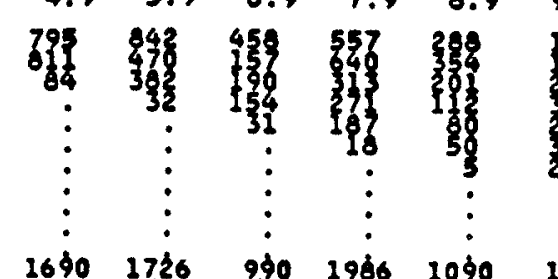

AVE HS(M) $=0.7$

$4791144 \quad 1690 \quad 17 \%$
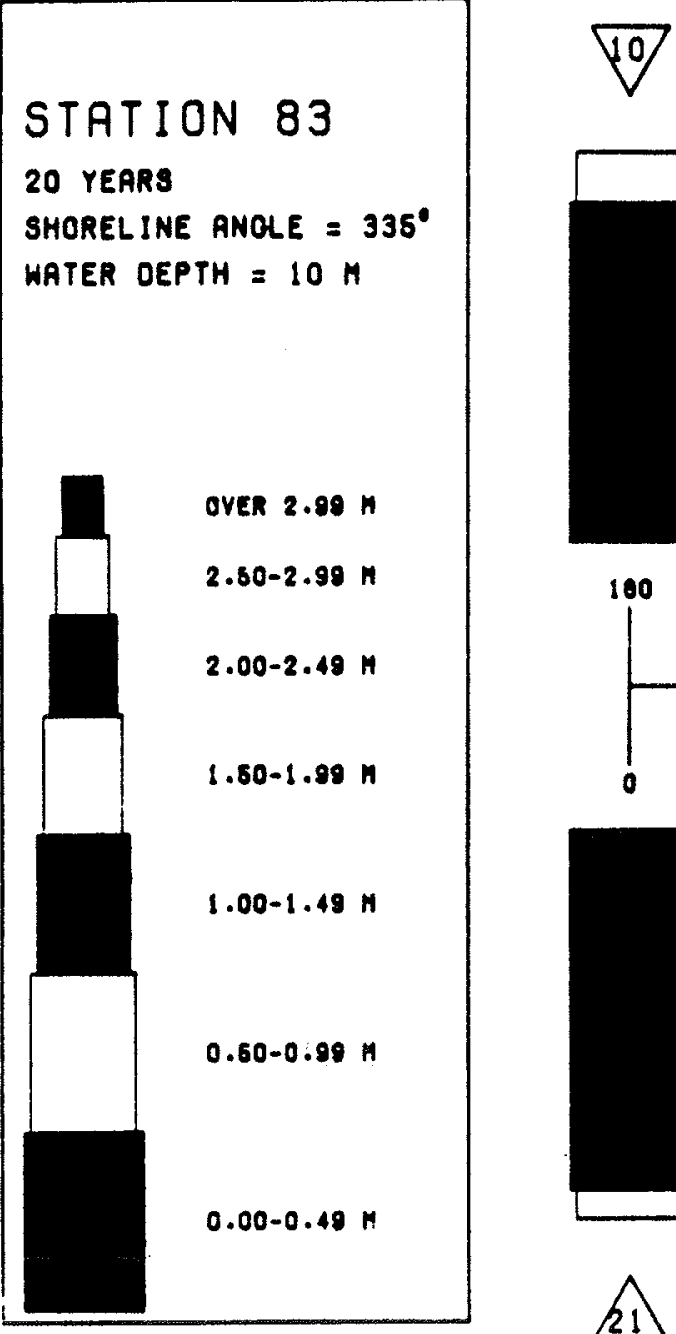

\section{YEARS}

SHORELINE ANOLE $=335^{\circ}$

WATER OEPTH $=10 \mathrm{M}$

$2.80-2.99 n$

2.00-2.49 M
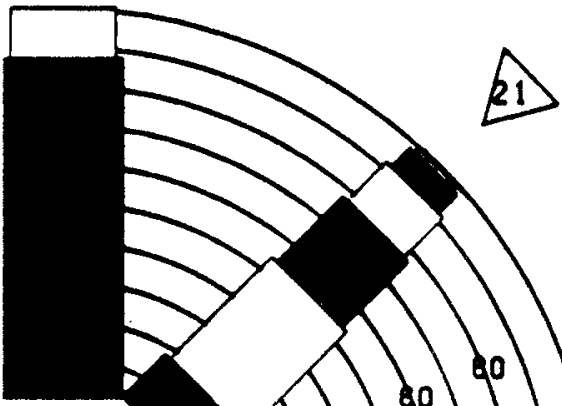

180
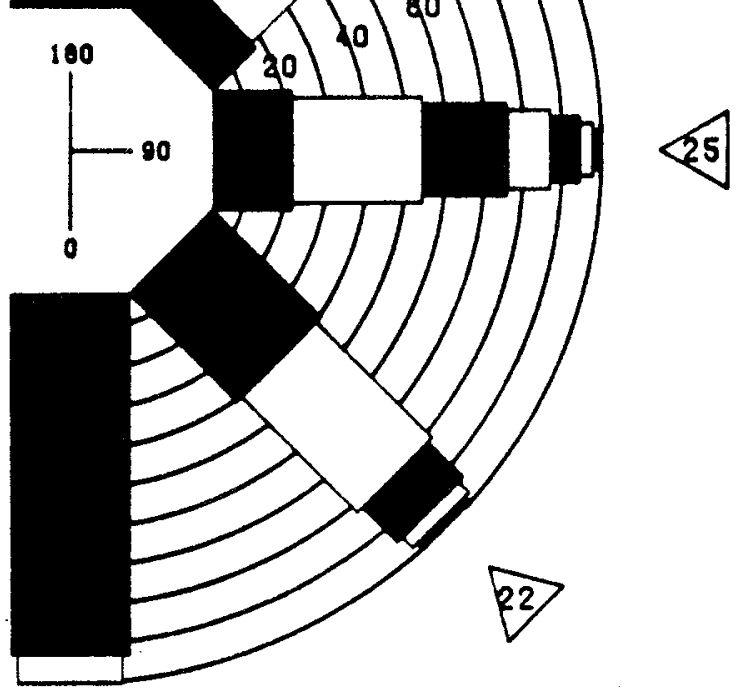

21

Figure B2. Phase III wave rose, Nagshead, NC 
Table B3

Phase III Wave Data, Daytona Beach, FL SHORELINE STATTON 142 O 20 YEARS PERCENT OCCURREMCEE (X1OO) OF HEIGHT AND PERICD FOR ALL DIRECTIONS HEIGHT(METRES) PERIOO ( SECONOS)

TOTAL

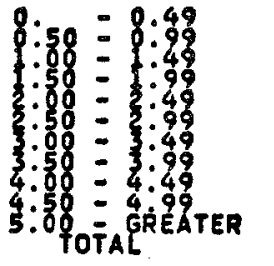

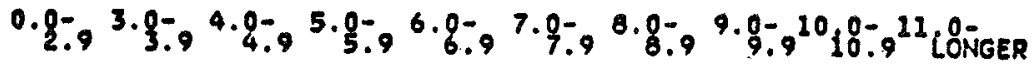

$$
3383894
$$

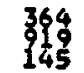

AVE HS(M) $=0.82$

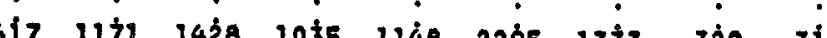

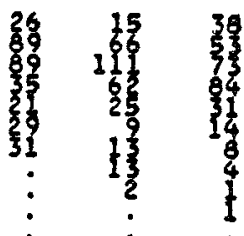

LARGEST HS(M) $=5.03$ TOTAL CASES =

58440

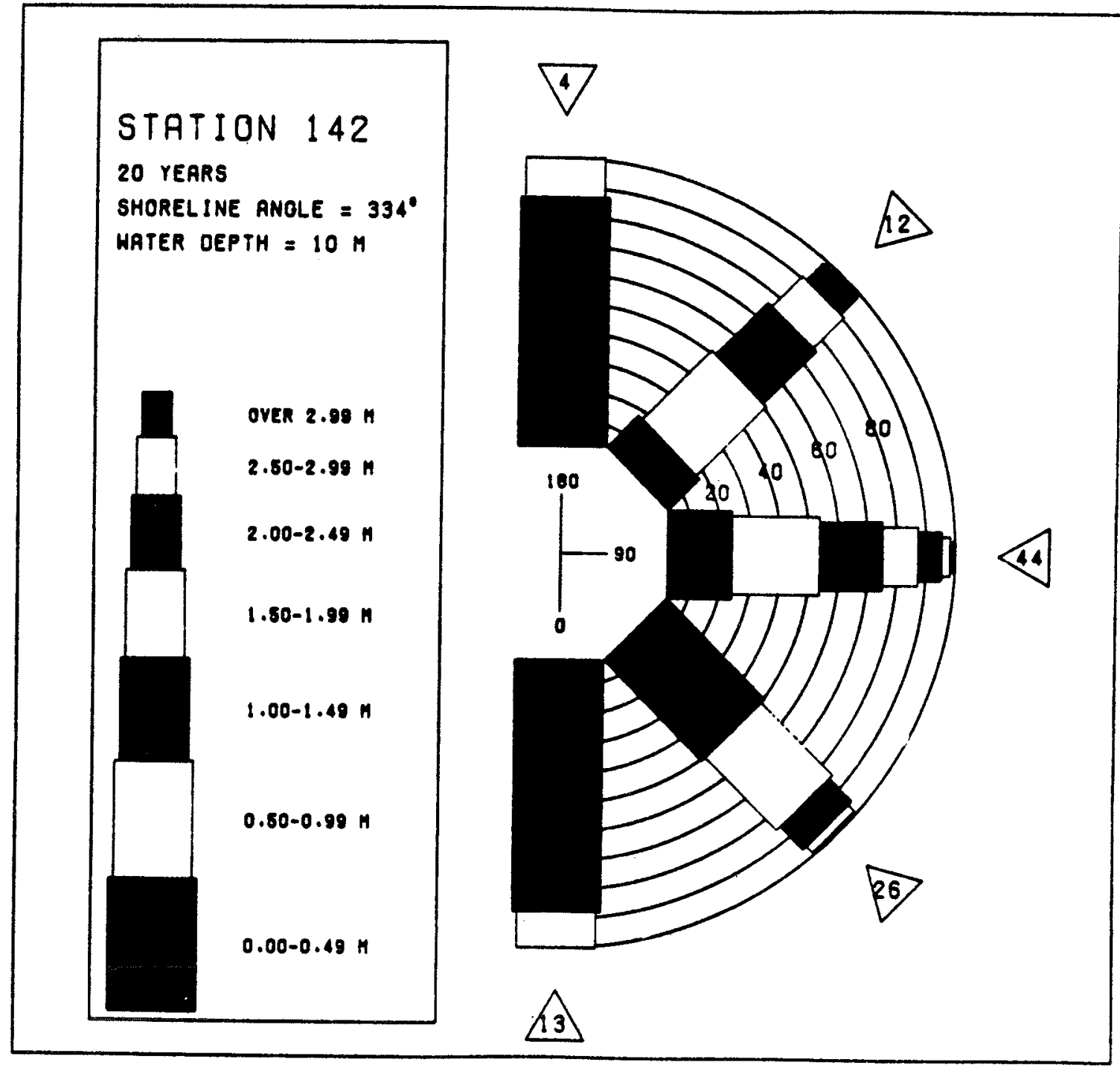

Figure B3. Phase III wave rose, Daytona Beach, FL 
Table. B4

Phase III Wave Data, Newport, OR

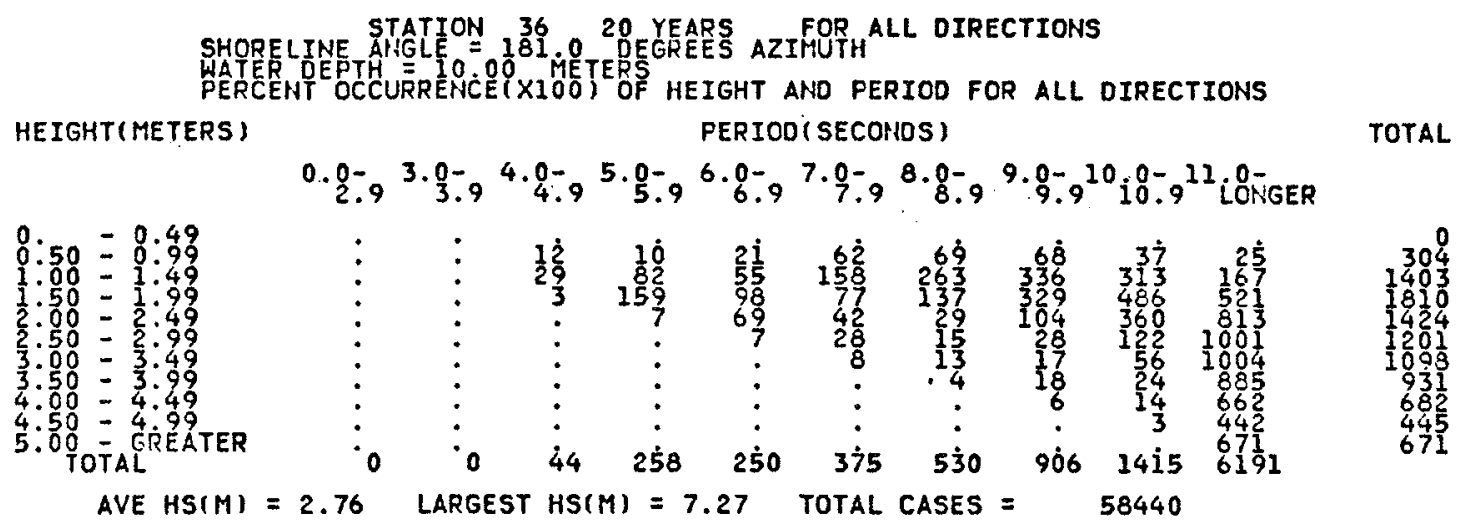

Table B5

Phase II I Wave Data, Half-Moon Bay, CA

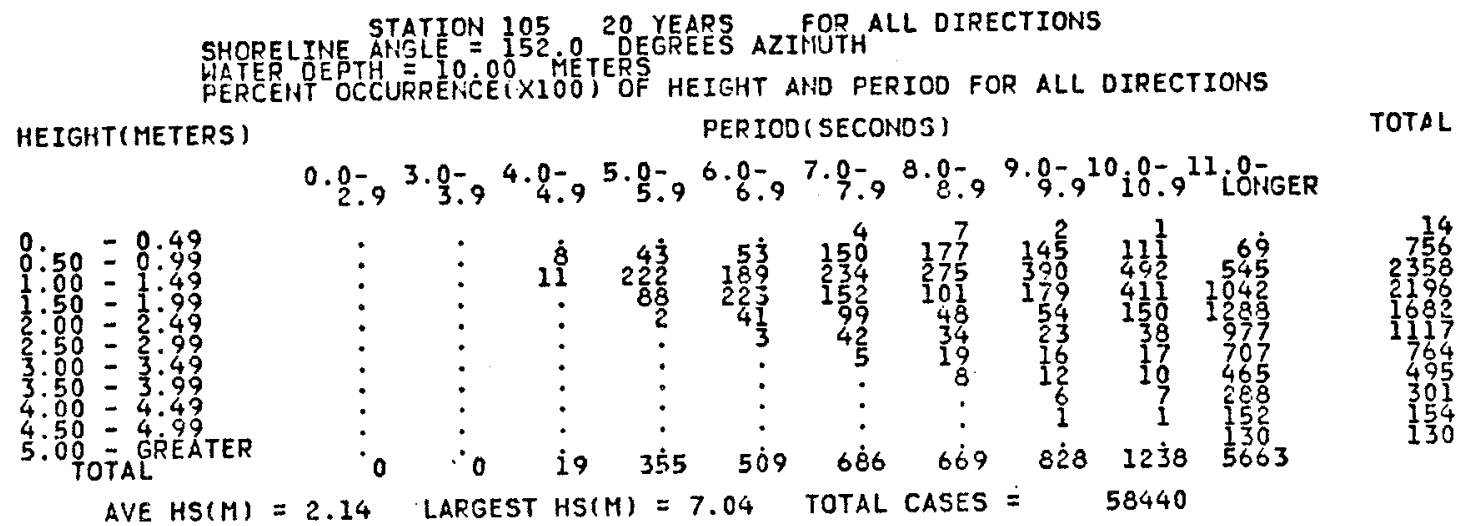


Table B6

Phase III Duration Data, Atlantic Coast

Duration, hr, of Waves with Hs over a Specified Have Helght.

\begin{tabular}{|c|c|c|c|c|c|c|c|c|c|c|c|c|c|c|c|c|c|c|c|c|c|c|c|c|c|}
\hline $\begin{array}{c}\text { Station } \\
\text { No. }\end{array}$ & $\begin{array}{l}\text { Dure- } \\
\text { tion }\end{array}$ & 0.5 & 1.0 & .5 & 2.0 & $\begin{array}{r}7.5 \\
2.5\end{array}$ & 3.0 & 3.5 & 4.0 & 4.5 & 3.0 & 5.5 & $\begin{array}{c}\text { Station } \\
\text { No. }\end{array}$ & $\begin{array}{l}\text { Dura- } \\
\text { tion }\end{array}$ & 0.5 & 1.0 & 1.5 & 2.0 & $\frac{\mathrm{H}_{\mathrm{S}}-1}{2.5}$ & $2 \frac{2}{3.0}$ & 3.5 & 4.0 & 4.5 & 5.0 & 5.5 \\
\hline 1 & $\begin{array}{l}\text { Mean } \\
\text { Max }\end{array}$ & 531 * & $\begin{array}{r}18 \\
222\end{array}$ & $\begin{array}{r}14 \\
138\end{array}$ & 9 & $\begin{array}{r}6 \\
33\end{array}$ & 24 & $\begin{array}{l}5 \\
9\end{array}$ & $\begin{array}{l}9 \\
9\end{array}$ & $\ddot{--}$ & 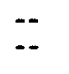 & 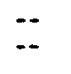 & 20 & $\begin{array}{l}\text { Mean } \\
\text { Max }\end{array}$ & $\begin{array}{r}29 \\
633\end{array}$ & $\begin{array}{r}22 \\
360\end{array}$ & $\begin{array}{r}18 \\
153\end{array}$ & $\begin{array}{r}15 \\
108\end{array}$ & $\begin{array}{l}11 \\
60\end{array}$ & $\begin{array}{r}8 \\
33\end{array}$ & $\begin{array}{r}7 \\
15\end{array}$ & $\begin{array}{l}5 \\
6\end{array}$ & $=$ & $=$ & -- \\
\hline 2 & $\begin{array}{l}\text { Mean } \\
\text { Hax }\end{array}$ & $\begin{array}{r}28 \\
534\end{array}$ & $\begin{array}{r}20 \\
240\end{array}$ & $\begin{array}{r}16 \\
164\end{array}$ & $\begin{array}{l}10 \\
69\end{array}$ & $\begin{array}{r}7 \\
39\end{array}$ & $\begin{array}{r}6 \\
27\end{array}$ & $\begin{array}{r}6 \\
21\end{array}$ & $\begin{array}{l}5 \\
9\end{array}$ & $\begin{array}{l}-- \\
--\end{array}$ & $\begin{array}{l}-- \\
--\end{array}$ & 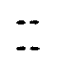 & 21 & $\begin{array}{l}\text { Mean } \\
\text { Max }\end{array}$ & $\begin{array}{r}19 \\
282\end{array}$ & $\begin{array}{r}18 \\
132\end{array}$ & $\begin{array}{r}17 \\
114\end{array}$ & $\begin{array}{r}11 \\
102\end{array}$ & $\begin{array}{l}10 \\
63\end{array}$ & $\begin{array}{r}8 \\
18\end{array}$ & $\begin{array}{l}11 \\
12\end{array}$ & $=$ & $\because$ & 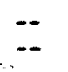 & $\because$ \\
\hline 3 & $\begin{array}{l}\text { Hean } \\
\text { Hax }\end{array}$ & $\begin{array}{r}30 \\
534\end{array}$ & $\begin{array}{r}21 \\
263\end{array}$ & $\begin{array}{r}18 \\
144\end{array}$ & $\begin{array}{l}11 \\
69\end{array}$ & $\begin{array}{r}8 \\
42\end{array}$ & $\begin{array}{r}6 \\
36\end{array}$ & $\begin{array}{r}7 \\
24\end{array}$ & $\begin{array}{l}5 \\
9\end{array}$ & $\begin{array}{l}\mathbf{3} \\
\mathbf{3}\end{array}$ & $=$ & 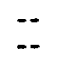 & 22 & $\begin{array}{l}\text { Mean } \\
\text { Max }\end{array}$ & $\begin{array}{r}23 \\
735\end{array}$ & $\begin{array}{r}19 \\
324\end{array}$ & $\begin{array}{r}14 \\
102\end{array}$ & $\begin{array}{l}10 \\
84\end{array}$ & $\begin{array}{r}8 \\
39\end{array}$ & $\begin{array}{r}5 \\
21\end{array}$ & $\begin{array}{l}4 \\
9\end{array}$ & $\ddot{--}$ & 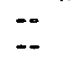 & $=$ & 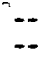 \\
\hline 4 & $\begin{array}{l}\text { Mean } \\
\text { Max }\end{array}$ & $\begin{array}{r}31 \\
534\end{array}$ & $\begin{array}{r}21 \\
243\end{array}$ & $\begin{array}{r}19 \\
150\end{array}$ & $\begin{array}{l}12 \\
75\end{array}$ & $\begin{array}{r}9 \\
42\end{array}$ & $\begin{array}{r}6 \\
36\end{array}$ & $\begin{array}{r}6 \\
24\end{array}$ & $\begin{array}{r}6 \\
21\end{array}$ & 3 & $\begin{array}{l}3 \\
3\end{array}$ & $\because-$ & 23 & $\begin{array}{l}\text { Mean } \\
\text { Max }\end{array}$ & $\begin{array}{r}22 \\
735\end{array}$ & $\begin{array}{r}19 \\
456\end{array}$ & $\begin{array}{r}16 \\
114\end{array}$ & $\begin{array}{l}12 \\
96\end{array}$ & 69 & $\begin{array}{l}10 \\
30\end{array}$ & $\begin{array}{r}8 \\
15\end{array}$ & $=$ & 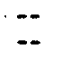 & $\because$ & $=$ \\
\hline 5 & $\begin{array}{l}\text { Mean } \\
\text { Max }\end{array}$ & $\begin{array}{r}35 \\
3,567\end{array}$ & $\begin{array}{r}23 \\
294\end{array}$ & $\begin{array}{r}18 \\
153\end{array}$ & $\begin{array}{l}12 \\
69\end{array}$ & $\begin{array}{r}9 \\
42\end{array}$ & $\begin{array}{r}7 \\
36\end{array}$ & $\begin{array}{r}6 \\
21\end{array}$ & $\begin{array}{r}5 \\
12\end{array}$ & -- & $\because-$ & $\cdots$ & 24 & $\begin{array}{l}\text { Mean } \\
\text { Max }\end{array}$ & $\begin{array}{r}.23 \\
633\end{array}$ & $\begin{array}{r}20 \\
456\end{array}$ & $\begin{array}{r}17 \\
168\end{array}$ & $\begin{array}{r}13 \\
111\end{array}$ & $\begin{array}{l}13 \\
96\end{array}$ & .12 & $\begin{array}{r}9 \\
36\end{array}$ & $\begin{array}{l}6 \\
9\end{array}$ & $\ddot{--}$ & 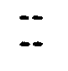 & $=$ \\
\hline 6 & $\begin{array}{l}\text { Mean } \\
\text { Max }\end{array}$ & $\begin{array}{r}34 \\
3,564\end{array}$ & $\begin{array}{r}22 \\
294\end{array}$ & $\begin{array}{r}17 \\
153\end{array}$ & $\begin{array}{l}11 \\
69\end{array}$ & 39 & $\begin{array}{r}7 \\
36\end{array}$ & $\begin{array}{r}5 \\
18\end{array}$ & $\begin{array}{r}8 \\
12\end{array}$ & $\ddot{--}$ & $=$ & $=$ & 25 & $\begin{array}{l}\text { Mean } \\
\text { Max }\end{array}$ & $\begin{array}{r}25 \\
798\end{array}$ & $\begin{array}{r}22 \\
456\end{array}$ & $\begin{array}{r}18 \\
153\end{array}$ & $\begin{array}{r}14 \\
123\end{array}$ & $\begin{array}{r}14 \\
102\end{array}$ & $\begin{array}{l}12 \\
69\end{array}$ & $\begin{array}{l}16 \\
39\end{array}$ & $\begin{array}{l}7 \\
9\end{array}$ & $=$ & $\cdots$ & $\ddot{-}$ \\
\hline 7 & $\begin{array}{l}\text { Mean } \\
\text { Max }\end{array}$ & $\begin{array}{r}26 \\
834\end{array}$ & $\begin{array}{r}19 \\
360\end{array}$ & $\begin{array}{r}16 \\
123\end{array}$ & $\begin{array}{l}12 \\
84\end{array}$ & $\begin{array}{l}10 \\
57\end{array}$ & $\begin{array}{r}8 \\
24\end{array}$ & $\begin{array}{r}6 \\
12\end{array}$ & $\begin{array}{l}6 \\
6\end{array}$ & $\ddot{-\cdot}$ & $=$ & $=$ & 26 & $\begin{array}{l}\text { Mean } \\
\text { Max }\end{array}$ & $\begin{array}{r}23 \\
798\end{array}$ & $\begin{array}{r}21 \\
456\end{array}$ & $\begin{array}{r}17 \\
186\end{array}$ & $\begin{array}{r}13 \\
120\end{array}$ & $\begin{array}{l}14 \\
99\end{array}$ & $\begin{array}{l}12 \\
69\end{array}$ & $\begin{array}{l}16 \\
39\end{array}$ & $\begin{array}{l}7 \\
9\end{array}$ & -- & $\cdots$ & 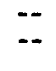 \\
\hline 8 & $\begin{array}{l}\text { Mean } \\
\text { Max }\end{array}$ & $\begin{array}{r}30 \\
606\end{array}$ & $\begin{array}{r}19 \\
357\end{array}$ & $\begin{array}{r}16 \\
126\end{array}$ & $\begin{array}{l}12 \\
63\end{array}$ & si & $\begin{array}{r}6 \\
30\end{array}$ & $\begin{array}{r}6 \\
15\end{array}$ & $\begin{array}{r}8 \\
12\end{array}$ & $\because$. & -- & $=$ & 27 & $\begin{array}{l}\text { Mean } \\
\text { Max }\end{array}$ & $\begin{array}{r}16 \\
246\end{array}$ & $\begin{array}{r}15 \\
243\end{array}$ & $\begin{array}{r}15 \\
117\end{array}$ & $\begin{array}{l}11 \\
96\end{array}$ & $\begin{array}{l}10 \\
45\end{array}$ & $\begin{array}{r}6 \\
18\end{array}$ & $\begin{array}{l}6 \\
6\end{array}$ & -- & $=$ & $=$ & $=$ \\
\hline 9 & $\begin{array}{l}\text { Hean } \\
\text { Max }\end{array}$ & $\begin{array}{r}28 \\
606\end{array}$ & $\begin{array}{r}19 \\
360\end{array}$ & $\begin{array}{r}16 \\
135\end{array}$ & $\begin{array}{l}12 \\
63\end{array}$ & $\begin{array}{l}10 \\
48\end{array}$ & 27 & $\begin{array}{r}6 \\
15\end{array}$ & $\begin{array}{l}9 \\
9\end{array}$ & $\because-$ & $=$ & $=$ & 28 & $\begin{array}{l}\text { Mean } \\
\text { Max }\end{array}$ & $\begin{array}{r}26 \\
1,265\end{array}$ & $\begin{array}{r}22 \\
795\end{array}$ & $\begin{array}{r}20 \\
360\end{array}$ & $\begin{array}{r}15 \\
186\end{array}$ & $\begin{array}{r}15 \\
108\end{array}$ & $\begin{array}{l}14 \\
72\end{array}$ & $\begin{array}{l}13 \\
39\end{array}$ & 9 & $=$ & $=$ & $=$ \\
\hline 10 & $\begin{array}{l}\text { Hean } \\
\text { Max }\end{array}$ & $\begin{array}{r}32 \\
594\end{array}$ & $\begin{array}{r}21 \\
192\end{array}$ & $\begin{array}{r}18 \\
105\end{array}$ & $\begin{array}{l}13 \\
63\end{array}$ & $\begin{array}{r}9 \\
42\end{array}$ & $\begin{array}{r}7 \\
24\end{array}$ & $\begin{array}{r}5 \\
15\end{array}$ & $\begin{array}{l}3 \\
3\end{array}$ & -- & $\because$ & -- & 29 & $\begin{array}{l}\text { Mean } \\
\text { Max }\end{array}$ & $\begin{array}{r}26 \\
603\end{array}$ & $\begin{array}{r}22 \\
492\end{array}$ & $\begin{array}{r}21 \\
270\end{array}$ & $\begin{array}{r}17 \\
147\end{array}$ & $\begin{array}{r}14 \\
102\end{array}$ & $\begin{array}{l}13 \\
69\end{array}$ & $\begin{array}{l}13 \\
39\end{array}$ & $\begin{array}{r}8 \\
18\end{array}$ & $\begin{array}{l}3 \\
3\end{array}$ & 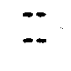 & 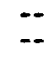 \\
\hline 11 & $\begin{array}{l}\text { Mean } \\
\text { Max }\end{array}$ & $\begin{array}{r}32 \\
597\end{array}$ & $\begin{array}{r}21 \\
192\end{array}$ & $\begin{array}{r}18 \\
105\end{array}$ & $\begin{array}{l}12 \\
63\end{array}$ & $\begin{array}{r}9 \\
45\end{array}$ & $\begin{array}{r}7 \\
24\end{array}$ & $\begin{array}{r}6 \\
15\end{array}$ & $\begin{array}{l}3 \\
3\end{array}$ & -- & 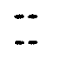 & $=$ & 30 & $\begin{array}{l}\text { Mean } \\
\text { Max }\end{array}$ & $\begin{array}{r}25 \\
585\end{array}$ & $\begin{array}{r}21 \\
492\end{array}$ & $\begin{array}{r}19 \\
240\end{array}$ & $\begin{array}{r}16 \\
129\end{array}$ & $\begin{array}{l}14 \\
99\end{array}$ & $\begin{array}{l}11 \\
69\end{array}$ & $\begin{array}{l}12 \\
39\end{array}$ & $\begin{array}{r}7 \\
15\end{array}$ & $\begin{array}{l}3 \\
3\end{array}$ & $\because$ & $=$ \\
\hline 12 & $\begin{array}{l}\text { Mean } \\
\text { Max }\end{array}$ & $\begin{array}{r}25 \\
594\end{array}$ & $\begin{array}{r}18 \\
231\end{array}$ & $\begin{array}{l}15 \\
66\end{array}$ & $\begin{array}{l}11 \\
45\end{array}$ & $\begin{array}{r}8 \\
33\end{array}$ & $\begin{array}{r}8 \\
24\end{array}$ & $\begin{array}{r}6 \\
18\end{array}$ & $\begin{array}{l}5 \\
9\end{array}$ & $\begin{array}{l}3 \\
3\end{array}$ & $\ddot{--}$ & 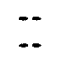 & 31 & $\begin{array}{l}\text { Mean } \\
\text { Max }\end{array}$ & $\begin{array}{r}29 \\
1,431\end{array}$ & $\begin{array}{r}22 \\
405\end{array}$ & $\begin{array}{r}20 \\
186\end{array}$ & $\begin{array}{r}15 \\
.120\end{array}$ & $\begin{array}{l}12 \\
72\end{array}$ & $\begin{array}{r}9 \\
45\end{array}$ & $\begin{array}{r}9 \\
30\end{array}$ & $\begin{array}{r}7 \\
12\end{array}$ & $=$ & $\because-$ & $\because$ \\
\hline 13 & $\begin{array}{l}\text { Mean } \\
\text { Mox }\end{array}$ & $\begin{array}{r}23 \\
594\end{array}$ & $\begin{array}{r}17 \\
228\end{array}$ & $\begin{array}{l}14 \\
66\end{array}$ & $\begin{array}{l}10 \\
45\end{array}$ & 33 & $\begin{array}{r}7 \\
21\end{array}$ & $\begin{array}{r}6 \\
15\end{array}$ & $\begin{array}{l}6 \\
9\end{array}$ & $=$ & $=$ & $=$ & 32 & $\begin{array}{l}\text { Mean } \\
\text { Max }\end{array}$ & $\begin{array}{r}32 \\
621\end{array}$ & $\begin{array}{r}24 \\
618\end{array}$ & $\begin{array}{r}22 \\
528\end{array}$ & $\begin{array}{r}18 \\
186\end{array}$ & $\begin{array}{r}16 \\
117\end{array}$ & $\begin{array}{l}16 \\
63\end{array}$ & $\begin{array}{l}12 \\
48\end{array}$ & $\begin{array}{r}8 \\
18\end{array}$ & $\begin{array}{l}6 \\
6\end{array}$ & $=$ & $=$ \\
\hline 14 & $\begin{array}{l}\text { Mean } \\
\text { Max }\end{array}$ & $\begin{array}{r}24 \\
429\end{array}$ & $\begin{array}{r}19 \\
213\end{array}$ & $\begin{array}{l}15 \\
96\end{array}$ & $\begin{array}{l}12 \\
57\end{array}$ & $\begin{array}{l}11 \\
45\end{array}$ & 8 & $\begin{array}{r}7 \\
18\end{array}$ & $\begin{array}{l}3 \\
3\end{array}$ & -. & 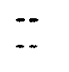 & $=$ & 33 & $\begin{array}{l}\text { Mean } \\
\text { Max }\end{array}$ & $\begin{array}{r}48 \\
2,775\end{array}$ & $\begin{array}{r}26 \\
435\end{array}$ & $\begin{array}{r}19 \\
189\end{array}$ & $\begin{array}{r}15 \\
132\end{array}$ & $\begin{array}{l}12 \\
60\end{array}$ & $\begin{array}{r}9 \\
30\end{array}$ & $\begin{array}{r}8 \\
27\end{array}$ & $\begin{array}{r}6 \\
18\end{array}$ & $\begin{array}{r}8 \\
12\end{array}$ & 3 & $\overline{--}$ \\
\hline 15 & $\begin{array}{l}\text { Mean } \\
\text { Max }\end{array}$ & $\begin{array}{r}25 \\
786\end{array}$ & $\begin{array}{r}19 \\
228\end{array}$ & $\begin{array}{l}16 \\
96\end{array}$ & $\begin{array}{l}12 \\
54\end{array}$ & $\begin{array}{l}10 \\
42\end{array}$ & 36 & $\begin{array}{r}6 \\
18\end{array}$ & $\begin{array}{l}5 \\
6\end{array}$ & -- & $\because$ & $=$ & 34 & $\begin{array}{l}\text { Mean } \\
\text { Max }\end{array}$ & $\begin{array}{r}49 \\
2,775\end{array}$ & $\begin{array}{r}28 \\
567\end{array}$ & $\begin{array}{r}20 \\
195\end{array}$ & $\begin{array}{r}15 \\
132\end{array}$ & $\begin{array}{l}12 \\
60\end{array}$ & $\begin{array}{l}10 \\
33\end{array}$ & $\begin{array}{r}8 \\
27\end{array}$ & 21 & $\begin{array}{r}8 \\
12\end{array}$ & $\begin{array}{l}3 \\
3\end{array}$ & 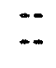 \\
\hline 16 & $\begin{array}{l}\operatorname{Mean} \\
\max \end{array}$ & $\begin{array}{r}27 \\
861\end{array}$ & $\begin{array}{r}21 \\
825\end{array}$ & $\begin{array}{r}15 \\
153\end{array}$ & $\begin{array}{l}11 \\
69\end{array}$ & $\begin{array}{r}9 \\
33\end{array}$ & 21 & $\begin{array}{r}6 \\
12\end{array}$ & $\ddot{--}$ & $=$ & $\because-$ & $\ddot{--}$ & 35 & $\begin{array}{l}\text { Mean } \\
\text { Max }\end{array}$ & $\begin{array}{r}42 \\
1,971\end{array}$ & $\begin{array}{r}23 \\
231\end{array}$ & $\begin{array}{r}17 \\
186\end{array}$ & $\begin{array}{r}14 \\
108\end{array}$ & $\begin{array}{l}11 \\
60\end{array}$ & 30 & $\begin{array}{r}7 \\
27\end{array}$ & $\begin{array}{r}6 \\
21\end{array}$ & $\begin{array}{l}12 \\
12\end{array}$ & $\begin{array}{l}6 \\
6\end{array}$ & 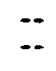 \\
\hline 17 & $\begin{array}{l}\text { Mean } \\
\text { Max }\end{array}$ & $\begin{array}{r}29 \\
864\end{array}$ & $\begin{array}{r}22 \\
477\end{array}$ & $\begin{array}{r}17 \\
156\end{array}$ & $\begin{array}{r}13 \\
105\end{array}$ & $\begin{array}{l}10 \\
60\end{array}$ & $\begin{array}{r}8 \\
30\end{array}$ & $\begin{array}{r}7 \\
15\end{array}$ & $\begin{array}{l}5 \\
6\end{array}$ & $=$ & $\because$ & $=$ & 36 & $\begin{array}{l}\text { Mean } \\
\operatorname{Max}\end{array}$ & $\begin{array}{r}37 \\
894\end{array}$ & $\begin{array}{r}22 \\
537\end{array}$ & $\begin{array}{r}18 \\
309\end{array}$ & $\begin{array}{r}13 \\
222\end{array}$ & $\begin{array}{r}10 \\
129\end{array}$ & $\begin{array}{r}9 \\
42\end{array}$ & $\begin{array}{l}10 \\
24\end{array}$ & $\begin{array}{r}6 \\
15\end{array}$ & 9 & $\begin{array}{l}3 \\
3\end{array}$ & $=$ \\
\hline 18 & $\begin{array}{l}\text { Mean } \\
\text { Max }\end{array}$ & $\begin{array}{r}29 \\
864\end{array}$ & $\begin{array}{r}22 \\
477\end{array}$ & $\begin{array}{r}18 \\
168\end{array}$ & $\begin{array}{r}12 \\
102\end{array}$ & $\begin{array}{l}10 \\
60\end{array}$ & $\begin{array}{r}9 \\
27\end{array}$ & $\begin{array}{r}6 \\
15\end{array}$ & $\overline{--}$ & $\ddot{--}$ & $\begin{array}{l}-- \\
--\end{array}$ & $\because$ & 37 & $\begin{array}{l}\text { Mean } \\
\text { Max }\end{array}$ & $\begin{array}{r}33 \\
597\end{array}$ & $\begin{array}{r}19 \\
189\end{array}$ & $\begin{array}{r}15 \\
129\end{array}$ & $\begin{array}{l}12 \\
63\end{array}$ & $\begin{array}{r}9 \\
45\end{array}$ & 24 & 26 & $\begin{array}{r}6 \\
12\end{array}$ & $\begin{array}{l}12 \\
12\end{array}$ & $\begin{array}{l}6 \\
6\end{array}$ & $\because$ \\
\hline 19 & $\begin{array}{l}\text { Mean } \\
\text { Max }\end{array}$ & $\begin{array}{r}30 \\
696\end{array}$ & $\begin{array}{r}23 \\
474\end{array}$ & $\begin{array}{r}17 \\
159\end{array}$ & $\begin{array}{l}12 \\
69\end{array}$ & $\begin{array}{r}9 \\
60\end{array}$ & $\begin{array}{r}8 \\
27\end{array}$ & $\begin{array}{r}6 \\
15\end{array}$ & -. & $=$ & $\because$ & $\because-$ & 38 & $\begin{array}{l}\text { Mean } \\
\text { Max }\end{array}$ & $\begin{array}{r}4.3 \\
1,665\end{array}$ & $\begin{array}{r}73 \\
432\end{array}$ & $\begin{array}{r}17 \\
183\end{array}$ & $\begin{array}{l}14 \\
66\end{array}$ & $\begin{array}{l}11 \\
54 .\end{array}$ & 30 & $\begin{array}{r}7 \\
27\end{array}$ & $\begin{array}{r}5 \\
12\end{array}$ & 9 & $\begin{array}{l}3 \\
3\end{array}$ & $\because-$ \\
\hline
\end{tabular}

- Duration is show in hours for $H_{\text {g }}$ readings "greater than" 0.5, 1.0, etc.

(Sheet 1 of 5) 
Table B6 (Continued)

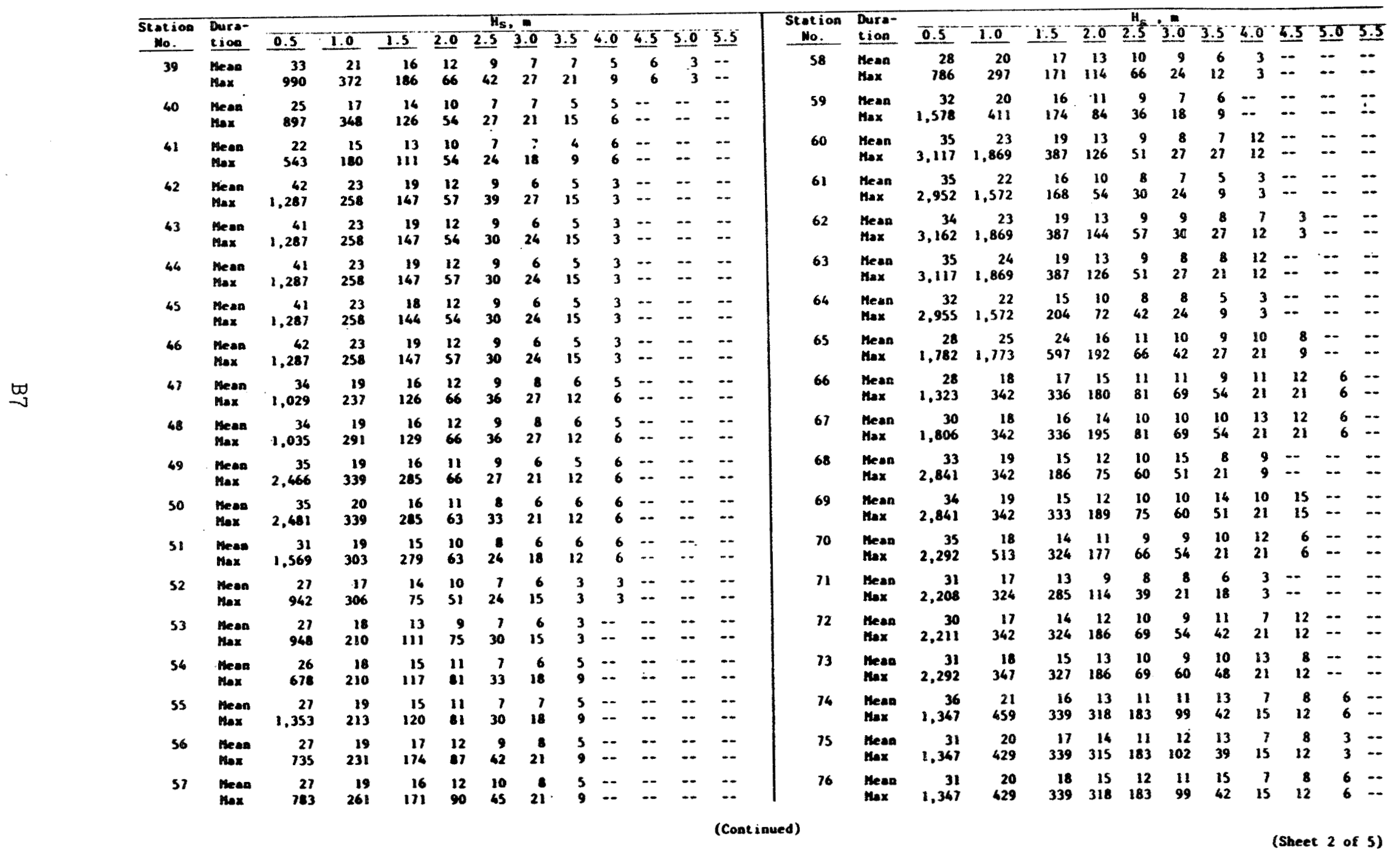


Table B6 (Continued)

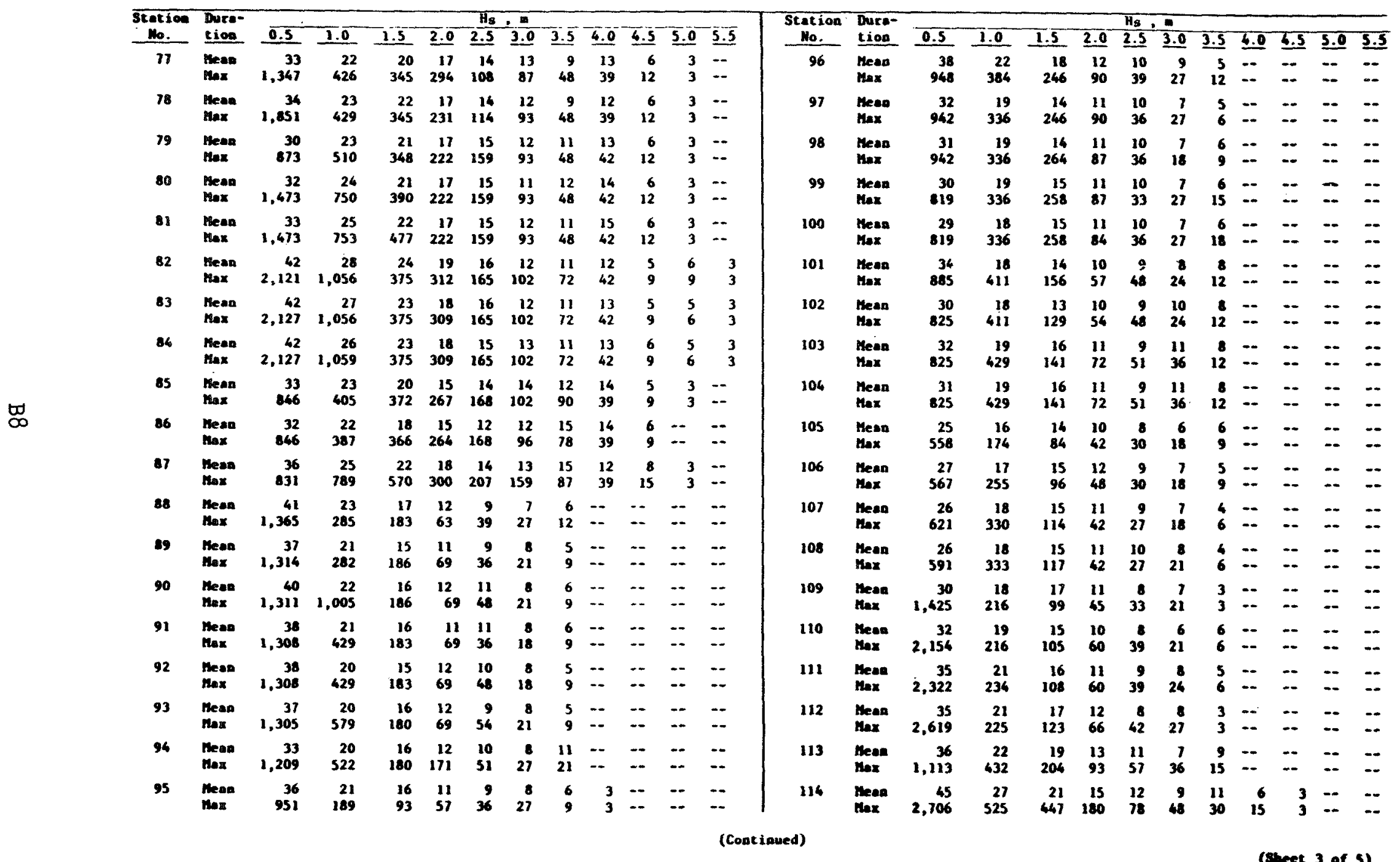

(sweet 3 of S) 
Table B6 (Continued)

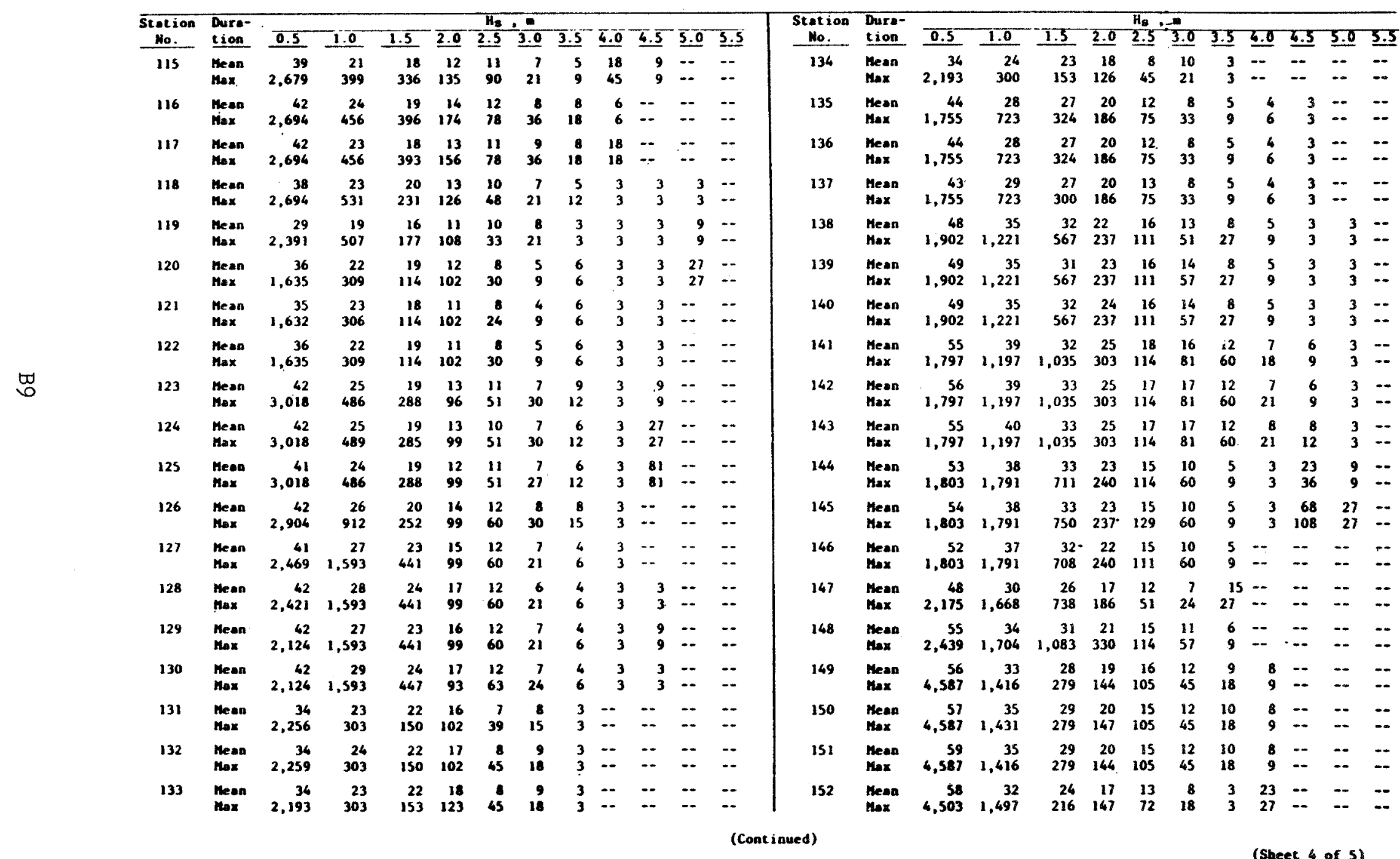


Table B6 (Concluded)

\begin{tabular}{|c|c|c|c|c|c|c|c|c|c|c|c|c|c|c|c|c|c|c|c|c|c|c|c|c|c|}
\hline $\begin{array}{l}\text { Stetion } \\
\text { Mo. } \\
\end{array}$ & $\begin{array}{l}\text { Dure- } \\
\text { tien }\end{array}$ & 0.5 & 1.0 & 1.5 & 2.0 & $\underline{\mathrm{H}_{8}}$ & 3.0 & .5 & 4.0 & 45 & 56 & 55 & Station & Dura- & & & & & & & & & & & \\
\hline 153 & Meax & $\begin{array}{r}58 \\
4,503\end{array}$ & 1,405 & $\begin{array}{r}24 \\
213\end{array}$ & $\begin{array}{r}17 \\
147\end{array}$ & $\begin{array}{l}13 \\
72\end{array}$ & $\begin{array}{r}8 \\
18\end{array}$ & $\begin{array}{l}3 \\
3\end{array}$ & $\begin{array}{l}\frac{4.0}{68} \\
81\end{array}$ & $\begin{array}{l}\frac{4.2}{a} \\
\therefore\end{array}$ & $\stackrel{0.0}{\cdots}$ & $\frac{3.3}{-.}$ & $\frac{10 .}{160}$ & $\frac{\text { tion }}{\text { theon }}$ & 0.5 & 1.0 & 1.5 & $\underline{2.0}$ & $\underline{2.5}$ & 3.0 & 3.5 & 4.0 & 4.5 & 3.0 & $\underline{5.5}$ \\
\hline 154 & $\begin{array}{l}\text { Mean } \\
\text { Max }\end{array}$ & $\begin{array}{r}58 \\
4,503\end{array}$ & $\begin{array}{r}332 \\
1,485\end{array}$ & 24 & 17 & 13 & 8 & 3 & 203 & $\cdots$ & -- & -- & & $\max$ & 3,450 & $\begin{array}{r}26 \\
816\end{array}$ & $\begin{array}{r}23 \\
576\end{array}$ & $\begin{array}{r}16 \\
156\end{array}$ & $\begin{array}{l}11 \\
60\end{array}$ & $\begin{array}{l}11 \\
33\end{array}$ & $\begin{array}{l}3 \\
3\end{array}$ & $\begin{array}{l}81 \\
11\end{array}$ & $=$ & $=$ & 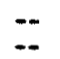 \\
\hline 155 & $\begin{array}{l}\text { Mean } \\
\text { max. }\end{array}$ & $\begin{array}{r}58 \\
2,259\end{array}$ & 1,560 & $\begin{array}{r}313 \\
816\end{array}$ & $\begin{array}{r}147 \\
20\end{array}$ & 14 & 11 & 3 & 243 & -- & $\therefore$ & $\overline{-}$ & 161 & $\begin{array}{l}\text { Mean } \\
\text { Max }\end{array}$ & $\begin{array}{r}26 \\
348\end{array}$ & 137 & $\begin{array}{l}13 \\
90\end{array}$ & $\begin{array}{r}8 \\
39\end{array}$ & $\begin{array}{r}5 \\
18\end{array}$ & $\because$ & $=$ & $=$ & $=$ & $\therefore$ & $=$ \\
\hline 156 & $\begin{array}{l}\text { Mean } \\
\text { Max }\end{array}$ & $\begin{array}{r}57 \\
2,259\end{array}$ & $\begin{array}{r}38 \\
1,560\end{array}$ & $\begin{array}{r}31 \\
798\end{array}$ & $\begin{array}{r}252 \\
20\end{array}$ & $\begin{array}{l}78 \\
14\end{array}$ & $\begin{array}{l}39 \\
10\end{array}$ & 9 & 6 & - & $\cdots$ & $\because$ & 162 & $\begin{array}{l}\text { Mesan } \\
\text { Max }\end{array}$ & $\begin{array}{r}26 \\
348\end{array}$ & $\begin{array}{r}17 \\
204\end{array}$ & $\begin{array}{l}13 \\
90\end{array}$ & 42 & $\begin{array}{r}5 \\
18\end{array}$ & $\because$ & $\because$ & $\because-$ & $=$ & 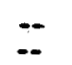 & $\therefore$ \\
\hline 157 & $\begin{array}{l}\text { Mean } \\
\text { Max }\end{array}$ & $\begin{array}{r}57 \\
2,259\end{array}$ & $\begin{array}{r}37 \\
1,551\end{array}$ & $\begin{array}{r}798 \\
30 \\
798\end{array}$ & $\begin{array}{r}252 \\
19\end{array}$ & $\begin{array}{l}78 \\
14\end{array}$ & 39 & 9 & 3 & $\cdots$ & 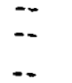 & $\because$ & 163 & $\begin{array}{l}\text { Mean } \\
\text { Max }\end{array}$ & $\begin{array}{r}26 \\
348\end{array}$ & $\begin{array}{r}17 \\
204\end{array}$ & $\begin{array}{l}13 \\
90\end{array}$ & $\begin{array}{r}9 \\
42\end{array}$ & 21 & 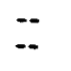 & $\because$ & $=$ & 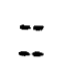 & 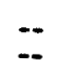 & $\because$ \\
\hline 150 & $\begin{array}{l}\text { Mean } \\
\text { max }\end{array}$ & $\begin{array}{r}44 \\
3,600\end{array}$ & $\begin{array}{r}29 \\
1,026\end{array}$ & $\begin{array}{r}27 \\
585\end{array}$ & $\begin{array}{r}252 \\
18 \\
225\end{array}$ & $\begin{array}{l}78 \\
13 \\
84\end{array}$ & 21 & 9 & 3 & -- & $\cdots$ & -- & 164 & $\begin{array}{l}\text { Meon } \\
\operatorname{Max}\end{array}$ & $\begin{array}{r}25 \\
366\end{array}$ & $\begin{array}{r}16 \\
162\end{array}$ & $\begin{array}{l}12 \\
87\end{array}$ & $\begin{array}{r}6 \\
42\end{array}$ & $\begin{array}{l}6 \\
9\end{array}$ & $\ddot{-}$ & $=$ & $\because$ & $\because$ & $\because$ & $\because$ \\
\hline 159 & $\begin{array}{l}\text { Mean } \\
\text { Max }\end{array}$ & $\begin{array}{r}42 \\
3,450\end{array}$ & $\begin{array}{r}26 \\
999\end{array}$ & $\begin{array}{r}23 \\
537\end{array}$ & $\begin{array}{r}12 \\
156\end{array}$ & $\begin{array}{l}84 \\
12 \\
57\end{array}$ & $\begin{array}{l}33 \\
12 \\
33\end{array}$ & $\begin{array}{l}3 \\
3\end{array}$ & $\begin{array}{r}9 \\
27 \\
27\end{array}$ & $\because$ & 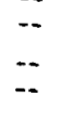 & $\begin{array}{l}\cdots \\
\cdots \\
\cdots\end{array}$ & 166 & $\begin{array}{l}\text { Mean } \\
\text { Max } \\
\text { Mean } \\
\text { hax }\end{array}$ & $\begin{array}{r}24 \\
366 \\
23 \\
363\end{array}$ & $\begin{array}{r}15 \\
201 \\
14 \\
201\end{array}$ & $\begin{array}{l}10 \\
87\end{array}$ & $\begin{array}{r}5 \\
27 \\
5 \\
15\end{array}$ & $\begin{array}{l}3 \\
3 \\
9 \\
9\end{array}$ & $\begin{array}{l}-- \\
-- \\
--\end{array}$ & $\begin{array}{l}a \\
--\end{array}$ & $\because=$ & $\begin{array}{l}-- \\
\therefore \\
\therefore-\end{array}$ & $\begin{array}{l}-- \\
--\end{array}$ & $\begin{array}{l}\because- \\
-- \\
-\end{array}$ \\
\hline
\end{tabular}


APPENDIX C

COMPUTER PROGRAM STRMDIST

Page

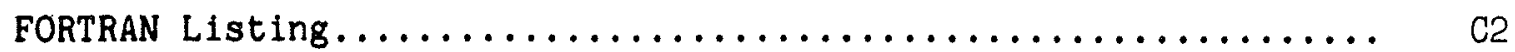

Sample Output.................................... 014 


\section{FORTRAN Listing - Program "STRMDIST"}

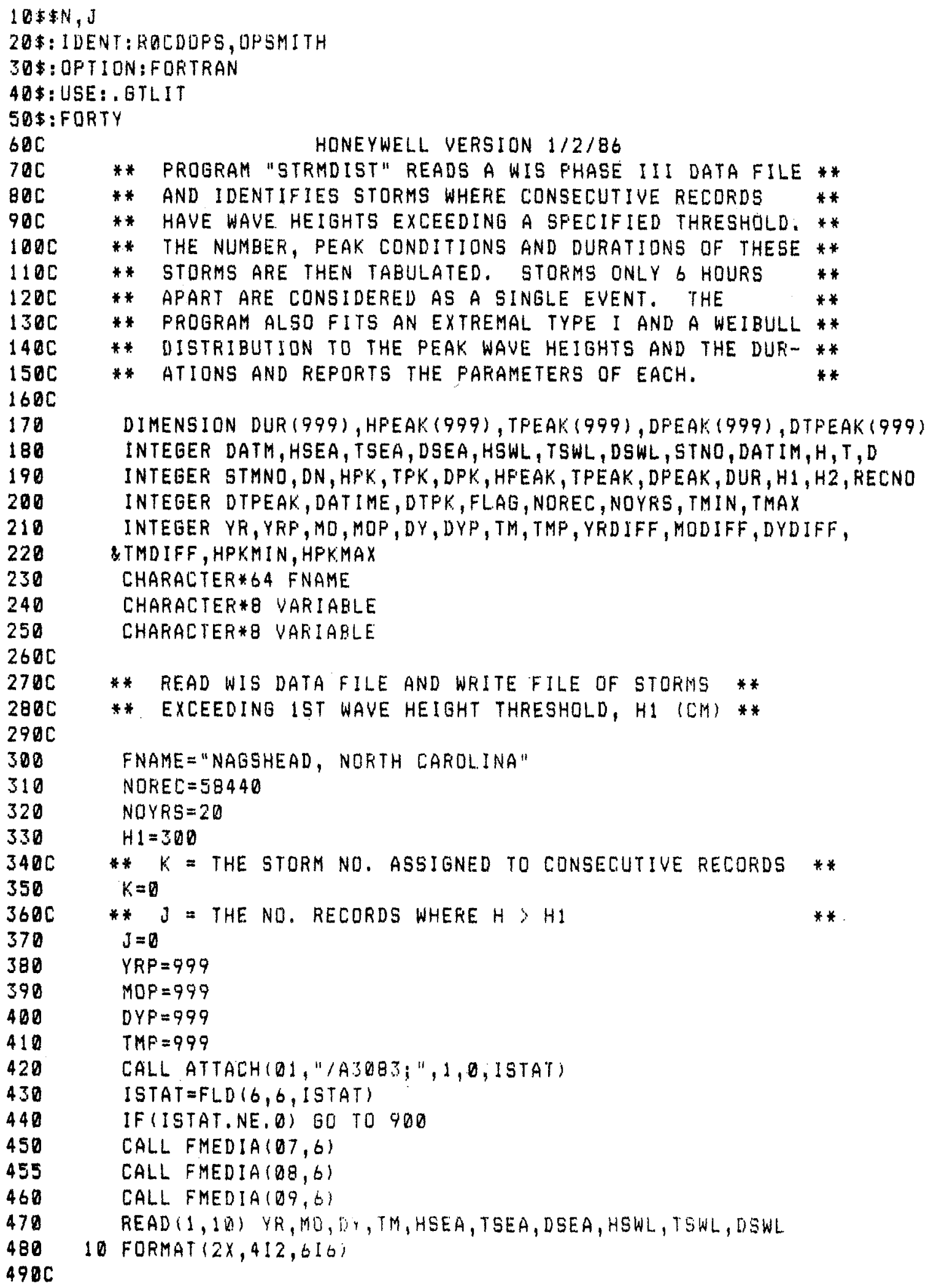




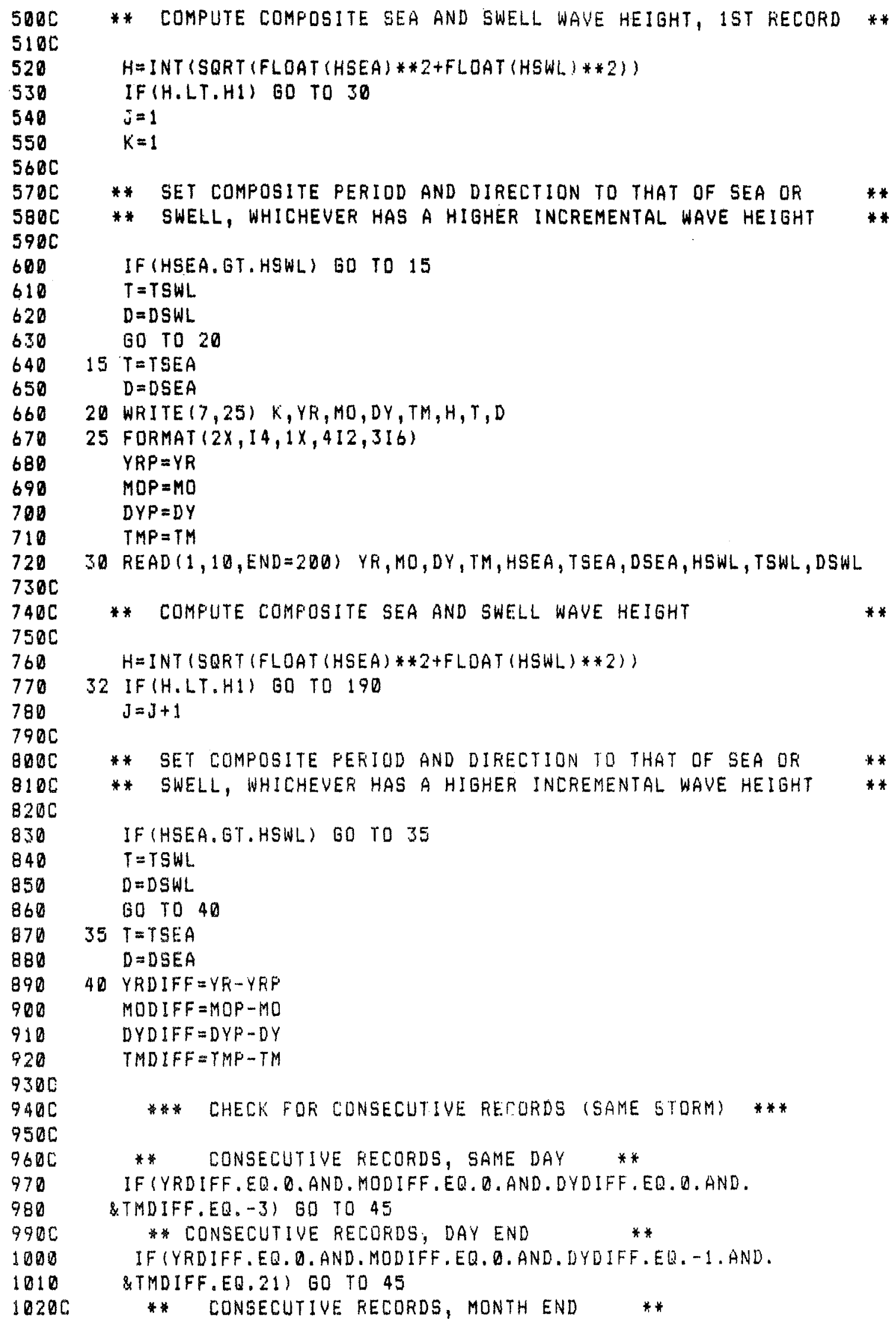


1030

1040

1050

1860

1970

1880

1890

1180

$1110 \mathrm{C}$

1120

1130

$1148 \mathrm{C}$

$1159 \mathrm{C}$

$1168 \mathrm{C}$

$1170 \mathrm{C}$

$118 \mathrm{CC}$

$1198 \mathrm{C}$

$1298 \mathrm{C}$

1210

1228

$1238 \mathrm{C}$

1240

1250

12686

$\lcm{278}$

1289

1290

1388

1310

1328

1330

1340

$1350 \mathrm{C}$

1360

1370

1388

1390

1480

1418

1420

1430

1440

1450

1460

1470

1480

1490

158

1510C

152.6

15306

15406

Is50C

IFIYRDIFF.EQ, O. AND. MODIFF. EQ. -1. AND.OYDIFF,EQ.27.AND. QTHDIFF.EQ.21) 60 TO 45

IFIYRDIFF.EQ. . AND . MODIFF.EQ. - I. AND. DYDIFF. EQ. 2B. AND. QTMDIFF.EQ.21) 60 TO 45

IF IYRDIFF. EQ. D. AND. MODIFF.EQ. - I. AND.OYDIFF.EQ.29. AND. GTHOIFF.EQ.2L) 60 TO 45

IF YYRDIFF. EQ. O. ANO MODIFF. EQ.-1. AND. DYDIFF. EQ. 3Q. ANO. UTMDIFF. EQ.21) 60 . TO 45

* CONSECUTIVE RECORDS, YEAR END

IF IYRDIFF.EQ.1.AND. HODIFF.EQ. II . AND. DYDIFF.EO. 3Q. AND. QTMDIFF.EQ.2UI 60 TO 45

* CHECK FOR RECORDS 6 HRS APART AND ADJUST RECOAD

* BETHEEN SUCh that THE PROgRAM SEES DNE CONT-

* INUOUS STORH (IGNORING THE ONE RECORO BELOH

** THE THRESHOLD)

* RECoRds 6 hRs apart, same daY *

IFIYRDIFF.EO. Q.AND. MODIFF. EQ. O. AND. DYDIFF.EQ. . AND. LTMDIFF. EO. -6) 60 TO 47

- RECORDS 6 HRS APART, DAY END

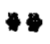

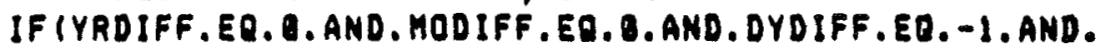

\&TMDIFF.EQ.1B) 60 TO 47

* RECQRDS 6 HRS APART, MONTH END

IF IYROIFF. EQ.8.AND.MODIFF.EQ.-1.AND. OYDIFF,EQ, 27. ANO. LTMOIFF.EQ.18) 60 TO 47

IFIYRDIFF. EQ. Q. AND. MODIFF. EQ.-I . AND. DYDIFF.EQ. 28. AND.

WTHDIFF.EQ.18) 60 TD 47

IF (YRDIFF. EQ. O. AND. MODIFF.EQ.-1. AND. DYDIFF, EQ. 29.AND.

WTMOIFF.EQ.181 60 TO 47

IF (YRDIFF. EQ. O. AND. MODIFF, EQ.-1. AND. DYDIFF. EQ, 3Q. AND.

LTHDIFF.EQ.18I 60 TO 47

* RECORDS 6 HRS APART, YEAR END

IFIYRDIFF.EQ, I. AND. MODIFF. EQ. II. AND. DYOIFF.EQ. 3E. AND. \&TMDIFF.EQ.18) GO TO 47

$K=K+1$

60 T0 45

47 BACKSPACE 1

BACKSPACE I

READ (1,18) YR, MO, DY, TH,HSEA, TSEA, DSEA, HSHL, TSWL, DSWL

$\mathrm{H}=\mathrm{HI}$

$60 \quad 10 \quad 32$

45 WRITE $(7,25) K, Y R, M O, D Y, T M, H, T, D$

YRPEYR

HOP AHO

DYPEOY

ThP $=$ Th

19080 T0 30

- FILE CODE 7 INCLUdeg RECoRDS WhERE H IS GREATER than

- THE FIRST WAVE HEIGHT THRESHOLD HI. CONSECUTIVE

- RECORdS shaRe a COMMON "STORM NUMBER", K. 


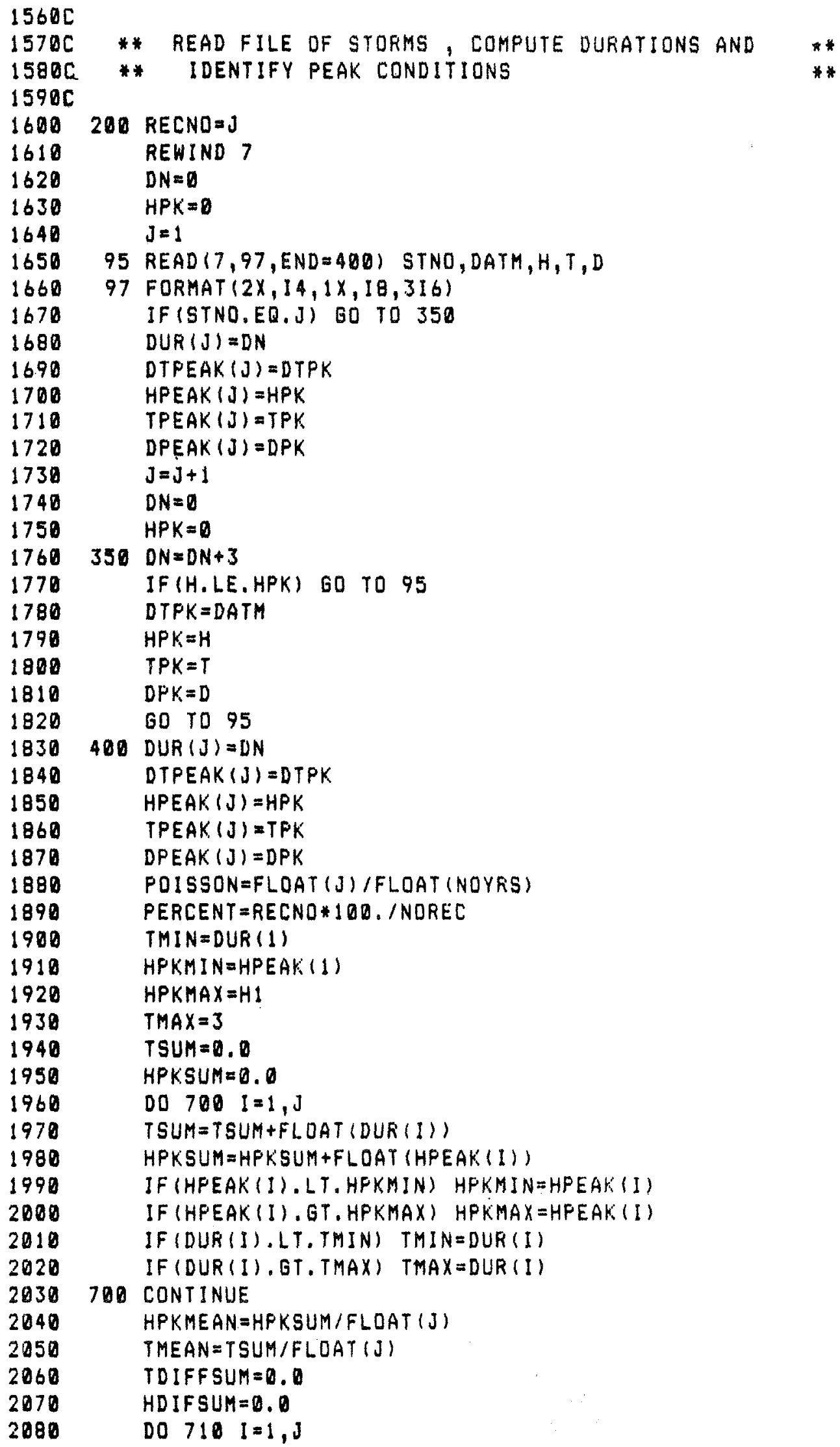




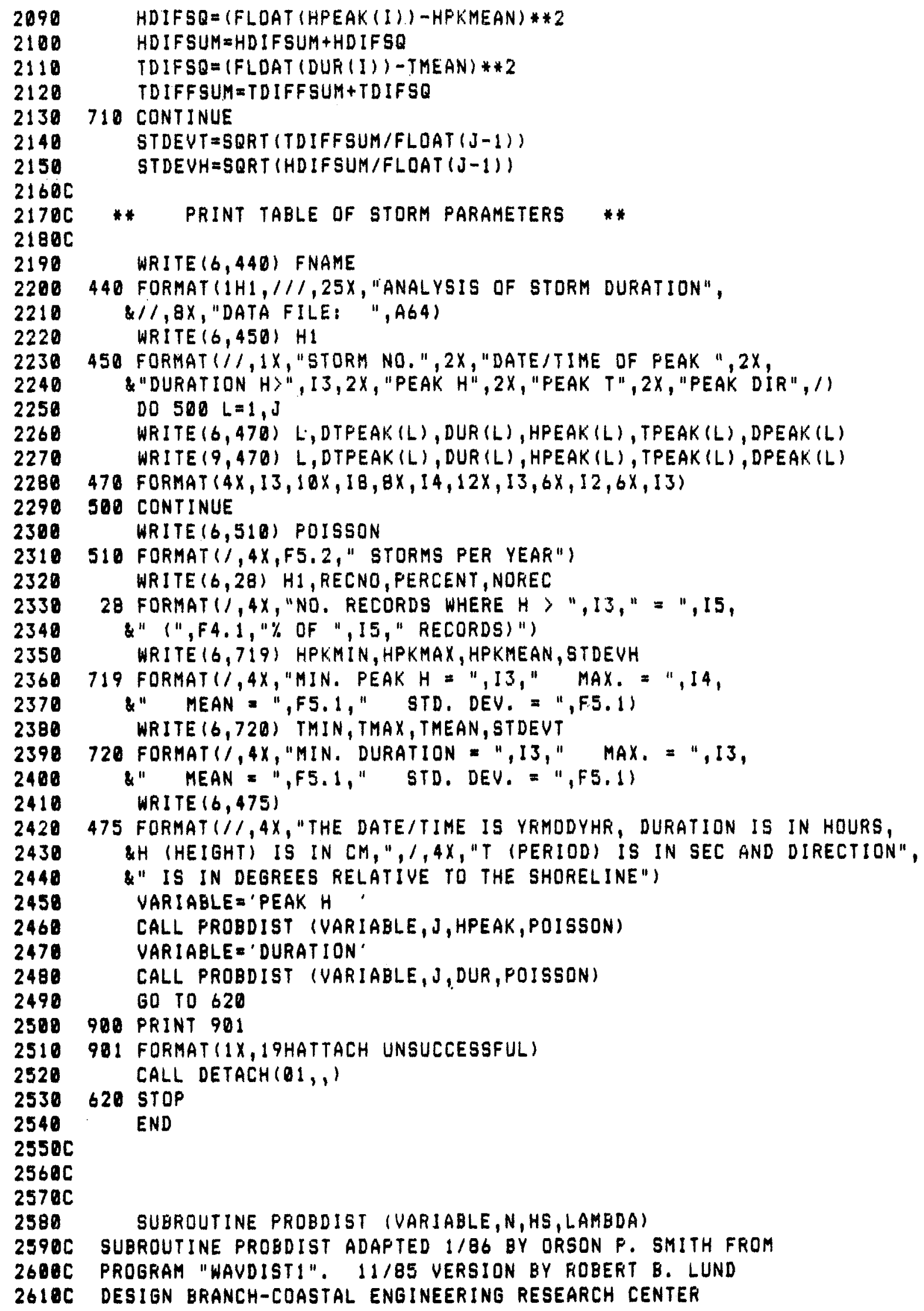


2620C U.S. ARMY ENGINEERS WATERWAYS EXPERIMENT STATION

$2630 \mathrm{C}$ P.O. BOX 631

2640C VICKSEURG, MS 39180-0631

2650C FOR FURTHER INFORMATION CONCERNING THE APPLICATION

$2660 C$ OF "WAVDISTI", CALL....

2670 C ROBERT B. LUND (601)-634-2068 FTS:2068

2680C DRSON P. SMITH (601)-634-2013 FTS:542-2013

2690C DOYLE L. JONES (601)-634-2069 FTS:542-2069

$2700 \mathrm{C}$

27IOC FDRTRAN 4 HONEYWELL DPS-8

2720C REF: "RELIABILITY OF LONG-TERM WAVE CONDITIONS PREDICTED WITH DATA SETS

2739C OF SHORT DURATION" CETN-1-5

2740C REF: "HANDBOOK OF MATHEMATICAL FUNCTIONS" BY ABRAMOWITZ AND SEGUN

2750C REF: "EXTREMAL PREDICTION IN WAVE CLIMATOLOGY" BY BORGMAN AND RESID

$2760 C$ REF. "LONG-TERM DISTRIBUTIONS OF OCEAN WAVES."

$2770 C$ ISAACSON AND MACKENZIE

$2780 \mathrm{C}$

$2790 \mathrm{C}$

28000

2810C LAMBDA = POISSON LAMBDA PARAMETER (AVERAGE NO. STORMS PER YEAR)

$2820 \mathrm{C}$

$2830 \mathrm{C}$

$2840 \mathrm{C}$

$2850 \mathrm{C}$

28600

$2870 \mathrm{C}$

$2880 \mathrm{C}$

$2890 \mathrm{C}$

$2900 \mathrm{C}$

29100

$2920 \mathrm{C}$

$2930 \mathrm{C}$

$2940 \mathrm{C}$

2950

2960 C

2970

2980

2990

3000

3010

3020

3030

3040

3050

3060

3070

3080

3090

3100

3110

3120

3130

3140

HS = THE INDEPENDENT VARIABLE

DIFF = THE RESIDUAL FOR EACH DATA POINT

YACT = THE PROBABILITY AS ESTIMATED BY THE PLOTTING FORMULA M/K+I

YEST = THE PROBABILITY AS ESTIMATED BY THE DISTRIBUTION

ALPHA = THE ARRAY OF LOCATION PARAMETERS FOR THE DISTRIBUTIONS

BETA = THE ARRAY OF SCALE PARAMETERS FOR THE DISTRIEUTIONS

$A=$ THE SLOFE OF EACH "PLOTTED LINE"

$B=$ THE Y-INTERCEPT OF EACH "PLDTTED LINE"

$C=$ THE ARRAY DF COEFFICIENTS FOR THE GAMMA INTEGRAL EXPANSION

ST = THE SUM OF THE SQUARE RESIDUALS

CORR = THE NON-LINEAR CORRELATION FOR EACH DISTRIBUTION

STE = THE STANDARD ERRDR DF THE ESTIMATE OF $Y$ DN $X$

MSD = THE MEAN SQUARE DEVIATION

DECLARATION DF VARIABLES, FUNCTIONS, AND CHARACTERS

DIMENSION YACT $(999,3)$, YEST $(999,3)$, DUMI (999), DUM2 (999), HS(999)

DIMENSION YAVG (3), CORR (3), ALPHA (4), BETA (4), VAR (4),DM(3)

DIMENSION RET (5), CHS $(5,3), A(3), B(3), \operatorname{ST}(3), \operatorname{SB}(3), \operatorname{STE}(3)$

DIMENSION STDEV(3)

REAL MEAN (3), MSD (3)

REAL LAMBDA

INTEGER HS

$F I(X)=E X P(-E X P(-(X-E P S I) / P H I))$

$F 2(X)=1,0-E X P(\{-(X / S I G M A) * * C))$

$F 3(X)=E X P(-($ (SIGMAZ $/ X) * * U))$

CHARACTER*20 IFLAG (4)

CHARACTER 17 DEF

CHARACTER*34 FORM (3)

CHARACTER 24 TITLE

CHARACTER*1 LOGIC

CHARACTER $\#$ GO BOX (16) 


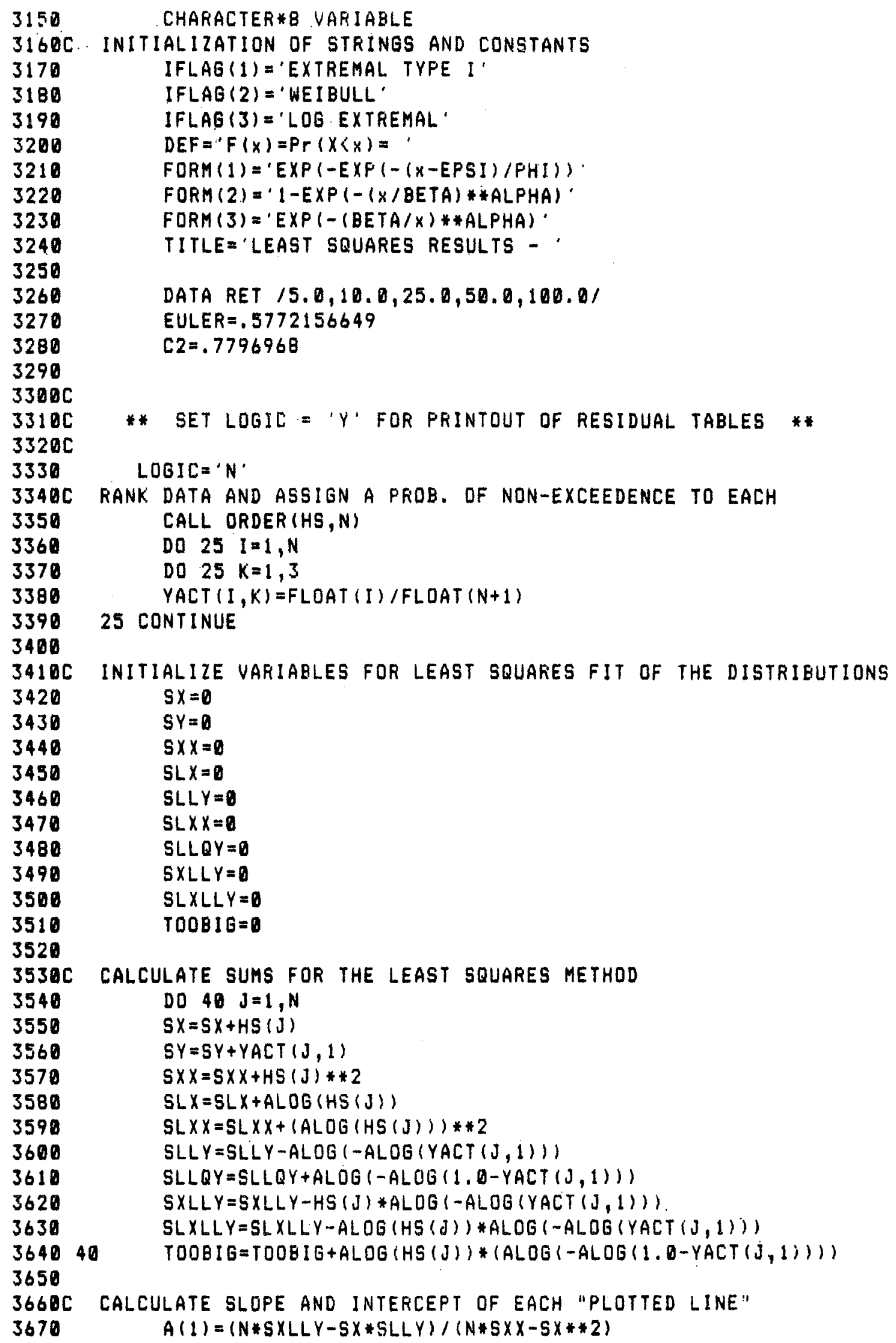




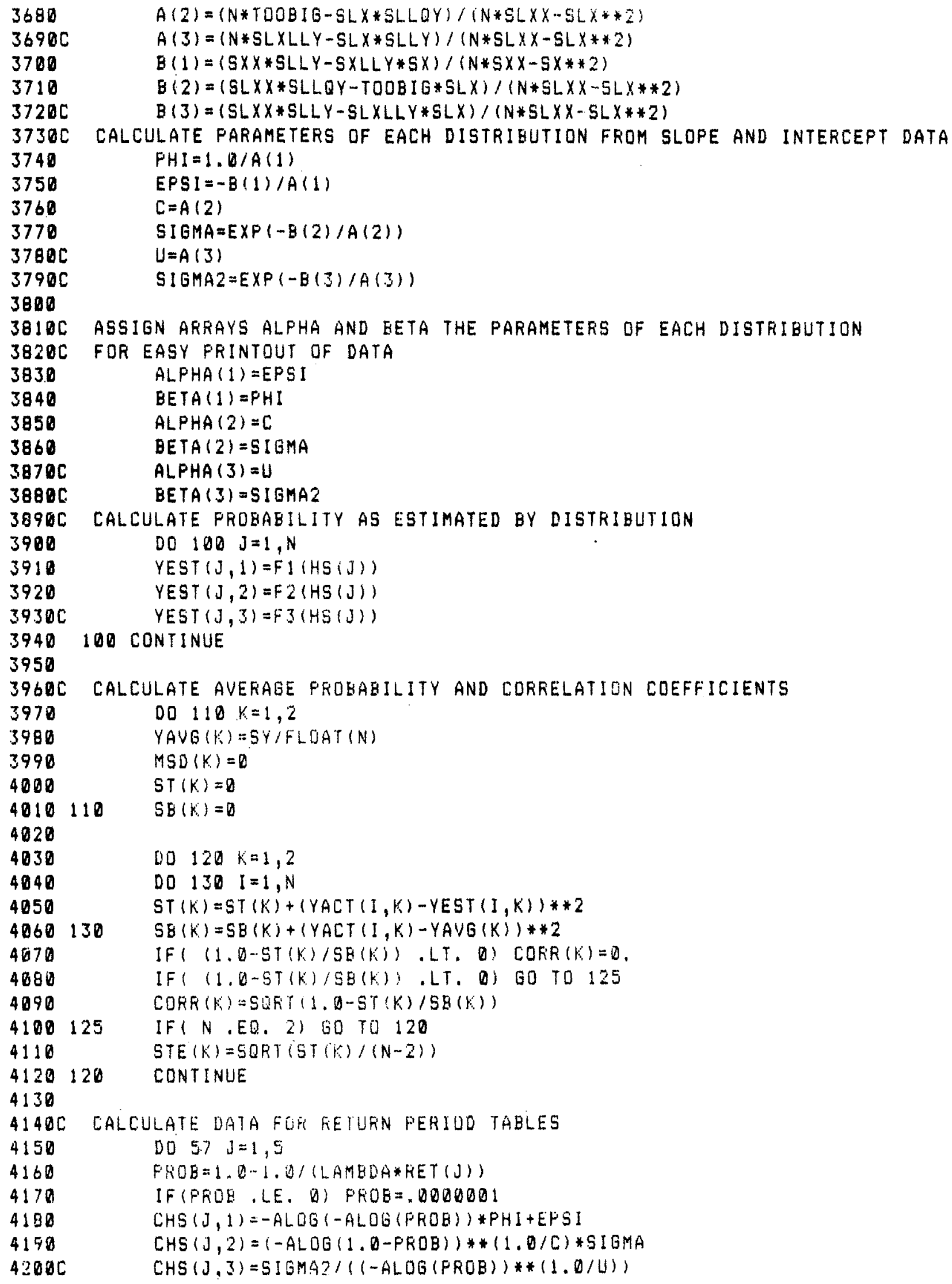




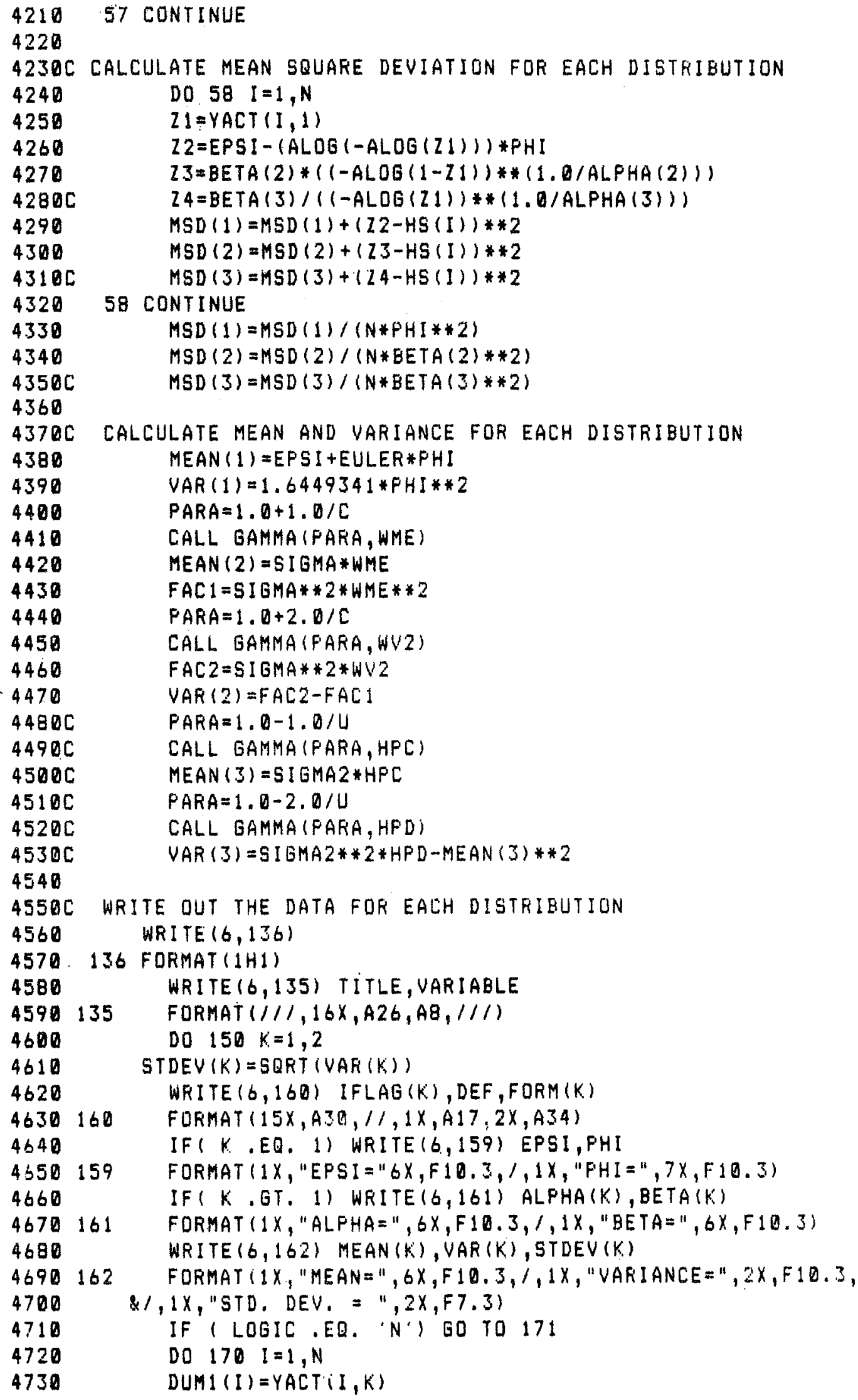




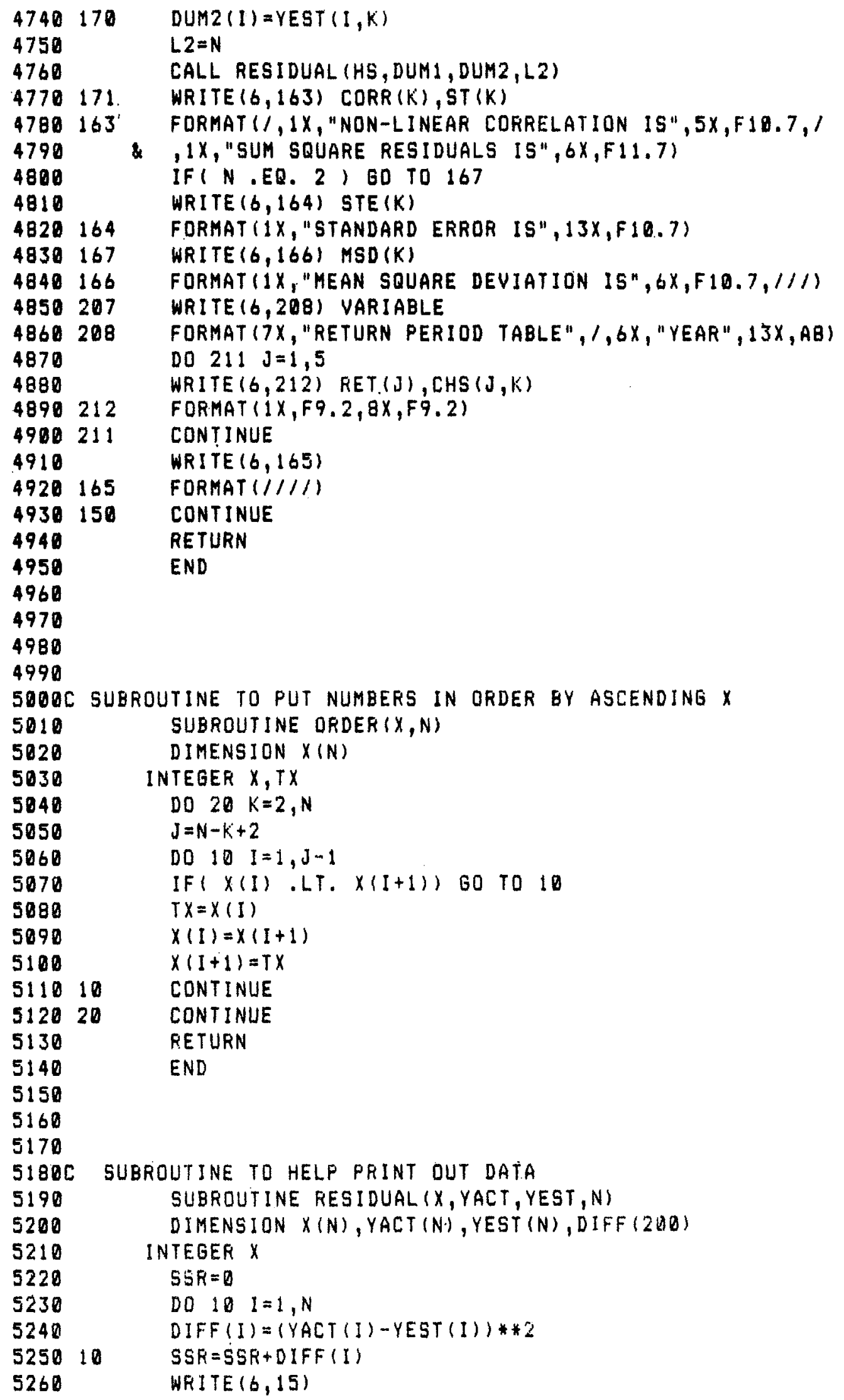




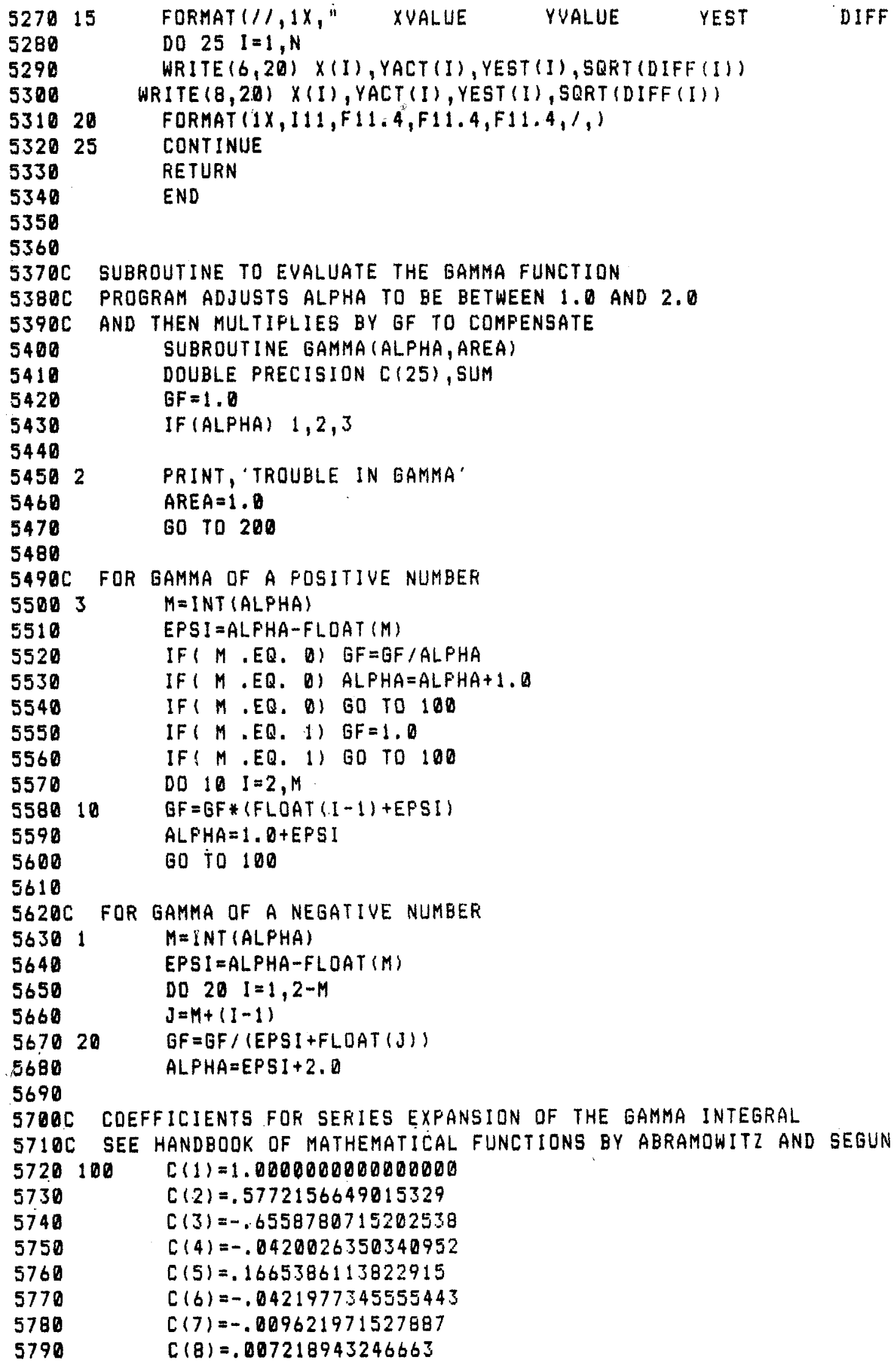




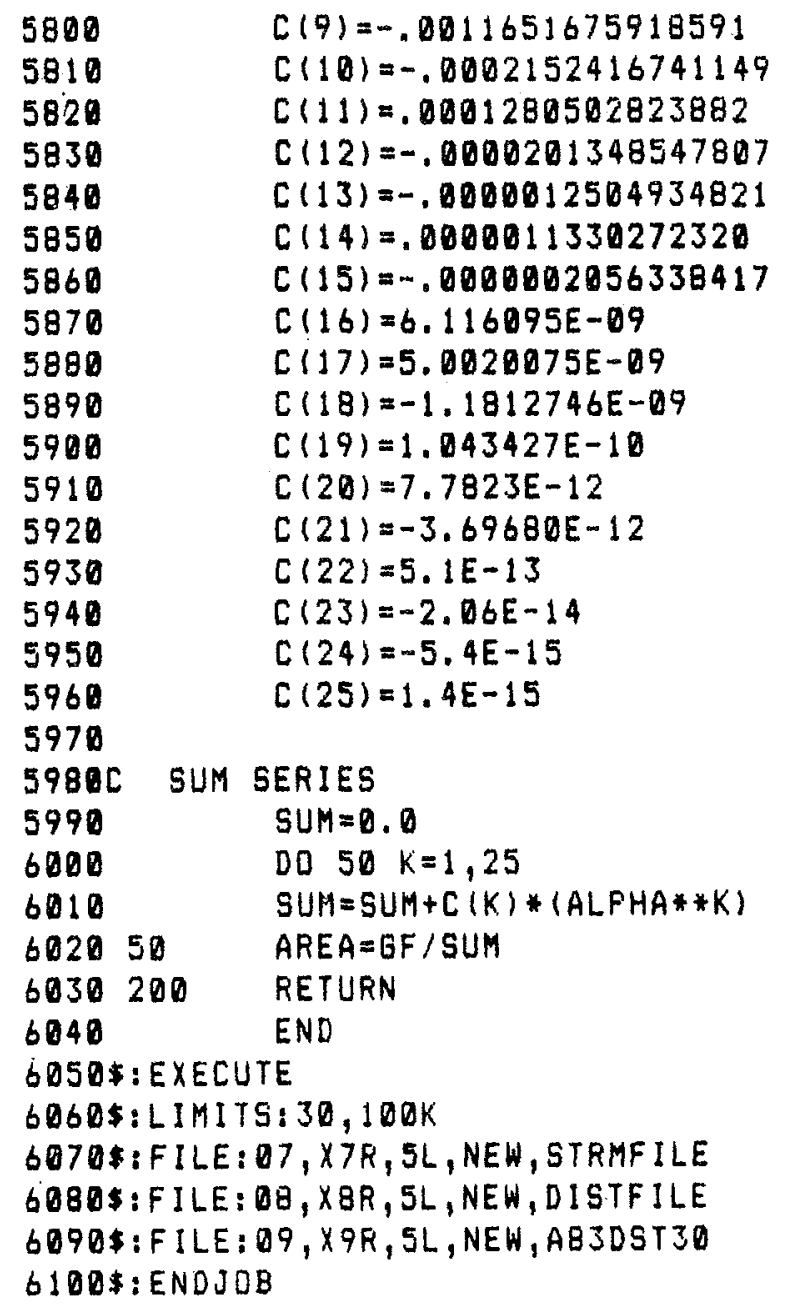


ANALYSIS OF STORM DURATION

DATA FILE NAGSHEAD, NORTH CAROLINA

\begin{tabular}{|c|c|c|c|c|c|}
\hline STORM NO. & $\begin{array}{c}\text { DATE/TIME DF PEAK } \\
56011015\end{array}$ & $\begin{array}{l}\text { DURATION H>350 } \\
27\end{array}$ & $\begin{aligned} \text { FEAK H } \\
449\end{aligned}$ & $\begin{array}{c}\text { PEAK T } \\
11\end{array}$ & $\begin{array}{l}\text { PEAK DIR } \\
98\end{array}$ \\
\hline 2 & 56892718 & 6 & 379 & 10 & 101 \\
\hline 3 & 56102703 & 3 & 461 & 11 & 83 \\
\hline 4 & 56102800 & 9 & 405 & 11 & 75 \\
\hline 5 & 56103100 & 3 & 377 & 8 & 69 \\
\hline 6 & 56103109 & 6 & 364 & 11 & 74 \\
\hline 7 & 58102103 & 3 & 352 & 10 & 91 \\
\hline$B$ & 58102118 & 9 & 488 & 10 & 75 \\
\hline 9 & 58102212 & 27 & 508 & 11 & 88 \\
\hline 10 & 60020100 & 9 & 386 & 10 & 93 \\
\hline 11 & 60020118 & 3 & 351 & 10 & 101 \\
\hline 12 & 60103121 & 3 & 354 & 10 & 97 \\
\hline 13 & 61102421 & 6 & 387 & 11 & 99 \\
\hline 14 & 62030721 & 18 & 459 & 11 & 114 \\
\hline 15 & 62030909 & 30 & 591 & 13 & 94 \\
\hline 16 & 62112806 & 84 & 466 & 12 & 97 \\
\hline 17 & 62120200 & 3 & 351 & 9 & 88 \\
\hline 18 & 62120212 & 15 & 371 & 9 & 88 \\
\hline 19 & 63020421 & 6 & 363 & 9 & 88 \\
\hline 20 & 64092221 & 21 & 391 & 10 & 111 \\
\hline 21 & 66061306 & 3 & 403 & 10 & 105 \\
\hline 22 & 68011121 & 12 & 400 & 10 & 100 \\
\hline 23 & 68022512 & 15 & 385 & 10 & 116 \\
\hline 24 & 69022109 & 3 & 355 & 10 & 114 \\
\hline 25 & 69030306 & 3 & 360 & 11 & 181 \\
\hline 26 & 70102718 & 12 & 364 & 10 & 103 \\
\hline 27 & 72052700 & 15 & 365 & 10 & 94 \\
\hline 28 & 73021112 & 33 & 465 & 11 & 111 \\
\hline 29 & 73021300 & 3 & 372 & 10 & 101 \\
\hline 30 & 73022806 & 9 & 379 & 10 & 107 \\
\hline 31 & 73120906 & 3 & 352 & 9 & 66 \\
\hline 32 & 75012118 & 6 & 389 & 10 & 186 \\
\hline 33 & 75070106 & 9 & 399 & 10 & 112 \\
\hline 34 & 75070215 & 9 & 430 & 11 & 104 \\
\hline 35 & 75112415 & 9 & 375 & 10 & 107 \\
\hline 36 & 75112506 & 3 & 397 & 10 & 102 \\
\hline
\end{tabular}

\subsection{STORMS PER YEAR}

NO. RECORDS WHERE H> $350=149(0.3 \%$ OF 58440 RECORDS $)$

MIN. PEAK H $=351$ MAX. $=591$ MEAN $=401.2$ STD. DEV. $=53.4$

MIN. DUFATION $=3$ MAX. $=84$ MEAN $=12.2$ STD. DEV. $=14.9$

THE DATE/TIME IS YRMOOYHF, DURATION IS IN HOURS, H IHEIGHTI IS IN CM, $T$ (PERIOD) IS IN SEC AND DIRECTION IS IN DEGREES RELATIVE TO THE SHORELINE 
EXTREMAL TYPE I

$\begin{array}{lc}F(X)=P R(X\langle X)= & \operatorname{EXP}(-E X P(-(X-E P S I) / P H I \\ E P S I= & 3.918 \\ \text { PHI }= & 15.246 \\ M E A N= & 12.718 \\ \text { VARIANCE }= & 382.333 \\ \text { STD. DEV. }= & 19.553 \\ & \\ \text { NON-LINEAR CORRELATION IS } & 0.8720683 \\ \text { SUM SQUARE RESIDUALS IS } & 0.6796928 \\ \text { STANDARD ERROR IS } & 0.1413894 \\ \text { MEAN SQUARE DEVIATION IS } & 0.3527218\end{array}$

$\begin{array}{cc}\text { RETURN PERIOD } & \text { TABLE } \\ \text { YEAR } & \text { DURATION } \\ 5.00 & 36.53 \\ 10.00 & 47.55 \\ 25.00 & 61.78 \\ 50.00 & 72.44 \\ 100.00 & 83.05\end{array}$

WE I BULL

$\begin{array}{lc}F(X)=P R(X<X)= & 1-E X P(-(X / B E T A) * \text { *ALPHA }) \\ \text { ALPHA }= & 1.156 \\ \text { BETA }= & 12.636: \\ \text { MEAN }= & 12.007 \\ \text { VARIANCE }= & 108.437 \\ \text { STD. DEV. }= & 10.413 \\ & \\ \text { NON-LINEAR CORRELATION IS } & 0.9607089 \\ \text { SUM SQUARE RESIDUALS IS } & 0.2186227 \\ \text { STANDARD ERROR IS } & 0.0801878 \\ \text { MEAN SQUARE DEVIATION IS } & 0.38580 B \text { IS }\end{array}$

$\begin{array}{cc}\text { RETURN PERIOU } & \text { TAELE } \\ \text { YEAR } & \text { DURATION } \\ 5.00 & 24.96 \\ 10.00 & 31.64 \\ 25.00 & 40.15 \\ 50.00 & 46.40 \\ 100.00 & 52.52\end{array}$


LEAST SQUARES RESULTS - PEAK H

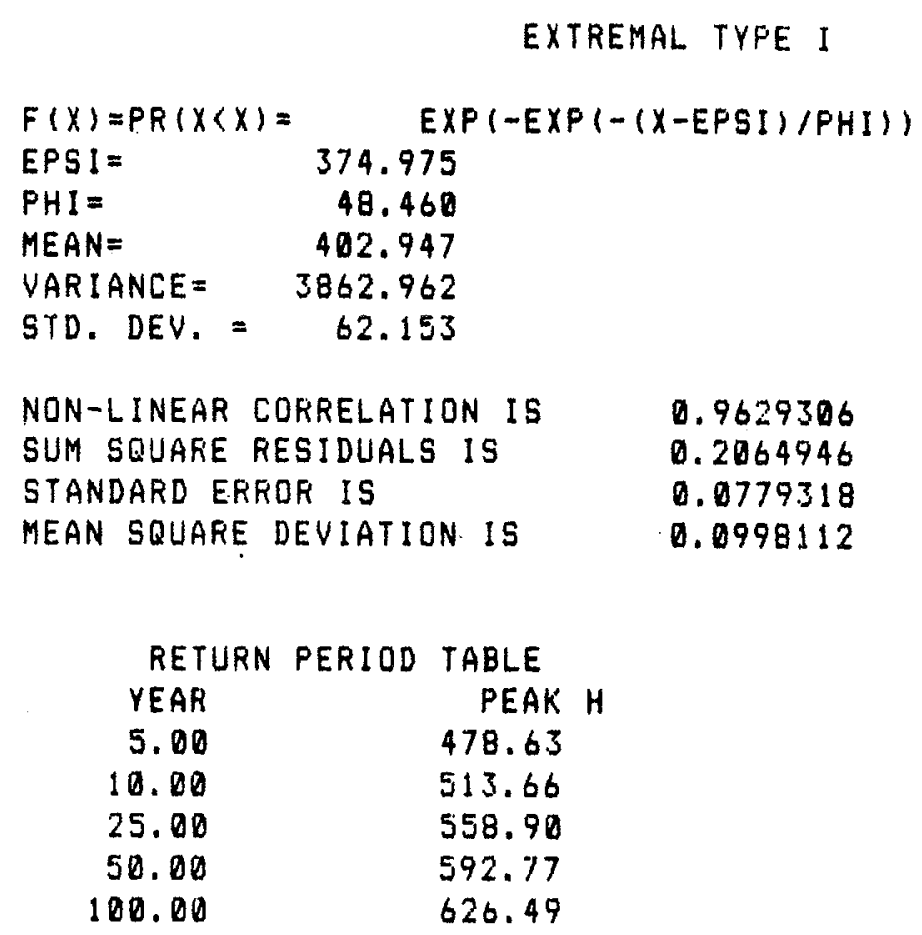

WEIBULL

$F(X)=F(X)(X)=\quad 1-E X P(-(X / B E T A) * A L P H A)$

ALPHA $=\quad 7.888$

BETA $=\quad 426.388$

MEAN $=\quad 401.273$

VARIANCE $=\quad 3638.859$

STD. DEV. $=60.323$

NON-LINEAR CORRELATION IS 0.9038882

SUM SQUARE RESIDUALS IS 0.5192849

STANDARD ERRDR IS 0.1235843

MEAN SQUARE DEVIATION IS 0.0047993

$\begin{array}{cc}\text { RETUFN PERIOD TAELE } \\ \text { YEAR } & \text { PEAK H. } \\ 5.00 & 4.71 .13 \\ 10.00 & 487.80 \\ 25.00 & 505.13 \\ 50.00 & 515.95 \\ 100.00 & 525.41\end{array}$


SPSS COMMAND FILE AS APPLIED IN

THE REGRESSION ANALYSIS

Page

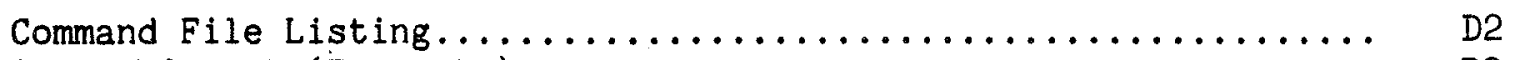

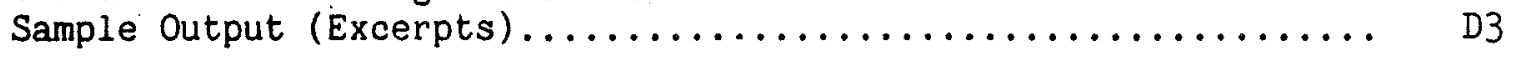




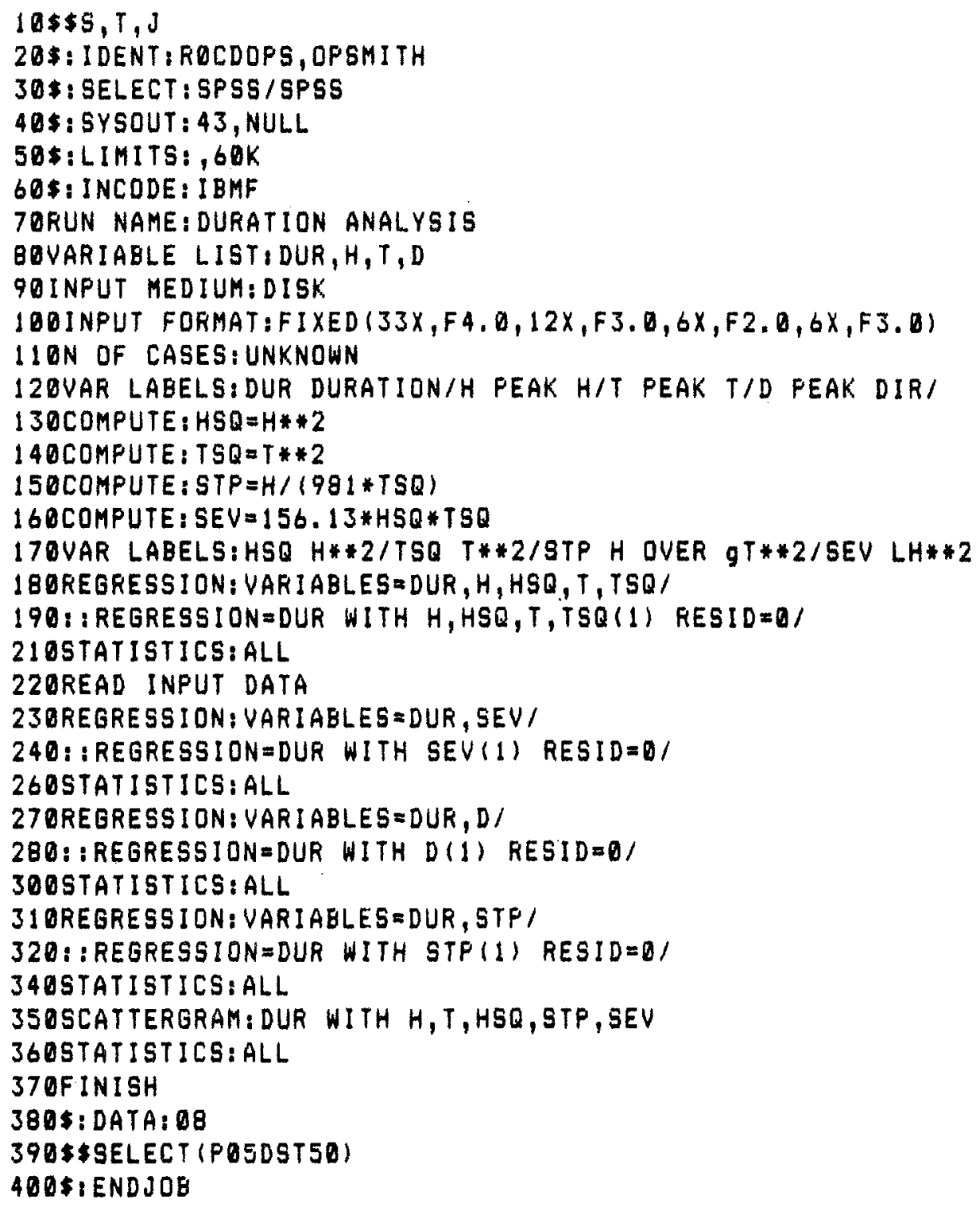




\section{Sample Output (Excerpts) - SPSS Regression Analysis}

DURATION ANALYSIS

File NONAME (CREATION DATE $=01 / 16 / 86)$

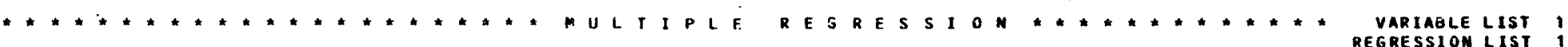

oependent variatle.. pur dijation

VÁRIAQLE(S) EHTFRF O ON STEP NUMBER 1.. HSQ H H*

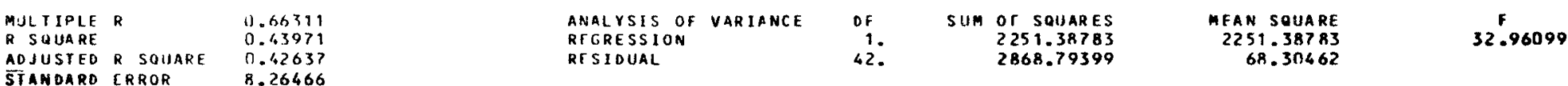

SIANOARO CRRORAE 0.42637

RFGRESSION
RTSIDUAL

42. 2868.79399

2.96099

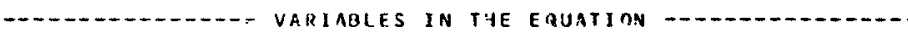

$\begin{array}{lccrc}\text { VARIABLE } & \text { BE } & \text { BETA } & \text { STD ERROR H } & \text { F } \\ \text { HSZ } & 0.00025 & 0.63311 & 0.00004 & 32.961 \\ \text { (CONSTANT) } & -101.43962 & & & \end{array}$

$\begin{array}{lrrrr}\text { VARIAGLE } & \text { BETA IN } & \text { PARTIAL } & \text { TOLERANCE } & \text { F } \\ \text { H } & -11.82259 & -0.25 \text { SAR7 } & 0.00025 & 2.744 \\ \text { TSQ } & 0.17425 & 0.21827 & 0.87916 & 2.051 \\ \text { ISR } & 0.17425 & 0.21827 & 0.87916 & 2.051\end{array}$

VARIABLE (S) ENTERED ON STEP NUHGeq $2 \ldots$..

PEAK T

\begin{tabular}{|c|c|c|c|}
\hline $\begin{array}{l}\text { MULIIFLF } \\
\text { R SQUARRE } \\
\text { DOJUSTED R SQUARE } \\
\text { SIANDARD ERROR }\end{array}$ & $\begin{array}{l}0.68294 \\
0.46640 \\
0.46037 \\
R .16315\end{array}$ & & $\begin{array}{l}\text { ANALYSIS } \\
\text { REGRESSIOI } \\
\text { RESIDUAL }\end{array}$ \\
\hline 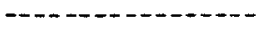 & AR I AGLES & HE EQUATI ON & $\ldots \ldots$ \\
\hline $\begin{array}{l}\text { YARIABLE } \\
\text { HS2 }\end{array}$ & $\begin{array}{l}\theta \\
0.00027 \\
1.2 \times 750\end{array}$ & $\begin{array}{c}\text { BETA } \\
0.72368 \\
0.17425\end{array}$ & $\begin{array}{l}\text { ERROR } \\
0.00005 \\
1.31795\end{array}$ \\
\hline
\end{tabular}

$\begin{array}{rrr}\text { OF SUM OF SOUARES } & \text { MEAN SQUARE } \\ 2 . & 2388.06289 & 1194.03145\end{array}$

17.91843

(CONSTANT) 140.16131

F-LEVEL OR TOLERANCE-LEVEL INSUFFICIENT FOR FURTHER COMPUTATION 


\section{DURATION AHALYSIS}

\section{FiLE NONAME (CREATION DATE $=01 / 16 / 86)$}

CORRELATION COEFFICIFNTS

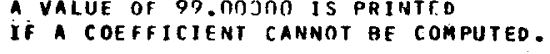

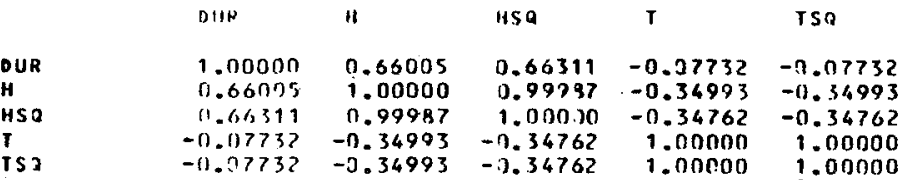

DJRATION MiNaLYis

File nuname (CReAtion Date = j1/16/86)

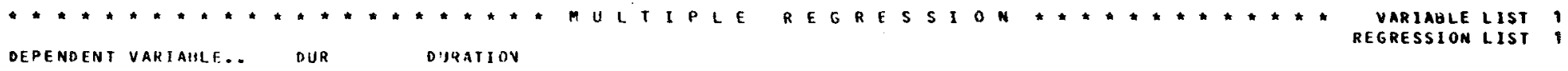

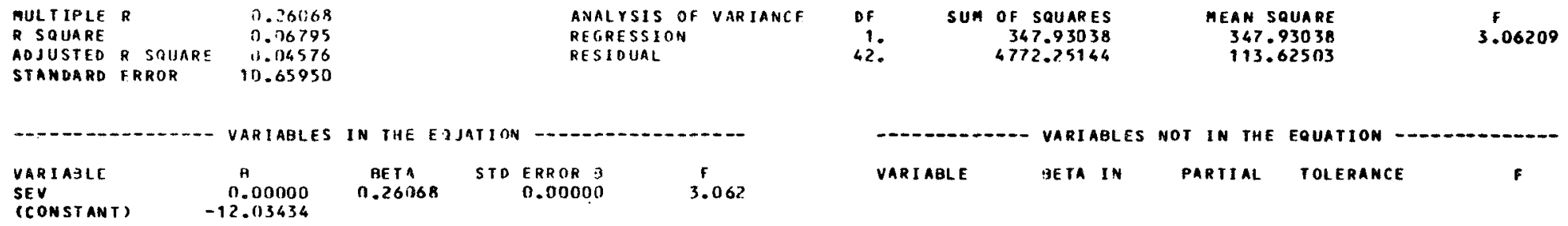

MAXIMUM STEP REACHED 
D.JRATION ANALYSIS

File NONAME (CRFATION DATE $=$ ')1/13/BG)

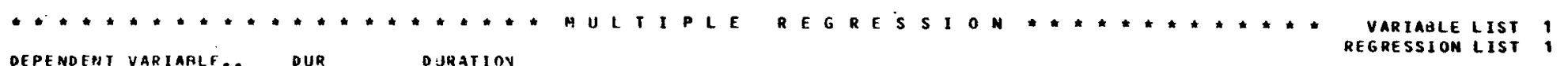

VARIAHLE (S) ENTERED ON STEP NIMAER 1.. D

PEAK DIR

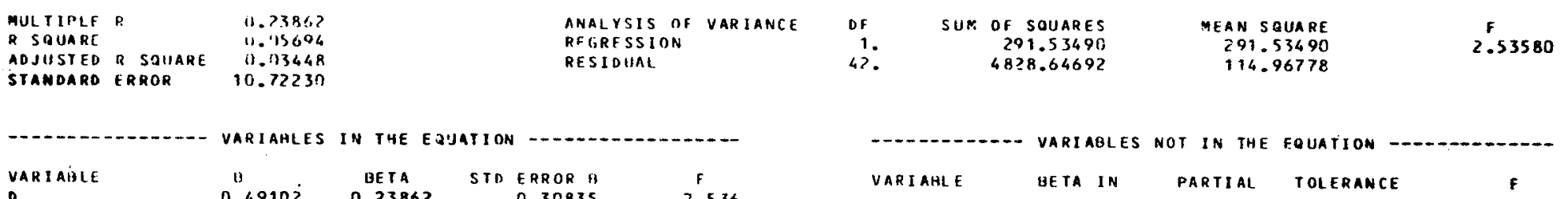

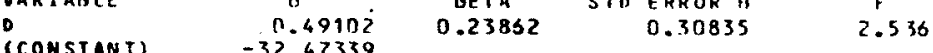

MAXIMUM SITP REACHEO

DJRATION AHALYSIS

FILE MOHAMF (CREATIOM DATE = M/16/R6)

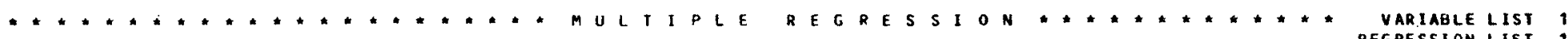
oEPE VDENT VARIAHLE.. DUR Distatiov

VARIAGLE(S) EHIERED ON STEP NUMGER 1.. STP H OVER GT**?

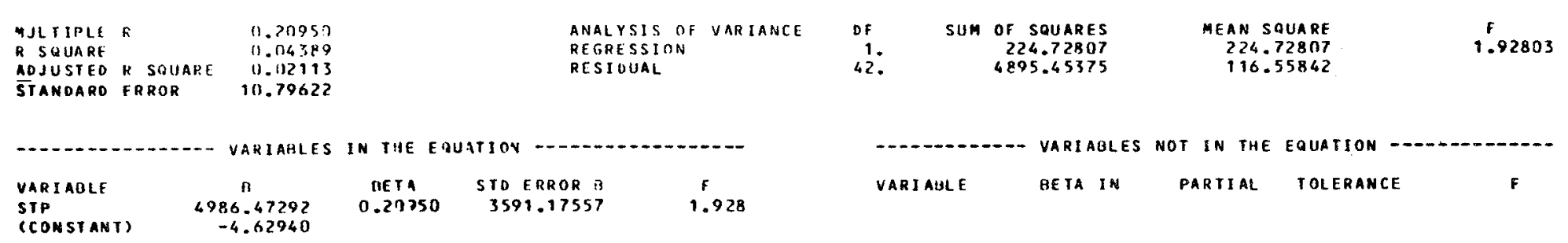

MAXIMUM STEP REACHED 


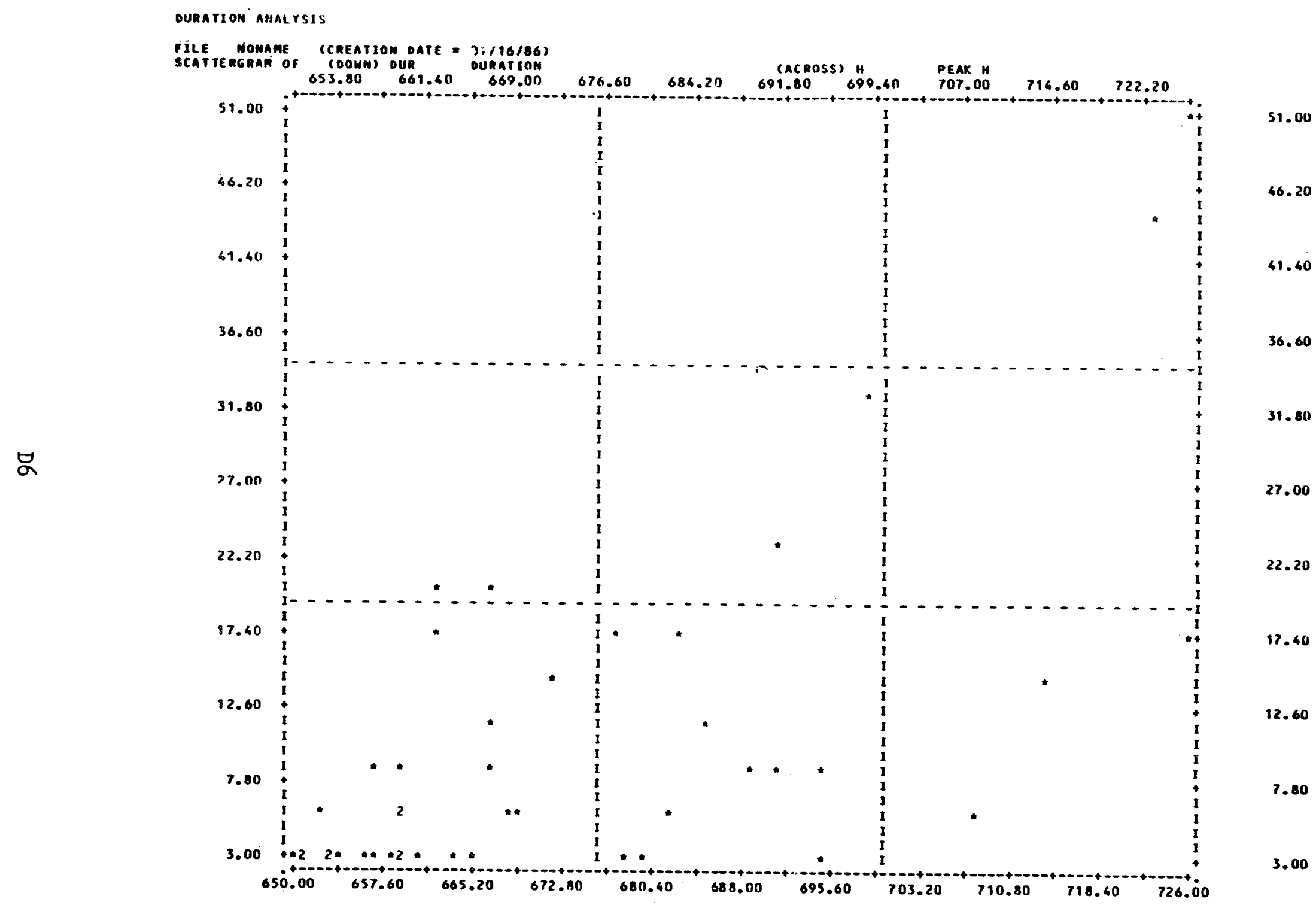




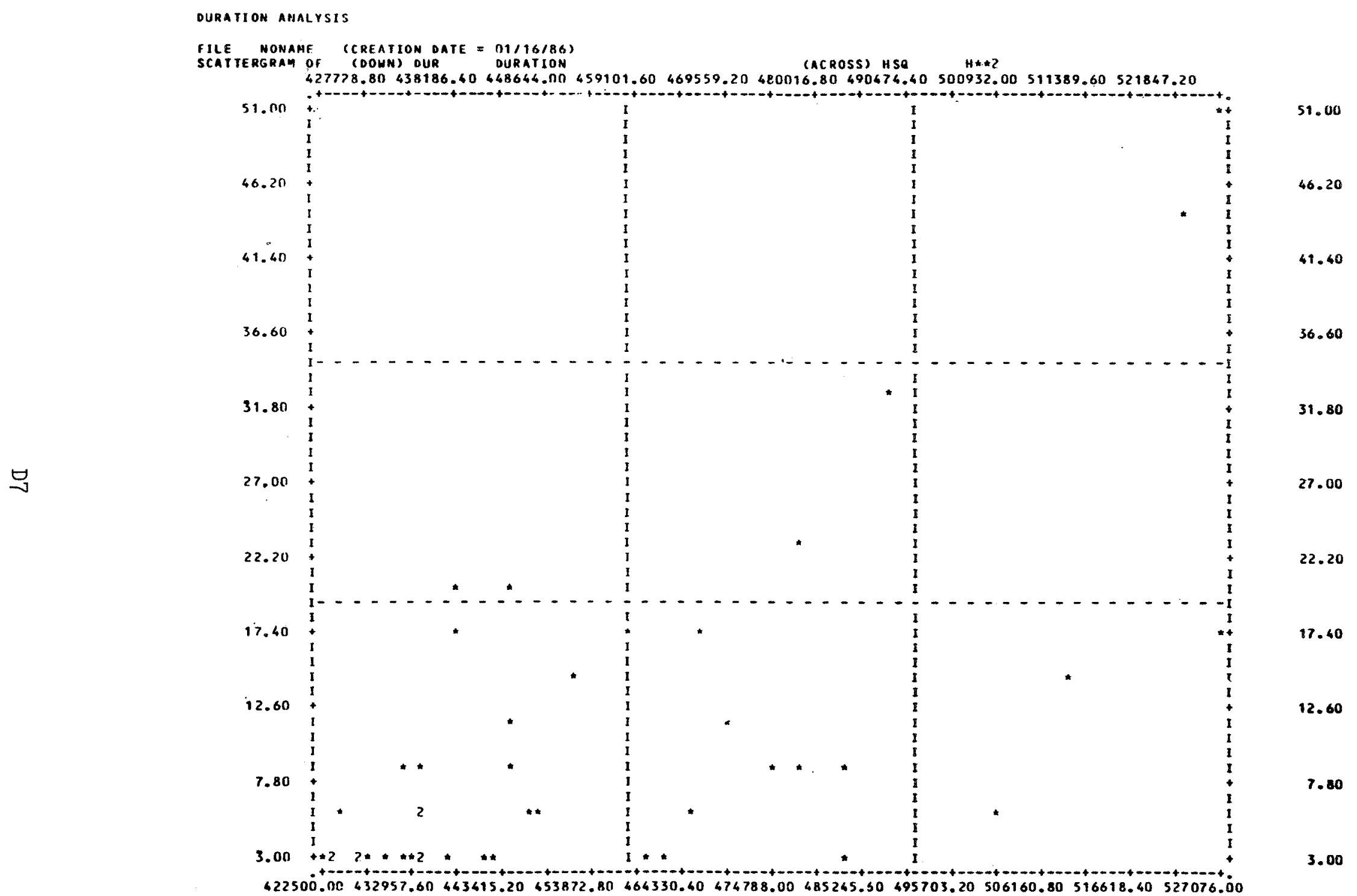




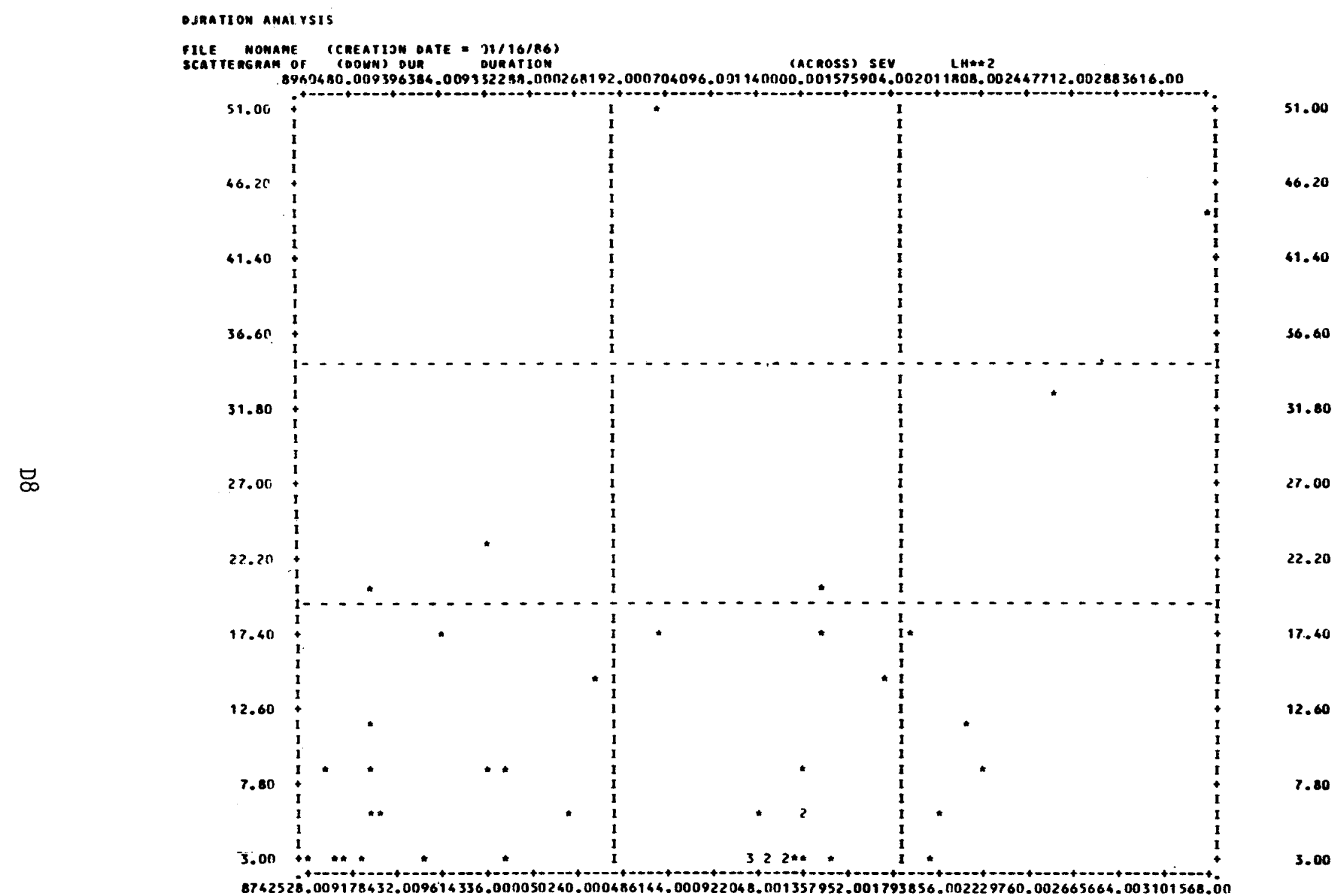

